PATRICIA ZORZETE

\title{
FUNGOS, MICOTOXINAS E FITOALEXINA EM VARIEDADES DE AMENDOIM DO PLANTIO AO ARMAZENAMENTO
}

Tese apresentada ao Programa de PósGraduação em Microbiologia do Instituto de Ciências Biomédicas da Universidade de São Paulo para obtenção do título de Doutor em Ciências.

São Paulo

2010 
PATRICIA ZORZETE

\section{FUNGOS, MICOTOXINAS E FITOALEXINA EM VARIEDADES DE AMENDOIM DO PLANTIO AO \\ ARMAZENAMENTO}

Tese apresentada ao Programa de PósGraduação em Microbiologia do Instituto de Ciências Biomédicas da Universidade de São Paulo para obtenção do título de Doutor em Ciências.

Área de concentração: Microbiologia

Orientador: Prof. Dr. Benedito Corrêa 
DADOS DE CATALOGAÇÃO NA PUBLICAÇĀO (CIP)

Serviço de Biblioteca e Informaçăo Biomédica do Instituto de Ciencias Biomédicas da Universidade de São Paulo

Creproduçāo total

Zorzete, Patrica.

Fungos, micotoxinas e fitoalexina em variedades de amendoim do plantio ao armazenamento / Patricia Zorzete, - Sẵo Paulo, 2010.

Orientador: Benedito Correa.

Tese (Doutorado) - Universidade de Săo Paulo. Instituto de Ciências Biomédicas. Departamento de Microbiologia. Área de concentraçảo: Microbiologia. Linha de pesquisa: Fungos Toxigênicos e micotoxinas

Versâo do titulo para o inglês: Fungi, mycotoxins phytoalexin in peanut varieties, during plant growth from the field to storage.

Descritores: 1. Amendoim 2. Micobiota 3. Aflatoxinas 4. Ácido Ciclopiazônico 5. Fitoalexins 6. Fatores abióticos 1. Corrêa, Benedito II. Universidade de São Paulo. Instituto de Ciências Biomédicas. Programa de Pós-Graduação em Microbiologia III. Titulo. 


\section{UNIVERSIDADE DE SÃO PAULO \\ INSTITUTO DE CIÊNCIAS BIOMÉDICAS}

Candidato(a):

Patricia Zorzete.

Título da Tese:

Fungos, micotoxinas $e$ fitoalexina em variedades de amendoim do plantio ao armazenamento. .

Orientador(a):

Benedito Correa.

A Comissão Julgadora dos trabalhos de Defesa da Tese de Doutorado, em sessão pública realizada a considerou
( ) Aprovado(a)
( ) Reprovado(a)

Examinador(a): Assinatura:

Nome:

Instituição:

Examinador(a): Assinatura:

Nome:

Instituiçāo:

Examinador(a): Assinatura:

Nome:

Instituição:

Examinador(a): Assinatura:

Nome:

Instituição:

Presidente: Assinatura:

Nome:

Instituição: 


\section{CERTIFICADO DE ISENÇ̃̃OO}

Certificamos que o Protocolo CEP-ICB N 111 , referente ao projeto intitulado "Distribuição de fungos e de aflatoxinas em variedades de amendoim do plantio ao armazenamento ${ }^{9 \times 6}$ sob a responsabilidade de Patrícia Zorzete, foi analisado na presente data pela CEEA - COMISSÃO DE ÉTICA EM EXPERIMENTAÇÃO ANIMAL e pela CEPSH - COMISSÃO DE ÉTICA EM PESQUiSA COM SERES HUMANOS, tendo sido deliberado que o referido projeto não envolve manipulação animal ou humana que justifique uma aprovação quanto aos principios éticos exigidos por ambas as Comissões.

São Paulo, 18 de outubro de 2005.

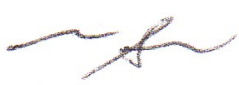

Profa. Dra. MARÍlIA C.L.SEELAENDER Coordenadora da CEEA - ICB/USP

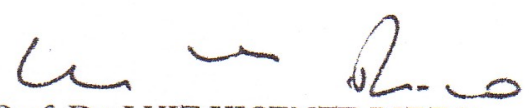

Prof. Dr. LUIZ VICENTE RIZZO

Coordenador da CEPSH - ICB/USP 
Aos meus pais, irmãos e sobrinhos por todo o apoio e carinho e pela compreensão nos momentos de ausência. 


\section{AGRADECIMENTOS}

Ao Prof. Dr. Benedito Corrêa, pela oportunidade, orientação e incentivo. Obrigada pelos aprendizado e compreensão.

Aos ensinamentos e apoio na execução do trabalho, gentilmente oferecidos pelo Prof. Dr. Homero Fonseca, Dra. Joana D’Arca Felício, Dra. Edlayne Gonçalez e Dra Adriana Palma de Almeida.

À Universidade de São Paulo e aos professores do Departamento de Microbiologia, pelos valiosos conhecimentos.

À Cooperativa Agrícola Mista da Alta Paulista (CAMAP) pelo plantio e armazenamento do amendoim e pelo suporte técnico prestado. Ao Engenheiro Agrônomo Paulo Makimoto (CATI / Regional Agrícola de Tupã) por toda a colaboração e ensinamentos durante a execução do trabalho.

À Tatiana Alves dos Reis, pelo auxílio técnico durante todo o experimento, pela oportunidade de convívio, apoio e amizade.

As estagiárias Sabrina M. Manrique, Tainah Drumond e Yvina Brito pelo companheirismo e incalculável ajuda na realização do trabalho.

À Arianne Costa Baquião, Danielle D. Atayde e Raquel Braghini pela ajuda, amizade e aprendizado.

Aos amigos do Laboratório de Micotoxinas do Instituto de Ciências Biomédicas, Viviane Nakai, Liliana de Oliveira Rocha, Fabiane L. Ferreira Castro, Valéria Nascimento Silva, Ednei A. A. Coelho, por todo companheirismo e convívio no laboratório.

À amiga Maria Jacinta de Farias, por sempre estar presente. 
As amigas da Seção de Soros Hiperimunes, do Instituto Butantan, Ana Cristina L. Luz, Érica da Silva, Maria Luiza Soares e Vivian Mie Ichicawa, pelos conselhos, apoio e o valioso convívio.

Ao Instituto Butantan, em especial ao José Roberto Marcelino e Alex Sandra Tributino, pela compreensão e ajuda, quando necessário.

As secretárias do Departamento de Microbiologia, Alice, Aninha e Naíde, pela atenção e carinho.

Aos funcionários do setor de Apoio Técnico (SAT), por toda a colaboração e ajuda prestada.

À Fundação de Amparo à Pesquisa do Estado de São Paulo (FAPESP) e ao Conselho Nacional de Desenvolvimento Científico e Tecnológico (CNPq), pelo auxílio financeiro à pesquisa.

À todos aqueles que tenham contribuído direta e indiretamente para a realização deste trabalho. 
A percepção do desconhecido é a mais fascinante das experiências. É esta a emoção fundamental que está na raiz de toda ciência e arte. Aquele que não a conhece e não pode se maravilhar com ela está com seus olhos ofuscados.

\section{(Albert Einstein)}




\section{RESUMO}

ZORZETE, P. Fungos, micotoxinas e fitoalexina em variedades de amendoim do plantio ao armazenamento. 2010. 188 f. Tese (Doutorado em Microbiologia) Instituto de Ciências Biomédicas, Universidade de São Paulo, São Paulo, 2010.

O trabalho teve como objetivo avaliar, no campo e no armazenamento, a micobiota, a contaminação por micotoxinas (aflatoxinas e ácido ciclopiazônico) e a presença de fitoalexina (trans-resveratrol) em duas variedades de amendoim (Runner IAC 886 e IAC-Caiapó). A micobiota foi determinada pela técnica da semeadura direta em meio de AFPA (Ágar Aspergillus flavus - parasiticus) e a determinação de micotoxinas e fitoalexina por Cromatografia Líquida de Alta Eficiência. Nas amostras de campo, nas duas variedades estudadas, constatou-se a predominância de Fusarium spp., seguido por Penicillium spp. e Aspergillus flavus, tanto nos grãos quanto nas cascas. Nas amostras armazenadas, observou-se maior frequência de isolamento de $A$. flavus, A. parasiticus, A. niger, Fusarium spp. e Penicillium spp., em ambas as variedades. Aflatoxina $B_{1}$ foi detectada em $30 \%$ das amostras coletadas no campo da variedade IAC 886 e em $25 \%$ das amostras da variedade IAC-Caiapó. Nas amostras de armazenamento da variedade IAC 886, aflatoxina $B_{1}$ foi detectada em $20 \%$ das amostras de grãos e $23,3 \%$ nas amostras de cascas e, na variedade IAC-Caiapó, foi detectada em 13,3\% das amostras, tanto nos grãos, como nas cascas. Para Ácido ciclopiazônico (ACP), o número de amostras positivas, no campo e no armazenamento, na variedade IAC 886, foi de 70 e $80 \%$, respectivamente. Na variedade IAC-Caiapó, 55\% das amostras de campo e $70 \%$ de armazenamento estavam contaminadas por ACP. Avaliação do potencial toxigênico das 130 cepas de $A$. flavus revelou $80,8 \%$ produtoras de aflatoxinas e $94,6 \%$ de ACP. Dos isolados, $75,5 \%$ produziram ambas as toxinas. Todas as cepas de $A$. flavus, produtoras de esclerócios, eram pertencentes ao grupo $\mathrm{L}$, caracterizado pela produção de baixos níveis de aflatoxinas. Foi detectado trans-resveratrol em $5 \%$ das amostras de grãos, na variedade IAC 886 e 15\% na variedade IAC-Caiapó. No entanto, nas folhas, elas estavam presentes em $70 \%$ das amostras em cada uma das variedades.

Palavras-chave: Amendoim. Micobiota. Aflatoxinas. Ácido ciclopiazônico. Fitoalexina. Fatores abióticos. 


\begin{abstract}
ZORZETE, P. Fungi, mycotoxins and phytoalexin in peanuts varieties, during plant growth from the field to storage. 2010. $188 \mathrm{f}$. Thesis (Ph. D. in Microbiology) - Instituto de Ciências Biomédicas, Universidade de São Paulo, São Paulo, 2010.

The objective of this present study was analyze, in the field and in the storage, mycobiota, the contamination by mycotoxins (aflatoxins and cyclopiazonic acid) and the presence of phytoalexin (trans-resveratrol) in two peanuts varieties (Runner IAC 886 e IAC-Caiapó). Mycobiota was determined by direct seeding technique in the middle of AFPA (Ágar Aspergillus flavus - parasiticus) and the determination of mycotoxins and phytoalexin by High Performance Liquid Chromatography. In the field samples, in the two studied varieties, the results showed a predominance Fusarium spp., followed by Penicillium spp. and Aspergillus flavus, both in the grains as in the shells. In the stored samples, it was observed a high isolation frequency of A. flavus, A. parasiticus, A. niger, Fusarium spp. and Penicillium spp., in both varieties. It was detected aflatoxin $B_{1}$ in $30 \%$ of the samples collected in the field of IAC 886 variety, and in $25 \%$ of the samples of the IAC-Caiapó variety. In the stored samples of the IAC 886 variety, afaltoxin $B_{1}$ was detected in $20 \%$ of the grains samples, and $23,3 \%$ in the shells samples. In the IAC-Caiapó variety it was detected in $13,3 \%$ of the samples, both in the grains as in the shells. For the cyclopiazonic acid (CPA), the number of positive samples, in the field and in the storage, in the IAC 886 variety, was of 70 and $80 \%$, respectively. In the IAC-Caiapó variety, $55 \%$ of the field samples, and $70 \%$ of storage were contaminated by CPA. The assessment of the toxigenic potential of the 130 strains of $A$. flavus revealed $80,8 \%$ aflatoxins producers and $94,6 \%$ CPA producers and $75,5 \%$ of the isolate produced both toxins. All strains of $A$. flavus, sclerotia producers, belonged to $L$ group, characterized by the low levels aflatoxins production. It was detected trans-resveratrol in $5 \%$ of the grains samples in the IAC 886 variety, and 15\% in the IAC-Caiapó variety. However, in the leaves, they were present in $70 \%$ of the samples in each one of the varieties.
\end{abstract}

Keywords: Peanut. Mycobiota. Aflatoxins. Ciclopiazonic acid. Fitoalexin. Abiotic factors 


\section{LISTA DE ILUSTRAÇÕES}

Figura 1 - Consumo Aparente = Produção + Importação - Exportação ... 26

Figura 2 - Consumo Per Capita Brasileiro …………………………...... 26

Figura 3 - $\quad$ Área de plantio e cultivar................................................. 48

Figura 4 - Croqui da área experimental............................................ 49

Figura 5 - $\quad$ Florescimento do amendoim …………............................ 49

Figura 6 - Formação de ginóforos.................................................... 49

Figura 7 - Grãos na fase água ...................................................... 50

Figura 8 - Início granação .............................................................. 50

Figura 9 - Grãos maduros ............................................................ 50

Figura 10 - Grãos secos ............................................................. 50

Figura 11 - Coleta de Fungos do ar no campo ................................... 51

Figura 12 - Micobiota fúngica da flor, ginóforo, grãos e cascas ................. 54

Figura 13 - Micobiota do solo pela Técnica de "Pour Plate"......................... 55

Figura 14 - Fungos anemófilos isolados no campo ................................. 56

Figura 15 - Aparelho medidor de Aa (Aqualab CX-2) …......................... 57

Figura 16 - Aparelho de cromatografia líquida de alta eficiência (Shimadzu), utilizados para deteç̧ão e quantificação de aflatoxinas, ACP e trans-resveratrol ..................................... 58

Figura 17 - Cromatograma de trans-resveratrol ................................. 58

Figura 18 - Armazém da Cooperativa Agrícola da Alta Mogiana (CAMAP), região de Tupã, SP. Visualização da fachada e interior do armazém

Figura 19 - Coletas do amendoim armazenado em 5 pontos diferentes em cada saca .............................................................. 60

Figura 20 - Micobiota isoladas das amostras de grãos e cascas, no período de armazenamento ................................................. 60

Figura 21 - Coleta de fungos do ar no armazenamento .............................

Figura 22 - Aparelho termohigrômetro digital utilizado na medição da temperatura e umidade relativa, no interior do armazém ......... 61

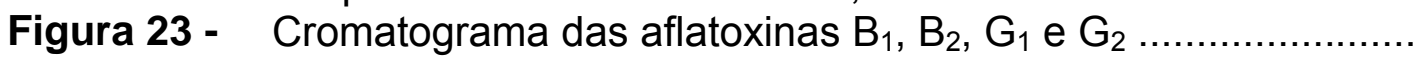

Figura 24 - Cromatograma do ácido ciclopiazônico ...................................

Figura 25 - Delineamento experimental, com as análises realizadas durante o crescimento do amendoim, no campo, na região de Tupã.

Figura 26 - Delineamento experimental, com as análises realizadas durante o período de armazenamento do amendoim, na região de Tupã.

Figura 27 - Frequência de isolamento fúngico (UFC/g) das amostras de solo colhidas durante o período experimental, no campo, da variedade IAC-Caiapó.

Figura 28 - 1 de isolamento fúngico (UFC/g) das amostras de solo colhidas durante o período experimental, no campo, da variedade IAC

Figura 29 - Frequência de fungos anemófilos $\left(\mathrm{UFC} / \mathrm{m}^{3}\right)$ isoladas do ar durante o crescimento da planta, no campo da variedade IAC-Caiapó 
Figura 30 - Frequência de fungos anemófilos $\left(\mathrm{UFC} / \mathrm{m}^{3}\right)$ isoladas do ar durante o crescimento da planta, no campo da variedade IAC 886

Figura 31 - Frequência de isolamento fúngico (\%) obtidas da flor, ginóforo e grãos da variedade IAC-Caiapó, durante o período de crescimento da planta, no campo

Figura 32 - Frequência de isolamento fúngico (\%) obtidas nas cascas da variedade IAC-Caiapó, durante o período de crescimento da planta, no campo

Figura 33 - Frequência de isolamento de $A$. flavus e $A$. parasiticus (\%) obtidas nas cascas da variedade IAC-Caiapó, durante 0 período de crescimento da planta, no campo

Figura 34 - Frequência de isolamento fúngico (\%) obtidas da flor, ginóforo e grãos da variedade IAC 886, durante o período de crescimento da planta, no campo.

Figura 35 - Frequência de isolamento fúngico (\%) obtidas nas cascas da variedade IAC 886, durante o período de crescimento da planta, no campo

Figura 36 - Frequência de isolamento fúngico (\%) em cascas de amendoim armazenadas, da variedade IAC-Caiapó, no período de abril a setembro de 2006, no município de Tupã ...

Figura 37 - Frequência de isolamento (\%) de $A$. flavus e $A$. parasiticus em cascas de amendoim armazenadas, da variedade IACCaiapó, no período de abril a setembro de 2006, no município de Tupã

Figura 38 - Frequência fúngica (\%) isolada dos grãos armazenados da variedade IAC-Caiapó, no período de abril a setembro de 2006, no município de Tupã

Figura 39 - Frequência de isolamento (\%) de $A$. flavus e $A$. parasiticus em grãos armazenadas da variedade IAC-Caiapó, no período de abril a setembro de 2006, no município de Tupã

Figura 40 - Frequência de isolamento fúngico (\%) em cascas armazenadas da variedade IAC 886, no período de abril a setembro de 2006, no município de Tupã

Figura 41 - Frequência de isolamento de $A$. flavus e $A$. parasiticus em cascas armazenadas da variedade IAC 886, no período de abril a setembro de 2006, no município de Tupã

Frequência de isolamento fúngico (\%) em grãos armazenadas da variedade IAC 886, no período de abril a setembro de 2006, no município de Tupã

Figura 43 - Frequência de isolamento (\%) de $A$. flavus e $A$. parasiticus em cascas armazenadas da variedade IAC 886, no período de

Figura 44 - Frequência de fungos anemófilos $\left(\mathrm{UFC} / \mathrm{m}^{3}\right)$ no interior do 92 armazém, ao redor da variedade IAC-Caiapó, no período de abril a setembro de 2006, no município de Tupã ....

Figura 45 - Frequência de fungos anemófilos $\left(\mathrm{UFC} / \mathrm{m}^{3}\right.$ ) no interior do 95 armazém, ao redor da variedade IAC 886, no período de abril a setembro de 2006, no município de Tupã 


\section{LISTA DE TABELAS}

Tabela 1 - Análises químicas do solo ( $\mathrm{pH}$, matéria orgânica, macronutrientes, soma de bases, total de bases e saturação de bases), após o plantio do amendoim, na região de Tupã.

Tabela 2 - Análises de micronutrientes do solo, após o plantio do amendoim, na região de Tupã

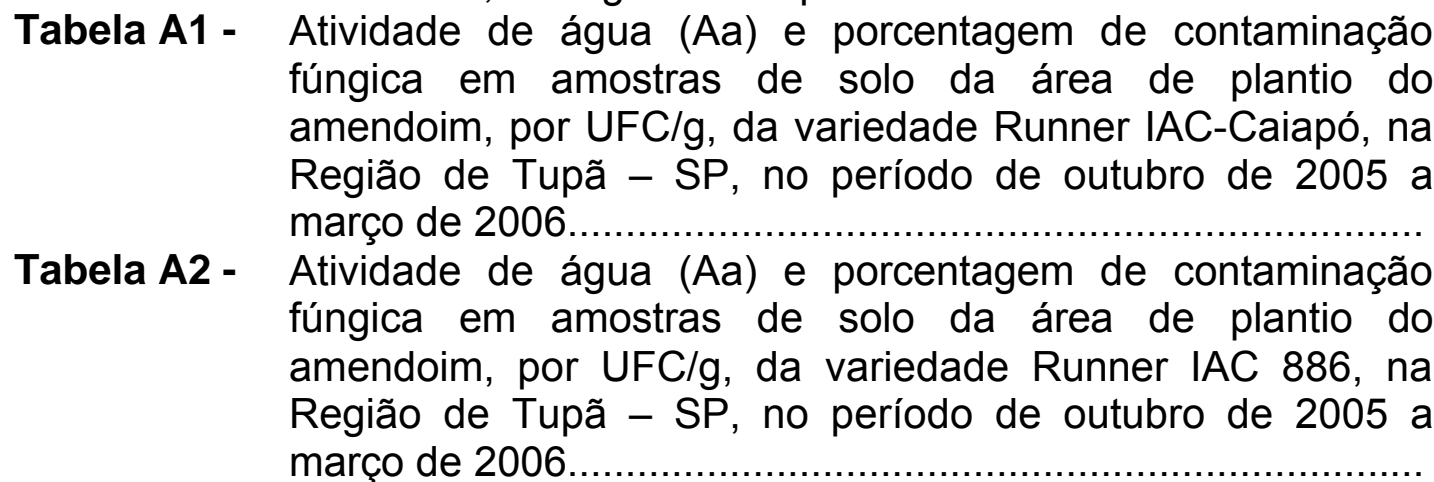

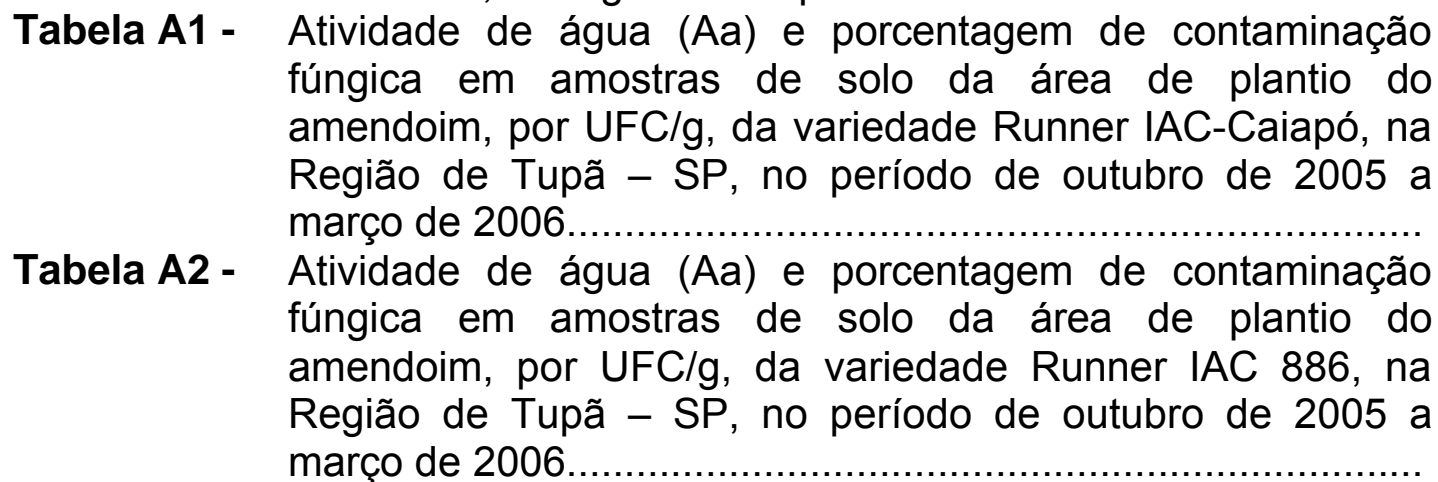

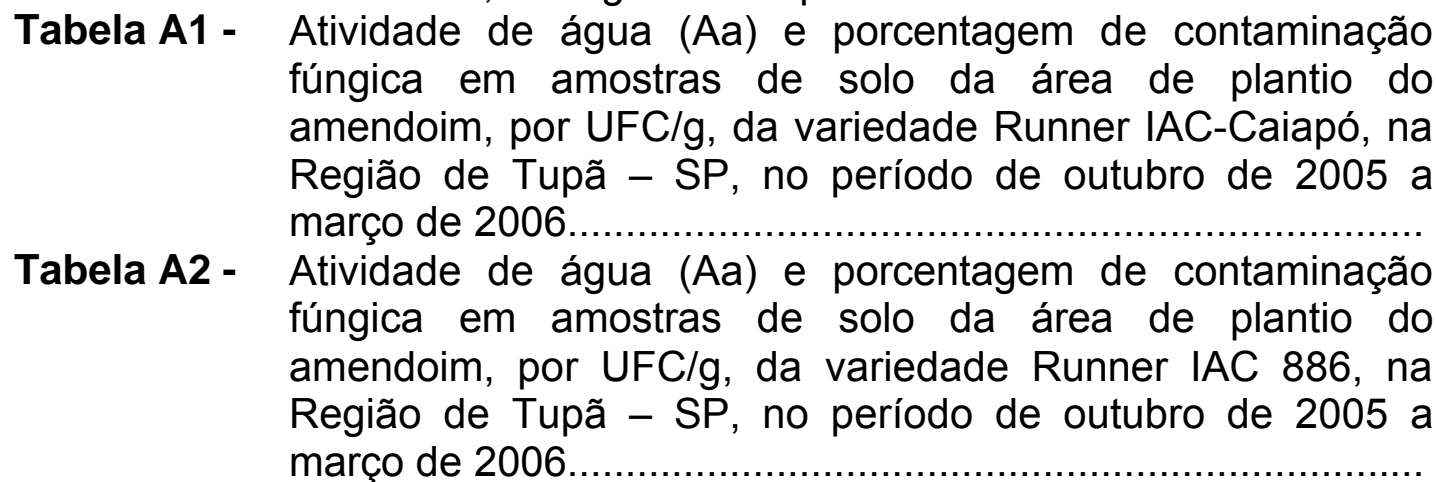

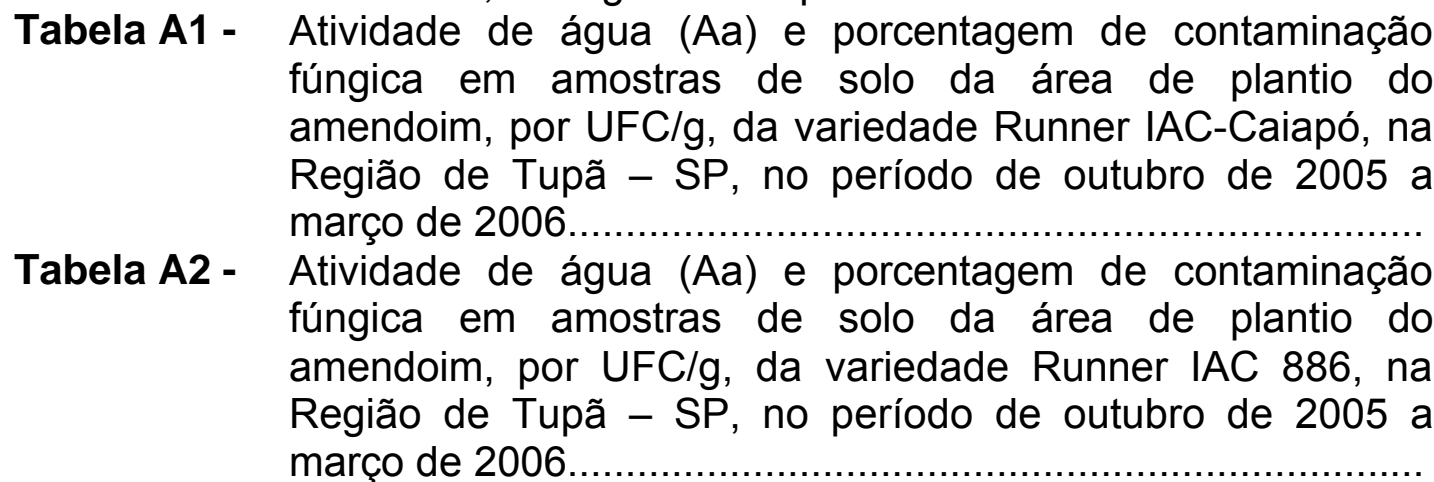

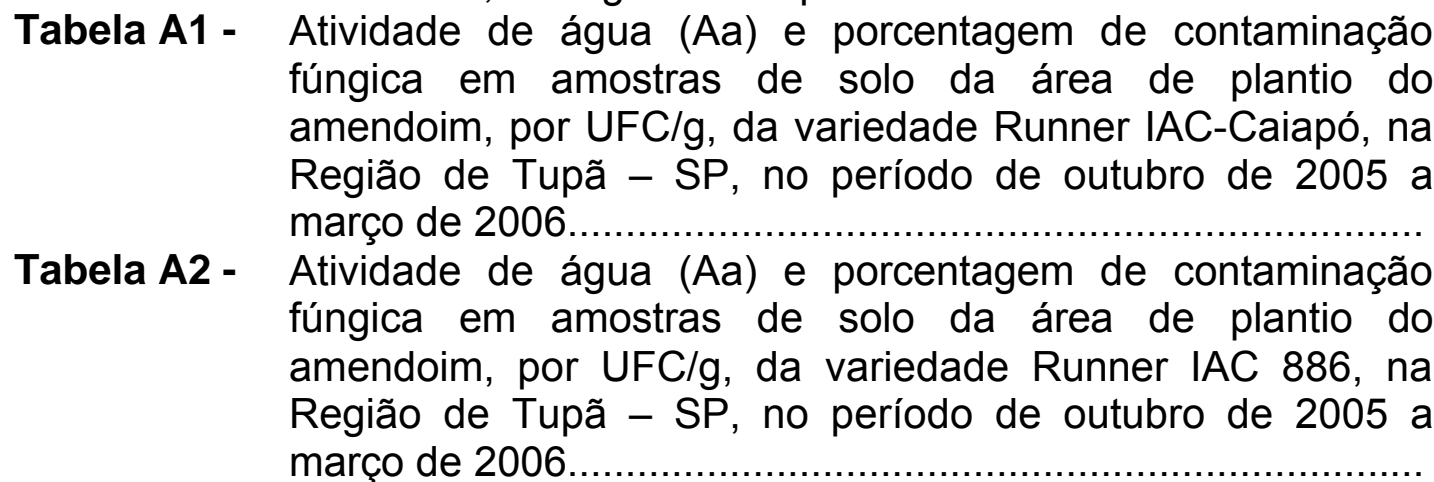

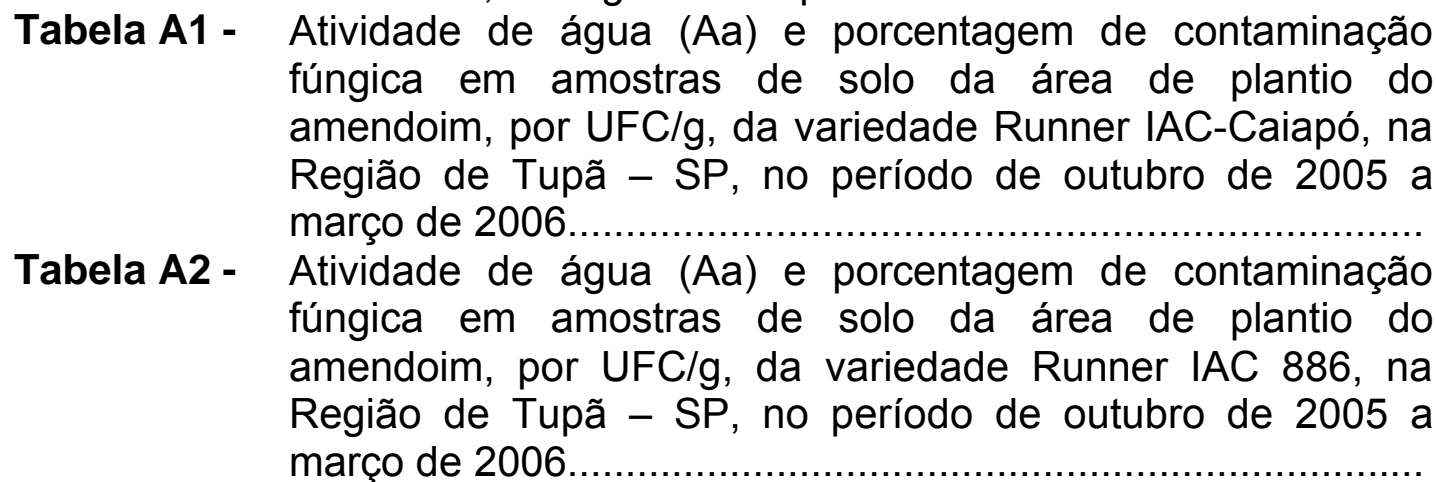

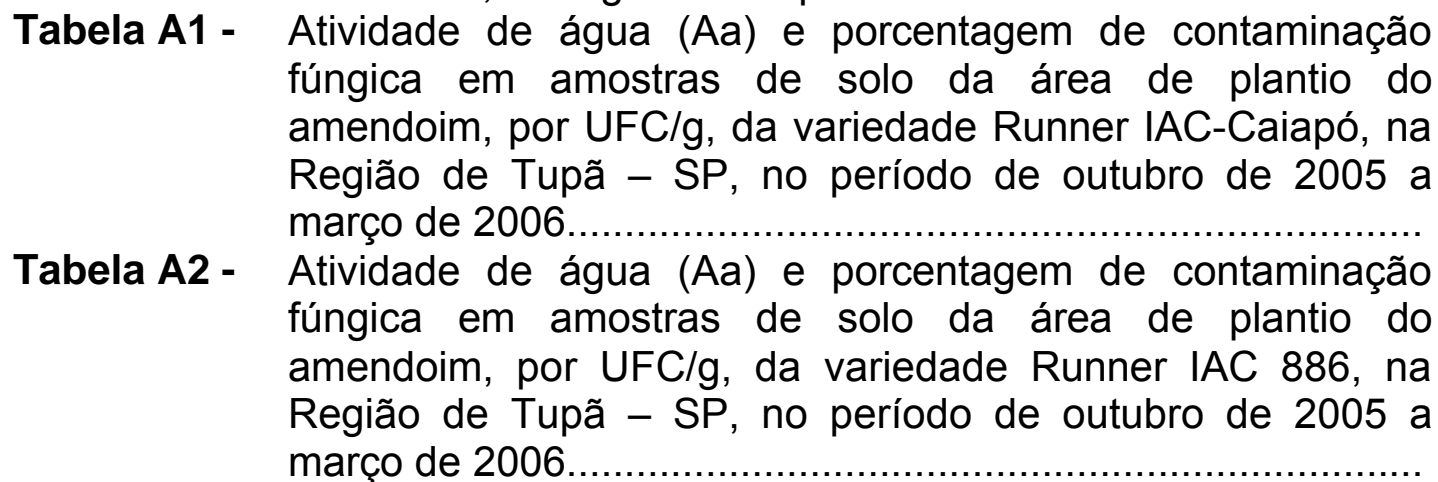

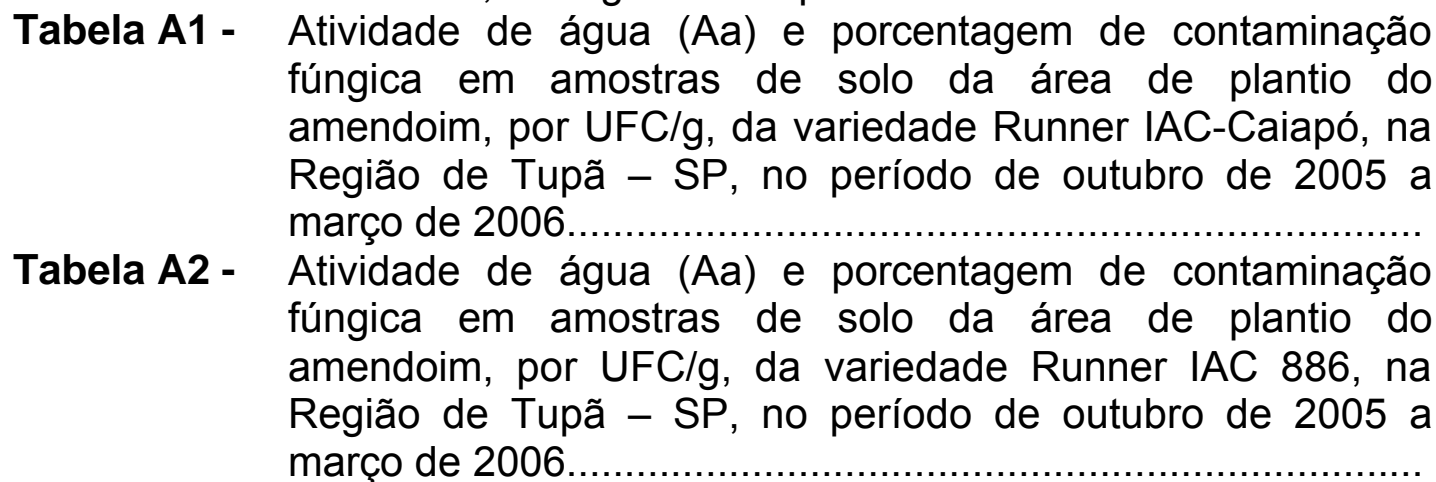

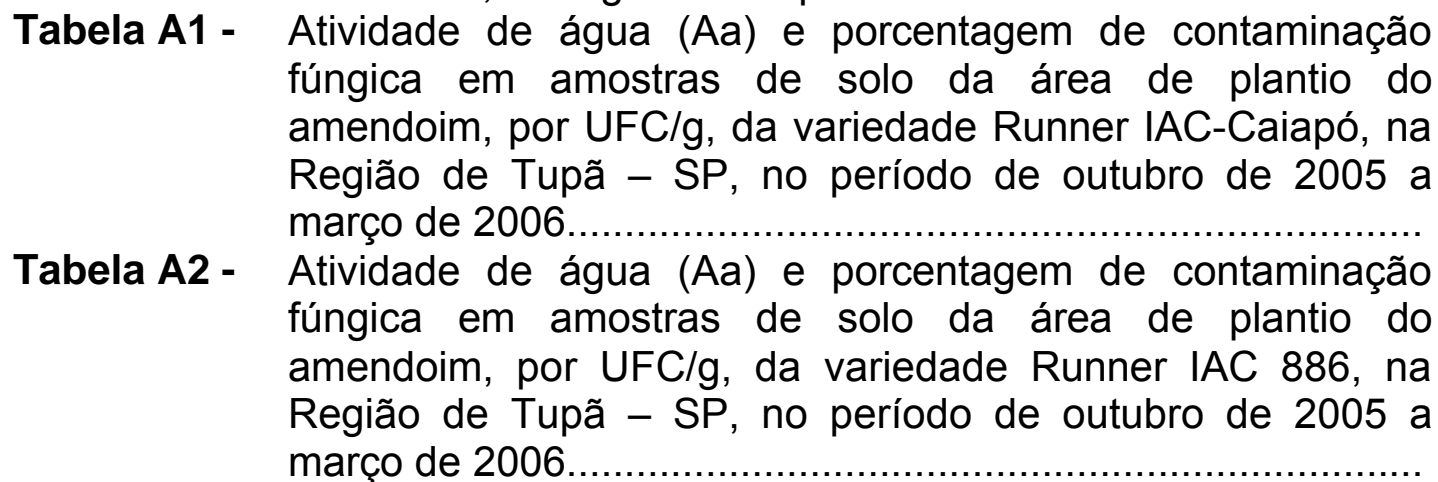

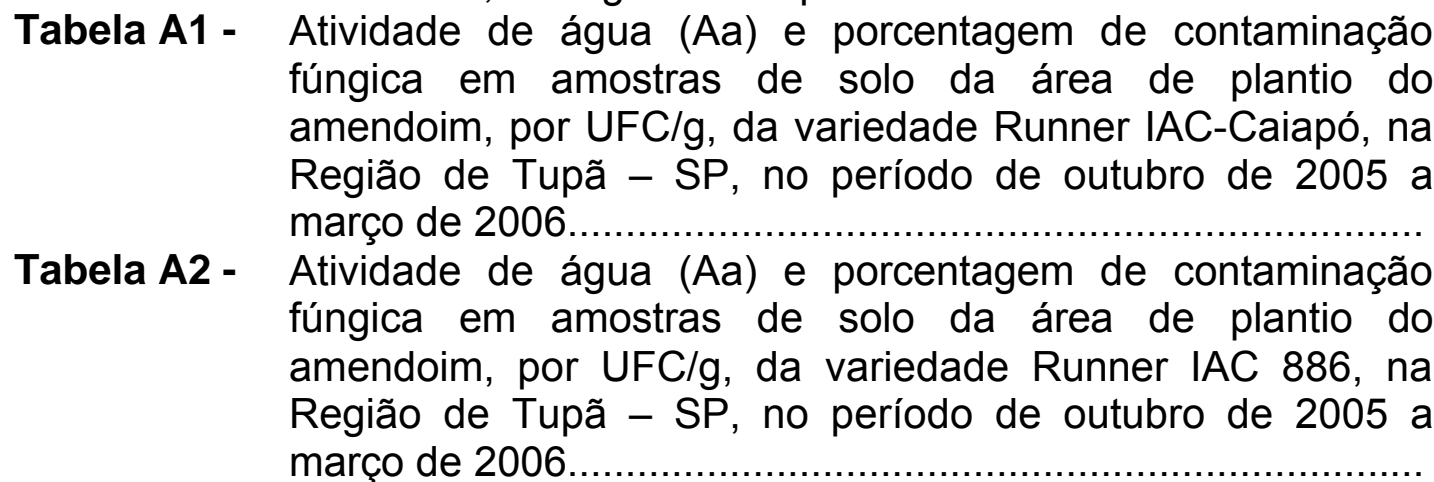

Tabela A3 - Porcentagem de fungos anemófilos (UFC/m $\mathrm{m}^{3}$ ) isolados da área de plantio do amendoim, da variedade Runner IACCaiapó, na Região de Tupã - SP, no período de dezembro de 2005 a março de 2006.

Tabela A4 - Porcentagem de fungos anemófilos $\left(\mathrm{UFC} / \mathrm{m}^{3}\right)$ isolados da área de plantio do amendoim, da variedade Runner IAC 886, na Região de Tupã - SP, no período de dezembro de 2005 a março de 2006.

Atividade de água $(\mathrm{Aa})$ e porcentagem de contaminação fúngica em amostras de flor, ginóforo e grãos de amendoim da variedade Runner IAC-Caiapó, colhidos na Região de Tupã - SP, no período de outubro de 2005 a março de 2006

Tabela A6 - Atividade de água (Aa) e porcentagem de contaminação fúngica em amostras de cascas de amendoim da variedade Runner IAC-Caiapó, coletados no campo, na Região de Tupã - SP, no período de fevereiro a março de 2006.

Tabela A7 - Atividade de água (Aa) e porcentagem de contaminação fúngica em amostras de flor, ginóforo e grãos de amendoim da variedade Runner IAC 886, colhidos na Região de Tupã SP, no período de outubro de 2005 a março de 2006

Tabela A8 - Atividade de água (Aa) e porcentagem de contaminação fúngica em amostras de cascas de amendoim da variedade Runner IAC 886, coletados no campo, na Região de Tupã SP, no período de fevereiro a março de 2006.

Tabela A9 - Temperatura $\left({ }^{\circ} \mathrm{C}\right)$ registrada no período experimental de campo, de outubro de 2005 a março de 2006, na região de Tupã.

Tabela A10 - Umidade Relativa do ar (\%), registrada no período de outubro de 2005 a setembro de 2006, na região de Tupã. 
Tabela A11 - Precipitação pluviométrica $(\mathrm{mm})$ registrada no período de outubro de 2005 a setembro de 2006, na região de Tupã........

Tabela A12 - Resultados das amostras positivas de aflatoxinas $B_{1}, B_{2}, G_{1}$ e 147 $\mathrm{G}_{2}(\mu \mathrm{g} / \mathrm{kg}$ ) encontradas nos grãos no campo, na Região de Tupã - SP, no período de janeiro a março de 2006

Tabela A13 - Resultados das amostras positivas de Ácido ciclopiazônico $(\mu \mathrm{g} / \mathrm{kg}$ ) encontradas nos grãos no campo, na Região de Tupã - SP, no período de janeiro a março de 2006

Tabela A14 - Resultados dos níveis de fitoalexina (trans-resveratrol), em $\mu \mathrm{g} / \mathrm{Kg}$, encontrados nas amostras de grãos e folhas (flor, ginóforo, Fase água, Início da granação e grãos maduros), durante o desenvolvimento do amendoim, no campo, no período de janeiro a março de 2006.

Tabela A15 - Atividade de água (Aa) e porcentagem de contaminação fúngica em amostras de cascas de amendoim da variedade Runner IAC-Caiapó, coletados durante o armazenamento, na Região de Tupã - SP, no período de abril a setembro de 2006

Tabela A16 - Atividade de água (Aa) e porcentagem de contaminação fúngica (\%) em amostras de grãos de amendoim da variedade Runner IAC-Caiapó, coletados durante 0 armazenamento, na Região de Tupã - SP, no período de abril a setembro de 2006 .

Tabela A17 - Atividade de água (Aa) e porcentagem de contaminação fúngica em amostras de cascas de amendoim da variedade Runner IAC 886, coletados durante o armazenamento, na Região de Tupã - SP, no período de abril a setembro de 2006

Tabela A18 - Atividade de água (Aa) e porcentagem de contaminação fúngica em amostras de grãos de amendoim da variedade Runner IAC 886, coletados durante o armazenamento, na Região de Tupã - SP, no período de abril a setembro de 2006.

Tabela A19 - Porcentagem de fungos anemófilos $\left(\mathrm{UFC} / \mathrm{m}^{3}\right)$ isolados no interior do armazém, próximo da variedade Runner IACCaiapó, no período de abril a setembro de 2006.

Tabela A20 - Porcentagem de fungos anemófilos $\left(\mathrm{UFC} / \mathrm{m}^{3}\right.$ ) isolados no interior do armazém, próximo da variedade Runner IAC 886, no período de abril a setembro de 2006 .

Tabela A21 - Temperatura $\left({ }^{\circ} \mathrm{C}\right)$ registrada no período experimental de armazenamento, de abril a março de 2006, na região de Tupã

Tabela A22 - Temperatura $\left({ }^{\circ} \mathrm{C}\right)$ registrada no interior do armazém, no período de abril a setembro de 2006, na região de Tupã.........

Tabela A23 - Umidade relativa do ar (\%) registrada no interior do armazém, no período de abril a setembro de 2006, na região de Tupã. 
Tabela A24 - Resultados das amostras positivas de aflatoxinas $B_{1}, B_{2}, G_{1}$ e $\mathrm{G}_{2}(\mu \mathrm{g} / \mathrm{kg})$ encontradas nos grãos no armazenamento, na Região de Tupã - SP, no período de abril a setembro de 2006.

Tabela A25 - Resultados das amostras positivas de aflatoxinas $B_{1}, B_{2}, G_{1}$ e $\mathrm{G}_{2}(\mu \mathrm{g} / \mathrm{kg})$ encontradas nas cascas no armazenamento, na Região de Tupã - SP, no período de abril a setembro de 2006

Tabela A26 - Resultados das amostras positivas de Ácido ciclopiazônico $(\mu \mathrm{g} / \mathrm{kg})$ encontradas nos grãos no armazenamento, na Região de Tupã - SP, no período de abril a setembro de 2006

Tabela A27 - Resultados obtidos na avaliação do potencial toxigênico (aflatoxinas e ACP), produção e diâmetro dos esclerócios e cultivo em meio AFPA, das 135 cepas de $A$. flavus e $A$. parasiticus isoladas das cascas e grãos de amendoim.

Tabela B1 - Estatísticas descritivas para a variável crescimento de $A$. flavus nas cascas de amendoim no campo em porcentagem de cascas contaminadas.

Tabela B2 - Estatísticas descritivas para a variável crescimento de $A$. flavus nos grãos de amendoim no campo em porcentagem de grãos contaminados.

Tabela B3 - Estatísticas descritivas para a variável crescimento de A.flavus no solo em UFC $\times 10^{4}$ por grama de solo.

Tabela B4 - Estatísticas descritivas para a variável crescimento de $A$. flavus nas cascas de amendoim no armazenamento em porcentagem de cascas contaminadas

Tabela B5 - Estatísticas descritivas para a variável crescimento de $A$. flavus nos grãos de amendoim no armazenamento em porcentagem de grãos contaminados.

Tabela B6 - Estatísticas descritivas para a variável produção de ACP nos grãos de amendoim no campo em $\mu \mathrm{g} / \mathrm{kg}$.

Tabela B7 - Estatísticas descritivas para a variável produção de ACP nos grãos de amendoim no armazenamento em $\mu \mathrm{g} / \mathrm{kg}$

Tabela B8 - Estatísticas descritivas para a variável produção de transresveratrol nos grãos de amendoim no campo em $\mu \mathrm{g} / \mathrm{kg} . . . \ldots \ldots$.

Tabela B9 - Estatísticas descritivas para a variável produção de transresveratrol nas folhas da planta de amendoim no campo em $\mu \mathrm{g} / \mathrm{kg}$

Tabela B10 - Estatísticas descritivas para a variável atividade de água das cascas no campo.

Tabela B11 - Estatísticas descritivas para a variável atividade de água dos grãos no campo.

Tabela B12 - Estatísticas descritivas para a variável atividade de água do solo

Tabela B13 - Estatísticas descritivas para a variável atividade de água das cascas no armazenamento.

Tabela B14 - Estatísticas descritivas para a variável atividade de água dos grãos no armazenamento. 
Tabela B15 - Correlação de Spearman e nível descritivo entre as variáveis de contaminação fúngica nas cascas de amendoim IACCaiapó no campo.

Tabela B16 - Correlação de Spearman e nível descritivo entre as variáveis de contaminação fúngica nas cascas de amendoim IAC 886 no campo

Tabela B17 - Correlação de Spearman e nível descritivo entre as variáveis de contaminação fúngica nos grãos de amendoim IACCaiapó no campo

Tabela B18 - Correlação de Spearman e nível descritivo entre as variáveis de contaminação fúngica nos grãos de amendoim IAC 886 no campo

Tabela B19 - Correlação de Spearman e nível descritivo entre as variáveis de contaminação fúngica no solo com plantação de amendoim IAC-Caiapó.

Tabela B20 - Correlação de Spearman e nível descritivo entre as variáveis de contaminação fúngica no solo com plantação de amendoim IAC 886

Tabela B21 - Correlação de Spearman e nível descritivo entre as variáveis de contaminação fúngica nas cascas de amendoim IACCaiapó no armazenamento.

Tabela B22 - Correlação de Spearman e nível descritivo entre as variáveis de contaminação fúngica nas cascas de amendoim IAC 886 no armazenamento.

Tabela B23 - Correlação de Spearman e nível descritivo entre as variáveis de contaminação fúngica nos grãos de amendoim IACCaiapó no armazenamento.

Tabela B24 - Correlação de Spearman e nível descritivo entre as variáveis de contaminação fúngica nos grãos de amendoim IAC 886 no armazenamento

Tabela C1 - Estimativas e níveis descritivos do ajuste do modelo de regressão beta binomial para a variável crescimento de $A$. flavus nas cascas de amendoim no campo

Tabela C2 - Valores ajustados pelo modelo de regressão beta binomial para a variável crescimento de $A$. flavus nas cascas de amendoim no campo.

Tabela C3 - Nível descritivo das variáveis não incluídas no modelo de regressão beta binomial para a variável crescimento de $A$. flavus nas cascas de amendoim no campo.

Tabela C4 - Estimativas e níveis descritivos do ajuste do modelo de regressão binomial para a variável crescimento de $A$. flavus nos grãos de amendoim no campo.

Tabela C5 - Valores ajustados pelo modelo de regressão binomial para a variável crescimento de $A$. flavus nos grãos de amendoim no campo

Tabela C6 - Nível descritivo das variáveis não incluídas no modelo de regressão binomial para a variável crescimento de $A$. flavus nos grãos do amendoim no campo. 
Tabela C7 - Estimativas e níveis descritivos do ajuste do modelo de regressão beta binomial para a variável crescimento de $A$. flavus nas cascas de amendoim no armazenamento.

Tabela C8 - Valores ajustados pelo modelo de regressão beta binomial para a variável crescimento de $A$. flavus nas cascas de amendoim no armazenamento

Tabela C9 - Nível descritivo das variáveis não incluídas no modelo de regressão beta binomial para a variável crescimento de $A$. flavus nas cascas de amendoim no armazenamento

Tabela C10 - Estimativas e níveis descritivos do ajuste do modelo de regressão beta binomial para a variável crescimento de $A$. flavus nos grãos de amendoim no armazenamento

Tabela C11 - Valores ajustados pelo modelo de regressão beta binomial para a variável crescimento de $A$. flavus nos grãos de amendoim no armazenamento

Tabela C12 - Nível descritivo das variáveis não incluídas no modelo de regressão beta binomial para a variável crescimento de $A$. flavus nos grãos do amendoim no armazenamento.

Tabela C13 - Nível descritivo das variáveis não incluídas no modelo de regressão gaussiano inverso ajustado no 0 para a variável produção de ACP nos grãos de amendoim no campo.

Tabela C14 - Estimativas e níveis descritivos do ajuste do modelo de regressão gaussiano inverso ajustado no 0 para a variável produção de ACP nos grãos do amendoim no armazenamento......

Tabela C15 - Valores ajustados pelo modelo de regressão gaussiano inverso ajustado no 0 para a variável produção de ACP nos grãos de amendoim no armazenamento.

Tabela C16 - Nível descritivo das variáveis não incluídas no modelo de regressão gaussiano inverso ajustado no 0 para a variável produção de ACP nos grãos de amendoim no armazenamento.

Tabela C17 - Estimativas e níveis descritivos do ajuste do modelo de regressão gaussiano inverso ajustado no 0 para a variável produção de trans-resveratrol nas folhas da planta de amendoim

Tabela C18 - Valores ajustados pelo modelo de regressão gaussiano inverso ajustado no 0 para a variável produção de transresveratrol nas folhas da planta de amendoim.

Tabela C19 - Nível descritivo das variáveis não incluídas no modelo de regressão gaussiano inverso ajustado no 0 para a variável produção de trans-resveratrol nas folhas da planta de amendoim. 
SUMÁRIO

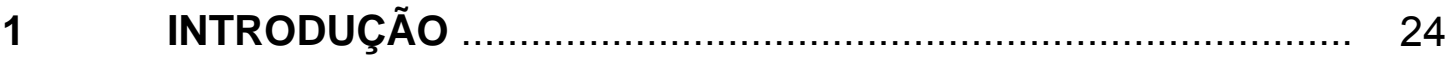

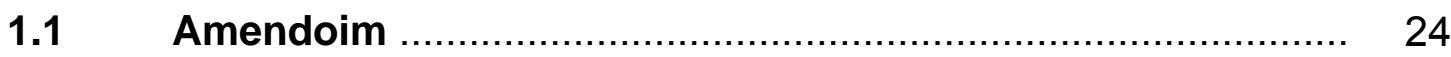

1.1.2 Variedades de amendoim .................................................... 27

$1.2 \quad$ Micobiota ................................................................ 30

1.2.1 Aspergillus flavus e Aspergillus parasiticus .............................. 31

1.2.2 Esclerócio ...................................................................... 32

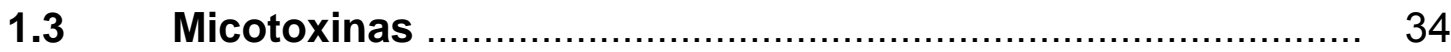

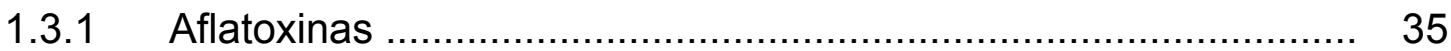

1.3.2 Ácido ciclopiazônico .............................................................. 38

$1.4 \quad$ Fatores abióticos ......................................................... 39

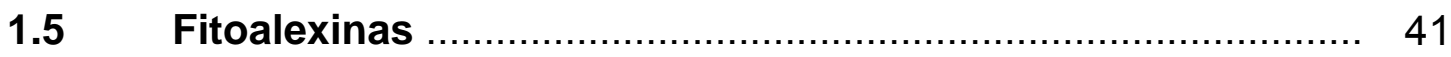

2 PROPOSIÇÔES E OBJETIVOS …..................................... 46

$3 \quad$ MATERIAIS E MÉTODOS …............................................ 48

3.1 Campo

3.1.1 Local do experimento e caracterização das parcelas ................. 48

3.1.2 Amostragens do amendoim, solo e ar ..................................... 48

3.1.3 Meios de Cultura ................................................................ 51

3.1.3.1 3.1.3.1. Ágar Batata Dextrose …............................................... 51

3.1.3.2 Ágar Sabouraud Dextrose ….............................................. 51

3.1.3.3 Meio Martim ................................................................. 52

3.1.3.4 Meio Ágar Aspergillus flavus e parasiticus (AFPA) …................. 52

3.1.3.5 Ágar Extrato de levedura - sacarose (Yes) ................................ 53

3.1.3.6 Ágar coco.......................................................................... 53

3.1.3.7 Ágar Czapek .................................................................. 53

3.1.4 Micobiota isolada das amostras de amendoim ......................... 54

3.1.5 Micobiota das amostras de solo pela técnica de "Pour

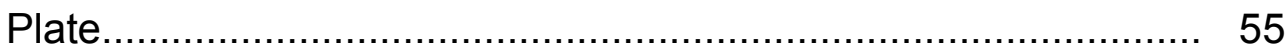

3.1.6 Micobiota do ar ............................................................. 55

3.1.7 Técnica de Microcultivo para a identificação da micobiota .......... 56

3.1.8 Determinação da atividade de água ......................................... 56

3.1.9 Pesquisa de fitoalexina (trans-resveratrol) .............................. 57 
3.1.10 Avaliação climática …......................................................... 58

3.2 Armazenamento ….......................................................... 59

3.2.1 Armazenamento do amendoim ............................................. 59

3.2.2 Amostragem do amendoim ............................................... 59

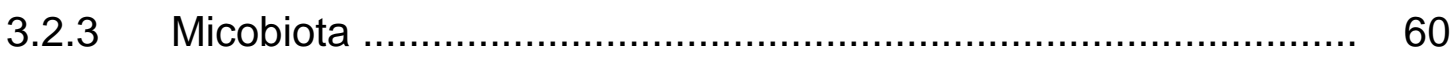

3.2.4 Micobiota das amostras de amendoim …................................ 60

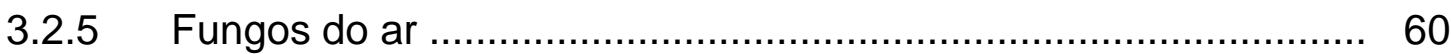

3.2.6 Determinação da atividade de água ........................................ 61

3.2.7 Avaliação climática................................................................. 61

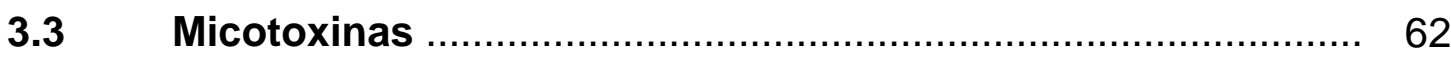

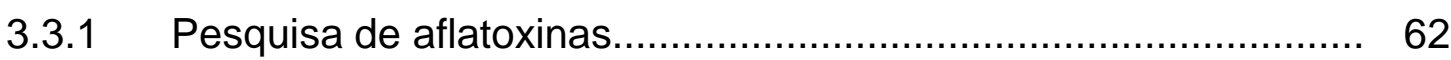

3.3.2 Pesquisa de ácido ciclopiazônico............................................ 63

3.3.3 Avaliação do potencial toxigênico para aflatoxinas das cepas de Aspergillus flavus e A. parasiticus.............................................. 64

3.3.4 Avaliação do potencial toxigênico para ácido ciclopiazônico das cepas de Aspergillus flavus..................................................... 65

3.4 Produção de esclerócios.................................................... 65

3.5 Análise estatística ......................................................... 66

4 DELINEAMENTO EXPERIMENTAL …..................................... 68

$5 \quad$ RESUTADOS E DISCUSSÃO ............................................... 70

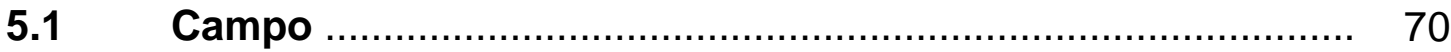

5.1.1 Avaliação Química do Solo .................................................. 70

5.1.2 Frequência de isolamento fúngico no ar, no solo, e nas sementes utilizadas no plantio ................................................. 71

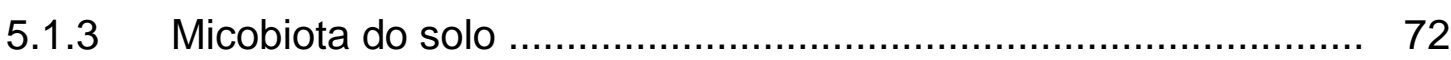

5.1.4 Fungos isolados do ar .......................................................... 75

5.1.5 Frequência de isolamento fúngico dos grãos e cascas das

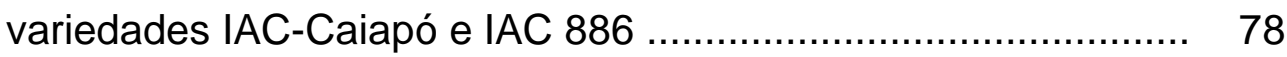

5.1.6 Fatores abióticos ........................................................... 83

5.1.7 Micotoxinas................................................................. 84

5.1.8 Fitoalexinas (trans-resveratrol) ........................................... 86

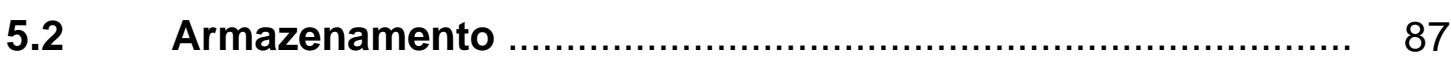


5.2.1 Frequência de isolamento fúngico nos grãos e cascas nas

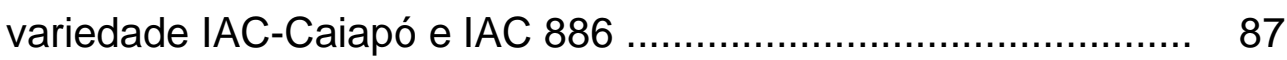

5.2.2 Frequência de fúngico anemófilos ............................................ 95

5.2.3 Fatores abióticos ............................................................... 97

5.2.4 Ocorrência de micotoxinas ..................................................... 98

5.3 Potencial das cepas para a produção micotoxinas ............... 99

5.3.1 Avaliação do potencial das cepas para a produção de

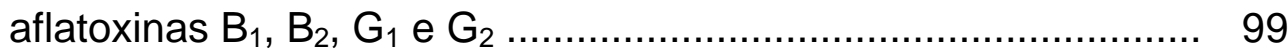

5.3.2 Potencial das cepas para a produção de Ácido ciclopiazônico .... 101

5.4 Produção de esclerócios .................................................. 101

5.5 Análise estatística ............................................................. 102

5.5.1 Análise exploratória ........................................................... 102

5.5.2 Análise de correlação .......................................................... 104

5.5.3 Análise inferencial .............................................................. 106

5.5.3.1 Análise da frequência de $A$. flavus nas cascas e grãos de amendoim, no campo .......................................................... 106

5.5.3.2 Análise da frequência de A. flavus nas cascas e grãos de amendoim, no armazenamento............................................... 107

5.5.3.3 Análise da produção de ACP nos grãos de amendoim, no

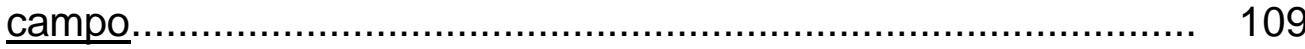

5.5.3.4 Análise da produção de ACP nos grãos de amendoim no

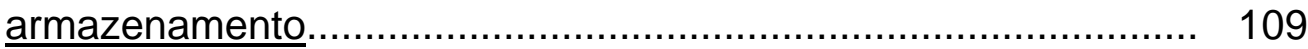

5.5.3.5 Análise da produção de trans-resveratrol nas folhas .................. 110

$6 \quad$ CONCLUSÕES ................................................................. 114

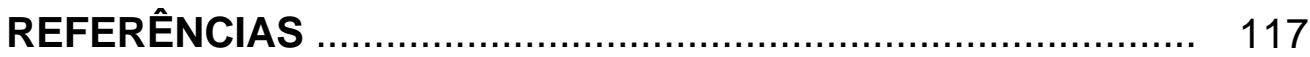

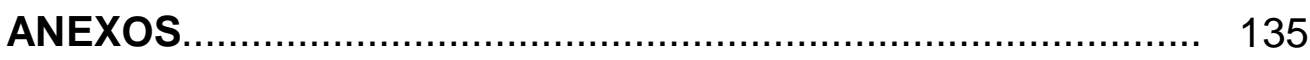

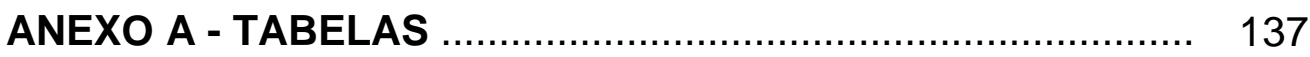

ANEXO B - ANÁLISE EXPLORATÓRIA ….............................. 165

ANEXO C - ANALISE INFERENCIAL................................. 178 


\section{LISTA DE ABREVIATURAS E SIGLAS}

IAC 886 - Instituto Agronômico de Campinas, variedade 886

IAC-Caiapó - Instituto Agronômico de Campinas, variedade Caiapó

$\mathrm{AFB}_{1}$ - Aflatoxina $\mathrm{B}_{1}$

$\mathrm{AFB}_{2}$ - Aflatoxina $\mathrm{B}_{2}$

$A F G_{1}-$ Aflatoxina $G_{1}$

$A F G_{2}$ - Aflatoxina $G_{2}$

ACP - Ácido ciclopiazônico

A. flavus - Aspergillus flavus

A. parasiticus - Aspergillus parasiticus

A. nomius - Aspergillus nomius

1 ppm - 1 parte por milhão $(\mu \mathrm{g} / \mathrm{g})$

$1 \mathrm{ppb}-1$ parte por bilhão $(\mu \mathrm{g} / \mathrm{kg})$

Aa - Atividade de água

AFPA - Meio Ágar Aspergillus flavus - parasiticus

CLAE - Cromatografia líquida de alta eficiência

Detector $\mathrm{D}_{2}$ - Detector Diiodo (detector do sistema CLAE)

$\mathrm{NaCl}$ - Cloreto de Sódio

TFA - Ácido tricloroacético

$\mathrm{KCl}$ - Cloreto de potássio

$\mathrm{HCL}$ - Ácido clorídrico

HPLC - High Performance Liquid Chromatography (termo em inglês para CLAE)

Ágar YES - Ágar Extrato de Levedura - Sacarose

FNE - Fungos não esporulados

spp. - espécie

A.niger - Aspergillus niger

A. terreus - Aspergillus terreus

A. ochraceus - Aspergillus ochraceus. 
1 INTRODUÇÃO 


\section{INTRODUÇÃO}

\subsection{Amendoim}

O amendoim foi cultivado pela primeira vez nos vales dos rios Paraguai e Paraná na região do Chaco, no Paraguai e na Bolívia. Os registros arqueológicos indicam o seu cultivo entre 300 e 2500 a.C, no oásis do deserto do Peru. Embora nenhuma evidência arqueológica do amendoim tenha sido descoberta na região Guarani do Paraguai, da Bolívia oriental e central, encontrou-se maior diversidade de variedades silvestres de Arachis (WEISS, 2000; SMITH, 2002). A variedade de Virginia foi retirada das Antilhas para o México, logo após o ano de 1500 e, em seguida, rapidamente introduzida na África Ocidental. Logo após foi levada para leste da América do Norte de ambas as regiões: as Antilhas e a África Ocidental no século 17. A variedade encontrada no Peru foi levada para o Brasil por galeões espanhóis e de lá para sudeste da China antes de 1600, onde era conhecido como "feijão estrangeiro". Espalhou-se a partir daí para toda a China e de lá para o Japão, onde era conhecido como feijão chinês. Colonos chineses foram responsáveis pela difusão no restante do Sudeste da Ásia e da Indonésia. O amendoim chegou à Índia, provavelmente, pela África como um dos nomes indígenas "feijão Moçambique" (KAPROVICKAS, 1969).

Hoje o amendoim é amplamente distribuído e adaptou-se em vários países do Mundo. Os países mais importantes para a produção são a China, Índia e EUA (UNITED STATES DEPARTMENT OF AGRICULTURE, 2010).

$O$ amendoim é uma planta dicotiledônea pertencente à família das leguminosas (Fabaceae), subfamília Papilonoidae, gênero Arachis. A planta é formada por uma parte aérea composta por ramificações, folhas e flores. O período de florescimento do amendoim inicia-se cerca de 3 a 4 semanas após a emergência, atinge o máximo em 6 a 7 semanas, para posteriormente, decrescer regularmente. Flores podem surgir na planta até próximo ao final do ciclo. Aproximadamente uma semana após a fecundação da flor, o tecido situado na base do ovário começa a crescer e o ovário se torna uma estrutura alongada e pontiaguda que trás os óvulos na sua extremidade. Essa estrutura é conhecida por ginóforo, esporão ou peg. crescimento do ginóforo encaminha-se para o solo onde penetra, se encurva e sua extremidade começa a se espessar dando início ao desenvolvimento do fruto e das 
sementes. Esse período de início da frutificação tem aproximadamente de 40 a 50 dias, no qual, ocorre a fase de desenvolvimento dos frutos e de maturação, evoluindo até a colheita (CÂMARA, 1998).

Em sistemas mecanizados, a máquina é usada para cortar a raiz principal da planta de amendoim, cortando o solo logo abaixo do nível das vagens de amendoim. A máquina tira a planta do chão e sacode, invertendo-a em seguida, deixando a unidade de cabeça para baixo no chão para manter o amendoim fora da terra. Isso permite que o amendoim seque lentamente para um pouco menos de um terço do seu nível de umidade original em um período de 3-4 dias. Depois do amendoim suficientemente seco, eles são debulhados, separando os frutos do amendoim do resto da planta (PEANUT COMPANY OF AUSTRALIA, 2010).

Todas as partes da planta do amendoim podem ser facilmente utilizadas. As videiras com folhas de feno fornecem excelente proteína para os cavalos e os animais ruminantes. As cascas podem ser utilizadas como alimento para o gado, queima de combustível, empregada em painéis de partículas, e muitos outros usos. As sementes podem ser usadas diretamente para a alimentação ou esmagadas para a produção de óleo (BUNTING et al., 1985). Óleo de amendoim pode ser usado na cozinha, como combustível para iluminação, como componente dos alimentos ou in natura (HAMMONS, 1982). O múltiplo uso do amendoim o torna uma excelente cultura para os mercados internos, bem como de comércio exterior.

Em 2001, a Associação Brasileira da Indústria de chocolate, cacau, balas e derivados $(A B I C A B)$ criou o Programa Pró-Amendoim para estabelecer padrões de qualidade (controlar o nível de aflatoxinas e implementar ações de segurança do alimento) e aumentar o consumo. Assim, a cadeia produtiva do segmento começou a se organizar e os produtores começaram a implantar processos modernos de secagem industrial (ZEPPER, 2006). De modo gradual, o Programa Pró-Amendoim foi tendo êxito, haja vista que suas ações já implicaram em um aumento de $8 \%$ no consumo em 2005 em relação a 2004. As ações de fomento da ABICAB também têm melhorado a dinâmica do comércio exterior brasileiro de amendoim e seus derivados. Em 2006, o Brasil quase que não fez importações ao passo que exportou o equivalente a US $\$ 52,225$ milhões de amendoim e seus derivados. (ZEPPER, 2006; MINISTÉRIO DO DESENVOLVIMENTO, INDÚSTRIA E COMÉRCIO EXTERIOR, Secretaria de Comércio Exterior, 2010). 
Nas figuras 1 e 2 observamos o aumento do consumo aparente nos últimos anos e o consumo per capto, referente ao amendoim, no Brasil.
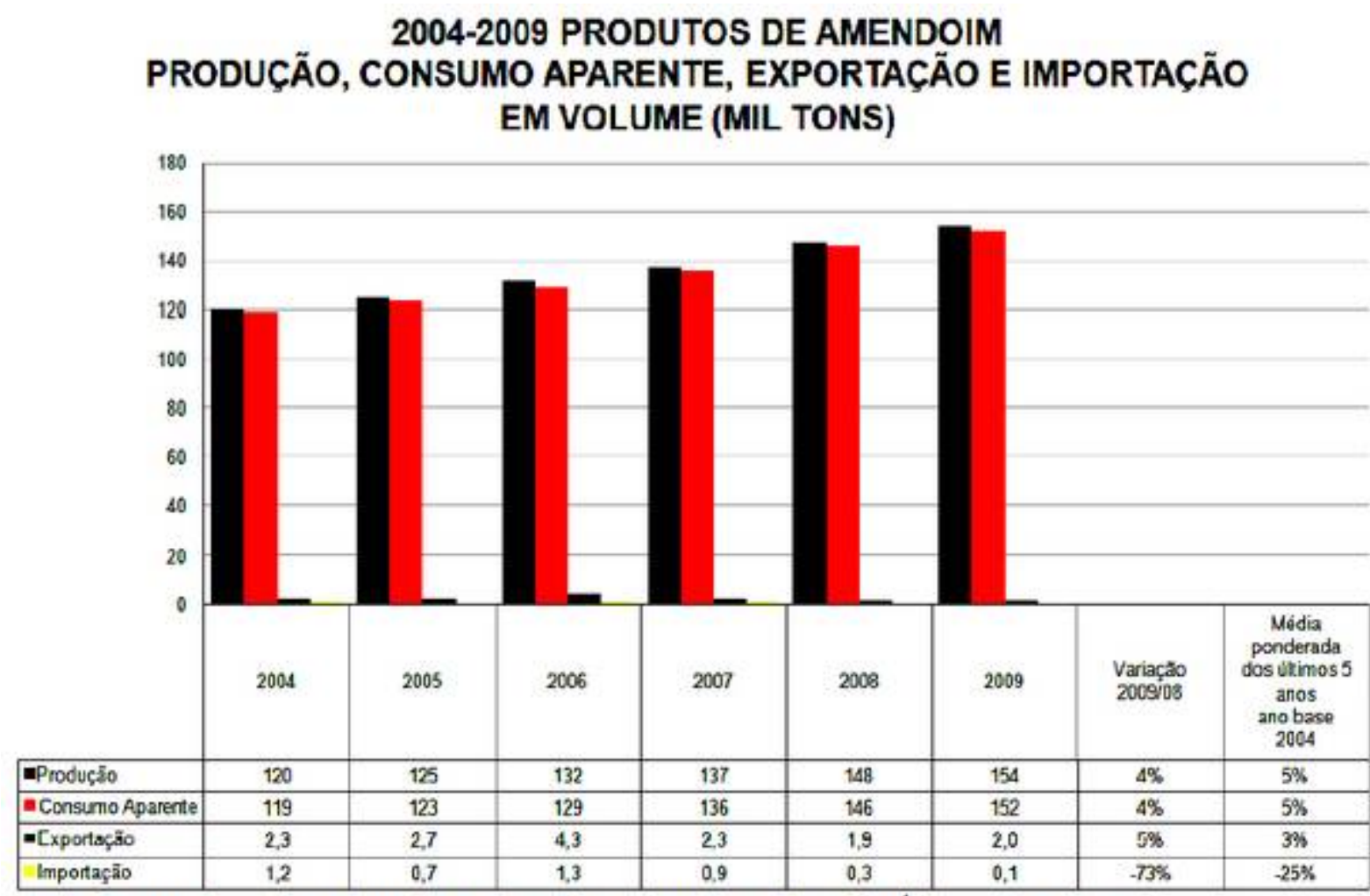

Figura 1 - Consumo Aparente = Produção + Importação - Exportação.

Fonte:UHY MOREIRA-AUDITORES. Elaborado pelo setor de Economia e Estatística ABICAB-SICAB. File: C. Economia / Consumo Aparente XLS.

\begin{tabular}{|l|l|}
\hline Regiões & $\mathbf{K g} /$ habitantes \\
\hline ES, MG e Interior RJ & 0,86 \\
\hline Grande RJ & 0,99 \\
\hline Grande SP & 1,08 \\
\hline Interior SP & 1,08 \\
\hline MG, GO e DF & 0,72 \\
\hline Nordeste & 0,40 \\
\hline PR, SC e RS & 1,02 \\
\hline Média & $\mathbf{0 , 8 0}$ \\
\hline
\end{tabular}

Figura 2 - Consumo Per Capita Brasileiro.

Fonte: Tendências 2008- Elaborado por N\&P Consultores- População das áreas do Norte foram excluídas, porquanto a Nielsem não monitora aquelas áreas. Foi considerada uma população, em 2007, de 171,1 milhões de brasileiros

No início de 2010 , a área destinada ao plantio do amendoim foi $20 \%$ menor em comparação com a safra anterior. Isso aconteceu por dois motivos: os preços baixos desestimularam os produtores e o excesso de chuva atrasou a colheita da 
cana, o que acabou reduzindo a oferta de terras destinadas ao plantio do grão. Segundo estimativas da Companhia Nacional de Abastecimento (Conab), por causa da redução de área, a safra terá 60 mil toneladas a menos em comparação com a safra passada. No ano passado, a saca de 25 quilos foi comercializada por uma média de $R \$ 14,00$. Para este ano, a expectativa é ficar entre $R \$ 18,00$ e $R \$ 20,00$. Apesar da diminuição da área de plantio, a produtividade por hectare deverá crescer. Calcula-se um aumento de $25 \%$ na produtividade este ano (Globo Rural, 2010).

Segundo o relatório lançado pelo USDA em maio de 2010, a China foi a maior produtora de amendoim em 2008/09, com 14,29 milhões de toneladas. A área de produção e as revisões são baseadas em dados recém publicados a partir de oleaginosas do Departamento Nacional das Estatísticas, que relatou que a produção mundial da oleaginosa em 2008/09, teve o valor de 34,51 milhões de toneladas. Os países que seguem como maiores produtores (em milhões de toneladas) são: Índia $(6,25)$, Estados Unidos (2,34), Nigéria $(1,55)$ e Indonésia $(1,25)$ (USDA, 2010).

Na América do Sul, a produção obtida com a safra de 2008/2009 foi de 0,30 milhões de toneladas no Brasil e 0,90 milhões de toneladas na Argentina (USDA, 2010).

\subsubsection{Variedades de amendoim}

No estado de São Paulo, as duas principais regiões produtoras são a regiões norte, em municípios próximos a Ribeirão Preto (Alta Mogiana) e a região oeste em municípios próximos a Marília e Tupã (Alta Paulista) (SANCHES, 2003). Esta última região merece destaque, pois nela além da produção, acontece também a industrialização do amendoim. Segundo Martins e Perez (2006) esta região forma atualmente o Arranjo Produtivo Organizado (APO) em alimentos, atuando no processamento do amendoim, balas, bolachas, panificação e confeitos.

De acordo com João e Lourenzani (2006), a produção paulista é realizada em duas safras: a das águas (outubro a março) e a da seca (fevereiro a julho), sendo que esta é praticada tradicionalmente na região da Alta Paulista, correspondendo a aproximadamente $20 \%$ da produção. Na região da Alta Mogiana, como o amendoim é plantado em rotação com a cana-de-açúcar, a produção se concentra na safra das águas (80\% da produção). 
A produção agrícola nessas regiões tem o apoio de cooperativas. Na região da Alta Paulista, a Cooperativa Agrícola Mista da Alta Paulista (CAMAP) desempenha papel fundamental no cultivo do amendoim, sendo provedora de insumos e dos serviços de assistência técnica, secagem, armazenagem e comercialização. Além de grande investidora em técnicas que melhorem a produção, produtividade, preço e qualidade do amendoim, a CAMAP aplicou, na ordem de 5 milhões, na construção de um complexo de secagem que atualmente atende toda a região. Outro fato importante a ser considerado na região de Marília e Tupã é a mudança na dinâmica de ocupação nas áreas de plantio pelo avanço da cultura da cana-de-açúcar no oeste paulista, reduzindo assim a área destinada ao amendoim das secas. Isso porque o período destinado à produção da safra da seca coincide com parte do ciclo produtivo da cana-de-açúcar, dessa forma, a região da Alta Paulista, principal produtora dessa safra, vem apresentando tendência a um comportamento semelhante ao que ocorre na região de Alta Mogiana, onde predomina a safra das águas realizada na renovação de canaviais (MARTINS e PEREZ, 2006).

No Estado de São Paulo o grupo de variedades de maior importância é o Runner. Seu destaque está na sua já consagração no mercado internacional, por ser semelhante aos grãos de outros países exportadores, como Argentina, Estados Unidos e China. Runner tem alto desempenho e é recomendada para áreas com boa distribuição de chuvas e para lavouras tecnificadas. Também requer solos bem preparados e adubados. Em boas condições, sua produtividade pode ultrapassar $6.500 \mathrm{~kg} / \mathrm{ha}$. É uma boa alternativa para a rotação com a cana-de-açúcar (FAGUNDES, 2008; GODOY et al., 2003).

Entre as variedades Runner existentes no mercado, a mais utilizada nas regiões produtoras do Brasil, é a IAC 886, sendo também utilizada, mas em escala menor, a variedade IAC-Caiapó. O cultivar Runner IAC 886 descende da cultivar Florunner, de origem americana. As sementes foram cedidas em 1970 pelo programa de melhoramento da Flórida (EUA) e introduzidas na coleção de germoplasma do Instituto Agronômico de Campinas (IAC) com o número 886. A população original assim obtida passou por 18 gerações de cultivo e seleção, resultando em material genético uniforme e mais bem adaptado às condições de clima e solo das regiões produtoras paulistas quando comparado a cultivares do 
mesmo tipo, genericamente conhecidos como "runners" (sementes sem origem definida encontradas regionalmente com produtores) (GODOY et al., 2003).

As médias de produtividade de amendoim em casca, da cultivar Runner IAC 886, supera as médias de IAC-Caiapó em $9 \%$ a $11 \%$, podendo ultrapassar 6.500 $\mathrm{kg} / \mathrm{ha}$ (potencial produtivo). Em experimentos comparativos a outras cultivares genericamente denominadas "runners", a cv. Runner IAC 886 apresentou produtividade média entre $10 \%$ e $27 \%$ superiores (GODOY et al., 2003).

A cultivar Runner IAC 886 apresenta crescimento rasteiro. As plantas diferem das IAC-Caiapó (também do grupo rasteiro) por apresentarem folhagem de tonalidade ligeiramente mais escura e haste principal mais destacada. Nas condições de São Paulo, seu ciclo, do plantio à maturação é, em média, de 130 dias. A duração do ciclo geralmente é mais definida quando comparada ao cultivar IACCaiapó, que muitas vezes atinge 135-140 dias. Após a semeadura, as plântulas apresentam emergência mais rápida do que as da IAC-Caiapó, a fase de florescimento e emissão de vagens também são mais rápidas, com o final do desenvolvimento vegetativo praticamente em 90-100 dias. As vagens são uniformes, apresentam baixa reticulação e produzem duas sementes com película clara, de tonalidade rosada. Em condições normais de cultivo, sua produção varia entre 18-20 $\mathrm{kg}$ de grãos $/ 25 \mathrm{~kg}$ em cascas. As duas cultivares produzem significativas proporções de grãos comerciais classificados nas peneiras iguais ou maiores que 22, com predominância de 24 e 26, o que equivale à granulometria desejável para grãos do tipo comercial runner, no mercado de exportação. Runner IAC 886 é capaz de produzir, ainda, mais de $20 \%$ de grãos de peneiras iguais ou superiores que 28 , equivalente a grãos de maior valor comercial, nesse segmento de comercialização (GODOY et al., 2003).

A variedade IAC-Caiapó foi desenvolvida pelo Instituto Agronômico e lançada oficialmente em 1996, objetivando oferecer alternativa para aumento de rentabilidade ao produtor de amendoim. O IAC-Caiapó é composto de cinco linhagens irmãs obtidas por seleção genealógica do cruzamento entre 0 germoplasma 5329, da coleção do IAC, e o cultivar Tatuí. Os grãos da cultivar apresentam relação ácido oléico / ácido linoléico (O/L) próximo de 2,0, contra uma relação ao redor de 1,0 do amendoim tradicional. Quanto maior a relação O/L, maior o período para que o amendoim apresente oxidação (rancificação), ou seja, maior será a "vida de prateleira" do produto (CONAB, 2007). 
Segundo a Conab (2007), outro fator importante de qualidade do IAC-Caiapó é a redução nas contaminações por aflatoxinas, atribuída às seguintes características do cultivar:

1. Ciclo mais longo, adiando a colheita para época mais propícia à secagem de campo;

2. Dormência das sementes, propiciando colheitas sem a presença de amendoins "brotados", que são altamente suscetíveis às infecções por Aspergillus flavus e Aspergillus parasiticus;

3. Resistência a doenças de folhas e eficiente granação, resultando em maior proporção de vagens e grãos sadios, portanto mais protegidos de infecções por esses fungos.

\subsection{Micobiota}

Muitas doenças que acometem a planta de amendoim são causadas por agentes infecciosos (bióticos) e não-infecciosos (abióticos). Os agentes bióticos causadores de doenças de maiores importâncias são os fungos, bactérias, nematóides, vírus e viróides (PORTER, 1997). Os fungos podem causar uma série de danos aos grãos durante o plantio e a colheita, bem como durante o armazenamento (SILKER e ELLIOT, 1980). O impacto econômico da invasão fúngica inclui a diminuição do poder de germinação, emboloramento visível, descoloração, odor desagradável, perda de matéria seca, aquecimento, cozimento, mudanças químicas e nutricionais com consequente perda da qualidade, produção de micotoxinas, tornando-os impróprios para o consumo (CHRISTENSEN, 1982; PASTER e BULLERMAN, 1988).

Os fungos são os mais numerosos de todos os patógenos, sendo alguns parasitas, obtendo seus alimentos de outras plantas vivas, como o amendoim, podendo penetrar diretamente no hospedeiro, por aberturas ou pelo ar. No interior do tecido, o fungo cresce intercelularmente ou intracelularmente. Aproximadamente 50 gêneros de fungos são agentes causadores de doenças em amendoim (PORTER, 1997).

O solo é um reservatório primário de muitos microrganismos, como os fungos, inclusive do gênero Aspergillus. Informações sobre a densidade populacional de fungos no solo são importantes para o controle dos patógenos. Em culturas como o 
amendoim, após a fertilização aérea da flor e a penetração do ginóforo no solo, os frutos se desenvolvem em condições subterrâneas e podem ser invadidos por muitas espécies de fungos, durante o crescimento e desenvolvimento da planta. Condições ambientais e práticas agrícolas durante a produção, colheita, manipulação e estocagem podem afetar a natureza e grau da micoflora (DIENER e DAVIS, 1977; HOLADAY e LANSDEN, 1975).

A contaminação com aflatoxinas no campo é de difícil controle devido à influência das condições climáticas, como umidade relativa e temperatura. Teores de umidade no solo, danos provocados por insetos na planta, deficiência mineral, estresse hídrico, são importantes fatores na contaminação. No entanto, as mais altas concentrações de aflatoxinas estão associadas com o crescimento de $A$. flavus e $A$. parasiticus após a colheita em condições inadequadas de armazenamento (MOSS, 1991). Assim, concentrações em ppm (partes por milhão) podem ser facilmente detectadas em países de clima quente e úmido, em regiões tropicais e subtropicais no mundo, embora possam ser controladas com métodos adequados de secagem e conservação dos grãos (BHAT et al., 1997).

\subsubsection{Aspergillus flavus e Aspergillus parasiticus}

Aspergillus flavus e $A$. parasiticus são normalmente relatados como fungos produtores de aflatoxinas, que podem infectar culturas, como milho, algodão e amendoim, principalmente em regiões tropicais e subtropicais. Podem estar distribuídos pelo mundo todo, no solo, ar, material orgânico e partes de plantas. Causam grandes perdas econômicas por destruírem a planta ou por contaminar os grãos de amendoim com aflatoxinas (DIENER e DAVIS, 1977; COTTY et al., 1994).

Cepas de $A$. flavus produzem normalmente aflatoxinas do tipo $B_{1}$ e $B_{2}$. $A$. parasiticus produz aflatoxinas $B_{1}, B_{2}, G_{1}$ e $G_{2}$ (PITT, 1997). Há grande diferença quantitativa na capacidade toxigênica exibida por diferentes cepas dentro de cada espécie aflatoxigênica. A. flavus e $A$. parasiticus são contaminantes naturais de cereais, figos secos, oleaginosas, nozes, tabaco, e uma longa lista de outros produtos de ocorrência comum (DETROY et al., 1971; DIENER et al., 1987)

O solo é um grande reservatório de microrganismos e abriga muitos destes fungos, favorecendo a contaminação por aflatoxinas (ANGLE et al., 1982; HORN et al., 1994; LILLEHOJ et al., 1980). No entanto, A. flavus tem demonstrado ser mais 
agressivo que $A$. parasiticus na infecção dos grãos de amendoim (HILL et al., 1985; HORN et al., 1994). Apesar de menos agressivo, A. parasiticus é mais prevalecente em grãos de amendoim do que em outras culturas (DIENER et al., 1987).

A. flavus também pode lançar um grande número de conídios no ar, que são dispersos pelo vento e possivelmente por insetos. Os insetos transportam os conídios aderidos em seus corpos e órgãos, para as partes das plantas, podendo depositá-los nas fezes (DIENER et al., 1987).

Além das aflatoxinas, $A$. flavus também pode produzir o ácido ciclopiazônico (DORNER et al., 1984).

No Brasil, Gonçalez et al. (2008a) verificaram a presença de A. flavus em $17 \%$ das amostras de amendoim colhidas no período de crescimento da planta, na região de Junqueirópolis, SP. Nakai et al. (2008) analisaram amostras de amendoim colhidas durante o armazenamento, por 12 meses, na região de Tupã, SP e verificaram a presença de $A$. flavus em $21,2 \%$ das amostras. Outros pesquisadores brasileiros confirmaram a ocorrência de $A$. flavus em amostras de amendoim (FERNANDEZ et al., 1997; ROSSETO et al., 2005)

Vaamonde et al. (2003) isolaram 37 cepas de A. flavus e 30 cepas de A. parasiticus em 30 amostras de amendoim colhidas em Córdoba, Argentina. Dessas cepas isoladas, $73 \%$ eram aflatoxigênicas. Schroeder e Boller (1973) verificaram a presença de $A$. flavus e a produção de aflatoxinas em amendoim, sementes de algodão, arroz e sorgo e notaram maior proporção de $A$. flavus nas amostras de amendoim. Alguns autores relatam a elevada frequência de $A$. flavus em grãos de amendoim e em solos cultivados com a planta (LISKER et al., 1993; HORN et al., 1996).

\subsubsection{Esclerócio}

Esclerócios são estruturas de sobrevivência importante no ciclo de vida de muitos fungos.

Estudos sobre as condições responsáveis pelo surgimento de esclerócios podem ser importantes no desenvolvimento de métodos para evitar sua formação, resultando em reduzida sobrevivência do fungo e melhor controle da contaminação (McALPIN, 2004). 
Escleródios podem ser formados em resposta a condições adversas ou como uma etapa normal do ciclo de vida de Aspergillus (MOORE, 1995). Se esses fungos crescem no ecossistema de armazenamento sob condições ideais de atividade de água e temperatura (GQALENI et al. 1996), o ciclo de vida pode ser completo com a formação de esclerócios. Os esclerócios de Aspergillus servem principalmente para produzir conídios (WICKLOW e DONAHUE, 1984; WICKLOW e WILSON, 1986). Por conseguinte, a invasão de espécies de Aspergillus e concomitante produção de aflatoxinas podem ocorrer (McALPIN, 2004).

Com base nos critérios fisiológicos, morfológicos e genéticos, cepas de $A$. flavus podem ser divididas em dois grupos, $\mathrm{S}$ e $\mathrm{L}$. Isolados da cepa $\mathrm{S}$ produzem numerosos esclerócios ( $<400 \mu \mathrm{m}$ em diâmetro) e a cepa $\mathrm{L}$ produzem esclerócios maiores, mas em menores quantidades (>400 $\mu \mathrm{m}$ em diâmetro). Cepas $\mathrm{S}$ produzem, em média, mais aflatoxina do que a cepa L (GARBER e COTTY, 1997).

Isolados de cepas $L$ podem produzir aflatoxinas $B_{1}$ e $B_{2}$ ou $A C P$, ou ambos ou nenhuma toxina (EGEL et al., 1994), enquanto que todas as cepas $S$ produzem relativamente grandes quantidades de aflatoxinas, algumas produzem somente AFB e outras produzem aflatoxinas B e G (SAITO et al., 1986; EGEL et al., 1994; COTTY e CARDWELL, 1999). Isolados de $A$. parasiticus produzem aflatoxinas $B_{1}, B_{2}, G_{1} e$ $\mathrm{G}_{2}$, mas não produzem ACP (PITT, 1997).

Muitas pesquisas relatam a importância de trabalhos envolvendo o estudo da produção de esclerócios. Barros, Torres e Chulze (2005), avaliaram a distribuição de cepas $L$ e $S$ entre $A$. flavus isolados de solo de regiões produtoras de amendoim. Os resultados revelaram que $73 \%$ das cepas eram $A$. flavus, com $59 \%$ de cepas $L, 22 \%$ de cepas S e 19\% não produziram esclerócios. Vaamonde et al. (2003), verificaram a produção de esclerócios e a relação com a produção de aflatoxinas e ACP em cepas de $A$. flavus isoladas de amendoim, soja e trigo. As cepas de $A$. flavus foram identificadas como $S$, onde $73 \%$ foram aflatoxigênicas e $94 \%$ produtoras de ACP. Nesci e Etcheverry (2002) isolaram apenas cepa de $A$. flavus, fenótipo $L$ de insetos e solo com plantio alternado de milho, amendoim e soja, em algumas regiões. Em regiões de cultivo de amendoim nos EUA, Horn e Dorner (1998) verificaram que a cepa $S$ foi mais prevalecente no oeste do Texas e Louisiana. 


\subsection{Micotoxinas}

Todas as micotoxinas são produtos naturais de baixo peso molecular, produzidos por fungos filamentosos como metabólitos secundários. Estes metabólitos podem causar doenças e morte em seres humanos e outros vertebrados (BENNETT, 1987).

O termo "micotoxinas" foi criado em 1962, em decorrência de uma crise na Inglaterra, na qual, cerca de 100 mil perus morreram (BLOUT, 1961; BRESSAC et al., 1991). Essa misteriosa doença estava ligada ao farelo de amendoim contaminado com metabólitos secundários de $A$. flavus (aflatoxinas), que sensibilizou os cientistas a possibilidade de que esses metabólitos poderiam ser mortais.

O período de ouro das micotoxinas ocorreu entre 1960 e 1975, denominado como o rush das micotoxinas (MAGGON et al., 1977), pois muitos cientistas se juntaram em busca de financiamentos em prol desses agentes toxigênicos. De acordo com a definição utilizada, e reconhecendo que as toxinas de fungos podem ocorrer em grupos de metabólitos quimicamente relacionados, cerca de 300 a 400 compostos são agora reconhecidos como micotoxinas, dos quais, cerca de uma dúzia de grupos recebem regularmente a atenção como ameaças à saúde humana e animal (COLE e COX, 1981). Micotoxicoses são as doenças dos animais causadas por micotoxinas; Micotoxicologia é o estudo de micotoxinas (FORGACS e CARLL, 1962).

Apesar de todas as micotoxinas serem de origem fúngica, nem todos os compostos tóxicos produzidos por fungos são chamados de micotoxinas. $\mathrm{O}$ alvo e a concentração do metabólito são importantes. Os metabólitos produzidos por fungos que são tóxicos para as bactérias (tais como penicilina) são geralmente chamados antibióticos. Metabólitos de fungos que são tóxicos para as plantas são chamados fitotoxinas por fitopatologistas (Confusamente, o termo "fitotoxina" também pode referir-se as toxinas produzida pelas plantas) (GRANITI, 1972).

Micotoxinas não são só difíceis de definir, mas também são desafiadoras para classificar. Muitas vezes, sua classificação é feita de acordo com o órgão que elas afetam. Assim, as micotoxinas podem ser classificadas como hepatotoxinas, nefrotoxinas, neurotoxinas, imunotoxinas, e assim por diante. Podemos classificá-las também em grupos genéricos, tais como: teratogênicos, mutagênicos, 
carcinogênicos e alergênicos. Químicos orgânicos tentaram classificá-las por suas características químicas estruturais (por exemplo, lactonas, cumarinas). Os bioquímicos, de acordo com suas origens biossintéticas (policetídeos, derivados de aminoácidos, etc). Os médicos, pelas doenças que provocam (por exemplo, Fogo de Santo António), e os micologistas, de acordo com os fungos que as produziram (por exemplo, Aspergillus toxinas, Penicillium toxinas) (BENNETT e KLICH, 2003).

\subsubsection{Aflatoxinas}

As espécies Aspergillus flavus, Aspergillus parasiticus e Aspergillus nomius são as principais produtoras de aflatoxinas $B_{1}, B_{2}, G_{1}$ e $G_{2}$, metabólicos secundários biologicamente ativos (SMITH e ROSS, 1991). Cepas de A. flavus podem produzir aflatoxinas do tipo $B_{1}$ e $B_{2}$ ou ACP, ou ambos ou nenhuma toxina (EGEL et al., 1994). Cepas de $A$. parasiticus produzem, normalmente, aflatoxinas B e G, mas não produzem ACP. A nomius é morfologicamente muito semelhante ao A. flavus, mas produz aflatoxinas $\mathrm{B}$ e $\mathrm{G}$ como o $A$. parasiticus e não é capaz de produzir ACP (PITT, 1993)

Todas as aflatoxinas têm efeito carcinogênico, sendo que a aflatoxina $B_{1}$ $\left(A F B_{1}\right)$ é considerada a mais tóxica do grupo, seguida das aflatoxinas $G_{1}, B_{2}$ e $G_{2}$, sendo também a mais comumente encontrada nos alimentos contaminados por aflatoxinas (BENNETT e KLICH, 2003; SHARMA e SALUNKE, 1991; ZERINGUE et al, 1993). A aflatoxina $B_{1}$ é uma das substâncias mais tóxicas de ocorrência natural registradas até hoje. As aflatoxinas foram classificadas na classe 1 dos carcinógenos humanos pela International Agency for Research on Cancer (IARC, 1993).

No caso do amendoim, por ser um fruto subterrâneo, suas vagens estão diretamente expostas à contaminação (HORN et al, 1994; HORN et al, 2000). As culturas podem ser contaminadas com aflatoxinas no campo, antes da colheita, onde é geralmente associada a estresse hídrico e ataque de insetos (DIENER et al., 1987; KLICH, 1987). No armazenamento, geralmente, as mais importantes variáveis que favorecem a contaminação são: o índice de umidade do substrato e a umidade relativa do ambiente (DETROY et al., 1971; WILSON e PAYNE, 1994). A contaminação por aflatoxinas tem sido associada ao aumento da mortalidade em animais e, portanto, redução significativamente no valor dos grãos para alimentação 
animal ou como um produto de exportação (SMITH e MOSS, 1985). Os produtos lácteos também podem servir como uma fonte indireta de aflatoxina. Quando vacas consomem alimentos contaminados por aflatoxinas, eles metabolicamente biotransformam aflatoxina $B_{1}$ em compostos hidroxilados chamado aflatoxina $M_{1}$ (VAN EGMOND, 1989).

Os baixos níveis de aflatoxinas em alimentos, às vezes em menos de 1 ppm, podem causar a queda no crescimento, interferir no sistema imunológico e resultar em danos no fígado e hemorragias. Doses elevadas podem causar a perda aguda de apetite, depressão, hemorragia, diarréia e morte. Os sinais de intoxicação com aflatoxinas podem revelar um crescimento lento, reduzir a produção de leite, hemorragias e icterícia (coloração amarela da pele e dos olhos). Com a exposição contínua, haverá danos ao fígado e supressão da resposta imune e capacidade de resistir a infecções, ou para responder adequadamente às vacinas (IOWA STATE UNIVERSITY, 2010).

Em 1974, um surto de hepatite afetou 400 pessoas na Índia, onde 100 morreram. Indícios de que tais danos tenham sido causados pela ingestão de aflatoxinas foram obtidos com a comprovação do milho consumido, contendo cerca de, $15 \mathrm{mg} / \mathrm{kg}$ de aflatoxinas. Em média, 2-6 mg de aflatoxinas foram consumidas por adultos em um único dia, indicando que a dose letal aguda para humanos adultos está na ordem de $10 \mathrm{mg}$ (KRISHNAMACHARI et al., 1975).

Aflatoxina $B_{1}$ tem sido demonstrada, em varias espécies de animais, como o mais potente carcinógeno em fígado. Já se sabe que a carcinogenicidade em animais é tão grande que todos os esforços devem ser feitos para monitorar os níveis de aflatoxinas na alimentação humana e para reduzi-las na medida do possível. Alta incidência de câncer de fígado em humanos tem sido registrado na África Central, parte do Sudeste da Ásia, China, Caribe e América do Sul (JELINEK et al., 1989). Estudos em muitos países africanos e na Tailândia mostraram uma correlação entre aflatoxinas e a ocorrência primária de câncer de fígado em humanos (VAN RENSBURG, 1977).

Há também evidências consideráveis associando aflatoxina com neoplasias em tecidos extra-hepáticos, em especial os pulmões. Por exemplo, um estudo epidemiológico com trabalhadores holandeses expostos a poeiras provenientes do processamento do amendoim, contaminadas com aflatoxinas $B_{1}$ mostrou uma correlação entre o câncer respiratório com o câncer total e no grupo exposto quando 
comparado com os não expostos (HAYES et al., 1984). Indícios de ocorrência de câncer após a exposição a aflatoxina, por via aérea, tem sido relatada. Deger (1976) concluiu que o pó contendo aflatoxina contribuiu para causar câncer em dois adultos jovens. A aflatoxina é um cancerígeno pulmonar em animais experimentais. Os efeitos não hepáticos de aflatoxina $B_{1}$ foram resumidos por alguns autores (COULOMBE et al.,1994; DEGER, 1976).

No Brasil, o Ministério da Saúde, resolução RDC no 274 (ANVISA, 2002) e o Ministério da Agricultura, Portaria MAARA No.183 (BRASIL, 1996) estabeleceu o limite máximo de aflatoxinas $\left(B_{1}+B_{2}+G_{1}+G_{2}\right)$ permitido em amendoim para consumo humano (com casca, descascado, cru ou tostado) e em pasta de amendoim (pasta de amendoim ou manteiga de amendoim), de $20 \mu \mathrm{g} / \mathrm{kg}$ (ppb).

Em outros países com elevada produção, como a China, a legislação estabelece em arroz e óleos comestíveis que o limite de $\mathrm{AFB}_{1}$ (aflatoxina $\mathrm{B}_{1}$ ) seja 10 $\mu \mathrm{g} / \mathrm{kg}$; farelo de amendoim e outros resíduos de amendoim (para ração) não podem exceder o limite de $50 \mu \mathrm{g} / \mathrm{kg}$. Na Índia, o limite permitido de AFB 1 é de $30 \mu \mathrm{g} / \mathrm{kg}$ para todos os alimentos e $120 \mu \mathrm{g} / \mathrm{kg}$ em farelo de amendoim, para exportação. $\mathrm{Na}$ Indonésia, o limite permitido para aflatoxinas $B_{1}+B_{2}+G_{1}+G_{2}$ é de $200 \mu \mathrm{g} / \mathrm{kg}$ para farelos de amendoim. Na Nigéria, o limite máximo de $A F B_{1}$ em todos os alimentos é de $5 \mu \mathrm{g} / \mathrm{kg}$ e $50 \mu \mathrm{g} / \mathrm{kg}$ em rações. Nos EUA, alimentos não podem apresentar mais que $20 \mu \mathrm{g} / \mathrm{kg}$ de aflatoxinas $B_{1}+B_{2}+G_{1}+G_{2}$ (FONSECA, 2010 a).

Fonseca et al. (1994), avaliaram a presença de aflatoxinas em grãos armazenados tratados com fungicidas e relataram que mesmo após o tratamento ocorreu a produção de aflatoxinas, embora tenha sido reduzido a micoflora presente na casca.

Sabino et al. (1999), analisaram trinta e sete amostras de amendoim coletadas no varejo, em SP, entre 1995 e 1997, e verificaram que 45\% das amostras foram positivas para aflatoxinas e que $27 \%$ excediam os limites de $30 \mu \mathrm{g} / \mathrm{kg}$ para aflatoxinas $B_{1}+G_{1}$, variando entre 5,0 a $494,0 \mu \mathrm{g} / \mathrm{kg}$.

Schroeder e Boller (1973) analisaram amostras provenientes do Texas durante 3 anos e constataram que 96\% das cepas de $A$. flavus isoladas produziram níveis elevados de aflatoxinas em amendoim.

Asis et al. (2005) estudaram a resistência de seis variedades de amendoim a infecção por $A$. flavus e $A$. parasiticus e a conseqüente contaminação por aflatoxinas. Os autores inocularam cepas isoladas de amendoins de regiões 
produtoras e verificaram que apesar da elevada produção de aflatoxinas (de 100 a $70000 \mu \mathrm{g} / \mathrm{kg}$ ), três variedades foram mais resistentes.

\subsection{2 Ácido ciclopiazônico}

O ácido ciclopiazônico (ACP) foi isolado pela primeira vez a partir do Penicillium cyclopium (HOLZAPFEL, 1968). Posteriormente, foi relatado como um metabólito do A. flavus Link (LUK et al.,1977). Gallagher et al. (1978) relataram que 28 de 54 cepas de $A$. flavus isoladas produziram ACP, enquanto 18 produziram apenas aflatoxinas.

Muitos trabalhos relatam o ACP como outra micotoxina comum em amendoim, resultante da contaminação por $A$. flavus, co-ocorrendo com as aflatoxinas (URANO et al., 1992). O Ácido ciclopiazônico é uma micotoxina potente que, se ingerida em elevada concentração, pode produzir focos de necrose em órgãos internos de vertebrados como o fígado, afetar os ductos, além de efeitos neurotóxicos (FRISVAD et al., 2006; PILDAIN, VAAMONDE e CABRAL, 2004).

Sinais clínicos da intoxicação com ACP, como anorexia, diarréia, degeneração e necrose dos músculos e vísceras, desidratação, perda de peso e convulsões, foram observados em ratos, cães, suínos, ovelhas e aves (CULLEN et al., 1988; COUNCIL FOR AGRICULTURE SCIENCE AND TECHNOLOGY, 2003). Efeitos neurotóxicos causados pelo ACP, como catalepsia e sedação, também foram descritos em suínos desmamados (LOMAX et al., 1984).

O ACP pode ser transferido para o leite e ovos após a administração oral, por ovelhas lactantes e galinhas poedeiras (DORNER et al., 1994), o que torna a ingestão desses subprodutos animais contaminados uma potencial fonte de exposição humana (OLIVEIRA et al., 2006).

Outros substratos como, milho, milho moído, queijo e amendoim também apresentaram contaminação com o ACP (LANSDEN, 1986; LE BARS, 1979; RAO e HUSAIN, 1985).

Pildain et al. (2004), isolaram cepas de $A$. flavus de 40 amostras de amendoim provenientes do campo em Formosa, Argentina e verificaram que 78\% dos isolados eram produtoras de esclerócios e que dessas cepas $89 \%$ eram L, produtoras de aflatoxinas e ACP. 
Gonçalez et al. (2008a) encontraram ACP em 32\% das amostras coletadas no campo, em Junqueirópolis, SP, em concentrações variando entre 206 a $600 \mu \mathrm{g} / \mathrm{kg}$. A co-ocorrência natural de aflatoxinas e ACP foram reportados por autores como Fernandez-Pinto et al. (2001), Mphame et al. (2004), Barros et al. (2005), Lansden e Davison (1983), Burdock e Flamm (2000) e Rao e Husain (1985).

Razzaghi-Abyanch et al. (2006) isolaram de solos do Iran cepas de Aspergillus seção Flavi e constataram que $87,9 \%$ eram $A$. flavus e $3,0 \%$ eram $A$. parasiticus. Das cepas de $A$. flavus apenas $27,5 \%$ eram aflatoxigênicas $\left(B_{1}\right.$ ou $B_{1} \mathrm{e}$ $B_{2}$ ) e $75 \%$ eram capazes de produzir ACP. Todas as cepas de $A$. parasiticus produziram aflatoxinas $B$ e $G$, mas não produziram $A C P$.

\subsection{Fatores abióticos}

O crescimento fúngico e a produção de micotoxinas são influenciados por um conjunto de fatores. A compreensão de cada fator envolvido é fundamental para o entendimento total do processo de contaminação, assim como para predizer e prevenir a produção de micotoxinas (CHABERLAIN et al., 1993). As condições ambientais exercem grande impacto no crescimento fúngico e a produção de micotoxinas é geneticamente regulada em resposta dessas condições (HOLLINGER e EKPERIGIN, 1999).

Os fatores que podem afetar o desenvolvimento fúngico dos grãos de cereais são: conteúdo de umidade e Atividade de água ( $\mathrm{Aa}$ ) dos grãos, umidade relativa do ar, temperatura, tempo de armazenamento, condições dos grãos antes da colheita, quantidade de inóculo presente nos grãos antes do armazenamento e oxigenação (WILSON et al., 1981).

A água é provavelmente, o mais importante determinante para o crescimento fúngico em produtos estocados. Embora outros fatores como temperatura seja relevante, a ausência de água inviabiliza o crescimento fúngico (LACEY, 1988).

Nem toda a água presente no substrato está disponível para a utilização pelo microrganismo, pois parte dela pode estar fortemente presa ao substrato por ligações químicas (LACEY, 1988). A determinação da Aa de um alimento possibilita a avaliação da água disponível aos microrganismos, com valores oscilando entre $0 \mathrm{e}$ 1, sendo que a Aa da maioria dos alimentos frescos é superior a 0,99 (TROLLER et al., 1984; JAY, 1978). 
De acordo com Leitão (1988) e Lacey et al., (1991), a faixa de Aa ideal para o crescimento de $A$. flavus e $A$. parasiticus está entre 0,78 a 0,80 e 0,78 a 0,82, respectivamente. Para a produção de aflatoxinas, os níveis necessários de Aa estão entre 0,83-0,87 para o $A$. flavus e 0,87 para o $A$. parasiticus.

No momento do arranquio, o amendoim contém cerca de $40 \%$ de umidade ou mais. Enquanto a umidade estiver acima de 20-22\% a atividade metabólica da vagem oferece resistência à penetração do fungo e o risco de contaminação é reduzido. Abaixo de 11\% (no amendoim em casca) não há umidade suficiente para os fungos crescerem e também não há perigo de contaminação. O intervalo de 2220 até $11 \%$ de umidade é, portanto, o período crítico e se houver demora da secagem nesta fase, a probabilidade de contaminação do amendoim será maior. Desta forma, abaixo de $20 \%$ de umidade o amendoim deve ser seco o mais rapidamente possível até $11 \%$ e só então ser batido ou despencado e ensacado, para se evitar o desenvolvimento do $A$. flavus e, consequentemente, que haja contaminação com a aflatoxina. Nem sempre esta secagem rápida pode ser conseguida porque, na hora da colheita da safra de maior volume, que é a chamada "das águas", e que ocorre nos meses de janeiro/fevereiro, às vezes chove muitos dias em seguida ou faz dias nublados, o que impede uma secagem rápida (FONSECA, 2010b).

A queda da umidade relativa do ar está intimamente ligada à diminuição do índice pluviométrico. Schneider e Pendery (1983) constataram que, em épocas do ano com deficiência de água, a senescência da raiz das plantas é acelerada, resultando no envelhecimento precoce da planta, aumentando sua predisposição a contaminação por fungos.

A temperatura também é um fator importante para o crescimento fúngico no substrato. A maioria dos fungos que infectam as plantas na colheita é capaz de se desenvolver a temperatura de 0 a $30{ }^{\circ} \mathrm{C}$. Alguns podem crescer a temperaturas próximas a $35{ }^{\circ} \mathrm{C}$ e outros, próximo a temperaturas de congelamento. Tanto $0 A$. flavus como o $A$. parasiticus pode crescer entre $6-45{ }^{\circ} \mathrm{C}$, com faixa ótima de crescimento de $35{ }^{\circ} \mathrm{C}$ para o A. flavus e $35-37^{\circ} \mathrm{C}$ para o $A$. parasiticus (LACEY, 1991).

A contaminação do amendoim por $A$. flavus e $A$. parasiticus e a consequente produção de aflatoxinas pode ocorrer em vários estágios da produção, no campo e no armazenamento (DIENER et al., 1987). No campo, a contaminação por 
aflatoxinas pode estar associada com estações de seca, com a ocorrência de estresse hídrico da planta e desidratação do solo sob condições ambientais de elevada temperatura (COLE et al., 1989). Essa contaminação pré-colheita pode ser amenizada com irrigação adequada (DORNER et al., 1989). Após a colheita, antes do armazenamento, a contaminação pode ser evitada com uma pré-secagem do amendoim, diminuindo sua Aa (DIENER e DAVIS, 1970).

Mesmo com a presença de $A$. flavus no solo durante o desenvolvimento dos grãos de amendoim, a extensiva invasão por esse fungo e a contaminação com aflatoxinas dificilmente ocorre a menos que a planta de amendoim esteja submetida a estresse hídrico ou com frutos danificados por insetos (DICKENS, SATTERWHITE e SNEED, 1973; McDONALD e HARKNESS, 1967). Diener (1960) verificou no Sudeste dos Estados Unidos que, em anos de seca nas áreas produtoras de amendoim, ocorreram grandes perdas econômicas pela contaminação com aflatoxinas.

\subsection{Fitoalexinas}

Apesar das aparências, as plantas não aceitam de modo passivo as agressões que sofrem de vírus, fungos, bactérias, insetos e demais organismos ou de agentes não-biológicos, como radiação, temperaturas extremas, poluição e outros. Para sobreviver, durante sua evolução, elas desenvolveram mecanismos de resposta a danos e doenças, acionados assim que reconhecem a agressão. Adaptação e resistência traduzem-se por profundas alterações no metabolismo da célula vegetal, entre elas a síntese de proteínas de defesa, expressas por genes específicos, ativados através de mecanismos complexos. Tais proteínas exercem vários papéis na resistência e sobrevivência da planta, de forma direta (combatendo o agente agressor) ou indireta (mantendo a estrutura e as funções celulares). Saber como os vegetais se protegem é essencial para obter variedades agrícolas mais resistentes, o que pode aumentar a produção e a qualidade dos alimentos. (MARGIS-PINHEIRO et al., 1999).

Um grupo de substâncias que vem sendo estudada como mecanismo de defesa produzida pela planta é a fitoalexina. Segundo Müller e Borger (1940) a palavra fitoalexina origina do grego Phyton (planta) e alexin (composto de defesa). As fitoalexinas são antibióticos que apresentam baixo peso molecular, produzidas 
por muitas plantas em resposta a infecção por microrganismos como bactérias e fungos fitopatogenicos. Acredita-se que a maioria das plantas seja capaz de sintetizar fitoalexinas, mas algumas a fazem de maneira muito lenta, permitindo que o microrganismo complete a infecção antes que haja o acúmulo dessas substâncias em quantidades suficientes para inibi-lo. Para diversas interações planta-patógeno foi demonstrado que a velocidade de acúmulo das fitoalexinas é um dos fatores decisivos para o estabelecimento ou não da infecção (SOCIEDADE BRASILEIRA DE QUÍMICOS, 2005).

As fitoalexinas não são compostas por uma classe uniforme de substâncias, mas por vários grupos de produtos naturais. Fitoalexinas incluem os isoflavonóides, sesquiterpenes, diterpenes, furanoterpenoides, poliacetilenos, stilbene e outros compostos (STOESSL et al., 1976). O único critério para classificação destas substâncias como fitoalexinas é que elas se acumulam em altas concentrações apenas após a infecção e que inibam o crescimento de certos microrganismos (INGHAM e HARBORNE, 1976).

A produção de fitoalexinas sofre a influência de diversos fatores, como umidade, disponibilidade de água e temperatura, luz UV ou tratamento com íons de metais pesados, como os sais de mercúrio. Folhas, caules, raízes, sementes, tubérculos, flores e frutos podem sintetizar tal substância em resposta à presença de um patógeno, porém a idade e tipo de tecido podem ter uma forte influência sobre o nível de resposta (PAXTON e CHAMBERLAIN, 1969; LAZAROVITS et al., 1981; INGHAM, 1973).

No caso do amendoim, já se sabe que a planta produz fitoalexinas e que estas funcionam como proteção da planta a contaminação por Aspergillus. Alguns autores relataram à importância das fitoalexinas (WOTTON e STRANGE, 1985 e 1987; DORNER et al., 1989; TOKUSOGLU et al., 2005) e verificaram que a produção está relacionada com o estresse hídrico sofrido pela planta, podendo diminuir a produção com esse fenômeno climático, e com a variação da frequência de isolamento de $A$. flavus e A parasiticus. Wotton e Strange (1985), em seu estudo registraram que a variação da resistência entre os cultivares de amendoim estão correlacionados com a capacidade de rápido acúmulo de fitoalexinas em cada variedade.

Resveratrol é uma das maiores fitoalexinas fenólicas produzidas por diferentes partes da planta de amendoim, podendo ocorrer nas formas isoméricas de 
trans- e cis-. A infecção fúngica ou a luz UV podem estimular a produção e a reação de catalase de 4-hidroxicinamoil-CoA e malonil-CoA para a produção de transresveratrol (FRITZEMEIER e KINDL, 1981).

O resveratrol foi primeiramente detectado em Vitis vinifera, L., onde se acumulou nas folhas em resposta a danos mecânicos e exposição à luz ultravioleta, ao cloreto de alumínio (ADRIAN et al., 2000; OKUDA e YOKOTSUKA, 1996) ou ataque de fungos, principalmente por Botrytis cinerea e Plasmospora viticola. Irradiação de tecidos vegetais com a luz UV tem efeitos importantes sobre metabolismo de fenólicos. Irradiação com luz UVB parece estar associada a um aumento da concentração de enzima responsável pela biossíntese de flavonóides. (LISTER et al., 1994; GOLDBERG et al., 1995a, 1995b; THRELFALL, MORRIS e MAUROMOUSTAKOS, 1999). Tal composto pode ser produzido depois de tratamentos químicos, tais como aplicações de herbicidas ou fungicidas e pela exposição à luz UV (LANGCAKE e PRYCE,1976; THRELFALL et al., 1999).

Em estudo realizado por Sobolev et al. (2007) foi avaliado a produção de trans-resveratrol nas condições de estresse hídrico, infestações por broca, Aa e estádios de maturidade em 6 variedades de amendoim, na Geórgia (USA). Os autores verificaram maior produção de trans-resveratrol em vagens que sofreram ataques de insetos.

Como mencionado anteriormente, as fitoalexinas não são somente induzidas ou elicitadas nas plantas por microrganismos, mas também por irradiação UV e uma grande quantidade de químicos, incluindo sais de metais pesados e alguns componentes da parede celular dos fungos, incluindo a quitina. Portanto, uma alternativa para proteger as plantas de colheita, seria pulverizá-las com agentes elicitores (todos agentes que induzem a produção de fitoalexinas e outras respostas de defesa) de fitoalexinas de baixa toxicidade ambiental. Sinha (1994) testou uma grande variedade de elicitores para encontrar algum que possuísse efeito na prevenção de doenças fúngicas de plantas, e obteve bons resultados. Entretanto, de acordo com Kuc (1991), a aplicação repetida de elicitores de fitoalexinas pode causar um importante desvio nas fontes de carbono e energia que seriam utilizadas em processos vitais, resultando em uma planta resistente, porém atrofiada. Por essa razão, a colheita seria mais prejudicada do que se a planta estivesse infectada (GRAYER e KOKUBUN, 2001). 
A resistência das plantas também pode ser aumentada através da incorporação de genes codificadores da síntese de fitoalexinas. Por exemplo, o gene para a estilbeno sintase (enzima responsável pela síntese do resveratrol, a principal fitoalexina da videira) tem sido transferido de maneira eficaz da uva verde, Vitis vinifera, para o tabaco. Sendo assim, o tabaco produz a fitoalexina estilbeno resveratrol, e adquire resistência à infecção por Botrytis cinerea (HAIN et al., 1993). Entretanto, a melhor maneira de se utilizar o conhecimento na produção de fitoalexinas em plantas para a proteção da colheita, é selecionar genótipos que produzem suas próprias fitoalexinas rapidamente e em grandes quantidades. Isto pode ser feito de maneira análoga à imunização, inoculando essas plantas com microrganismos não patogênicos ou com uma cepa de um patógeno incompatível. Isto causa uma resistência sistêmica: em uma subsequente infecção a planta responderá rapidamente acumulando fitoalexinas no sítio da infecção (KUC, 1991). Por exemplo, a resistência sistêmica à Pyricularia oryzae em arroz é induzida através de uma pré-inoculação com a bactéria Pseudomonas syringae, que causa uma resposta no arroz. Esta resistência deve acontecer devido a uma rápida produção de fitoalexinas, embora isso ainda não tenha sido investigado (GRAYER e KOKUBUN, 2001). 
1 PROPOSIÇÕES E OBJETIVOS 


\section{PROPOSIÇÕES E OBJETIVOS}

Em termos de produção, a qualidade do amendoim depende muito de sua variedade e práticas culturais. Sabemos que todos os grãos são expostos, tanto no campo quanto no armazenamento, à ação de fatores físicos, químicos e biológicos, que interagem entre si favorecendo os processos de deterioração, que podem acarretar perdas substanciais na economia e alto risco à saúde humana e animal. A manutenção adequada das culturas durante o plantio, bem como durante o período de entressafra, permite a conservação das características organolépticas e nutricionais, preservando assim a qualidade do produto. Até o presente momento pouco se sabe a respeito de como e quando, efetivamente, se dá a contaminação do amendoim, tanto no campo quanto no armazenamento. Sendo o amendoim uma cultura de grande significado econômico, é imprescindível a elucidação dos mecanismos de contaminação, para que medidas preventivas possam ser tomadas, amenizando-se, com isso, as perdas econômicas.

Com base nessas informações, pretendemos na presente investigação, como objetivo geral, efetuar o monitoramento, no campo e no armazenamento, de duas variedades de amendoim, as mais cultivadas no Brasil, quanto à contaminação por fungos e por micotoxinas (aflatoxinas e ácido ciclopiazônico) e a capacidade em produzir fitoalexina. Os objetivos específicos a serem atingidos são:

- Determinar a micobiota e a ocorrência de aflatoxinas e ácido ciclopiazônico em duas variedades runner de amendoim (IAC 886 e IAC-Caiapó), durante o crescimento no campo e no armazenamento, visando identificar a contaminação;

- Comparar a resistência das variedades IAC 886 e IAC-Caiapó à invasão por Aspergillus flavus, A. parasiticus e à contaminação por aflatoxinas;

- Correlacionar os resultados obtidos com a atividade de água dos mesmos e os elementos de clima na região de estudo, no período de desenvolvimento da cultura, no campo, e durante o armazenamento.

- Determinar a presença de fitoalexina (trans-resveratrol) na planta (folhas e grãos) durante o cultivo, relacionando a quantidade metabolizada pela planta com a variedade de amendoim, fatores abióticos e micobiota.

- Verificar o potencial toxigênico das cepas isoladas no ambiente e no amendoim, quanto à produção de esclerócios, aflatoxinas e ACP. 
3 MATERIAIS E MÉTODOS 


\section{MATERIAIS E MÉTODOS}

\subsection{Campo}

\subsubsection{Local do experimento e caracterização das parcelas}

O estudo foi realizado na região de Tupã, Estado de São Paulo, com o cultivo de amendoins das variedades IAC 886 e IAC-Caiapó, em outubro de 2005 (Figura 3).

A lavoura de amendoim foi instalada seguindo as recomendações básicas relativas à exploração das espécies em áreas comerciais, sendo para tanto empregado o espaçamento de $90 \mathrm{~cm}$ entre linhas, em plantio convencional. Antes da implantação do ensaio, a área utilizada foi devidamente caracterizada com o levantamento químico do solo (macro e micronutrientes).

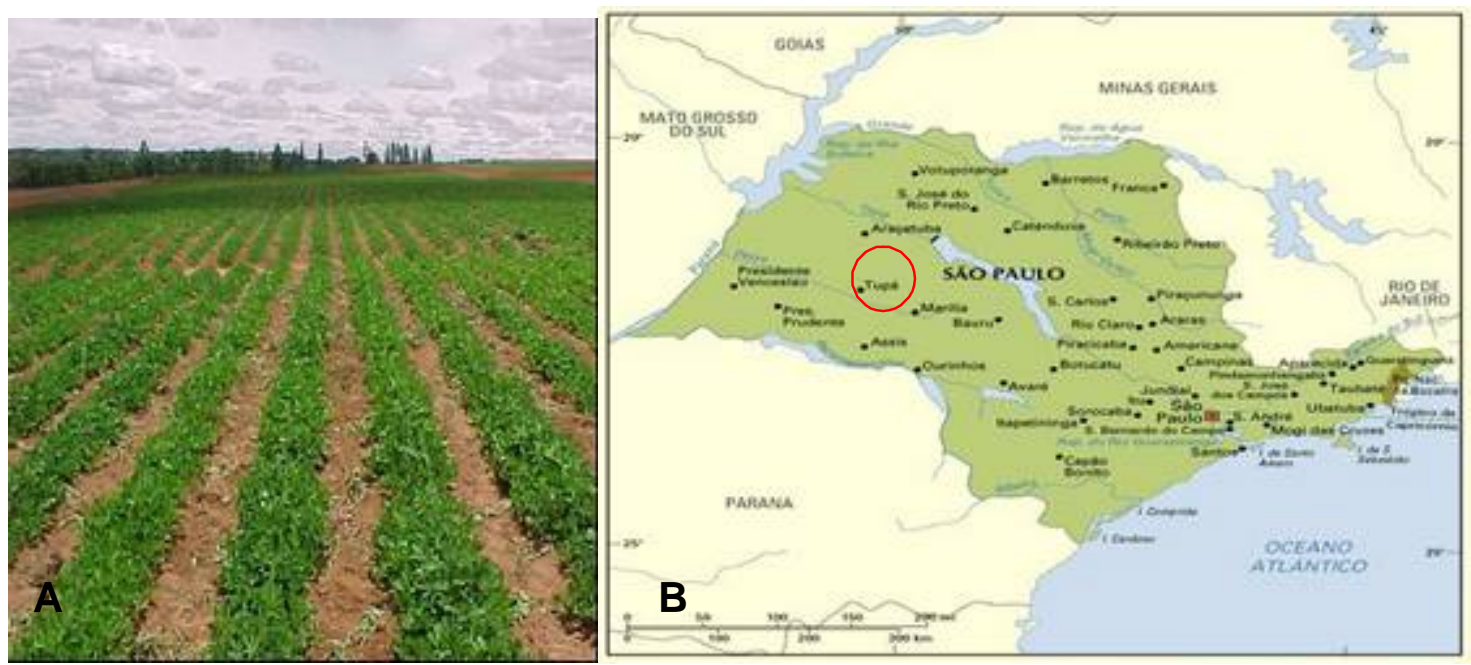

Figura 3 - Área de plantio (A) e localização da CAMAP, município de Tupã, São Paulo (B)

\subsubsection{Amostragens do amendoim, solo e ar}

Para amostragem das parcelas experimentais foi utilizada a metodologia proposta por Delp et al. (1986). A região do plantio foi dividida em duas áreas, uma por variedade, onde cada uma foi formada por 10 parcelas uniformes de $80 \mathrm{~m}^{2}$, conforme apresentado na Figura 4. Para cada coleta foram escolhidas, ao acaso, 5 parcelas e de cada uma delas foram colhidas amostras de solo, ar e amendoim. 


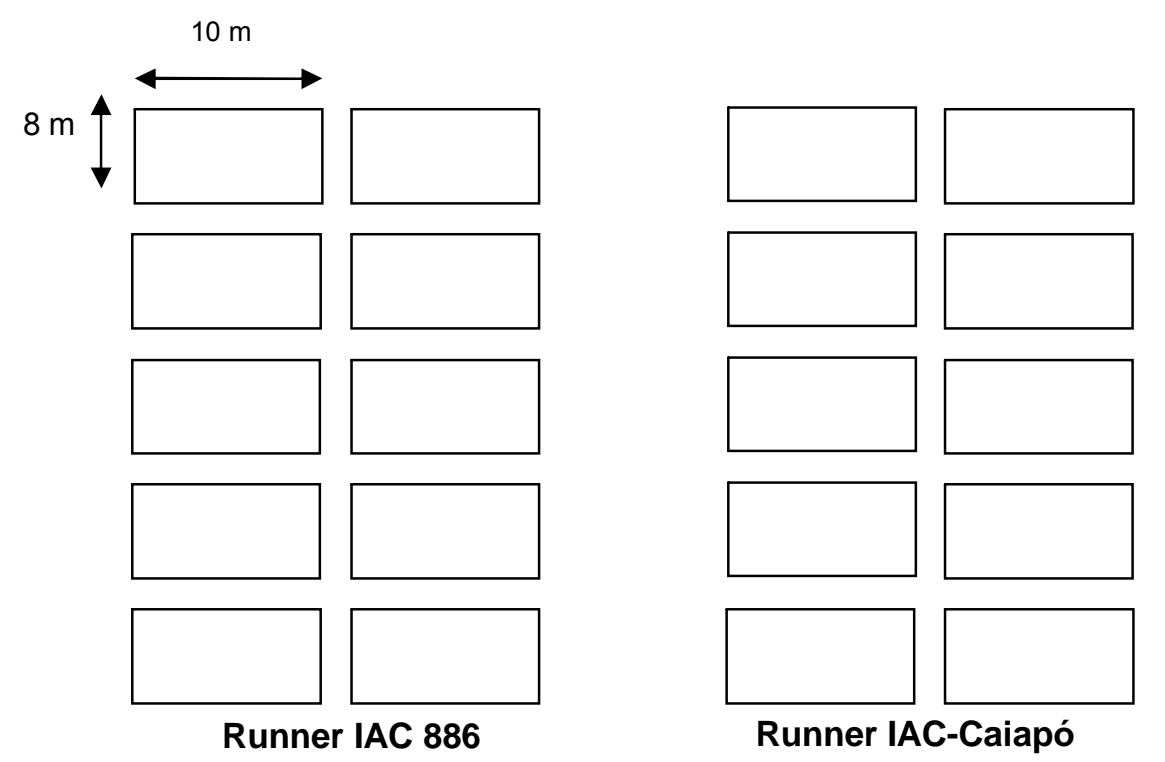

Figura 4 - Croqui da área experimental

As coletas de amendoim foram realizadas nos seguintes períodos:

1. no momento do plantio (sementes utilizadas no plantio);

2. quando as plantas estavam florescendo (10 amostras de flores) - Figura 5;

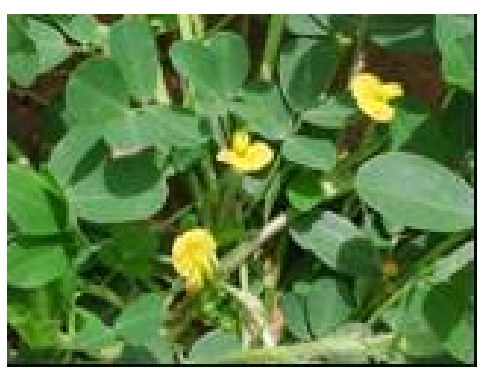

Figura 5 - Florescimento do amendoim

3. durante a formação do ginóforo ou esporão ( 5 amostras de ginóforos, por variedade) - Figura 6;

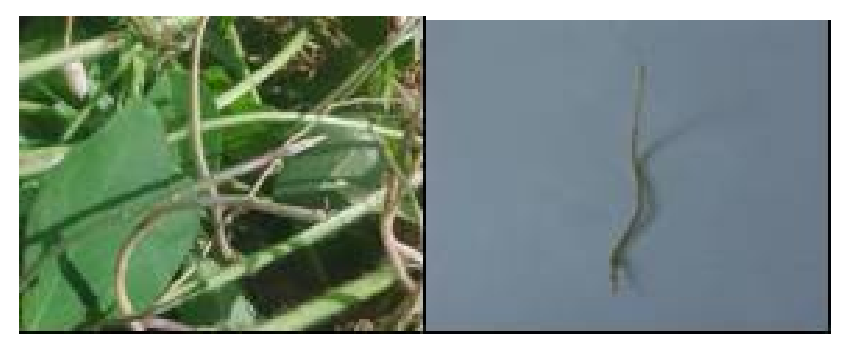

Figura 6 - Formação de ginóforos 
4. durante o desenvolvimento da planta, com os grãos na fase água e início da granação (5 amostras de cada fase, por variedade) - Figuras 7 e 8;

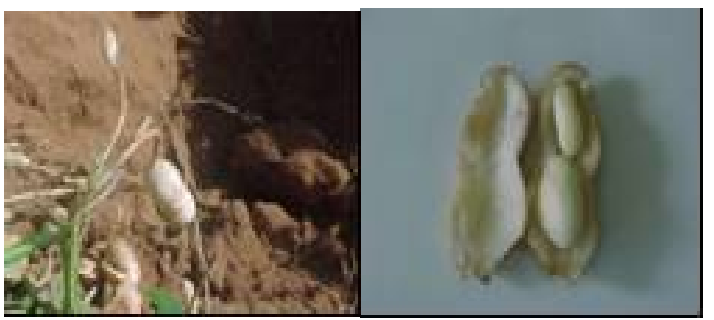

Figura 7 - Grãos na fase água

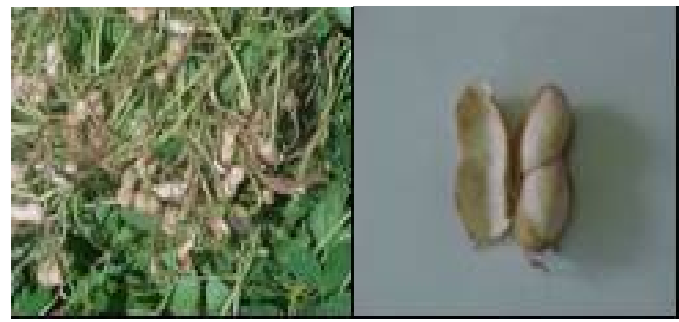

Figura 8 - Início granação

5. na maturação da semente - colheita (5 amostras de cada fase, por variedade) Figura 9;

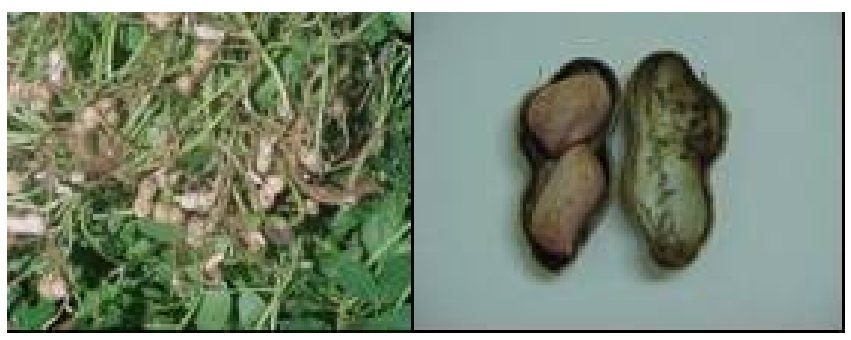

Figura 9 - Grãos maduros

6. após a secagem, no campo (5 amostras de cada fase, por variedade) - Figura 10 ;

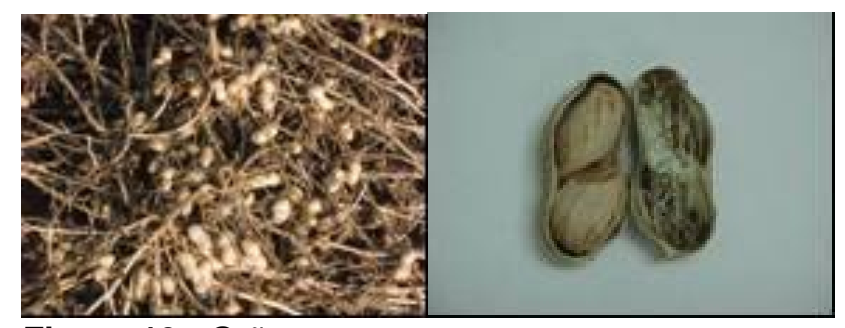

Figura 10 - Grãos secos

Para as amostras colhidas do solo, de cada parcela, escolhida ao acaso, foram coletados 5 pontos do solo, na superfície e ao redor das plantas, em seguida homogeneizados, resultando em uma amostra por parcela. Em cada coleta foram recolhidas 5 amostras por variedade, totalizando 50 amostras colhidas no campo (5 coletas). As coletas de solo ocorreram no momento do plantio, no florescimento, na formação do ginóforo, após a formação da semente (fase água e início da granação) e na maturação da semente (colheita).

Para a amostragem de fungos do ar, foram obtidas duas amostras por parcela, resultando em 10 amostras por variedade, por coleta. Foram coletadas ao todo, somando as duas variedades, 120 amostras de fungos do ar, resultante de 6 coletas. As amostragens de fungos do ar foram realizadas por meio do Aparelho 
Monitor de ar (T-air, Millipore), representado na Figura 11. Este método se baseia na quantificação da sedimentação, por $\mathrm{m}^{3}$ de ar, dos esporos de fungos anemófilos em placas de petri contendo Ágar Sabouraud Dextrose, no interior do aparelho.

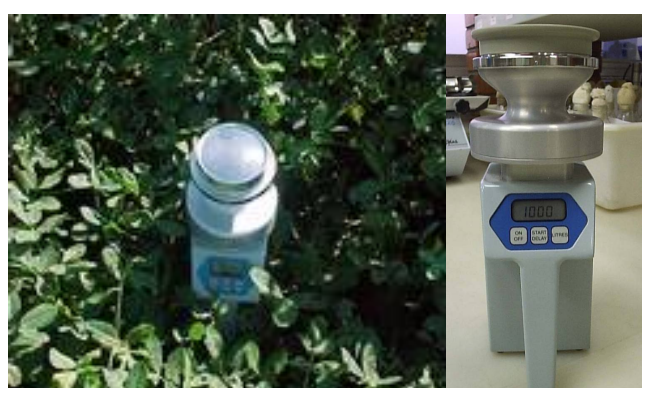

Figura 11 - Coleta de fungos anemófilos utilizando o aparelho Monitor de ar (T-Air, Millipore)

\subsubsection{Meios de Cultura}

\subsubsection{1 Ágar Batata Dextrose (OXOID)}

No preparo, foi acrescido cloranfenicol e corrigido para pH 5,6. Foi utilizado no isolamento, identificação e manutenção dos fungos isolados.

Preparo: $O$ meio de cultura foi dissolvido em água fervente conforme determinação do fabricante e em seguida, foi adicionado o antibiótico $(100 \mu \mathrm{g} / \mathrm{mL})$. O meio foi então autoclavado a $121^{\circ} \mathrm{C}$ durante 15 minutos. Foram distribuídos $15 \mathrm{~mL}$ em tubos de ensaio.

\subsubsection{2 Ágar Sabouraud Dextrose (OXOID)}

Foi utilizado para a pesquisa de fungos do ar. No preparo, foi acrescido cloranfenicol e corrigido o $\mathrm{pH}$ para 5,6.

Preparo: O meio de cultura foi dissolvido em água fervente conforme determinação do fabricante e em seguida, foi adicionado o antibiótico $(100 \mu \mathrm{g} / \mathrm{mL})$. O meio foi então autoclavado a $121^{\circ} \mathrm{C}$ durante 15 minutos. Em seguida, o meio foi colocado em placas de petri para serem utilizadas no Aparelho Monitor de ar (T-air, Millipore). 


\subsubsection{Meio Martin}

Meio utilizado para isolamento e contagem de fungos do solo (Martim, 1950).

\section{Composição:}

Dextrose $10 \mathrm{~g}$

Peptona $5 \mathrm{~g}$

$\mathrm{KH}_{2} \mathrm{PO}_{4}$ $1 \mathrm{~g}$

$\mathrm{MgSO}_{4}$ $0,5 \mathrm{~g}$

Rosa Bengala $0,0034 \mathrm{~g}$

Ágar ágar (OXOID) $20 \mathrm{~g}$

Estreptomicina $0,044 \mathrm{~g}$

Água destilada q.s.p. $1000 \mathrm{~mL}$

\section{Preparo:}

Foram dissolvidos os componentes em água fervente e em seguida autoclavados a $121^{\circ} \mathrm{C}$ durante 15 minutos. Volumes de $15 \mathrm{~mL}$ foram distribuídos em placas de petri esterilizadas, contendo as diluições do solo (Técnica de Pour Plate).

\subsubsection{Meio Ágar Aspergillus flavus - parasiticus (AFPA)}

Meio seletivo utilizado para isolamento de $A$. flavus e $A$. parasiticus nas amostras de grãos e cascas de amendoim (PITT et al., 1983).

\section{Composição:}

Peptona (OXOID) $10 \mathrm{~g}$

Extrato de levedura (OXOID) .................. $20 \mathrm{~g}$

Citrato férrico amoniacal $0,5 \mathrm{~g}$

Ágar ágar (OXOID) $15 \mathrm{~g}$

Cloranfenicol $0,1 \mathrm{~g}$

Dicloran $2 \mathrm{mg}(0,2 \%$ em etanol)

Água destilada q.s.p. $1000 \mathrm{~mL}$

Preparo: Os componentes foram dissolvidos em água destilada fervente, e em seguida foram adicionados o dicloran $2 \%$ e o cloranfenicol. O meio foi autoclavado a $121^{\circ} \mathrm{C}$ durante 15 minutos e volumes de $15 \mathrm{~mL}$ foram distribuídos em placas de petri esterilizadas. 


\subsubsection{5 Ágar Extrato de Levedura - Sacarose (Yes)}

Meio utilizado para a avaliação da produção de ACP pelas cepas de A. flavus e A. parasiticus.

\section{Composição:}

Extrato de levedura (OXOID).............. $10 \mathrm{~g}$

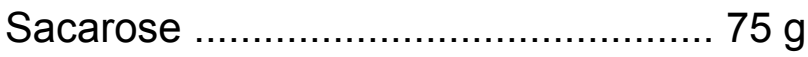

Agar ágar (OXOID) .............................. $10 \mathrm{~g}$

Água destilada q.s.p. ...................... $500 \mathrm{~mL}$

Preparo:

Os componentes foram dissolvidos em água fervente e em seguida o meio foi autoclavado a $121{ }^{\circ} \mathrm{C}$ durante 15 minutos. Foram distribuídos $15 \mathrm{~mL}$ em placas de petri estéreis.

\subsubsection{6 Ágar Coco}

Utilizado para a avaliação do potencial aflatoxigênico das cepas de $A$. flavus e A. parasiticus (LIN e DIANESE, 1976). O pH foi corrigido para 6,9.

\section{Composição:}

Leite de côco $200 \mathrm{~mL}$

Ágar ágar (OXOID) $18 \mathrm{~g}$

Água destilada q.s.p. $600 \mathrm{~mL}$

Preparo:

Os componentes foram dissolvidos em água fervente e em seguida o meio foi autoclavado a $121{ }^{\circ} \mathrm{C}$ durante 15 minutos. Foram distribuídos $15 \mathrm{~mL}$ em placas de petri estéreis.

\subsubsection{7 Ágar Czapek}

Meio utilizado para a avaliação de produção de esclerócios de cepas de $A$. flavus e A. parasiticus.

Composição:

Czapek-Dox (OXOID) $33,4 \mathrm{~g}$ 
Ágar ágar (OXOID) $15 \mathrm{~g}$

Água destilada q.s.p $1000 \mathrm{~mL}$

Preparo:

Os componentes foram dissolvidos em água fervente e em seguida o meio foi autoclavado a $121{ }^{\circ} \mathrm{C}$ durante 15 minutos. Foram distribuídos $15 \mathrm{~mL}$ em placas de petri estéreis.

\subsubsection{Micobiota isolada das amostras de amendoim}

A técnica utilizada para 0 isolamento de fungos das amostras de amendoim foi a de semeadura direta (BERJAK, 1984). De cada amostra de amendoim foram retirados aproximadamente $30 \mathrm{~g}$ para desinfecção em solução de hipoclorito de sódio $0,4 \%$, por 3 minutos, seguida de lavagem com água destilada estéril, por três vezes, para eliminação dos contaminantes externos. Após a desinfecção, foram separadas as cascas dos grãos do amendoim e alguns grãos foram selecionados ao acaso e semeados diretamente em placa de petri contendo meio de AFPA. Foram utilizadas, para cada amostra, 3 placas contendo 11 grãos cada, totalizando 33 grãos por amostra. Para as cascas foram utilizadas 4 placas, onde foram colocados 4 pares de casca em cada placa, totalizando 16 cascas por amostra. $O$ mesmo procedimento foi usado para o isolamento da micobiota da flor e ginóforo, onde foram colocados 11 flores por placa, em triplicata, totalizando 33 flores por amostra e 8 ginóforos, por placa de petri, em triplicata, no total de 24 ginóforos por amostra.

Todas as placas foram incubadas a $25{ }^{\circ} \mathrm{C}$ por 5 dias e os resultados expressos em percentagem do total de grãos e cascas infectados por fungos (Figura 12). Em seguida, colônias de diferentes tipos morfológicos foram isoladas em Ágar Sabouraud Dextrose e submetidas à identificação por meio da técnica de microcultivo em Ágar Batata Dextrose. O limite de detecção do método foi de 0,6\% na frequência de isolamento fúngico dos grãos e flor, $0,8 \%$ no ginóforo e $1,2 \%$ nas cascas.

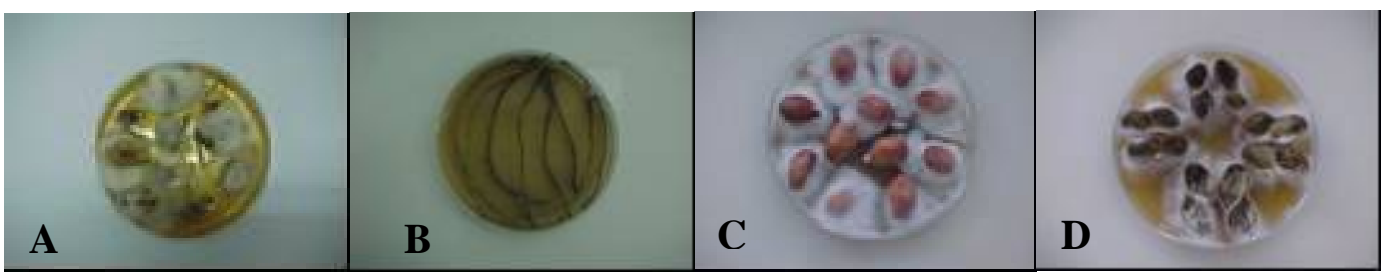

Figura 12 - Micobiota da flor (A), ginóforo (B), grãos (C) e cascas (D) 
De cada amostra de solo, foram retirados $10 \mathrm{~g}$ e diluídos em $90 \mathrm{~mL}$ de salina 0,85\% esterilizada, obtendo-se diluição de $10^{-1}$. A partir desta, foram preparadas diluições decimais e sucessivas até $10^{-6}$. Foram retirados $1,0 \mathrm{~mL}$ de cada diluição e depositado em placa de petri e, em seguida, vertidos 10 a $15 \mathrm{~mL}$ de meio de Martin (SWANSON et al., 1982). Após a homogeneização e solidificação do meio, as placas foram incubadas a $25^{\circ} \mathrm{C}$ por aproximadamente 5 dias. Todas as amostras foram processadas em duplicatas (PITT e HOCKING, 1997).

Após a incubação, foi feita a contagem das colônias multiplicando-se o número obtido pelo fator de diluição, a fim de se obter o número de unidades formadoras de colônia por grama de substrato (UFC/g) (Figura 13). Colônias de diferentes tipos morfológicos foram isoladas e submetidas à técnica de microcultivo utilizando os meios de cultura Ágar Sabouraud Dextrose e Ágar Batata Dextrose. O limite de detecção do método é de $10^{-3} \mathrm{UFC} / \mathrm{g}$ de solo.

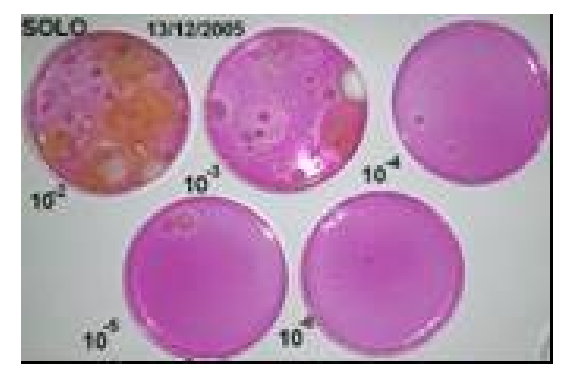

Figura 13 - Micobiota do solo pela Técnica de "Pour Plate".

\subsubsection{Fungos do ar}

Após a exposição das placas de Petri através aparelho monitor de ar, estas foram incubadas a $25^{\circ} \mathrm{C}$ por 5 dias e as colônias isoladas e submetidas à técnica de microcultivo, utilizando os meios de cultura Ágar Sabouraud Dextrose e Ágar Batata Dextrose (Figura 14). Os fungos foram classificados em nível de gênero. O limite de detecção do método foi de 0,1 Unidade Formadora de colônia $/ \mathrm{m}^{3}$ (UFC/ $\mathrm{m}^{3}$ ). 


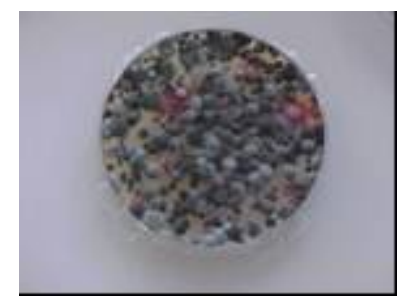

Figura 14 - Fungos anemófilos isolados no campo.

\subsubsection{Técnica de Microcultivo para a identificação da micobiota}

Para a realização da técnica estabelecida por Ridell (1950) foi utilizado uma lâmina de vidro sobre um bastão de vidro em $U$, no interior de uma placa de petri, forrada com papel de filtro. Após a montagem, o material foi esterilizado em forno Pasteur. Um pedaço de ágar Sabouraud Dextrose, no formato de um pequeno quadrado foi colocado sobre a lâmina, com o máximo de cuidado e assepsia. Com a alça de platina em L, o fungo foi semeado em todos os lados do ágar. Uma lamínula estéril foi colocada sobre o ágar, para permitir que o fungo crescesse e fixasse seus órgãos vegetativos e de frutificação. Todo esse material, protegido pela placa de petri, foi mantido em estufa a $25{ }^{\circ} \mathrm{C}$, até que o fungo obtivesse um crescimento satisfatório. Ao atingir esse estágio, o material foi submetido à ação do formol $(0,5$ $\mathrm{mL}$ por 1 hora) para inativar o fungo. Em seguida, foi feita a coloração da lâmina e lamínula com solução de lactofenol-azul-algodão, e montado a lâmina para ser observada ao microscópio.

Os fungos foram classificados em nível de gênero. Somente aqueles pertencentes ao gênero Aspergillus foram classificadas as espécies de acordo com o descrito nos seguintes compêndios: Raper e Fennel (1965), Arx (1974), Barron (1972), Kozakiewicz (1989), Pitt e Hocking (1997).

\subsubsection{Determinação da atividade de água}

A atividade de água ( $\mathrm{Aa}$ ) das amostras de amendoim (grãos e cascas, separadamente), flores, ginóforo e de solo foi determinada por meio do aparelho Aqualab CX-2 (Decagon Devices Inc.), representado pela Figura 15. 


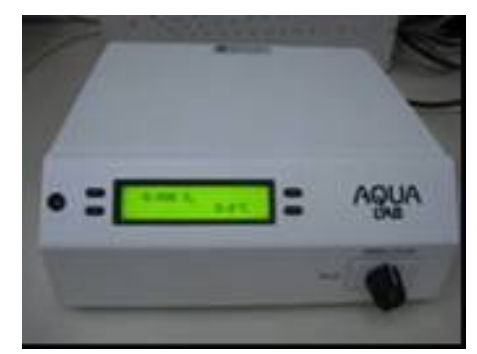

Figura 15 - Aparelho medidor de Aa (Aqualab CX-2)

\subsubsection{Pesquisa de fitoalexina (trans-resveratrol)}

A metodologia utilizada para a extração das folhas foi a estabelecida por Felício et al. (2001), com algumas adaptações (SANDERS et al., 2000). Para a determinação de trans-resveratrol, $10 \mathrm{~g}$ de folhas secas e moídas foram extraídas com etanol em Soxhlet, por 4 horas. O solvente foi, em seguida, evaporado e uma alíquota de $0,3 \mathrm{~g}$ do extrato foi acrescida de $1000 \mu \mathrm{L}$ de ácido cítrico a 0,1 M e agitado em vortex por 1 minuto, seguido de centrifugação (3000 rpm/ 20 minutos). $O$ sobrenadante foi filtrado em membrana de $0,45 \mu \mathrm{m}$ e analisado em cromatografia líquida de alta eficiência (CLAE).

Para a extração dos grãos, foram utilizadas $0,5 \mathrm{~g}$ de grãos, acrescidos de $1000 \mu \mathrm{L}$ de ácido cítrico a $0,1 \mathrm{M}$. Foram agitados em vortex por 1 minuto e submetidos à centrifugação $(3000 \mathrm{rpm} / 20 \mathrm{~min})$. O sobrenadante foi filtrado em membrana de 0,45 $\mu \mathrm{m}$ e analisado em CLAE.

Para as análises foi utilizando padrão (Sigma) de trans-resveratrol diluído em metanol e analisado em CLAE, detector de $D_{2}$ SPD MxA (Shimadzu) com comprimento de onda de $290 \mathrm{~nm}$ (Figura 16), coluna Luna C(18) 4,6×250 mm de 5 micron (Phenomenex), tendo como fase móvel metanol:água (55:45, v/v), acrescido de $5 \%$ de ácido acético, fluxo de $1 \mathrm{~mL} / \mathrm{min}$ (Figura 17). Para a curva de calibração foram utilizadas as concentrações $0,005,0,01,0,02,0,05$ e $0,1 \mu \mathrm{g} / \mathrm{mL}$ e a curva obtida foi de $r^{2}=0,999$. O limite de detecção obtido foi de $26 \mu \mathrm{g} / \mathrm{mL}$ e o de quantificação de $52 \mu \mathrm{g} / \mathrm{mL}$. A recuperação da folha foi de $82 \%$ nas cascas e nos grãos de $88 \%$. 


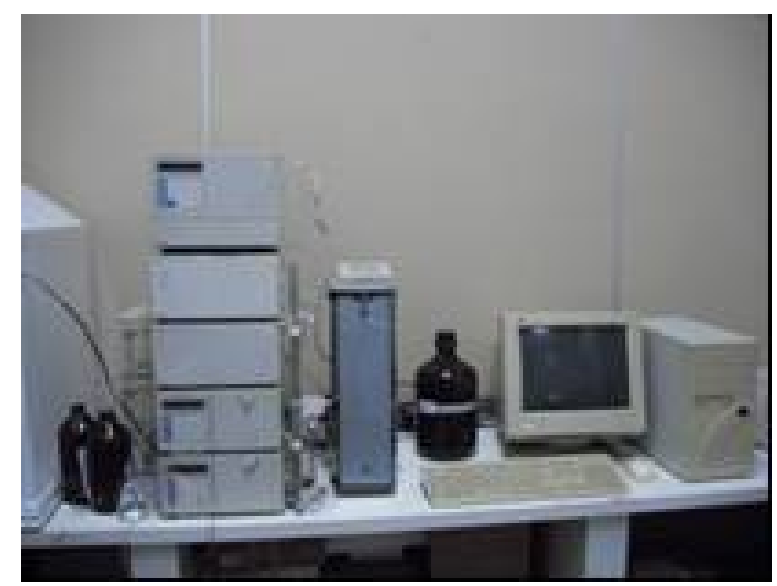

Figura 16 - Aparelho de cromatografia líquida de alta eficiência (Shimadzu), utilizados para detecção e quantificação de aflatoxinas, ACP e trans-resveratrol

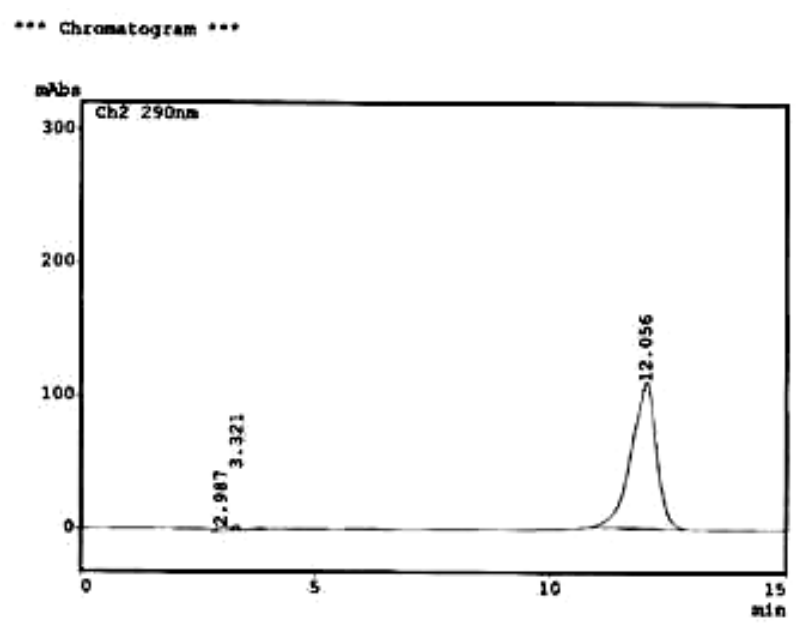

Figura 17 - Cromatograma de trans-resveratrol

\subsubsection{Avaliação climática}

Os dados referentes à temperatura $\left({ }^{\circ} \mathrm{C}\right)$, umidade relativa do ar $(\%)$ e precipitação pluvial $(\mathrm{mm})$ foram fornecidos pela estação climatológica do Instituto Agronômico da região de Adamantina, São Paulo. Os resultados foram analisados para elaboração do estudo dos fatores abióticos na região avaliada, objetivando a correlação entre as variações dos elementos de clima com a frequência de fungos, produção de micotoxinas e trans-resveratrol. 


\subsection{Armazenamento}

\subsubsection{Armazenamento do amendoim}

Depois do arranquio e secagem do amendoim, ainda no campo, por uma semana, foram avaliados o teor de umidade dos grãos antes do armazenamento. A variedade IAC 888 apresentava teor de umidade de 10,4\% e a variedade IACCaiapó de $10,7 \%$, todas abaixo de $11 \%$, conforme o recomendado (FONSECA, 2010b).

Em seguida, as amostras de amendoim, de ambas as variedades ainda na vagem, foram colocadas em sacas de $25 \mathrm{~kg}$, empilhadas sobre estrados de madeira, num total de 10 sacas por estrado e armazenados por período de 6 meses (abril a setembro de 2006), com boas condições de ventilação, em armazém da Cooperativa Agrícola da Alta Mogiana (CAMAP), localizado na mesma região de plantio, município de Tupã, SP (Figura 18).

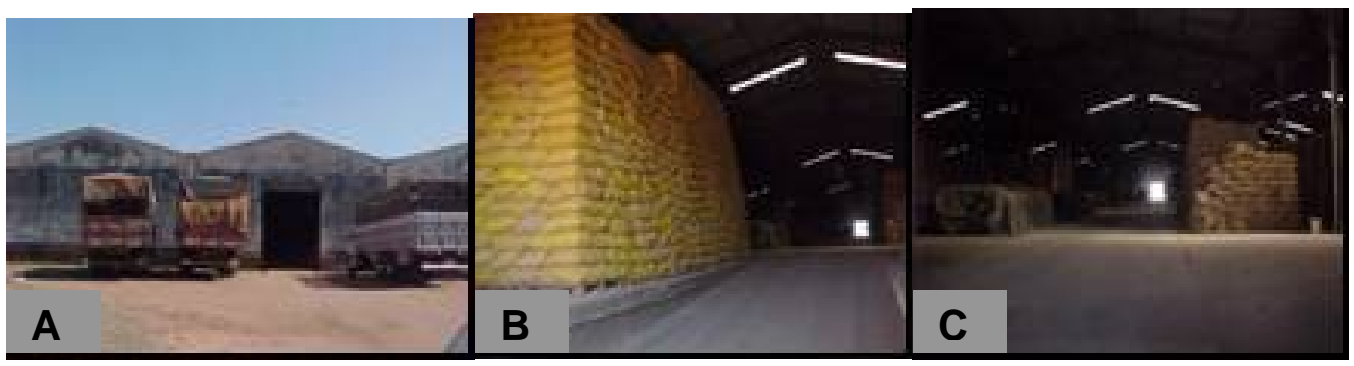

Figura 18 - Armazém da Cooperativa Agrícola da Alta Mogiana (CAMAP), região de Tupã, SP. Visualização da fachada $(A)$ e interior do armazém (B e C)

\subsubsection{Amostragem do amendoim}

Foram retiradas amostras de amendoim em 5 pontos diferentes de cada saca (Figura 19), até compor uma amostra de $400 \mathrm{~g}$ (FONSECA, 1991). As coletas foram feitas mensalmente até completar 6 meses, onde foram colhidas 5 amostras por variedade, totalizando 60 amostras no final do experimento ( 6 coletas). Desse total, foram analisadas a presença de fungos nas cascas e nos grãos, atividade de água e micotoxinas (aflatoxinas e ácido ciclopiazônico). 


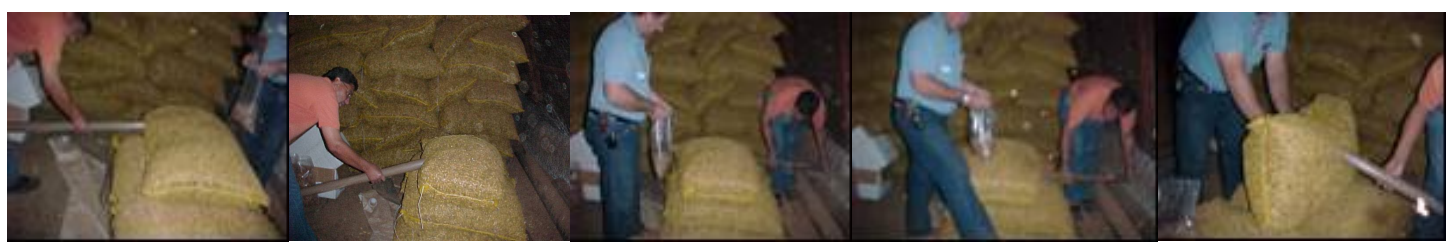

Figura 19 - Coletas do amendoim armazenado em 5 pontos diferentes em cada saca.

\subsubsection{Micobiota}

Após isolamento dos fungos nas amostras de amendoim e ar, os fungos foram submetidos à técnica de microcultivo e classificados em nível de gênero. Somente aqueles pertencentes ao gênero Aspergillus foram classificadas até espécie de acordo com os seguintes compêndios: Raper e Fennel (1965), Arx (1974), Barron (1972), Kozakiewicz (1989), Pitt e Hocking (1997).

\subsubsection{Micobiota das amostras de amendoim}

A metodologia utilizada para o isolamento da micobiota dos grãos e cascas foi a mesma descrita no item 3.1.4 (BERJAK, 1984).

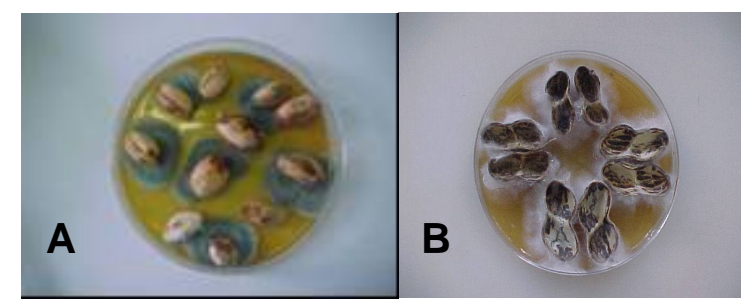

Figura 20 - Micobiota isoladas das amostras de grãos (A) e cascas (B), no período de armazenamento.

\subsubsection{Fungos do ar}

No interior do armazém foram realizadas 5 exposições de placas de petri por variedade, em cada período de coleta. Ao todo foram realizadas 60 exposições de placas para o isolamento de fungos do ar, resultantes de 6 coletas. As coletas foram realizadas com o Aparelho Monitor de ar (T-air, Millipore), com base na quantificação da sedimentação de esporos de fungos anemófilos por $\mathrm{m}^{3}$ de ar (Figura 21). 
Após a exposição das placas de petri, estas foram incubadas a $25^{\circ} \mathrm{C}$ por 5 dias e as colônias isoladas e submetidas à técnica de microcultivo utilizando os meios de cultura Ágar Sabouraud Dextrose e Ágar Batata Dextrose. Os fungos foram classificados em nível de gênero.

O limite de deteç̧ão do método foi de $0,2 \mathrm{UFC} / \mathrm{m}^{3}$.

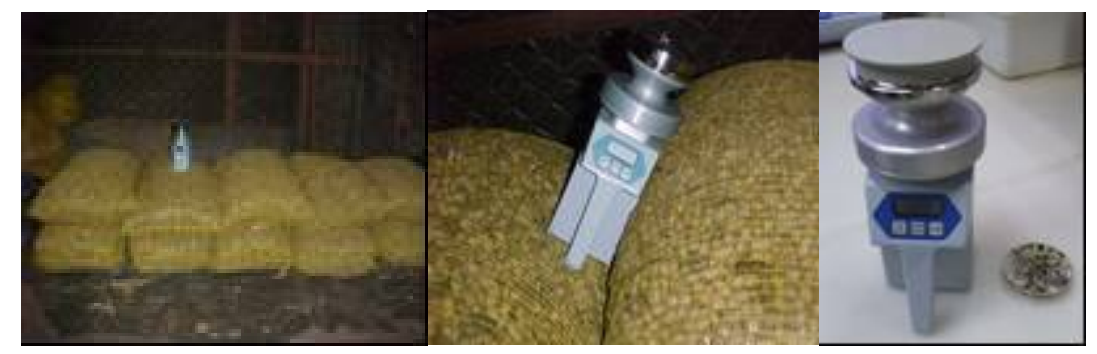

Figura 21 - Coleta de fungos do ar, utilizando o aparelho monitor de ar (T-air, Millipore)

\subsubsection{Determinação da atividade de água}

A atividade de água ( $\mathrm{Aa}$ ) das amostras de amendoim (grãos e cascas, separadamente) foi determinada por meio do aparelho Aqualab CX-2 (Decagon Devices Inc.).

\subsubsection{Avaliação climática}

Durante todo o período de armazenamento (6 meses), os dados climatológicos referentes à temperatura $\left({ }^{\circ} \mathrm{C}\right)$, umidade relativa do $\operatorname{ar}(\%)$ e precipitação pluvial $(\mathrm{mm})$ foram obtidos na região do experimento, através da estação climatológica do Instituto Agronômico de Adamantina, SP. No interior do armazém, a temperatura e umidade relativa do ar foram mensuradas com o aparelho termohigrômetro digital da marca Sphere (Figura 22).

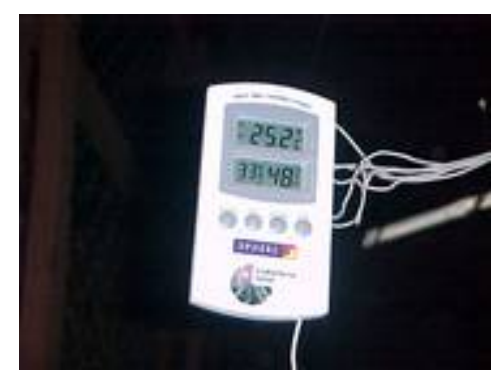

Figura 22 - Aparelho termohigrômetro digital utilizado na medição da temperatura e umidade relativa, no interior do armazém. 


\subsection{Micotoxinas}

\subsubsection{Pesquisa de aflatoxinas}

Para a extração de $A F B_{1}, A F B_{2}, A F G_{1}$ e $A F G_{2}$ das cascas e dos grãos de amendoim das 50 amostras por variedade, $25 \mathrm{~g}$ de cada amostra de amendoim previamente moída foram adicionados $5 \mathrm{~g}$ de sal $(\mathrm{NaCl})$ e $125 \mathrm{~mL}$ de metanol: água (70:30, v/v) e agitada por 30 minutos em mesa agitadora horizontal (TRUCKSESS et al., 1991). A amostra foi filtrada, foram recolhidos $15 \mathrm{~mL}$ e diluídos com $30 \mathrm{~mL}$ de água destilada. Após filtração através de filtro de microfibra, foram recolhidos $15 \mathrm{~mL}$ do extrato e passados através de uma coluna de imunoafinidade (Aflatest, Vican) a um fluxo de cerca de 1-2 gotas/segundo até a passagem do ar pela coluna. A coluna foi lavada com $10 \mathrm{~mL}$ de água destilada e eluída com 1,0 mL de metanol. O metanol foi evaporado e as amostras foram armazenadas em freezer $(-20 \stackrel{\circ}{\circ})$ até o momento das análises.

A padronização do método foi estabelecida de acordo com a metodologia de Tarin et al. (2004), utilizando padrões (Sigma) de $\mathrm{AFB}_{1}, \mathrm{AFB}_{2}, \mathrm{AFG}_{1}$ e $\mathrm{AFG}_{2}$ diluídos em metanol e cromatografia líquida de alta eficiência (CLAE), detector de fluorescência - RF 10XA (Shimadzu), com comprimento de onda de $360 \mathrm{~nm}$ de excitação e $440 \mathrm{~nm}$ de emissão (Figura 14), coluna Luna C(18) 4,6x250 mm de 5 micron (Phenomenex), tendo como fase móvel água:acetonitrila:metanol (60:25:15, $\mathrm{v} / \mathrm{v} / \mathrm{v}$ ), fluxo de $1 \mathrm{~mL} / \mathrm{min}$. Para aumentar o sinal cromatográfico e confirmar a identidade das aflatoxinas $B_{1}$ e $G_{1}$ tanto os padrões quanto as amostras foram derivatizados da seguinte maneira: $500 \mu \mathrm{L}$ de cada padrão foram transferidos para um frasco âmbar e evaporados até a secagem. Logo após, foram acrescidos aos padrões e às amostras $50 \mu \mathrm{L}$ de ácido trifluoracético (TFA) e $200 \mu \mathrm{L}$ de n-hexano aquecido a $40{ }^{\circ} \mathrm{C}$ em estufa, agitando manualmente por 15 minutos. A solução foi evaporada e ressuspendida em $200 \mu \mathrm{L}$ de acetonitrila:água (3:7, v/v) e $20 \mu \mathrm{L}$ foram injetados no cromatógrafo (Figura 23). O limite de detecção foi de $0,03 \mu \mathrm{g} / \mathrm{kg}$ para $A F B_{1}, 0,03 \mu \mathrm{g} / \mathrm{kg}$ para $A F B_{2}, 0,03 \mu \mathrm{g} / \mathrm{kg}$ para $A F G_{1}$ e $0,01 \mu \mathrm{g} / \mathrm{kg}$ para $\mathrm{AFG}_{2}$ e o de quantificação foi de $0,18 \mu \mathrm{g} / \mathrm{kg}$ para $\mathrm{AFB}_{1}, 0,15 \mu \mathrm{g} / \mathrm{kg}$ para $\mathrm{AFB}_{2}, 0,15 \mu \mathrm{g} / \mathrm{kg}$ para $A F G_{1}, 0,07 \mu \mathrm{g} / \mathrm{kg}$ para $A F G_{2}$. Para a curva de calibração foram utilizadas as concentrações de $\mathrm{AFB}_{1} 1,55 ; 3,10 ; 6,20 ; 12,40 ; 24,79 \mathrm{ng} / \mathrm{mL}$, de $\mathrm{AFB}_{2}$ de 1,$47 ; 2,95$; 5,90 e $23,60 \mathrm{ng} / \mathrm{mL}, \mathrm{AFG}_{1} 1,78 ; 3,56 ; 7,12 ; 14,25$ e $28,50 \mathrm{ng} / \mathrm{mL}$, e de $A F G_{2}$ de 1,48 ; 
2,95; 5,$91 ; 11,81$ e 23,62 ng/mL. O valor obtido na curva de calibração de todas as aflatoxinas foi de $r^{2}=0,999$.

As recuperações obtidas nos grãos foram de $87 \%$ para $A F B_{1}, 79 \%$ para $\mathrm{AFB}_{2}$, $76 \%$ para $A F G_{1}$ e $81 \%$ para $A F G_{2}$. Nas cascas, as recuperações encontradas foram de $75 \%$ para $A F B_{1}, 83 \%$ para $A F B_{2}, 78 \%$ para $A F G_{1}$ e $73 \%$ para $A F G_{2}$.

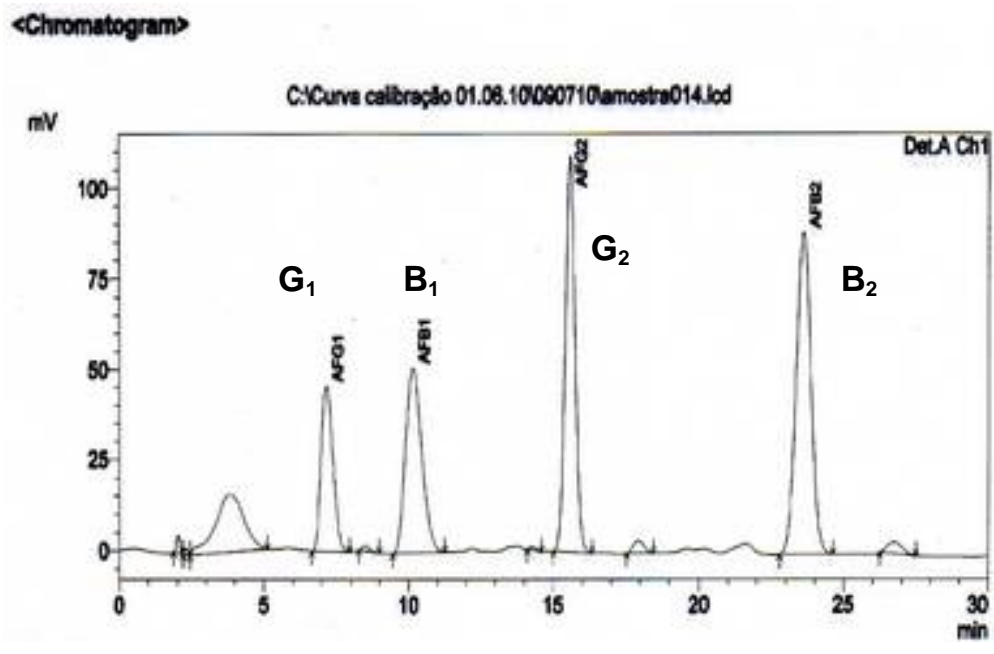

Figura 23 - Cromatograma das aflatoxinas $B_{1}, B_{2}, G_{1}$ e $G_{2}$

\subsubsection{Pesquisa de ácido ciclopiazônico}

Para a análise de ácido ciclopiazônico (ACP), foram utilizadas $25 \mathrm{~g}$ de cada uma das 50 amostras de grãos (URANO et al., 1992). As amostras foram trituradas e transferidas para um erlenmeyer, onde foram adicionados $100 \mathrm{~mL}$ de metanol:bicarbonato de sódio $2 \%$ em água (7:3, v/v). Após agitação por 30 minutos em agitador mecânico horizontal, o conteúdo do frasco foi filtrado em papel de filtro e $50 \mathrm{~mL}$ do extrato transferido para um funil de separação e adicionado $100 \mathrm{~mL}$ de hexano. Após a agitação, a fração com hexano foi descartada e acrescentado $50 \mathrm{~mL}$ de solução aquosa de $\mathrm{KCl}$ a $10 \%$. A mistura foi acidificada com 2,0 mL de $\mathrm{HCl} 6 \mathrm{~N}$. O ACP foi extraído com $50 \mathrm{~mL}$ de clorofórmio por duas vezes e evaporado até a secura. Em seguida, a amostra foi ressuspendida em $10 \mathrm{~mL}$ de clorofórmio e transferido para uma coluna de extração de fase sólida Micotox® MS2300 (Micotox Ltda, Bogotá D.C., Colombia), anteriormente condicionada com $5 \mathrm{~mL}$ de clorofórmio, a um fluxo de cerca de 1-2 gotas/segundo até que o ar passasse pela coluna. Logo após, a coluna foi lavada com $10 \mathrm{~mL}$ de éter etílico, $10 \mathrm{~mL}$ de clorofórmio/acetona $(1: 1, v / v)$ e $10 \mathrm{~mL}$ de clorofórmio/metanol (95:5, v/v). O ACP foi eluído com $10 \mathrm{~mL}$ de 
clorofórmio/metanol $(75: 25, \mathrm{v} / \mathrm{v})$ a um fluxo de $2,0 \mathrm{~mL} / \mathrm{min}$. O extrato foi evaporado sob nitrogênio até a secura, ressuspendido em 1,0 mL de metanol grau HPLC e armazenado em freezer $\left(-20^{\circ} \mathrm{C}\right)$ até o momento da cromatografia.

A quantificação do ACP foi realizada por cromatografia líquida de alta eficiência (CLAE), já representado na Figura 16, tendo como fase móvel acetonitrila:tampão acetato de amônio $(0,05 \mathrm{M}, \mathrm{pH} 5)(8: 2, \mathrm{v} / \mathrm{v})$, fluxo de $0,6 \mathrm{~mL} / \mathrm{min}$, detector de $\mathrm{D}_{2}$ (Shimadzu) em $284 \mathrm{~nm}$ (Losito et al, 2002), coluna Luna C(8) 4,6x250 mm de 5 micron (Phenomenex), (Figura 24). O valor obtido no limite de detecção foi de $80 \mu \mathrm{g} / \mathrm{kg}$ e o de quantificação de 156,2 $\mu \mathrm{g} / \mathrm{kg}$. Para a curva de calibração foram utilizadas as concentrações 0,$625 ; 1,25 ; 2,50 ; 5,00$ e $10,00 \mu \mathrm{g} / \mathrm{mL}$ e a curva obtida foi de $r^{2}=0,998$. A recuperação obtida nos grãos foi de $72 \%$.

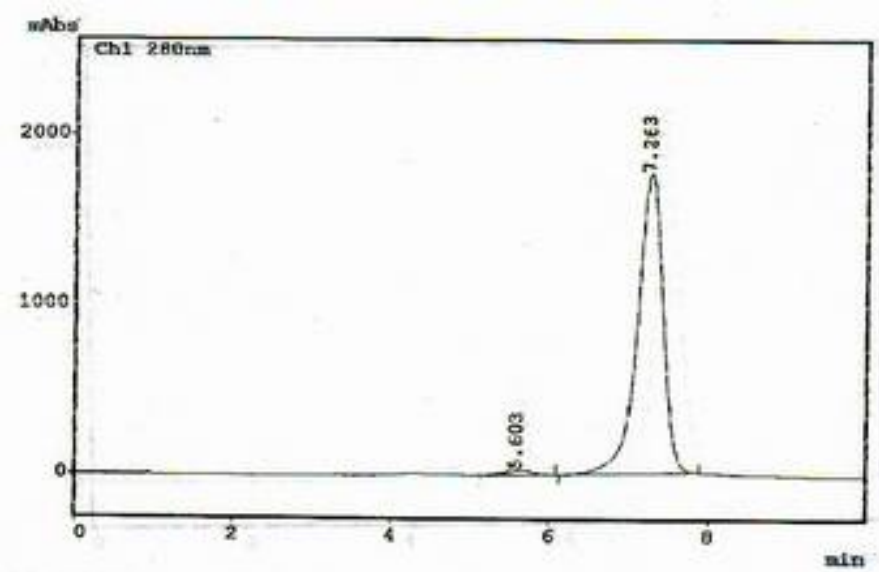

Figura 24 - Cromatograma do ácido ciclopiazônico

3.3.3 Avaliação do potencial toxigênico para aflatoxinas das cepas de Aspergillus flavus e $A$. parasiticus

Após a identificação morfológica, 135 isolados de A. flavus e A. parasiticus, mantidas em Ágar batata dextrose, foram semeadas em placas de petri com meio de ágar coco e incubada por 14 dias a $25^{\circ} \mathrm{C}$ (LIN e DIANESE, 1976). A colônia com o ágar foi pesada e transferida para um frasco, adicionado clorofórmio na proporção de $10 \mathrm{~g}$ do cultivo para $30 \mathrm{~mL}$ de clorofórmio e agitado por 30 minutos. O solvente foi filtrado em papel de filtro contendo sulfato de sódio e terra diatomácea e evaporado até resíduo. Em seguida, o extrato foi ressuspendido em volume conhecido e aplicado em placa de sílica gel G 60 (Merck), acompanhado de um padrão 
quantitativo de aflatoxinas $B_{1}, B_{2}, G_{1}$ e $G_{2}$. A placa foi eluída unidimensionalmente com a mistura de solventes clorofórmio:acetona (9:1 v/v) (AOAC, 1980). Após a secagem do solvente, foi a realizada a leitura das amostras e do padrão em fotodensitômetro (CS 9000, Shimadzu). A quantificação foi feita por comparação das áreas das amostras com as dos padrões de aflatoxinas.

3.3.4 Avaliação do potencial toxigênico para ácido ciclopiazônico das cepas de Aspergillus flavus

As 135 cepas de $A$. flavus e $A$. parasiticus utilizadas para a quantificação de aflatoxinas também foram analisadas na avaliação de produção de ACP. Com esta finalidade, cada cepa foi semeada em Ágar Yes e incubada a $25^{\circ} \mathrm{C}$ por 12 dias (BARROS et al., 2005). Após o crescimento, a colônia com o ágar foi pesada e transferida para um frasco onde foi adicionado clorofórmio na proporção de $10 \mathrm{~g}$ do cultivo para $30 \mathrm{~mL}$ de clorofórmio. Decorridos 30 minutos de agitação, o solvente foi filtrado em papel de filtro contendo $5 \mathrm{~g}$ de sulfato de sódio anidro e evaporado até a secura (TRUCKSESS et al., 1987). Os extratos foram rediluídos com 1,0 mL de metanol grau HPLC, filtrados em membrana de 0,45 $\mu \mathrm{m}$ e analisado em CLAE., como descrito no item 3.3.2.

\subsection{Produção de esclerócios}

Após a avaliação do potencial toxigênico das 135 cepas selecionadas, as mesmas foram também avaliadas e relacionadas com a capacidade em produzir esclerócios. Cada cepa de A. flavus foi cultivada em Ágar Czapek e mantida a $30{ }^{\circ} \mathrm{C}$, por 14 dias. Em seguida, foi lavada a superfície da cultura com solução Tween 20 (100 $\mu \mathrm{L} / \mathrm{L})$ e filtrada em papel de filtro Whatmann (BARROS et al. 2005). Os esclerócios foram armazenados em micro tubos, a $4{ }^{\circ} \mathrm{C}$. Quando produzidos, 10 esclerócios foram selecionados aleatoriamente e verificada a média do diâmetro, em micrômetros, em microscópio Nikon, com o auxílio de uma lâmina milimétrica (5+ $100 / 100 \mathrm{~mm} \pm 0,2 \mu \mathrm{m})$ e ocular com retículo (CRL W 10x/18) da marca Zeiss do Brasil.

As cepas foram classificadas como produtoras ou não produtoras, quantificados os esclerócios quando em quantidades inferiores a 200 unidades e 
determinado como produtores superiores a 200 esclerócios, quando os valores foram ultrapassados.

\subsection{Análise estatística}

Para as análises estatísticas foram utilizados os softwares $R 2.9$ pacote Gamlss e SAS 9.1. Os testes realizados foram Análise exploratória, Análise de correlação pelo coeficiente de Pearson e Spearman e Análise inferencial. 


\section{DELINEAMENTO EXPERIMENTAL}




\section{DELINEAMENTO EXPERIMENTAL}

\section{CAMPO}

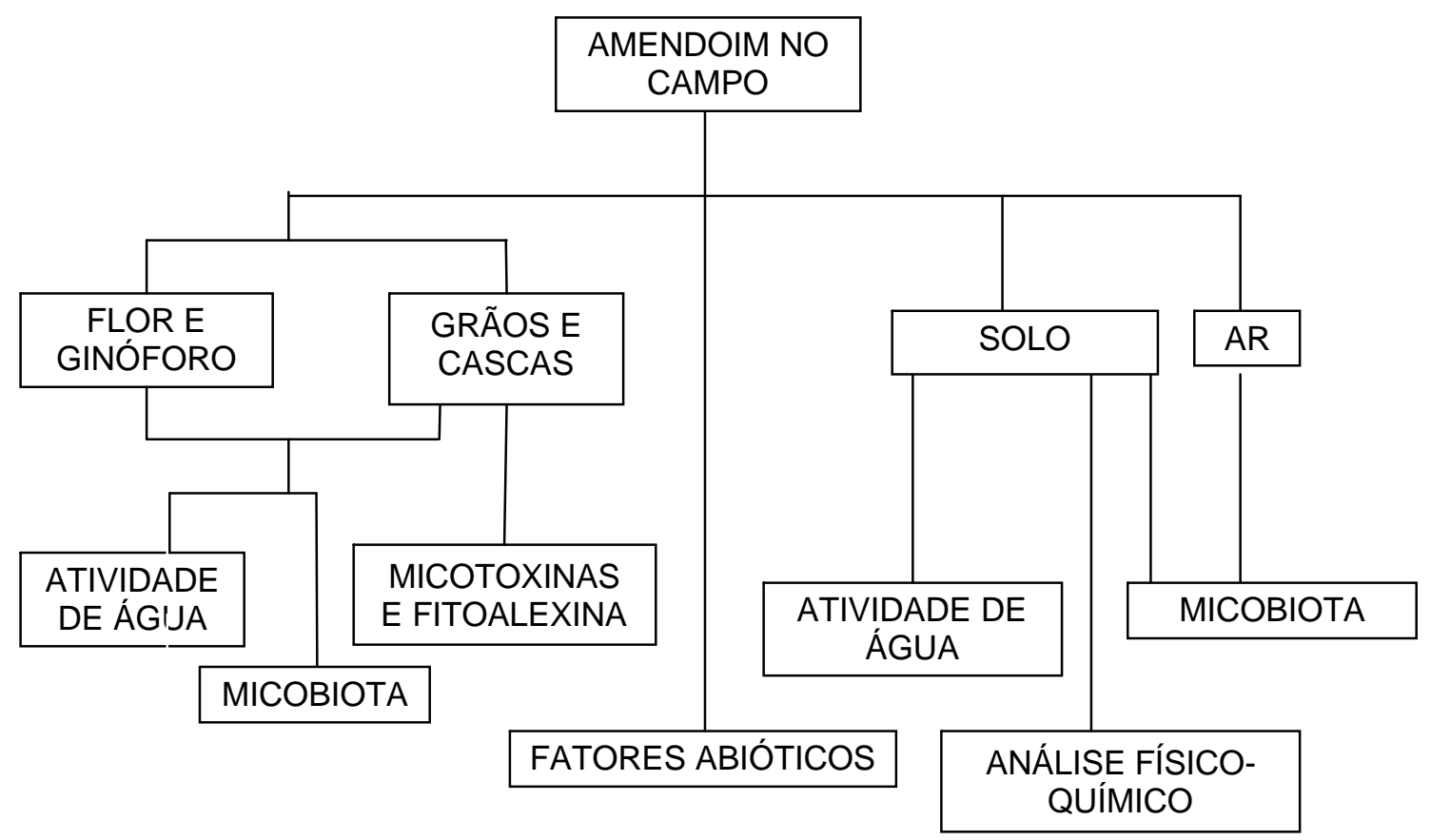

Figura 25 - Delineamento experimental, com as análises realizadas durante o crescimento do amendoim, no campo, na região de Tupã.

\section{ARMAZENAMENTO}

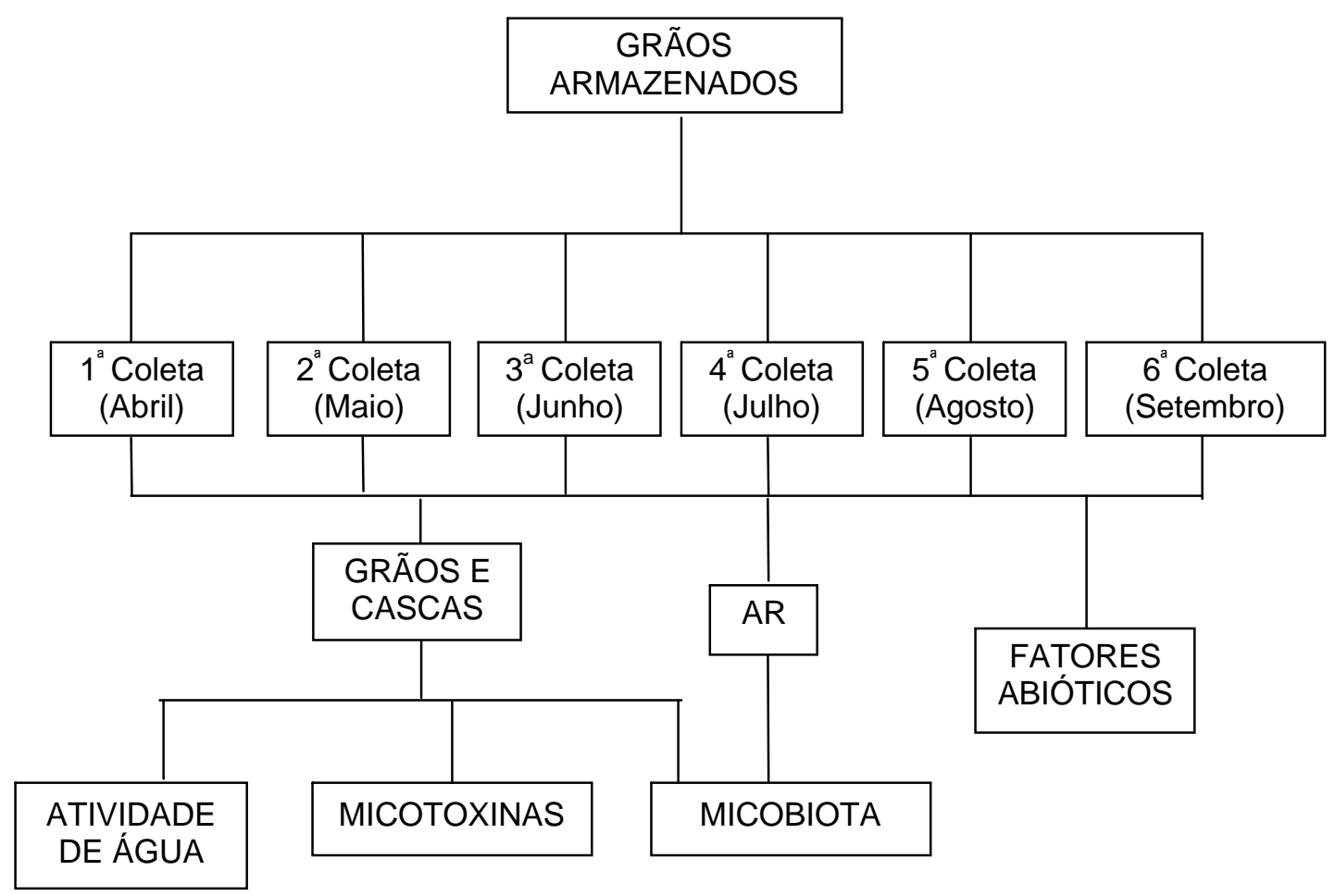

Figura 26 - Delineamento experimental, com as análises realizadas durante o período de armazenamento do amendoim, na região de Tupã. 
5 RESULTADOS E DISCUSSÃO 


\section{RESULTADOS E DISCUSSÃO}

\subsection{Campo}

\subsubsection{Avaliação Química do Solo}

As Tabelas 1 e 2 mostram os resultados da avaliação química do solo, após o plantio do amendoim.

Tabela 1 - Análises químicas do solo $(\mathrm{pH}$, matéria orgânica, macronutrientes, soma de bases, total de bases e saturação de bases), após o plantio do amendoim, na região de Tupã.

\begin{tabular}{|c|c|c|c|c|c|c|c|c|c|c|c|c|}
\hline \multirow[t]{2}{*}{ Amostras } & \multirow{2}{*}{$\begin{array}{c}\mathrm{pH} \\
\mathrm{CaCl}_{2}\end{array}$} & \multirow{2}{*}{$\begin{array}{l}\text { M.O. } \\
\mathrm{g} \mathrm{dm}^{-3}\end{array}$} & \multicolumn{2}{|c|}{$\mathrm{mg} \mathrm{dm}^{-3}$} & \multicolumn{8}{|c|}{$\mathrm{mmolc} \mathrm{da}^{-3}$} \\
\hline & & & $\mathbf{P}$ & $\mathbf{S}$ & $\mathrm{K}$ & $\mathrm{Ca}$ & Mg & $\overline{\mathrm{Al}}$ & $\mathrm{H}+\mathrm{Al}$ & SB & $T$ & V \\
\hline IAC-Caiapó & 5,4 & 16 & 4 & 4 & 0,8 & 12 & 10 & 0 & 13 & 22,8 & 35,8 & 64 \\
\hline IAC 886 & 5,4 & 14 & 12 & 1 & 0,9 & 17 & 12 & 0 & 12 & 29,9 & 41,9 & 71 \\
\hline
\end{tabular}

$\mathrm{S}=\mathrm{Ca}\left(\mathrm{H}_{2} \mathrm{PO}_{4}\right)_{2} 0,01 \mathrm{~mol} / \mathrm{l}(10 \mathrm{~mL} \mathrm{TFSA} / 25 \mathrm{~mL})$

Análise realizada pela ESALQ / Dep. Departamento de Solos e Nutrição de Plantas.

Tabela 2 - Análises de micronutrientes do solo, após o plantio do amendoim, na região de Tupã.

\begin{tabular}{cccccc}
\hline Amostras & \multicolumn{5}{c}{$\mathbf{m g ~ d m}^{-3}$} \\
\cline { 2 - 6 } & $\mathbf{B}$ & $\mathbf{C u}$ & Fé & Mn & Zn \\
\hline IAC-Caiapó & 0,57 & 0,3 & 16 & 4,0 & 0,4 \\
\hline IAC 886 & 0,61 & 1,5 & 39 & 2,5 & 0,7
\end{tabular}

Método utilizado: $\mathrm{Cu}$, Fé, $\mathrm{Mn}, \mathrm{Zn}$ - DTPA - TEA; $\mathrm{pH} 7,3 ; \mathrm{B}=\mathrm{BaCl}_{2} \cdot \mathrm{H}_{2} \mathrm{O}$ 0,125\% microondas (10 mL TFSA $/ 20 \mathrm{~mL}$ $\mathrm{BaCl}_{2}$ 0,125\%).

Análise realizada pela ESALQ / Dep. Departamento de Solos e Nutrição de Plantas.

Avaliação química do solo é um fator importante, já que uma nutrição mineral balanceada com macronutrientes e micronutrientes protege as plantas contra ataques fúngicos. A nutrição inadequada, por sua vez, pode aumentar a severidade das doenças, reduzir a produtividade e favorecer a produção de micotoxinas (STACK et al., 1986; AMÉZQUITA et al., 1993; CUERO et al., 1991).

Para alguns autores (RINCÓN et al., 1992; SIMPSON et al., 1994), os solos ideais são aqueles de média fertilidade, com matéria orgânica igual ou superior a $3 \%$, bem drenado, $\mathrm{pH}$ em torno de 6,0-6,5, tolerante a má drenagem e encharcamento temporário. A cultura de amendoim adapta-se a solos pobres em nutrientes, deficientes em fósforo, potássio, cálcio e magnésio, ácidos $(\mathrm{pH} 5,0)$ e alta toxidade de alumínio (75\%). 
De acordo com Malavolta (1976, 1985), em condições de campo, o melhor desenvolvimento e produção das plantas ocorre em $\mathrm{pH}$ na faixa entre 5,5 a 6,0-6,5. Entretanto, em relação a planta de amendoim, o pH ideal situa-se entre 5,0 e 6,5.

A variação do $\mathrm{pH}$ também pode influenciar a micobiota do solo. Neste sentido, segundo Buchanam e Ayres (1975), o efeito do pH depende da composição do meio de cultivo. Para produção de aflatoxinas, maior produção foi observada em $\mathrm{pH}$ entre 4 e 6, sendo menor que 6, favorável à produção de $A_{F} B_{1}$ e $A F B_{2}$ e maior que 6 , à produção de $A F G_{1}$ e $A F G_{2}$.

$\mathrm{O} \mathrm{pH}$ ótimo para o desenvolvimento de $A$. flavus e $A$. parasiticus situa-se entre 5 e 8, porém, os fungos podem crescer em ampla faixa de $\mathrm{pH}(2 \mathrm{a}>11) . \mathrm{O} \mathrm{pH}$ para a produção de aflatoxinas por $A$. parasiticus varia entre 2 a $>8$, sendo $6 \circ \mathrm{pH}$ mais favorável (ICMSF, 1996).

Em nosso estudo, após o plantio, a análise do solo revelou pH favorável ao crescimento da planta, de $A$. flavus e $A$. parasiticus, assim como para a produção de aflatoxinas (Tabelas 1 e 2). É importante lembrar que, além do $\mathrm{pH}$ e da disponibilidade de nutrientes, outros fatores influenciam o crescimento fúngico e a produção de micotoxinas, tais como: Aa, temperatura, umidade e concentração de inóculo.

5.1.2 Frequência de fungos isolados do ar e do solo antes do plantio, e das sementes utilizadas

$\mathrm{Na}$ amostra de solo foram isolados os seguintes fungos: Penicillium spp.

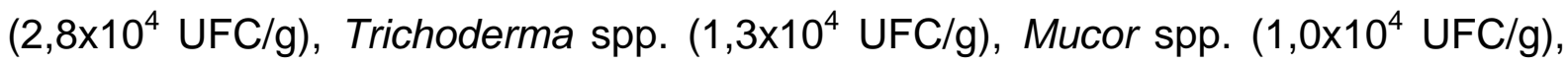
Fusarium spp. $\left(0,8 \times 10^{4} \mathrm{UFC} / \mathrm{g}\right)$ e Fungos não esporulados (FNE) $\left(0,2 \times 10^{4} \mathrm{UFC} / \mathrm{g}\right)$. A Aa encontrada nessa amostra foi de 0,85.

O solo agrícola serve como reservatório para diferentes espécies fúngicas, inclusive para $A$. flavus (BAYMAN e COTTY, 1991, COTTY, 1997; HORN e GREENE, 1995; MANABE et al., 1976), fungo com capacidade de invadir o tecido da planta viva (GARREN, 1966; GRIFFIN, 1972; PORTER e GARREN, 1970), como o amendoim, e em alguns casos infectar a semente durante a emergência, no solo (JACKSON e BELL, 1969). A presença de A. flavus tem sido reportada em solos de diferentes áreas de cultivo do amendoim no mundo (BELL e CRAWFORD, 1967; JOFFE, 1969; McDONALD, 1969). Entretanto, em algumas áreas, tem sido relatada 
baixa frequência do fungo (GRIFFIN e GARREN, 1974). A colonização do solo pode ser um importante fator na manutenção ou aumento da população de $A$. flavus no amendoim, no campo.

Análise dos fungos anemófilos, na área de plantio, resultou no isolamento dos seguintes fungos: Fusarium spp. (2,0 UFC $\left./ \mathrm{m}^{3}\right)$, Penicillium spp. $\left(0,7 \mathrm{UFC} / \mathrm{m}^{3}\right)$, Alternaria spp. $\left(0,7 \mathrm{UFC} / \mathrm{m}^{3}\right)$, FNE $\left(0,6 \mathrm{UFC} / \mathrm{m}^{3}\right)$, Cladosporium spp. $\left(0,6 \mathrm{UFC} / \mathrm{m}^{3}\right)$, Drechslera spp. (0,3 UFC/m $\left.\mathrm{m}^{3}\right)$, Trichoderma spp. (0,3 UFC $\left./ \mathrm{m}^{3}\right)$ e Curvularia spp. $(0,3$ $\left.\mathrm{UFC} / \mathrm{m}^{3}\right)$.

Em relação às sementes de amendoim, foram isolados, na variedade IACCaiapó, Fusarium spp. (3,0\%) e Penicillium spp. (3,0\%). Na variedade IAC 886, o fungo com maior frequência de isolamento foi $A$. flavus $(12,1 \%)$, seguido por $A$. parasiticus (3,0\%) e A. terreus (3,0\%). A Aa detectada para a variedade IAC-Caiapó foi de 0,66 , para os grãos, e 0,55 , para as cascas. Para a variedade IAC 886 , os valores encontrados foram de 0,65 e 0,53, para grãos e cascas, respectivamente.

Apesar do $\mathrm{pH}$ favorável, a pesquisa da micobiota revelou ausência de $A$. flavus e $A$. parasiticus, tanto no solo, como no ar. Tais fungos, isolados apenas nas sementes utilizadas no plantio da variedade IAC 886, podem ter favorecido a contaminação do solo e o crescimento do fungo durante o desenvolvimento da planta. Apesar da Aa dessas sementes antes do plantio ser insuficiente para o crescimento desses fungos $(0,65)$, a presença deles indica o potencial risco de contaminação pelas más condições de armazenamento das sementes podendo favorecer a contaminação da planta e frutos, após o seu plantio.

\subsubsection{Micobiota do solo}

O estudo das amostras de solo coletadas na área de plantio do amendoim da variedade IAC-Caiapó, durante o desenvolvimento da planta, resultou no isolamento dos seguintes fungos, por UFC/g, por coleta (Tabela A1; Figura 27):

$1^{\text {a }}$ coleta: Penicillium spp. $\left(2,1 \times 10^{4}\right)$, Mucor spp. $\left(0,9 \times 10^{4}\right)$, Fusarium spp. $\left(0,6 \times 10^{4}\right)$, Trichoderma spp. $\left(0,5 \times 10^{4}\right)$, FNE $\left(0,2 \times 10^{4}\right)$, Aspergillus ochraceus $\left(0,2 \times 10^{4}\right)$ e $A$. flavus $\left(0,1 \times 10^{4}\right)$.

$2^{\mathrm{a}}$ coleta: Penicillium spp. $\left(1,0 \times 10^{4}\right)$, A. flavus $\left(0,5 \times 10^{4}\right)$, Fusarium spp. $\left(0,4 \times 10^{4}\right)$, Mucor spp. $\left(0,2 \times 10^{4}\right)$, Verticillium spp. $\left(0,2 \times 10^{4}\right)$, Trichoderma spp. $\left(0,1 \times 10^{4}\right)$, A. niger $\left(0,1 \times 10^{4}\right)$ e Cladosporium spp. $\left(0,1 \times 10^{4}\right)$. 
$3^{\text {a }}$ coleta: Trichoderma spp. $\left(1,8 \times 10^{4}\right)$, Penicillium spp. $\left(1,4 \times 10^{4}\right)$, Fusarium spp. $\left(0,4 \times 10^{4}\right)$, Aspergillus terreus $\left(0,4 \times 10^{4}\right)$, Neurospora spp. $\left(0,3 \times 10^{4}\right)$, Verticillium spp. $\left(0,2 \times 10^{4}\right)$, Mucor spp. $\left(0,1 \times 10^{4}\right)$.

$4^{\mathrm{a}}$ Coleta: Trichoderma spp. $\left(1,6 \times 10^{4}\right)$, Penicillium spp. $\left(1,1 \times 10^{4}\right)$, A. terreus $\left(0,8 \times 10^{4}\right)$, Neurospora spp. $\left(0,6 \times 10^{4}\right)$, Fusarium spp. $\left(0,5 \times 10^{4}\right)$, Mucor spp. $\left(0,4 \times 10^{4}\right)$, A. flavus $\left(0,1 \times 10^{4}\right)$ e FNE $\left(0,1 \times 10^{4}\right)$.

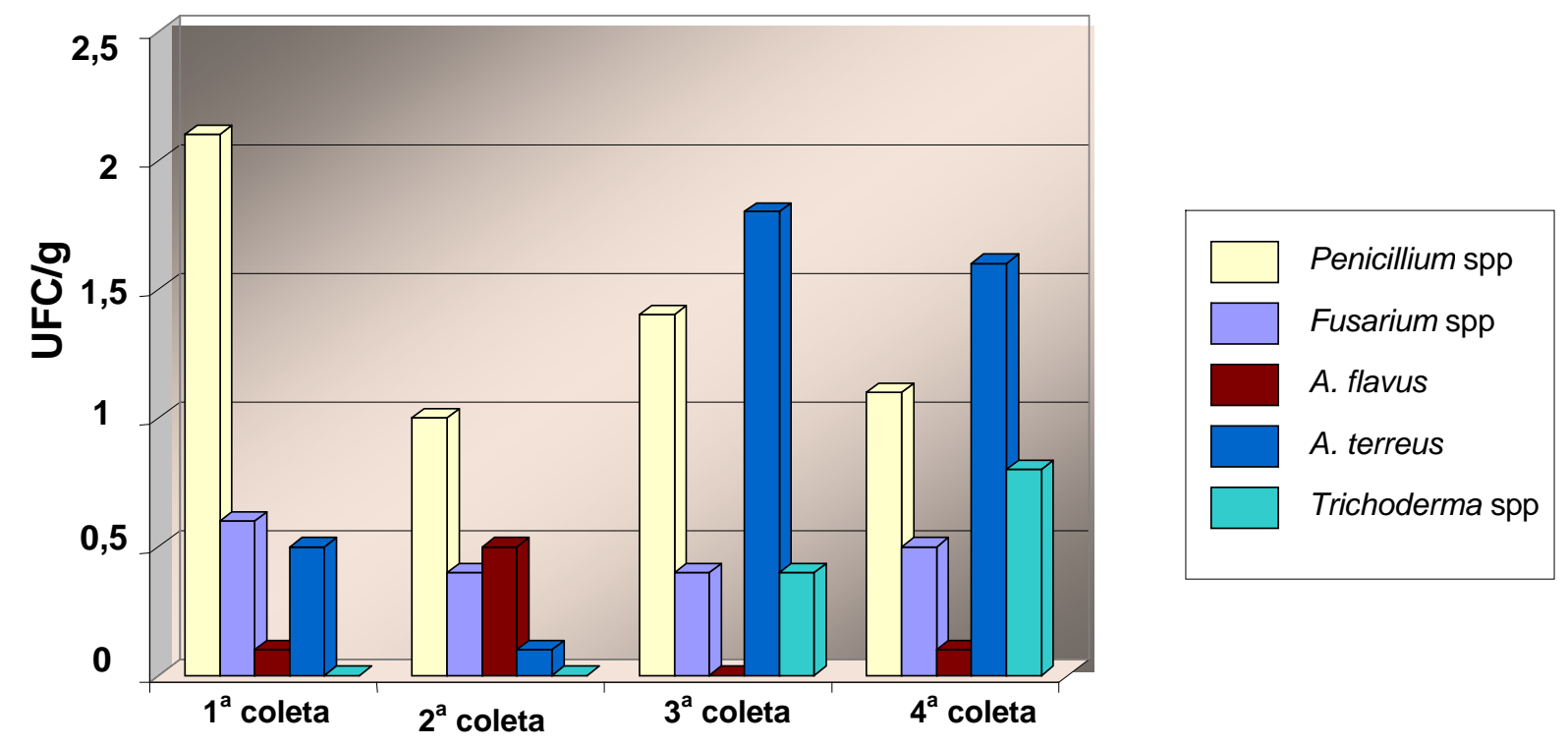

Figura 27 - Frequência de isolamento fúngico (UFC/g) das amostras de solo colhidas durante 0 período experimental, no campo, da variedade IAC-Caiapó.

Os valores encontrados para a micobiota do solo (UFC/g) na região de plantio na variedade IAC 886 foram (Tabela A2; Figura 28):

$1^{\text {a }}$ coleta: Penicillium spp. $\left(3,5 \times 10^{4}\right)$, Trichoderma spp. $\left(2,2 \times 10^{4}\right)$, A. flavus $\left(1,6 \times 10^{4}\right)$, Mucor spp. $\left(1,1 \times 10^{4}\right)$, Fusarium spp. $\left(1,1 \times 10^{4}\right)$ e FNE $\left(0,2 \times 10^{4}\right)$.

$2^{\mathrm{a}}$ coleta: Penicillium spp. $\left(4,4 \times 10^{4}\right)$, Trichoderma spp. $\left(1,4 \times 10^{4}\right)$, A. flavus $\left(1,4 \times 10^{4}\right)$, Fusarium spp. $\left(1,4 \times 10^{4}\right)$, Cladosporium spp. $\left(0,6 \times 10^{4}\right)$, Aspergillus niger $\left(0,2 \times 10^{4}\right)$, Mucor spp. $\left(0,2 \times 10^{4}\right)$ e Neurospora spp. $\left(0,2 \times 10^{4}\right)$.

$3^{\text {a }}$ coleta: Penicillium spp. $\left(2,0 \times 10^{4}\right)$, Trichoderma spp. $\left(0,6 \times 10^{4}\right)$, Fusarium spp. $\left(0,4 \times 10^{4}\right)$, A. terreus $\left(0,4 \times 10^{4}\right)$, Neurospora spp. $\left(0,3 \times 10^{4}\right)$, A. flavus $\left(0,1 \times 10^{4}\right)$, A. ochraceus $(0,1 \times 104)$, FNE $\left(0,1 \times 10^{4}\right)$ e Paemyces spp. $\left(0,1 \times 10^{4}\right)$.

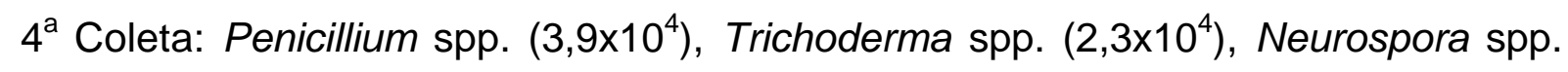
$\left(0,9 \times 10^{4}\right)$, A. terreus $\left(0,9 \times 10^{4}\right)$, Mucor spp. $\left(0,7 \times 10^{4}\right)$ Fusarium spp. $\left(0,5 \times 10^{4}\right)$ e Verticillium spp. $\left(0,1 \times 10^{4}\right)$. 


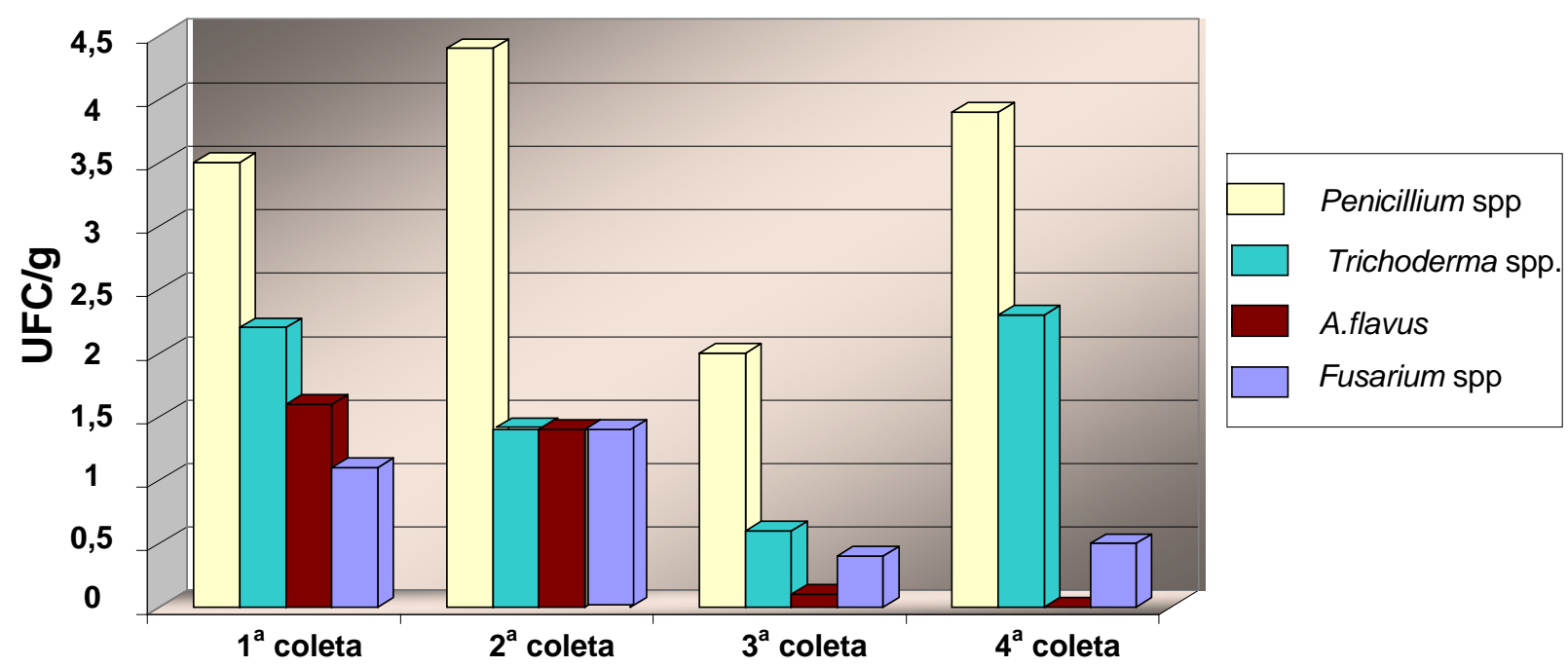

Figura 28 - Frequência de isolamento fúngico (UFC/g) das amostras de solo colhidas durante 0 período experimental, no campo, da variedade IAC 886.

A presença de $A$. flavus e $A$. parasiticus no solo pode ocasionar extensivas perdas econômicas, devido aos danos à planta e produção de aflatoxinas nos grãos. Após a fertilização aérea da flor do amendoim e prolongamento do ginóforo no solo, o fruto do amendoim desenvolve-se em ambiente subterrâneo e pode ser invadido por muitas espécies de microrganismos presentes no solo, durante o crescimento e desenvolvimento da planta (HILL et al., 1983).

Nossos resultados indicaram baixa frequência de isolamento de $A$. flavus e ausência do $A$. parasiticus no solo (Figuras 26 e 27). Nota-se que na variedade IAC 886 ocorreu maior frequência de isolamento do $A$. flavus nas $1^{\mathrm{a}}$ e $2^{\mathrm{a}}$ coletas, $1,6 \times 10^{4}$ $\mathrm{UFC} / \mathrm{g}$ e $1,4 \times 10^{4} \mathrm{UFC} / \mathrm{g}$, respectivamente, em relação a variedade IAC-Caiapó, $0,1 \times 10^{4} \mathrm{UFC} / \mathrm{g}$ e $0,5 \times 10^{4} \mathrm{UFC} / \mathrm{g}$, respectivamente.

Estatisticamente, na análise exploratória da micobiota no solo, a variedade IAC 886, indicou uma maior contaminação nas fases de flor e ginóforo. Observou-se, ainda, que não houve diferença no crescimento médio amostral em todas as fases de desenvolvimento da planta.

Análises de correlações de Spearman, entre as variáveis de crescimento fúngico no solo, nas variedades de amendoim estudadas, indicaram, na IAC-Caiapó, competição entre $A$. flavus e Penicillium spp. (correlação $=-0,505$ e $p=0,009$ ). No entanto, para a variedade IAC 886, não houve indícios de associação entre o crescimento dos fungos ( $p=0,597)$. 
Gonçalez et al. (2008a), estudando a micobiota do solo na cidade de Junqueirópolis, próximo a Tupã, verificaram a predominância de Penicillium spp.. Entretanto, fungos como Fusarium spp., A. terreus e Mucor spp., foram comuns em nosso experimento. Atayde (2009) isolou no solo de Tupã, após a emergência do amendoim e antes do arranquio, os fungos Penicillium spp., Fusarium spp., FNE, Cladosporium spp., Trichoderma spp., A. flavus e Alternaria spp. .

O contato direto do amendoim com populações de fungos do solo torna esta cultura ideal para a análise da relação entre a densidade populacional do solo e colonização de sementes (HORN, 2005). Baseado em observações no campo, Griffin e Garren (1974), sugeriram que A. flavus é capaz de colonizar frutos de amendoim em solos com baixa densidade populacional. No entanto, os autores afirmam que o controle de variáveis críticas, como temperatura do solo e atividade de água das sementes, possibilita avaliar com precisão o efeito da densidade populacional do solo na colonização da semente.

Horn e Pitt (1997) preconizam que A. flavus e A. parasiticus podem ser encontrados no solo, na forma de conídios e de esclerócios, e na planta na forma miceliana. Segundo eles, o grau de contaminação dos fungos, no campo, pode ultrapassar 5000 UFC/g de solo.

Os valores de Aa registrados nas amostras de solo variaram de 0,58 a 0,99, onde foi cultivada a variedade IAC-Caiapó (Tabela 3 - Anexo A), e de 0,61 a 0,99, onde foi plantada a variedade IAC 886 (Tabela 4 - Anexo A).

\subsubsection{Fungos do ar}

A pesquisa de fungos anemófilos realizada durante o crescimento da planta, na região de plantio da variedade IAC-Caiapó, resultou no isolamento dos seguintes fungos (Tabela A3; Figura 29):

$1^{\text {a }}$ Coleta: Fusarium spp. $\left(3,2 \mathrm{UFC} / \mathrm{m}^{3}\right)$, Penicillium spp. (0,9 UFC/m³ $)$, Alternaria spp. $\left(0,6 \mathrm{UFC} / \mathrm{m}^{3}\right)$, Drechslera spp. $\left(0,5 \mathrm{UFC} / \mathrm{m}^{3}\right)$, Trichoderma spp. $(0,4$ $\left.\mathrm{UFC} / \mathrm{m}^{3}\right)$, A. terreus $\left(0,4 \mathrm{UFC} / \mathrm{m}^{3}\right)$, FNE $\left(0,4 \mathrm{UFC} / \mathrm{m}^{3}\right)$, Mucor spp. $(0,3$ $\left.\mathrm{UFC} / \mathrm{m}^{3}\right)$, Curvularia spp. $\left(0,3 \mathrm{UFC} / \mathrm{m}^{3}\right), A$. flavus $\left(0,2 \mathrm{UFC} / \mathrm{m}^{3}\right)$ e Cladosporium spp. $\left(0,1 \mathrm{UFC} / \mathrm{m}^{3}\right)$.

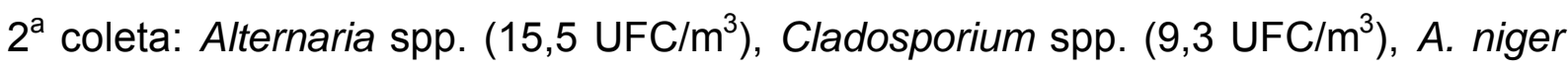
$\left(4,8 \mathrm{UFC} / \mathrm{m}^{3}\right)$, Fusarium spp. (1,9 UFC/m $\left.{ }^{3}\right)$, Mucor spp. $\left(1,1 \mathrm{UFC} / \mathrm{m}^{3}\right)$, 
Neurospora spp. $\left(0,2 \mathrm{UFC} / \mathrm{m}^{3}\right)$, A. flavus $\left(0,1 \mathrm{UFC} / \mathrm{m}^{3}\right)$ e Rhizopus spp. $\left(0,1 \mathrm{UFC} / \mathrm{m}^{3}\right)$.

$3^{\text {a }}$ coleta: A. niger (52,4 UFC/ $\left.\mathrm{m}^{3}\right)$, Alternaria spp. (36,0 UFC $\left./ \mathrm{m}^{3}\right)$, Cladosporium spp. $\left(14,0 \mathrm{UFC} / \mathrm{m}^{3}\right)$, A. flavus $\left(1,4 \mathrm{UFC} / \mathrm{m}^{3}\right)$, Mucor spp. (1,2 $\left.\mathrm{UFC} / \mathrm{m}^{3}\right)$, Fusarium spp. $\left(0,4 \mathrm{UFC} / \mathrm{m}^{3}\right)$, A. parasiticus $\left(0,2 \mathrm{UFC} / \mathrm{m}^{3}\right)$ e Rhizopus spp. $\left(0,2 \mathrm{UFC} / \mathrm{m}^{3}\right)$.

$4^{\text {a }}$ coleta: Alternaria spp. $\left(1038,4 \mathrm{UFC} / \mathrm{m}^{3}\right)$, Cladosporium spp. (68,2 UFC/m $\left.{ }^{3}\right)$, Mucor spp. $\left(7,0 \mathrm{UFC} / \mathrm{m}^{3}\right)$, Fusarium spp. $\left(0,6 \mathrm{UFC} / \mathrm{m}^{3}\right)$ e A. flavus $\left(0,2 \mathrm{UFC} / \mathrm{m}^{3}\right)$.

$5^{\text {a }}$ coleta: Cladosporium spp. $\left(15,2 \mathrm{UFC} / \mathrm{m}^{3}\right)$, Fusarium spp. $\left(13,6 \mathrm{UFC} / \mathrm{m}^{3}\right)$, Neurospora spp. (2,2 UFC/m $\left.\mathrm{m}^{3}\right)$, Trichoderma spp. $\left(1,6 \mathrm{UFC} / \mathrm{m}^{3}\right)$ e Rhizopus spp. $\left(0,4 \mathrm{UFC} / \mathrm{m}^{3}\right)$.

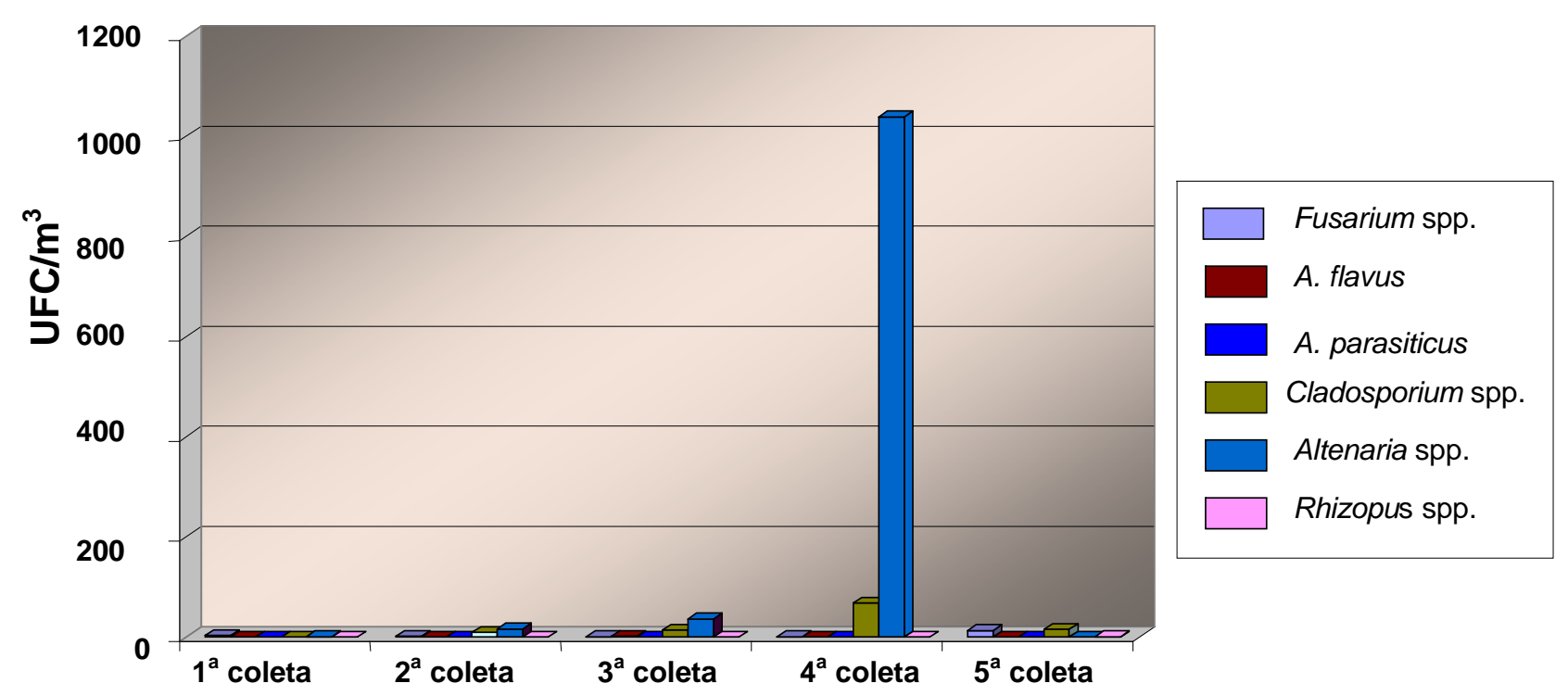

Figura 29 - Frequência de fungos anemófilos $\left(\mathrm{UFC} / \mathrm{m}^{3}\right)$ isoladas durante o crescimento da planta, no campo da variedade IAC-Caiapó.

$\mathrm{Na}$ área de plantio da variedade IAC 886, foram isolados os seguintes fungos anemófilos (Tabela A4; Figura 30):

$1^{\text {a }}$ Coleta: Cladosporium spp. $\left(1,1 \mathrm{UFC} / \mathrm{m}^{3}\right)$, Fusarium spp. $\left(0,9 \mathrm{UFC} / \mathrm{m}^{3}\right)$, Alternaria spp. $\left(0,8 \mathrm{UFC} / \mathrm{m}^{3}\right)$, Penicillium spp. $\left(0,5 \mathrm{UFC} / \mathrm{m}^{3}\right)$, Trichoderma spp. $(0,3$ $\left.\mathrm{UFC} / \mathrm{m}^{3}\right)$, FNE $\left(0,7 \mathrm{UFC} / \mathrm{m}^{3}\right)$, Curvularia spp. $\left(0,3 \mathrm{UFC} / \mathrm{m}^{3}\right)$, Nigrospora spp. $\left(0,3 \mathrm{UFC} / \mathrm{m}^{3}\right)$, Epicoccum spp. $\left(0,1 \mathrm{UFC} / \mathrm{m}^{3}\right)$ e Drechslera spp. $(0,1$ $\left.\mathrm{UFC} / \mathrm{m}^{3}\right)$.

$2^{\mathrm{a}}$ coleta: Alternaria spp. (4,7 UFC/ $\left.\mathrm{m}^{3}\right)$, Cladosporium spp. (3,5 UFC $\left./ \mathrm{m}^{3}\right)$, A. niger (7,7 UFC/m $\left.{ }^{3}\right)$, Fusarium spp. $\left(0,2 \mathrm{UFC} / \mathrm{m}^{3}\right)$, Neurospora spp. (0,8 UFC/ $\left.\mathrm{m}^{3}\right)$, 
Penicillium spp. $\left(0,3 \mathrm{UFC} / \mathrm{m}^{3}\right)$, Mucor spp. $\left(0,7 \mathrm{UFC} / \mathrm{m}^{3}\right)$, FNE $(0,4$ UFC $\left./ \mathrm{m}^{3}\right)$ e Rhizopus spp. $\left(0,1 \mathrm{UFC} / \mathrm{m}^{3}\right)$.

$3^{\text {a }}$ coleta: Alternaria spp. $\left(21,8 \mathrm{UFC} / \mathrm{m}^{3}\right)$, A. niger (19,0 UFC/m $\left.{ }^{3}\right)$, Curvularia spp. $(5,4$ $\left.\mathrm{UFC} / \mathrm{m}^{3}\right)$, Mucor spp. $\left(4,4 \mathrm{UFC} / \mathrm{m}^{3}\right)$, A. flavus $\left(2,2 \mathrm{UFC} / \mathrm{m}^{3}\right)$, Cladosporium spp.(1,2 UFC/m $\left.{ }^{3}\right)$, Fusarium spp. (0,8 UFC/m $\left.{ }^{3}\right)$, Neurospora spp. $(0,6$ $\left.\mathrm{UFC} / \mathrm{m}^{3}\right)$ e Rhizopus spp. $\left(0,2 \mathrm{UFC} / \mathrm{m}^{3}\right)$.

$4^{\text {a }}$ coleta: Alternaria spp. (1763,4 UFC/m $\left.{ }^{3}\right)$, Cladosporium spp. $\left(137,8 \mathrm{UFC} / \mathrm{m}^{3}\right)$, Rhizopus spp. $\left(0,4 \mathrm{UFC} / \mathrm{m}^{3}\right)$ e Fusarium spp. $\left(0,2 \mathrm{UFC} / \mathrm{m}^{3}\right)$.

$5^{\text {a }}$ coleta: Alternaria spp. (297,2 UFC/m $\left.{ }^{3}\right)$, Cladosporium spp. $\left(68,0 \mathrm{UFC} / \mathrm{m}^{3}\right), \mathrm{FNE}$ $\left(1,6 \mathrm{UFC} / \mathrm{m}^{3}\right)$, Mucor spp. $\left(1,0 \mathrm{UFC} / \mathrm{m}^{3}\right)$, Rhizopus spp. $\left(0,4 \mathrm{UFC} / \mathrm{m}^{3}\right) \mathrm{e}$ Verticillium spp. $\left(0,2 \mathrm{UFC} / \mathrm{m}^{3}\right)$.

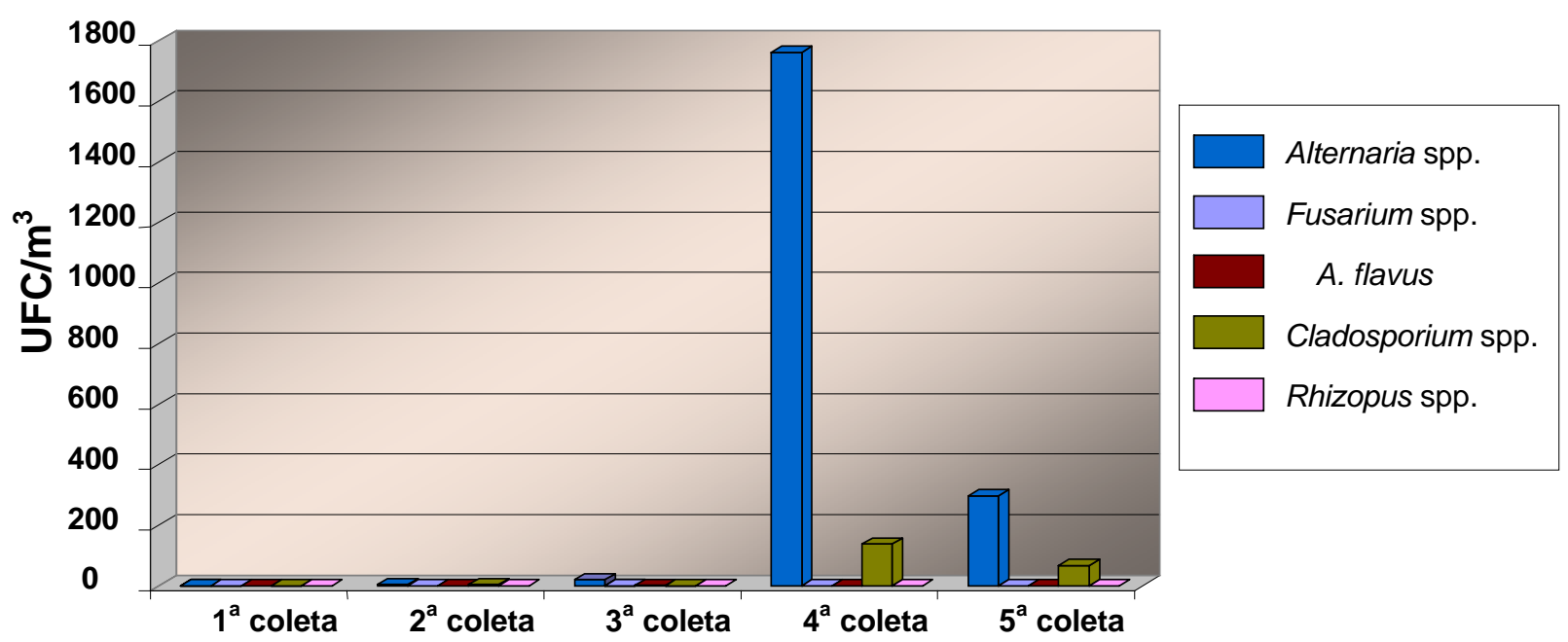

Figura 30 - Frequência de fungos anemófilos $\left(\mathrm{UFC} / \mathrm{m}^{3}\right)$ isoladas durante o crescimento da planta, no campo da variedade IAC 886.

A importância da pesquisa de fungos anemófilos foi observada em estudos anteriores realizados por Wells et al. (1972) e Lindsey e Turner (1975), avaliando a influência de fungos anemófilos na contaminação de partes aéreas do amendoim em desenvolvimento. Os autores constataram, sob condições gnotobióticas, a presença de A. flavus nas partes aéreas da planta. Este fato também foi constatado por Griffin e Garren (1976) que demonstraram, em condições de campo, a colonização de partes aéreas do amendoim como ginóforo e flores por $A$. flavus e $A$. niger.

Analisando os fungos contaminantes do ar, no local de plantio das duas variedades de amendoim, observamos que os fungos isolados são aqueles considerados dominantes universais, devido à elevada frequência de isolamento dos mesmos no ecossistema brasileiro (GAMBALE, 1998). 
Apesar de ser uma região produtora de amendoim, a área utilizada para o plantio das variedades apresentou baixa frequência de isolamento de Aspergillus spp.. As cepas de $A$. flavus foram isoladas em ambas as variedades com maior frequência apenas na $3^{\mathrm{a}}$ coleta, com $1,4 \mathrm{UFC} / \mathrm{m}^{3}$ na área do IAC-Caiapó e 2,2 $\mathrm{UFC} / \mathrm{m}^{3}$ na região de plantio do IAC 886. A espécie $A$. parasiticus foi isolada apenas na variedade IAC-Caiapó $\left(0,04 \mathrm{UFC} / \mathrm{m}^{3}\right)$, também na $3^{\mathrm{a}}$ coleta. Muitos fungos isolados no ar foram comuns aos encontrados por Gonçalez et al. (2008a), como Cladosporium spp., Mucor spp., Aspergillus spp., Rhizopus spp., Penicillium spp. e Alternaria spp..

5.1.5 Frequência de isolamento fúngico dos grãos e cascas das variedades IAC Caiapó e IAC 886

Análise da micobiota das amostras de flor, ginóforo e grãos do amendoim da variedade IAC-Caiapó, revelaram as seguintes frequências (Tabela A5; Figuras 31): Flor - Fusarium spp. (21,2\%), Mucor spp. (4,2\%), Alternaria spp. (4,8\%), Cladosporium spp. (3,6\%), FNE (2,4\%), Penicillium spp. (1,2\%), Nigrospora spp. (0,6\%), Neurospora spp. (0,6\%), Helminthosporium spp. $(0,6 \%)$ e Trichoderma spp. (0,6\%).

Ginóforo - Fusarium spp. (82,5\%) e Alternaria spp. (1,9\%).

Nas amostras de grãos do amendoim da variedade IAC-Caiapó, as frequências fúngicas encontradas em ordem decrescente foram (Tabela A5; Figura 31):

Fase água - Fusarium spp. (4,2\%) e A. flavus (1,2\%).

Início da granação - Penicillium spp. (43,0\%) e Fusarium spp. (0,6\%).

Grãos Maduros - Penicillium spp. (13,9\%), Fusarium spp. (12,7\%), A. flavus $(12,7 \%)$, A. niger (6,1\%), FNE (4,2\%) e Helminthosporium spp. $(0,6 \%)$.

Grãos secos - Fusarium spp. (77,6\%), Nigrospora spp. (4,8\%), Sepedonium spp. (4,2\%), A. flavus (1,8\%), Mucor spp. (1,8\%) e Alternaria spp. (1,2\%). 


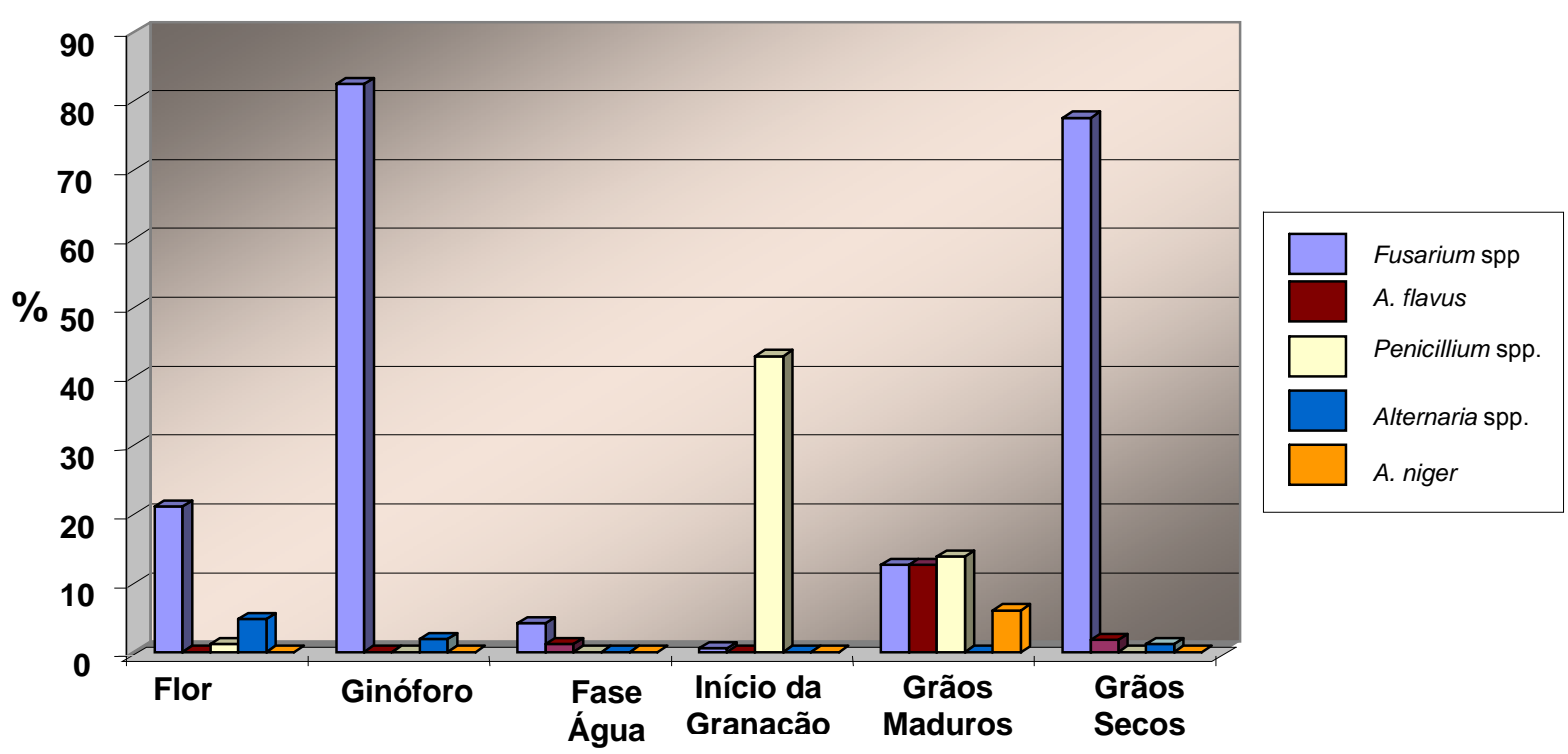

Figura 31 - Frequência de isolamento fúngico (\%) obtidas da flor, ginóforo e grãos da variedade IACCaiapó, durante o período de crescimento da planta, no campo.

Nas amostras das cascas do amendoim da variedade IAC-Caiapó, as frequências fúngicas encontradas em ordem decrescente foram (Tabela A6; Figuras 32 e 33):

Fase água - Fusarium spp. (82,5\%), A. flavus (2,5\%), Trichoderma spp. (1,2\%) e $A$. parasiticus $(1,2 \%)$.

Início da granação - Fusarium spp. (77,5\%), Penicillium spp. (18,7\%), A. flavus $(2,5 \%)$, A. terreus $(2,2 \%)$ e $A$. niger $(1,2 \%)$.

Grãos Maduros - Fusarium spp. (81,2\%), Mucor spp. (2,5\%) e A. flavus (1,2\%). Grãos secos - Fusarium spp. (96,2\%), Alternaria spp. (7,5\%), Nigrospora spp. $(1,2 \%)$ e Sepedonium spp. $(1,2 \%)$.

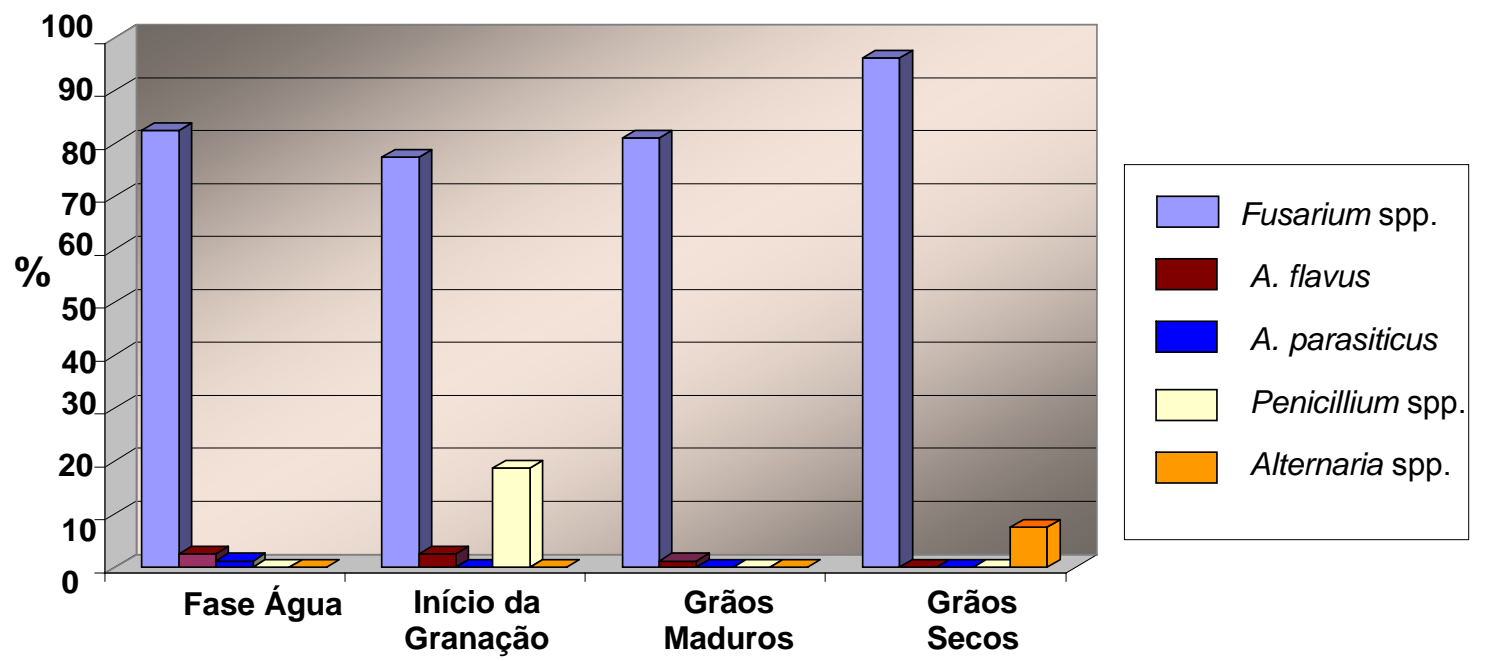

Figura 32 - Frequência de isolamento fúngico (\%) obtidas nas cascas da variedade IAC-Caiapó, durante o período de crescimento da planta, no campo. 


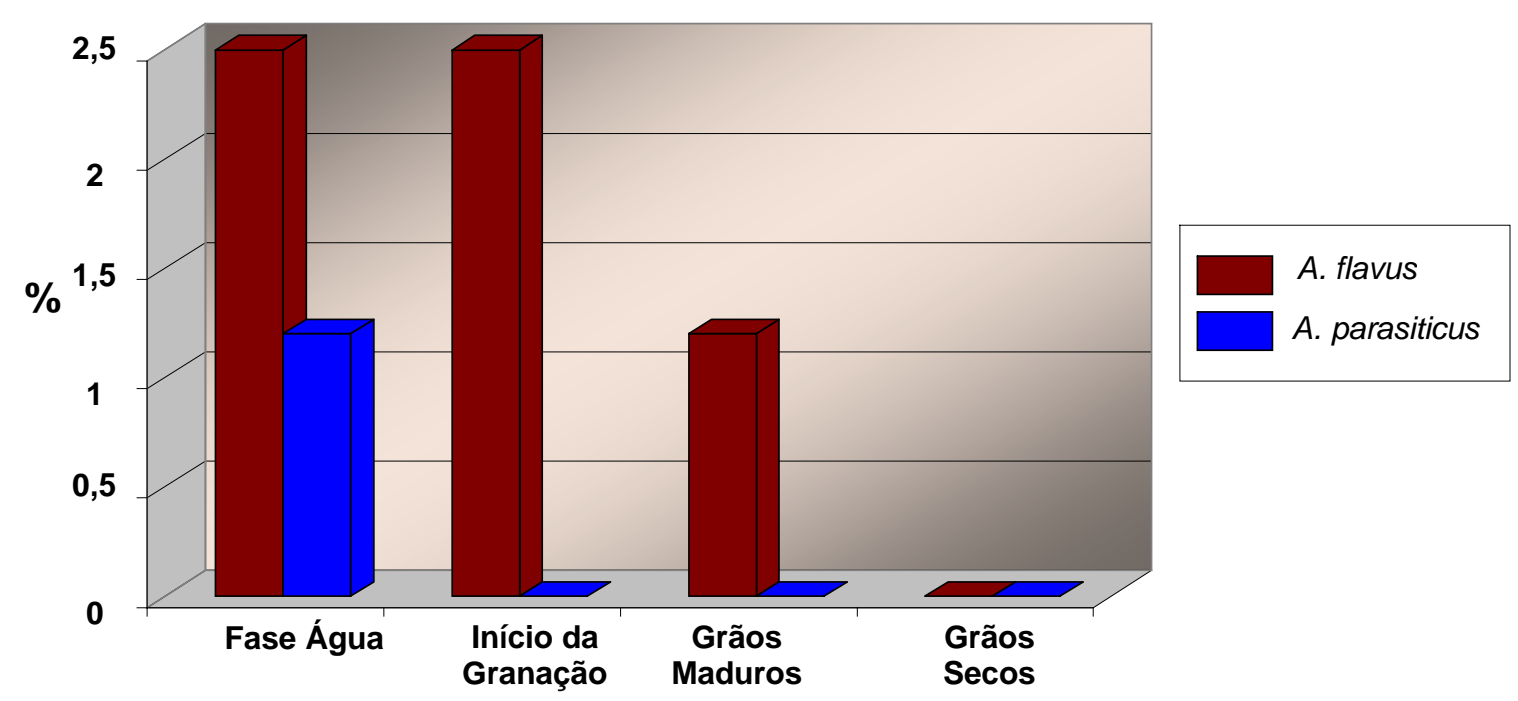

Figura 33 - Frequência de isolamento de $A$. flavus e $A$. parasiticus (\%) obtidas nas cascas da variedade IAC-Caiapó, durante o período de crescimento da planta, no campo.

A micobiota da flor, do ginóforo e dos grãos da variedade IAC 886, revelaram os seguintes resultados (Tabela A7; Figura 33):

Flor - Fusarium spp. (33,9\%), Mucor spp. (2,4\%), Rhizopus spp. (1,2\%), FNE (0,6\%) e Penicillium spp. (0,6\%), Nigrospora spp. (0,6\%) e Helminthosporium spp. $(0,6 \%)$.

Ginóforo - Fusarium spp. (88,7\%), Penicillium spp. (0,6\%) e Cladosporium spp. $(0,6 \%)$

Fase áqua: Fusarium spp. (16,4\%) e Penicillium spp. (1,8\%).

Início da granação: Penicillium spp. (77,0\%) e Fusarium spp. (6,1\%).

Grãos maduros: Fusarium spp. (30,3\%), A. flavus (3,6\%) e FNE (0,6\%).

Grãos secos: Fusarium spp. (7,3\%), A. flavus (3,6\%), Penicillium spp. (1,8\%), Drechslera spp. (0,6\%). 

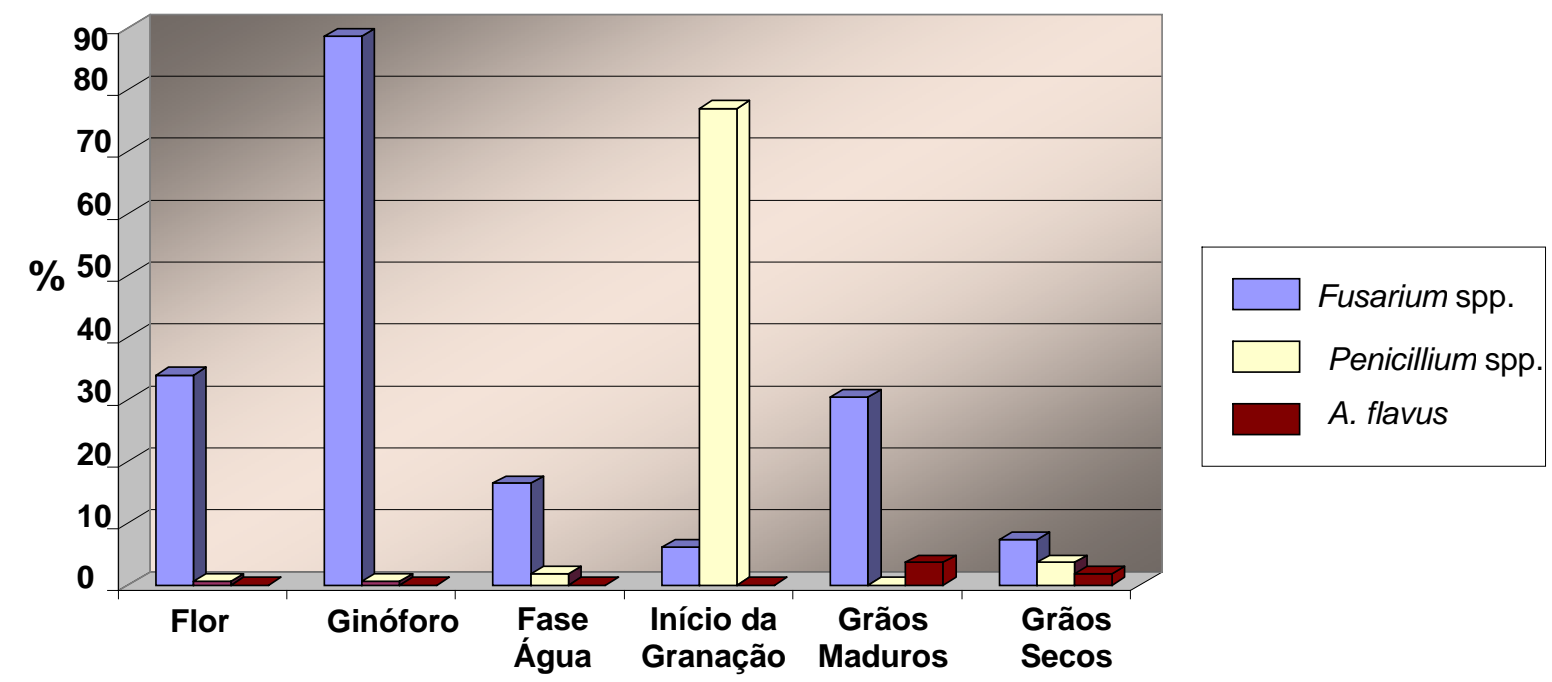

Figura 34 - Frequência de isolamento fúngico (\%) obtidas da flor, ginóforo e grãos da variedade IAC 886 , durante o período de crescimento da planta, no campo.

A análise da micobiota das cascas da variedade IAC 886 revelou maior incidência de Fusarium spp. e Penicillium spp., como é descrito nos resultados abaixo, nas diferentes fases de crescimento do amendoim (Tabela A8; Figura 35):

Fase água: Fusarium spp. (77,5\%), Penicillium spp. (2,5\%), Mucor spp. (2,5\%),

Trichoderma spp. (2,5\%) e Rhizopus spp. (1,2\%).

Início da granação: Penicillium spp. (70,0\%), Fusarium spp. (40,0\%) e Mucor spp. $(1,2 \%)$.

Grãos maduros: Fusarium spp. (63,7\%).

Grãos secos: Fusarium spp. (60,0\%), A. flavus (41,2\%), FNE (2,5\%), Alternaria spp. (2,5\%), Penicillium spp. (1,2\%), Pestalostiopsis spp. (1,2\%) e Drechslera spp. (1,2\%).

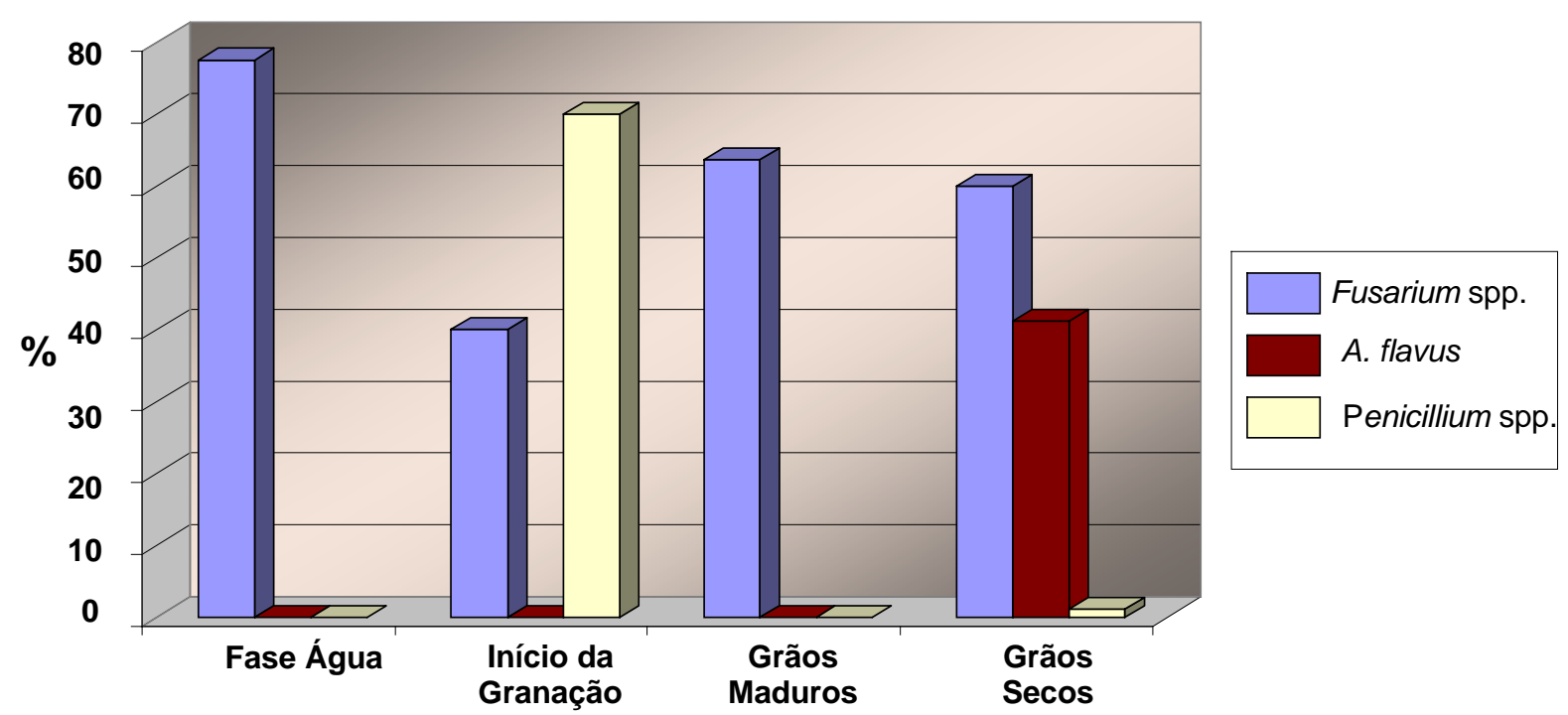

Figura 35 - Frequência de isolamento fúngico (\%) obtidas nas cascas da variedade IAC 886, durante o período de crescimento da planta, no campo. 
Análise estatística das amostras de cascas da variedade IAC-Caiapó, utilizando as correlações de Spearman, revelou correlação positiva alta e significante (correlação $=0,577$ e $p=0,008$ ) entre a frequência de $A$. flavus e Penicillium spp. Tais resultados sugerem, para a variedade IAC-Caiapó, que quanto maior a frequência de Penicillium spp. maior será a frequência de $A$. flavus. Para a variedade IAC 886 não houve indícios de associação entre os fungos $(p=0,410)$. No entanto, para essa variedade, foi possível constatar competição entre os gêneros Fusarium e Penicillium (correlação $=-0,482$ e $p=0,031$ ). Nas amostras colhidas a campo, em ambas as variedades, notou-se elevada frequência de Fusarium spp., tanto nas amostras de flor, ginóforo e cascas, como nos grãos. Estatisticamente, a única correlação significante observada nos grãos, ocorreu entre o Fusarium spp. e Penicillium spp. para a variedade IAC-Caiapó (correlação $=-0,446$ e $p=0,012$ ), sugerindo também uma possível competição entre esses fungos.

Análise estatística inferencial, revelou maior frequência de $A$. flavus nas cascas de amendoim, no campo, na fase de grãos secos da variedade IAC 886, do que nas demais fases do IAC 886 e em todas as fases da variedade IAC-Caiapó.

Gonçalez et al. (2008a), analisando diferentes estágios de maturidade do amendoim no campo, também observaram elevada frequência de isolamento de Fusarium spp.. O mesmo fungo também predominou em trabalho realizado por Atayde (2009), onde foram colhidos amendoins antes e após o arranquio, na região de Tupã.

A elevada frequência de Fusarium spp. pode ser atribuída ao seu caráter endofítico e aos níveis elevados de atividade de água das amostras (em torno de 0,99), considerados ótimos para o seu crescimento (LACEY et al., 1991). Estudo realizado por Torres et al. (2003), demonstrou frequência máxima de crescimento de Fusarium spp. em amendoim com Aa de 0,98. Segundo Frank e Bem-Yephet (1997), Fusarium spp. é comum em solos utilizados para o plantio de amendoim, sendo isolados de restos de plantas, sementes e tecidos de sementes germinadas. Nessas condições, a densidade populacional do Fusarium spp. no solo pode aumentar consideravelmente.

A baixa frequência do $A$. flavus nas primeiras fases do amendoim colhido, com exceção dos grãos maduros na variedade IAC-Caiapó, pode ser atribuída à elevada Aa das amostras $(0,99)$ e a baixa frequência de isolamento desse fungo no solo. Segundo Lacey et al. (1991), os níveis ideais de Aa para o crescimento de $A$. 
flavus é de 0,78 a 0,80 e de $A$. parasiticus entre 0,78 a 0,82. De modo geral, os níveis de Aa encontrados nas amostras são superiores aos necessários para o crescimento do fungo.

O aumento da frequência de $A$. flavus notada na fase de grãos secos, nas cascas da variedade IAC 886 também foi observada em trabalho realizado por Atayde (2009), onde a autora registrou frequência de isolamento de $A$. flavus na variedade IAC 886 de 15,6\% (cascas) e 26,6\% (grãos).

Nesse período, os níveis de Aa das amostras de cascas, avaliadas em nosso experimento, variaram de 0,58 a 0,64, o que pode não ter favorecido o crescimento do A. flavus, mas sim a permanência de esporos no amendoim.

\subsubsection{Fatores abióticos}

Os dados climatológicos registrados, no campo, durante o período experimental, mostraram dias quentes, com temperaturas médias mensais variando de 21,0 a $31,0{ }^{\circ} \mathrm{C}$, sendo registrada temperatura máxima diária de $38,0{ }^{\circ} \mathrm{C}$ em janeiro de 2006. Nesse mesmo mês, a umidade relativa do ar média teve um índice baixo $(63,9 \%)$, quando comparados aos meses de fevereiro e março $(72,4$ e $83,0 \%)$ (Tabelas A9 e A10).

Longos períodos de estiagem foram registrados no mês de novembro, com intervalos sem a ocorrência de precipitação. Alguns autores mencionam que o aumento da frequência de $A$. flavus e $A$. parasiticus está associado diminuição do sistema de defesa da planta, devido a longos períodos de estiagem (DORNER et al., 1989; OLANYA e HOYOS, 1997; SANDERS et al. 1984).

O período de maior índice pluviométrico ocorreu em fevereiro $(303,4 \mathrm{~mm})$ e março $(234,4 \mathrm{~mm})$, fato que pode ter favorecido o aumento da frequência de Fusarium spp. nas fases de grãos maduros e grãos secos, em ambas as variedades (Tabela A11).

Atividade de água das amostras de cascas e grãos de amendoim da variedade IAC-Caiapó (Tabelas A5 e A6), colhidas no período de fevereiro a março de 2006, foi de 0,99 (fase água a grãos maduros). Após o arranquio, com o amendoim seco prestes a serem armazenados, a Aa das cascas e grãos diminuiu para 0,65 e 0,77, respectivamente. Valores próximos de Aa foram encontrados na 
variedade IAC 886 (Tabela A7 e A8), com Aa variando entre 0,98 a 0,99 (cascas e grãos da fase água a grãos maduros) e de 0,62 para as cascas e grãos secos.

Segundo Lacey et al. (1991), a faixa de temperatura para o crescimento do $A$. flavus e $A$. parasiticus é de 6 a $45^{\circ} \mathrm{C}$, sendo a temperatura ótima a $35^{\circ} \mathrm{C}$. No entanto, a Aa de acordo com os autores, estavam fora do ideal para o crescimento do $A$. flavus $(0,78$ a 0,80$)$ e do $A$. parasiticus $(0,78$ a 0,82$)$, no campo.

Estatisticamente não houve indícios de associação para as variações observadas (frequência de isolamento fúngico) com as variáveis climatológicas (precipitação, temperatura e umidade relativa do ar).

\subsubsection{Micotoxinas}

Das 20 amostras de grãos colhidas a campo, na variedade IAC 886, foi detectada a presença de aflatoxinas em 6 amostras (30\%), com níveis médios variando de 0,03 a $1,0 \mu \mathrm{g} / \mathrm{kg}$. Na variedade IAC-Caiapó, das 20 amostras analisadas, a toxina foi detectada em apenas 5 amostras (25,0\%), com níveis entre 0,03 a $0,6 \mu \mathrm{g} / \mathrm{kg}$ (Tabela A12). Por sua vez, nas amostras de cascas, não foi registrada a presença de aflatoxinas nas variedades estudadas.

Gonçalez et al. (2008a), analisando amostras de amendoim colhidas durante o crescimento no campo, em Junqueirópolis (SP), registraram a presença de $\mathrm{AFB}_{1}$ em 32\% das amostras de grãos, com níveis entre 3,79 a 125,1 $\mu \mathrm{g} / \mathrm{kg}$. Atayde (2009) investigou a presença de aflatoxinas em amendoim recém-colhido, em regiões produtoras no Estado de São Paulo e verificou que em 80 amostras analisadas, $13,7 \%$ apresentaram contaminação nas cascas, com níveis entre 1,0 a 117,8 $\mu \mathrm{g} / \mathrm{kg}$ e 5\% nas amostras de grãos, com níveis entre 1,0 a 12,67 $\mu \mathrm{g} / \mathrm{kg}$.

Pesquisa realizada por Horn, Greene e Dorner (1995), utilizando amendoim coletados no campo, revelou baixa contaminação fúngica (5\%) de grãos íntegros por A. flavus e A. parasiticus. Em consequência, foi detectada baixa contaminação por aflatoxinas (até $8.2 \mathrm{ppb}$ ).

Em nossa investigação os níveis de aflatoxinas detectados em nossas amostras não ultrapassaram o limite máximo permitido pelo Ministério da Saúde e da Agricultura que é de e $20 \mu \mathrm{g} / \mathrm{kg}$, para a soma das aflatoxinas $B_{1}+B_{2}+G_{1}+G_{2}$.

Estatisticamente não ocorreu relação entre a produção de aflatoxinas com os fatores abióticos e a frequência de isolamento fúngico. 
Análise de Ácido ciclopiazônico nas amostras de grãos nas duas variedades, no campo, revelou alto índice de positividade. Na variedade IAC 886, o percentual de positividade atingiu 70,0\% (14 amostras), com níveis variando de 82,5 a 7835,5 $\mu \mathrm{g} / \mathrm{kg}$. A variedade IAC-Caiapó obteve $55 \%$ de amostras positivas (11 amostras), com níveis entre 89,9 a 2769,1 $\mu \mathrm{g} / \mathrm{kg}$ (Tabela A13).

Co-ocorrência de aflatoxinas e ACP nos grãos, foi constatada em 3 (15\%) amostras da variedade IAC-Caiapó, e na totalidade das amostras da variedade IAC 886.

Gonçalez et al. (2008a), analisando amendoins recém colhidos, detectaram $32 \%$ de amostras positivas para ACP, com níveis variando de 206 a $600 \mu \mathrm{g} / \mathrm{kg}$, Os autores também registraram a co-ocorrências das toxinas na maioria das amostras avaliadas.

No campo, a produção de ACP, por $A$. flavus pode ser atribuída às condições de umidade $(\mathrm{Aa})$ e temperatura, consideradas ideais para produção da toxina. Segundo Vaamonde et al. (2006), em condições experimentais, atividade de água de 0,94 e temperatura de $25{ }^{\circ} \mathrm{C}$ são ideais para a produção de ACP por $A$. flavus, após 28 dias de incubação. Gqaleni et al. (1997), constataram que a combinação de alta atividade de água e baixa temperatura favorece a produção de elevados níveis de ACP. Por outro lado, níveis reduzidos foram verificados em baixa atividade de água e altas temperaturas.

Análise estatística da frequência de $A$. flavus em relação à produção de ACP nos grãos indicou ausência de associação entre as duas variáveis, provavelmente em decorrência da baixa frequência de $A$. flavus observada no campo. Estatisticamente, as medidas de variabilidade (desvio padrão e erro padrão), a produção média de ACP não parece variar de acordo com a variedade de amendoim e com a fase de desenvolvimento.

Razzaghi-Abyaneh et al. (2006), analisando cepas de A. flavus isoladas do solo, verificaram que $27 \%$ das cepas eram produtoras de aflatoxinas e $75 \%$ produtoras de ACP. A elevada quantidade de amostras positivas para ACP também foi registrada por Vaamonde et al. (2006). Os autores verificaram que $69 \%$ e $94 \%$ das cepas de $A$. flavus isoladas de amendoim eram produtoras de aflatoxinas e de ACP, respectivamente. A co-ocorrência de ACP e aflatoxinas também foi reportada por outros autores (VAAMONDE et al., 2006; FERNANDEZ-PINTO et al., 2001). 


\subsubsection{Fitoalexinas (trans-resveratrol)}

Trans-resveratrol foi detectado, na variedade IAC 886, em apenas uma amostra de grãos (5\%), na fase água, com concentração de $790 \mu \mathrm{g} / \mathrm{kg}$. Por sua vez, na variedade IAC-Caiapó, 3 amostras de grãos (15\%) foram positivas com níveis entre 280 a $570 \mu \mathrm{g} / \mathrm{kg}$ (Tabela A14). O fato dos frutos se desenvolverem abaixo do solo, pode tê-los protegido da incidência direta do sol, diminuído a exposição a raios UV e a produção de trans-resveratrol (SIEMANN e CREASY, 1992). De acordo com Fritzemeier et al. (1983), a luz UV tem um significante efeito na formação do transresveratrol, podendo atingir produção máxima após 4 horas de irradiação.

A elevada frequência de Fusarium spp. e Penicilium spp., nas duas variedades, pode ser justificada pela estiagem (estresse hídrico) ocorrida nos primeiros meses de plantio e a pouca produção de trans-resveratrol registrada nos grãos, o que pode ter favorecido o aumento da invasão fúngica nesse período. As elevadas temperaturas registradas durante o crescimento da planta, no campo, também pode ter agravado o estresse hídrico. A influência do estresse hídrico na produção de fitoalexina foi avaliada por Sheikh et al. (1990) que comprovou o acumulo da fitoalexina em amendoins, sob condições de até $100 \%$ de umidade relativa e a consequente diminuição com o decréscimo dessa umidade. Dorner et al. (1989) demonstraram que, com a queda do teor de água de sementes de amendoim durante a seca, a capacidade das sementes para a produção de fitoalexinas diminuiu, podendo resultar em infecção por fungos e contaminação com aflatoxinas.

Nas folhas, o número de amostras positivas foi elevado (70,0\%), nas duas variedades estudadas. Níveis mais elevados de trans-resveratrol detectados na variedade IAC 886 são indicativos da resposta da planta a fatores externos. Nas folhas, os níveis médios encontrados variaram de 5100 a $157900 \mu \mathrm{g} / \mathrm{kg}$ (IAC 886) e de 3000 a $55600 \mu \mathrm{g} / \mathrm{kg}$ (IAC-Caiapó) (Tabela A14). A exposição das folhas diretamente ao sol (luz UV), além de danos causados por insetos, pode ser a causa do aumento de trans-resveratrol (SIEMANN e CREASY, 1992).

Pesquisa realizada por Grayer et al. (1995), induzindo a produção de fitoalexinas por meio de irradiação de ondas UV em folhas de arroz, revelaram rapidez na produção do metabólito. Segundo Chalutz e Stamasnn (1969), a indução de fitoalexina também pode ocorrer em resposta à utilização do fungo Uromyces phaseoli, como elicitador em folhas de feijão. 
Análise estatística demonstrou que a maior frequência fúngica foi acompanhado da maior produção de trans-resveratrol nas folhas. Na fase de grãos maduros, a produção de trans-resveratrol foi, em média, menor do que nas demais fases de desenvolvimento.

\subsection{Armazenamento}

5.2.1 Frequência de isolamento fúngico nos grãos e cascas nas variedade IACCaiapó e IAC 886

Durante o armazenamento, foram coletadas amostras mensais de grãos e cascas para pesquisa da micobiota, na variedade IAC-Caiapó.

Nas amostras de grãos de amendoim da variedade IAC-Caiapó, as frequências fúngicas encontradas em ordem decrescente foram (Tabela $A 15$; Figuras 36 e 37):

$1^{\text {a }}$ coleta: $A$. flavus (12,1\%), A. niger (6,1\%), Mucor spp. (6,1\%), Penicillium spp. (4,5\%), FNE (1,5\%) e Fusarium spp. (1,5\%).

$2^{\mathrm{a}}$ coleta: Penicillium spp. (14,5\%), A. flavus (6,1\%), A. terreus (4,2\%) A. niger (3,6\%), Fusarium spp. (0,6\%) e Cladosporium spp. (0,6\%).

$3^{\mathrm{a}}$ coleta: A. terreus (10,9\%), Fusarium spp. (8,5\%), Penicillium spp. (6,7\%), A. flavus $(6,1 \%)$, A. niger (1,8\%) e A. parasiticus $(0,6 \%)$.

$4^{\mathrm{a}}$ coleta: Rhizopus spp. (68,7\%), A. flavus (13,9\%), A. niger (12,1\%), Penicillium spp. (3,6\%), Cladosporium spp. (1,8\%), FNE (0,6\%).

$5^{\mathrm{a}}$ coleta: A. flavus $(11,5 \%)$, A. terreus $(4,2 \%)$, A. niger $(0,6 \%)$, A. penicillioides (0,6\%), Cladosporium spp. (0,6\%) e Penicillium spp. (2,5\%).

$6^{\mathrm{a}}$ coleta: A. terreus (16,4\%), Mucor spp. (13,3\%), Rhizopus spp. (6,7\%), Trichoderma spp. (6,7\%), A. flavus (5,4\%), Penicillium spp. (4,8\%), $A$. niger $(2,4 \%)$ e Fusarium spp. (2,4\%). 


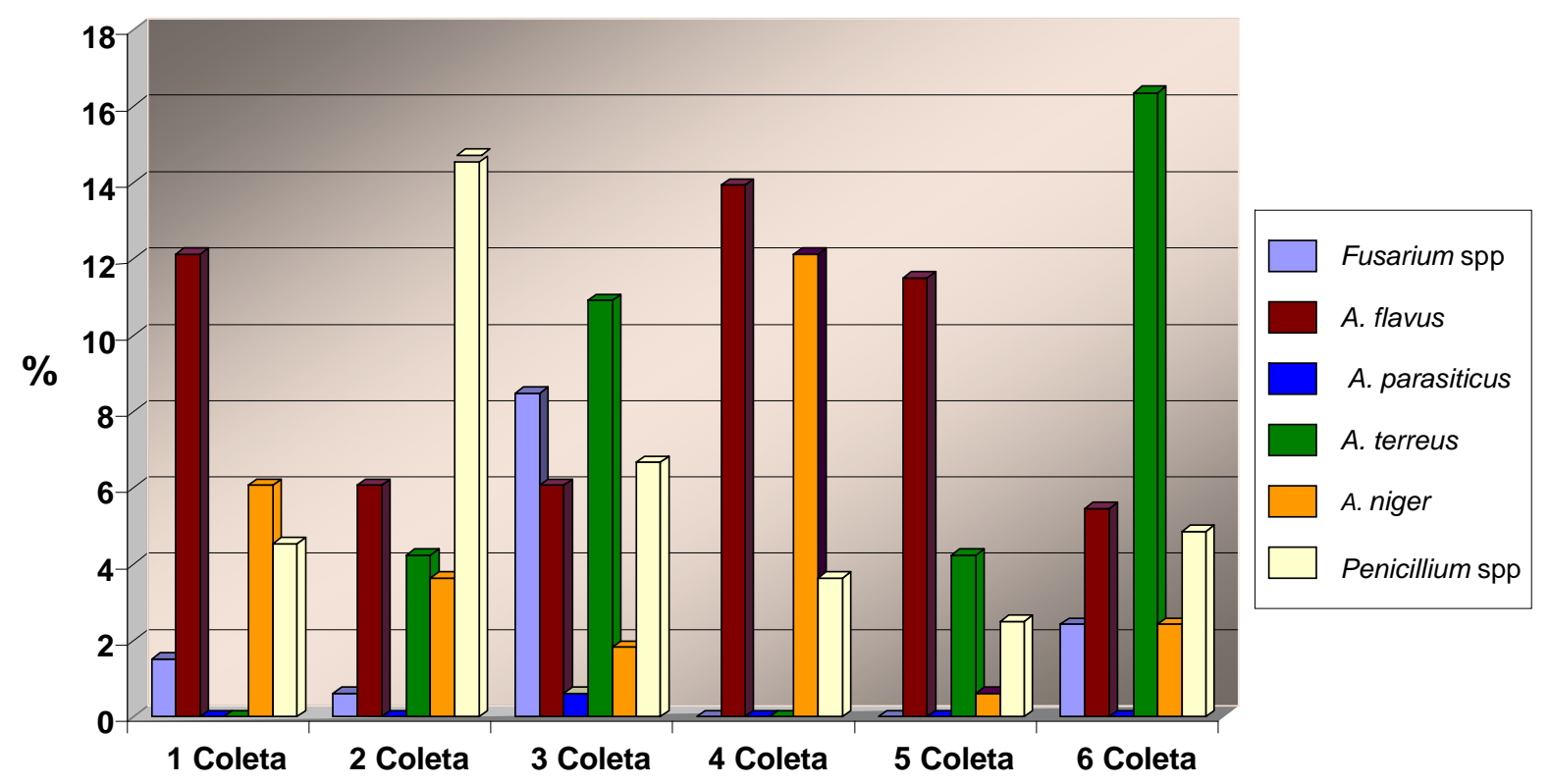

Figura 36 - Frequência fúngica (\%) isolada dos grãos armazenados da variedade IAC-Caiapó, no período de abril a setembro de 2006, no município de Tupã.

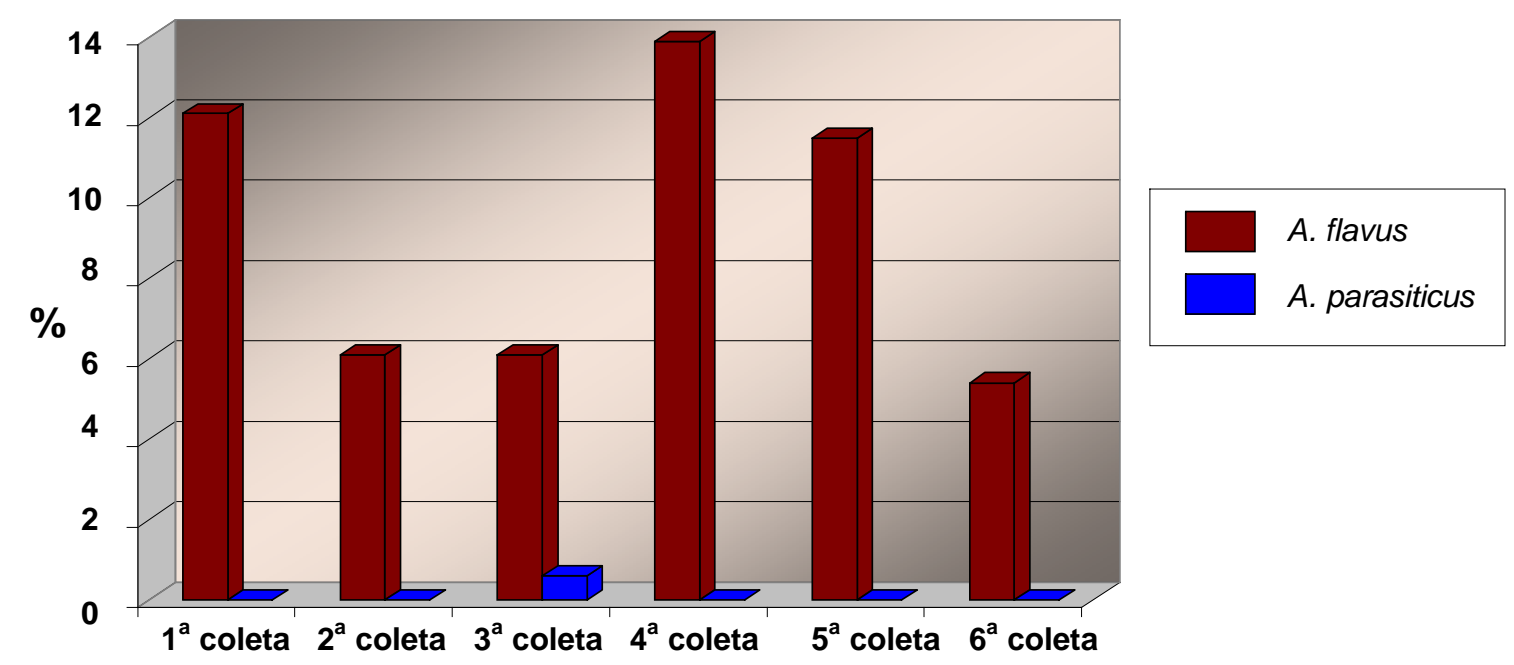

Figura 37 - Frequência de isolamento (\%) de A. flavus e A. parasiticus em grãos armazenadas da variedade IAC-Caiapó, no período de abril a setembro de 2006, no município de Tupã.

Nas cascas da variedade IAC-Caiapó, as frequências de fungos isolados nas diferentes coletas foram (Tabela A16; Figuras 38 e 39):

$1^{\mathrm{a}}$ coleta: A. flavus (91,7\%), Rhizopus spp. (22,2\%), Fusarium spp. (8,3\%) e Alternaria spp. (2,8\%).

$2^{a}$ coleta: A. flavus (41,2\%), Alternaria spp. (40,0\%), Rhizopus spp. (20,0\%), A. niger (11,2\%), Fusarium spp. (11,2\%), Penicillium spp. (6,2\%), Nigrospora spp. (3,7\%), Cladosporium spp. (1,2\%) e Mucor spp. (1,2\%). 
$3^{\text {a }}$ coleta: A. flavus (56,2\%), Fusarium spp. (28,7\%), Alternaria spp. (16,2\%), A parasiticus (8,7\%), A. niger (5,0\%), Penicillium spp. (3,7\%), Mucor spp. $(1,2 \%)$, Curvullaria spp. (1,2\%).

$4^{\text {a }}$ coleta: A. flavus (67,5\%), Rhizopus spp. (33,7\%), Alternaria spp. (22,5\%), A. niger (16,2\%), Fusarium spp. (12,2\%), Cladosporium spp. (1,2\%), Mucor spp. $(1,2 \%)$ e Penicillium spp. (1,2\%).

$5^{\text {a }}$ coleta: A. flavus (57,5\%), Rhizopus spp. (25,0\%), A. niger (20,0\%), Alternaria spp. (8,7\%), Fusarium spp. (2,5\%), Mucor spp. (2,5\%) e Penicillium spp. $(2,5 \%)$.

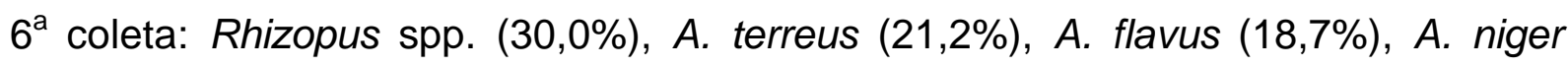
(18,0\%), Fusarium spp. (11,2\%), Penicillium spp. (11,2\%), Mucor spp. (7,5\%), Trichoderma spp. (5,0\%), FNE (5,0\%), Chaetomium spp. (2,5\%) e Cladosporium spp. (1,2\%).

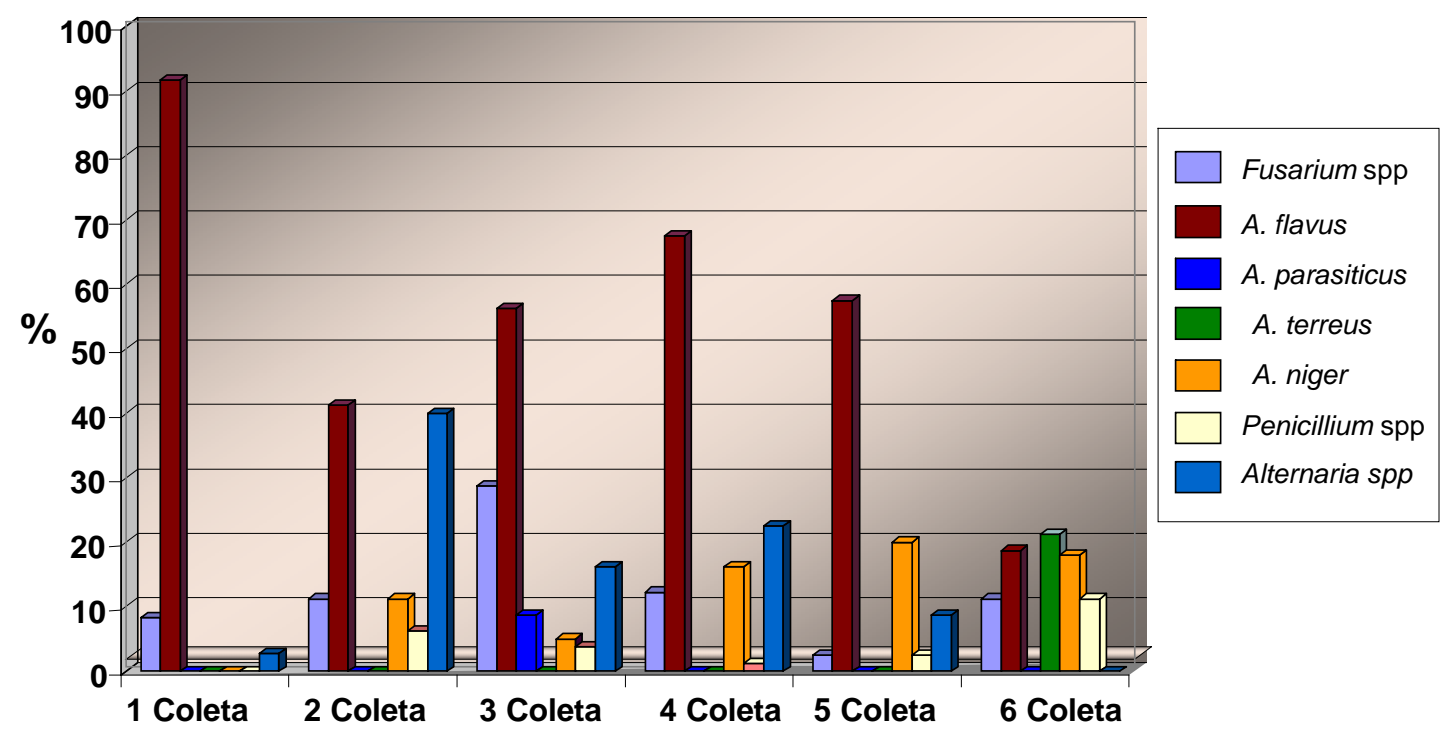

Figura 38 - Frequência de isolamento fúngico (\%) em cascas de amendoim armazenadas, da variedade IAC-Caiapó, no período de abril a setembro de 2006, no município de Tupã. 


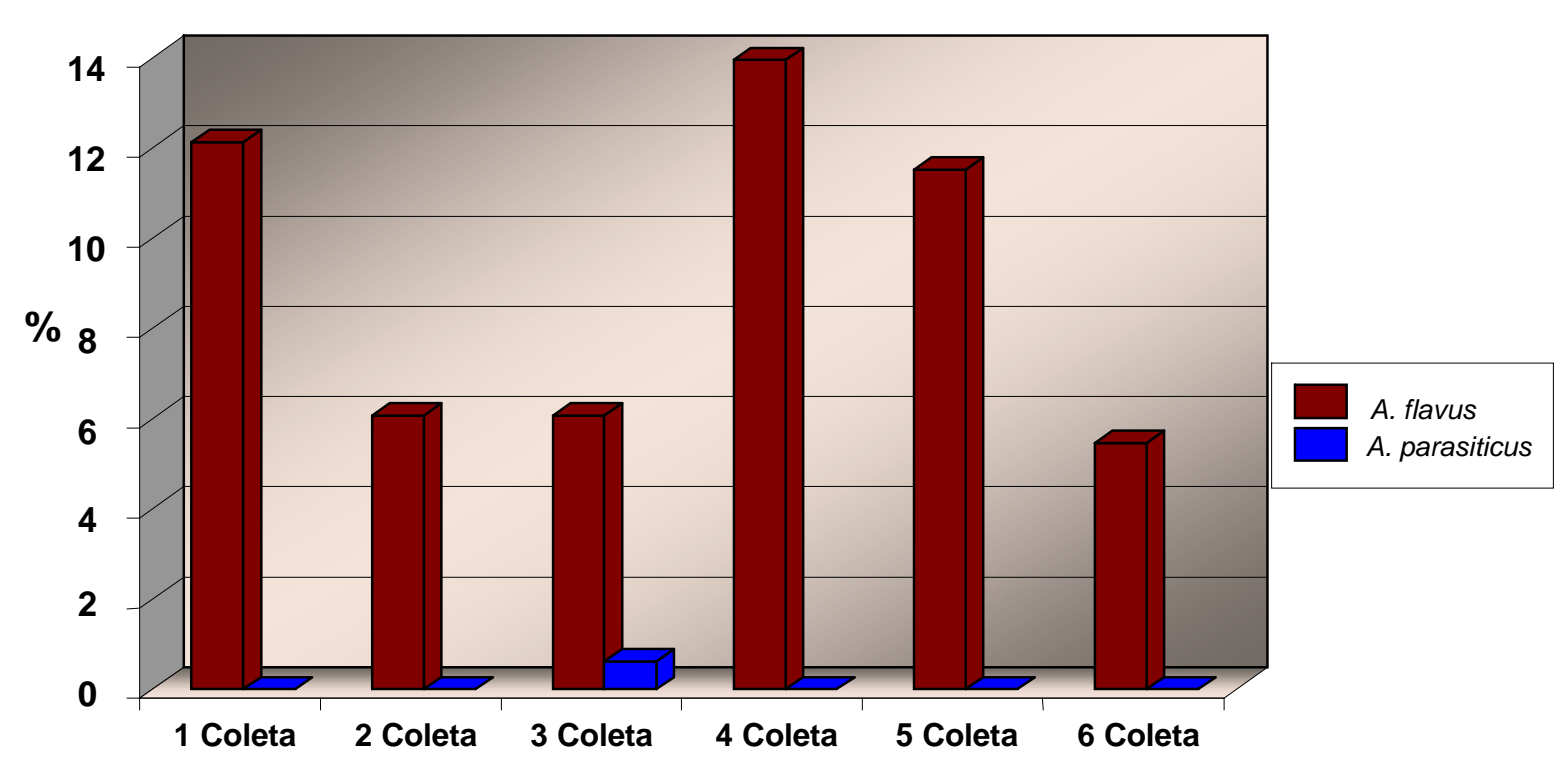

Figura 39 - Frequência de isolamento (\%) de A. flavus e A. parasiticus em cascas de amendoim armazenadas, da variedade IAC-Caiapó, no período de abril a setembro de 2006, no município de Tupã.

Nas amostras de grãos de amendoim da variedade IAC 886, as frequências fúngicas encontradas em ordem decrescente foram (Tabela A17; Figuras 40 e 41): $1^{\text {a }}$ coleta: Fusarium spp. (7,9\%), FNE (6,1\%), Penicillium spp. (4,8\%), A. niger $(4,2 \%)$, A. flavus $(2,4 \%)$ e Cladosporium spp. $(1,2 \%)$.

$2^{\mathrm{a}}$ coleta: Penicillium spp. (6,7\%), A. niger (5,4\%), Alternaria spp. (2,4\%), A. flavus $(1,8 \%)$, Fusarium spp. (1,2\%), FNE (0,6\%), Cladosporium spp. (1,2\%), Trichoderma spp. (1,2\%) e Epicoccum spp. $(0,6 \%)$.

$3^{\text {a }}$ coleta: A. flavus (25,4\%), A parasiticus (15,7\%), A. niger (7,9\%), Fusarium spp. (4,8\%), Penicillium spp. (1,2\%) e Wallemia spp. (1,2\%).

$4^{\text {a }}$ coleta: A. flavus (30,3\%), A. niger (7,3\%), Rhizopus spp. (6,7\%), Penicillium spp $(6,7 \%)$, A. terreus spp. (0,6\%), Nigrospora spp $(0,6 \%)$ e Fusarium spp. $(0,6 \%)$.

$5^{\text {a }}$ coleta: Rhizopus spp. (12,1\%), A. niger (1,8\%) e FNE (4,8\%).

$6^{a}$ coleta: Rhizopus spp. (13,3\%), A. niger (9,7\%), Fusarium spp. (7,3\%), A. flavus (5,5\%), Penicillium spp. (4,8\%), A. parasiticus (1,2\%), Nigrospora spp. $(0,6 \%)$, FNE $(0,6 \%)$ e Cladosporium spp. $(0,6 \%)$. 


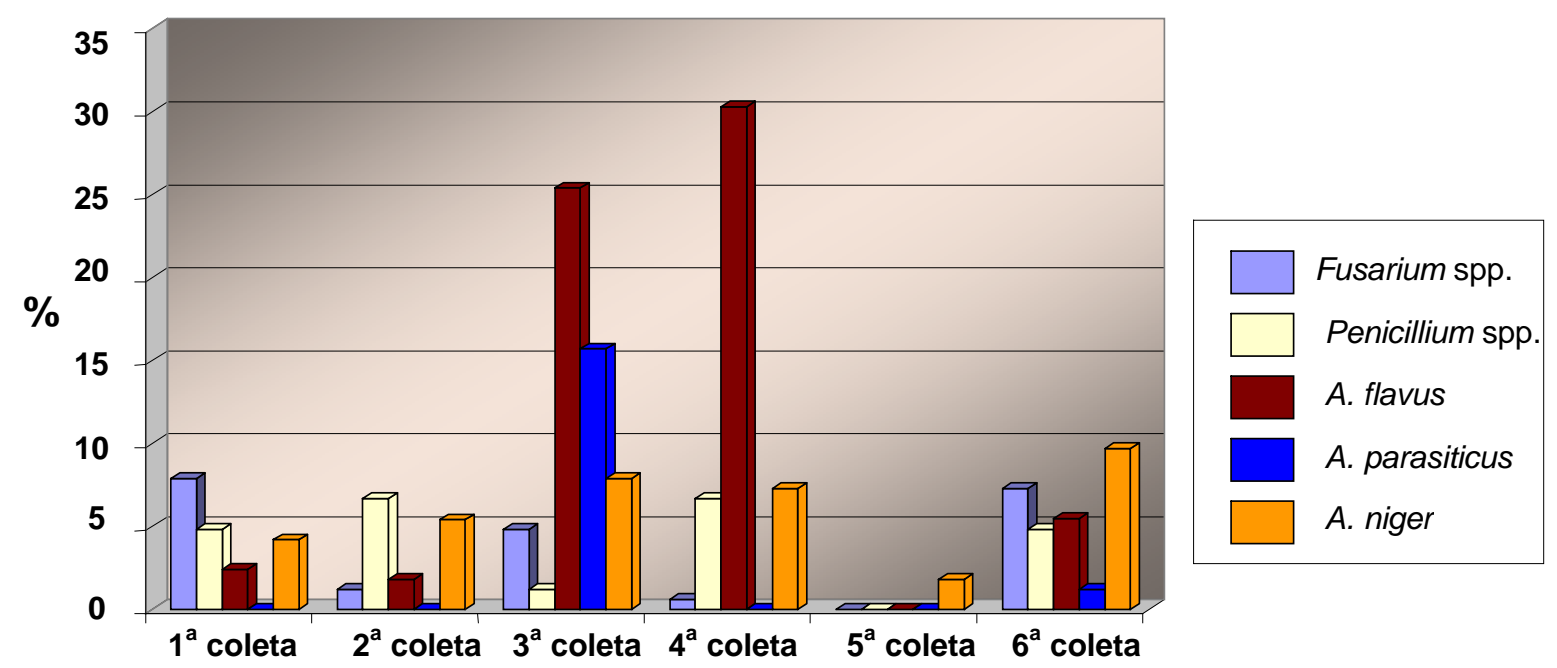

Figura 40 - Frequência de isolamento fúngico (\%) em grãos armazenadas da variedade IAC 886, no período de abril a setembro de 2006, no município de Tupã.

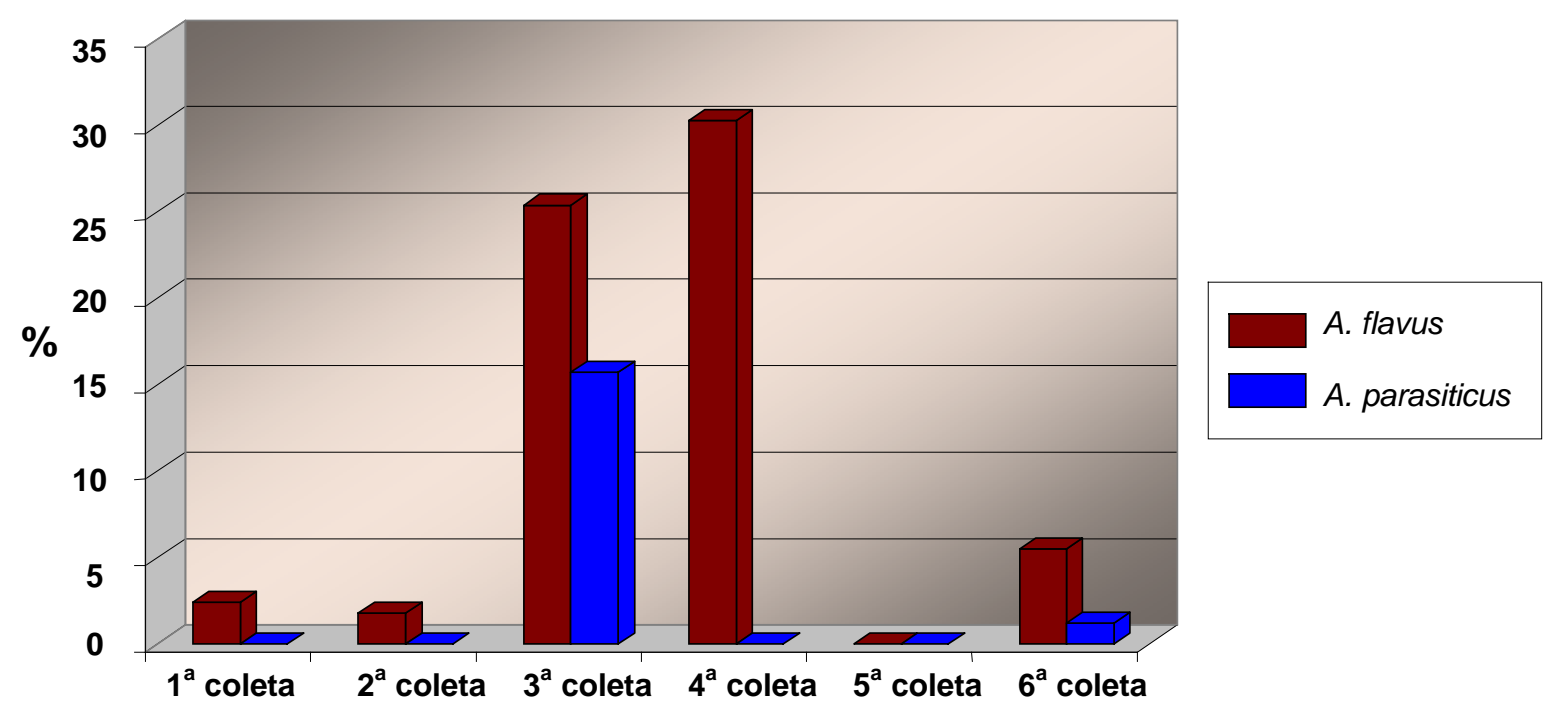

Figura 41 - Frequência de isolamento (\%) de A. flavus e A. parasiticus em grãos armazenadas da variedade IAC 886, no período de abril a setembro de 2006, no município de Tupã.

Análise das amostras de cascas de amendoim da variedade IAC 886, durante o armazenamento, revelou as seguintes frequências fúngicas, em ordem decrescente (Tabela A18; Figuras 42 e 43):

$1^{\text {a }}$ coleta: A. flavus $(72,5 \%)$, A. niger (52,5\%), Fusarium spp. (43,7\%), Penicillium spp. (18,7\%), Rhizopus spp. (10,0\%), Mucor spp. (8,7\%), Nigrospora spp. (7,5\%), Trichoderma spp. (3,7\%) e Cladosporium spp. (1,2\%).

$2^{\mathrm{a}}$ coleta: A. flavus (42,5\%), A. niger (23,0\%), Penicillium spp. (22,5\%), Rhizopus spp. (15,0\%), Fusarium spp. (8,7\%), FNE (8,7\%), Mucor spp. (2,5\%) e Cladosporium spp. (1,2\%). 
$3^{\mathrm{a}}$ coleta: $A$ parasiticus (41,2\%), A. flavus (35,0\%), A. niger (20,0\%), Alternaria spp. $(1,2 \%)$ e Mucor spp. $(1,2 \%)$.

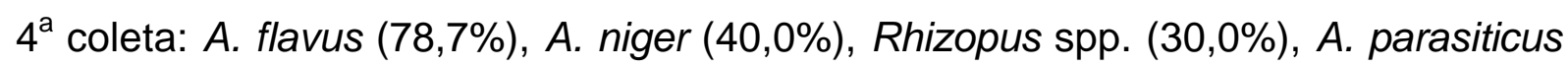
(5,0\%), Nigrospora spp. (2,5\%) e Fusarium spp. (1,2\%).

$5^{\text {a }}$ coleta: Rhizopus spp. (50,0\%), A. flavus (38,7\%), A. niger (32,5\%), Alternaria spp. (1,2\%), Cladosporium spp. (0,6\%) e A. parasiticus spp. (1,2\%).

$6^{\text {a }}$ coleta: Rhizopus spp. (55,0\%), A. niger (27,5\%), A. flavus (8,7\%), Mucor spp. (7,5\%), FNE (5,0\%), Fusarium spp. (5,0\%), Penicillium spp. (3,7\%) e Cladosporium spp. (1,2\%).

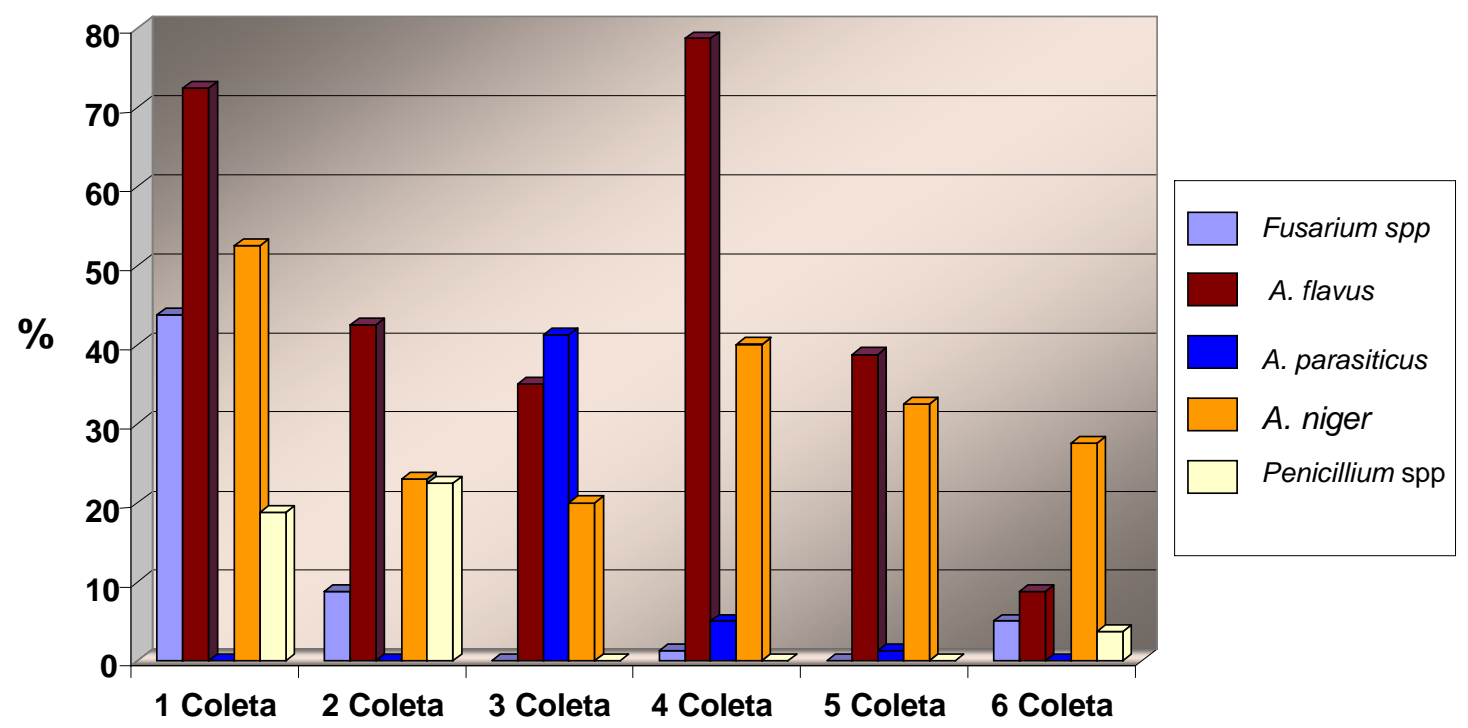

Figura 42 - Frequência de isolamento fúngico (\%) em cascas armazenadas da variedade IAC 886, no período de abril a setembro de 2006, no município de Tupã. 


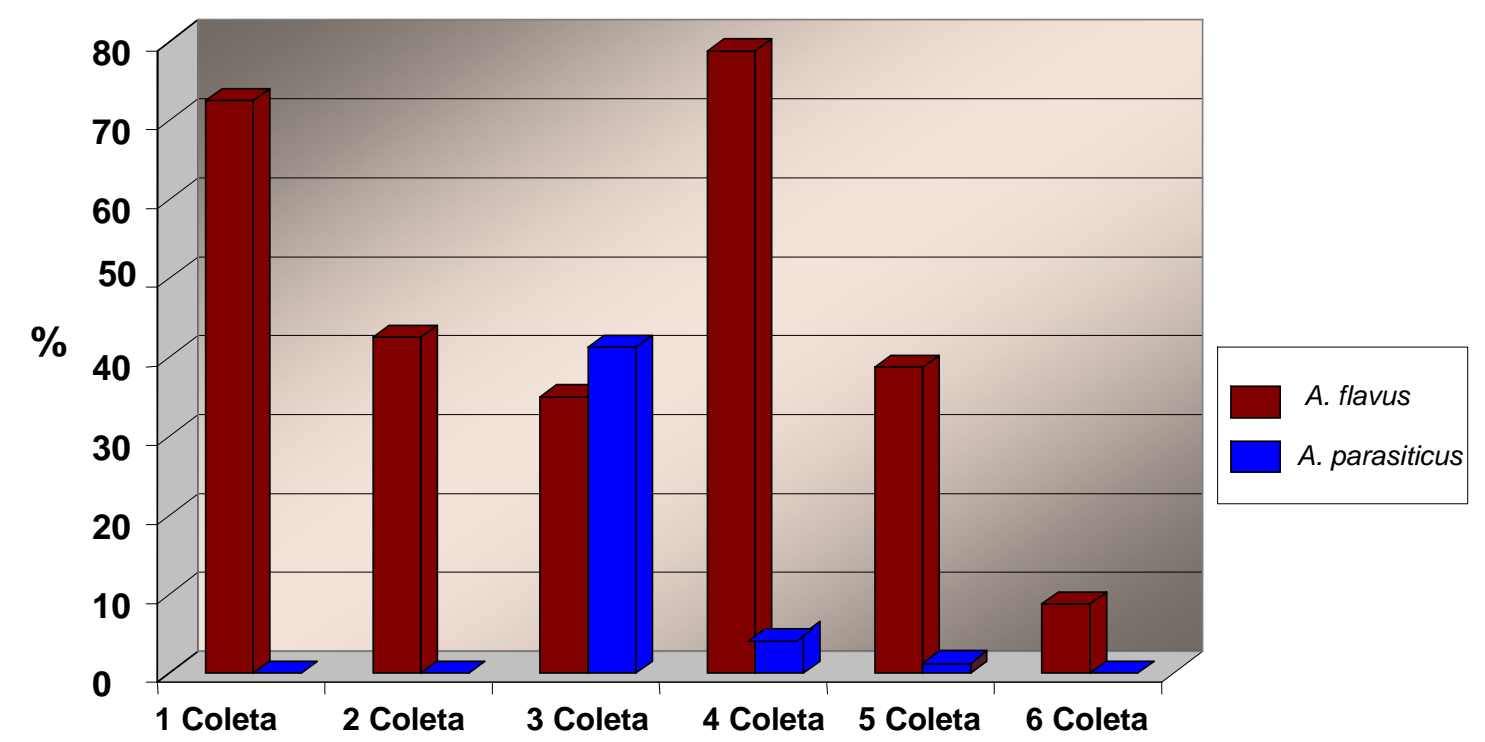

Figura 43 - Frequência de isolamento de $A$. flavus e $A$. parasiticus em cascas armazenadas da variedade IAC 886, no período de abril a setembro de 2006, no município de Tupã.

Em nossa investigação, o armazenamento das amostras de amendoim com teor de água de 10,7\% (variedade IAC-Caiapó) e 10,4\% (variedade IAC 886), seguiu as recomendações de Fonseca (2007) que sugere, para evitar a contaminação fúngica e a produção de micotoxinas, o armazenamento de grãos com casca em teor de umidade abaixo de $11 \%$.

Assim como na variedade IAC-Caiapó, também foi observado na variedade IAC 886 a diminuição da frequência de isolamento do Fusarium spp., no amendoim armazenado. Esse fato pode estar associado à diminuição da Aa do amendoim já na secagem dos grãos, antes do armazenamento, o que pode ter favorecido o aumento da frequência de fungos como $A$. flavus, $A$. niger e $A$. parasiticus.

Constatou-se, durante o armazenamento, o predomínio de A. flavus em ambas as variedades estudadas, porém, na variedade IAC-Caiapó, observou-se, também, elevada frequência de Alternaria spp. e de A. terreus. Convém mencionar o isolamento de $A$. parasiticus na variedade IAC 886. Segundo alguns autores, a menor frequência de isolamento de $A$. parasiticus, em relação ao $A$. flavus, deve-se a maior agressividade de $A$. flavus na infecção dos grãos de amendoim (HILL et al., 1985; HORN et al., 1994).

Análise estatística, utilizando correlações de Spearman entre as variáveis de freqüência fúngica nas cascas de amendoim, para a variedade IAC-Caiapó, revelou associação negativa fraca entre as frequências de $A$. flavus e de $A$. niger (correlação 
$=-0,389$ e $p=0,009)$, sugerindo alguma competição entre esses fungos. No entanto, para a variedade IAC 886, não foi constatado associação entre esses fungos ( $p=$ 0,362 ). Por sua vez, na variedade IAC 886 , as correlações sugerem uma possível competição de $A$. parasiticus, com Fusarium spp. (correlação $=-0,497$ e $p=0,005$ ) e Penicillium spp. (correlação $=-0,409$ e $p=0,025$ ). Nossos resultados também demonstraram correlação significante entre a frequência de $A$. niger e Fusarium spp. (correlação $=-0,378$ e $p=0,047$ ), para a variedade IAC-Caiapó, e entre a frequência de Fusarium spp. e Penicillium spp. (correlação $=0,438$ e $p=0,016$ ), para a variedade IAC 886. Para os grãos, as correlações de Spearman indicaram, na variedade IAC 886, correlação positiva entre $A$. flavus e A. parasiticus (correlação = 0,592 e $p=0,001$ ). Não foram observadas outras correlações significantes para ambas as variedades .

Análise estatística inferencial revelou que a média da frequência de $A$. flavus nas cascas de amendoim variou de forma quadrática com 0 tempo de armazenamento $(p=0,0001)$ e com a Aa nas cascas $(p=0,0463)$. Observando-se $o$ valor do exponencial, estimou-se que, mantido o tempo de armazenamento constante, a possibilidade da contaminação da casca de amendoim por A. flavus foi multiplicada por 0,946, a cada aumento de 0,01 na Aa nas cascas. Em outras palavras, essa possibilidade reduziu $5,4 \%$ a cada aumento de 0,01 na atividade de água. Nos grãos, a média do crescimento de $A$. flavus variou de acordo com a frequência do fungo nas cascas $(p=0,0046)$ e com a precipitação $(p=0,0213)$.

De acordo com alguns autores, $A$. niger é um importante competidor para $A$. flavus (ASHWORTH; SCHROEDER; LANGLEY, 1965; JOFFE, 1969), por apresentarem similares exigências nutricionais para o crescimento e germinação de conídios, além de serem isolados frequentemente no mesmo habitat (GRIFFIN e GARREN, 1974; JACKSON e BELL, 1969; PASS e GRIFFIN, 1972). Em nossa pesquisa, a elevada frequência de isolamento de $A$. niger, principalmente nas últimas coletas, pode ter influenciado na redução do isolamento de $A$. flavus.

Alguns pesquisadores associam o genótipo do amendoim à resistência a invasão por A. flavus e $A$. parasiticus (KISYOMBE et al., 1985; LINDSEY e TURNER, 1975; MIXON e ROGERS, 1973). Neste sentido, Laprade e Bartz (1972) sugeriram que a resistência pode ser atribuída às cascas do amendoim, espessura e/ou permeabilidade. Vários fenóis, taninos e pigmentos podem estar associados ao mecanismo de defesa do amendoim, contra a invasão por A. flavus (LINDSEY e 
TURNER, 1975; STAMBERG et al., 1950). A elevada frequência de isolamento de $A$. flavus e $A$. parasiticus detectada nos grãos da variedade IAC 886, após a $3^{\text {a }}$ coleta, pode ser atribuída a maior propensão da variedade à infecção pelos dois fungos. Segundo a Conab (2007), a variedade IAC-Caiapó é mais resistente à infecção por $A$. flavus e $A$. parasiticus. $\mathrm{O}$ ciclo mais longo desta variedade pode contribuir para a secagem dos grãos, ainda no campo, evitando a presença de amendoins "brotados", que são altamente suscetíveis às infecções por $A$. flavus e $A$. parasiticus.

\subsubsection{Fungos anemófilos}

Durante o armazenamento do amendoim da variedade IAC-Caiapó, os fungos isolados no ar foram (Tabela A19; Figura 43):

$1^{\text {a }}$ coleta: A. niger (148 UFC/m³ $)$, Penicillium spp. (5,2 UFC/m³), Fusarium spp. (3,8 $\left.\mathrm{UFC} / \mathrm{m}^{3}\right)$ e Rhizopus spp. $\left(1,0 \mathrm{UFC} / \mathrm{m}^{3}\right)$.

$2^{\text {a }}$ coleta: Cladosporium spp. (730,4 UFC/m $\left.{ }^{3}\right)$ e Rhizopus spp. (5,0 UFC/m $\left.{ }^{3}\right)$.

$3^{\text {a }}$ coleta: Cladosporium spp. $\left(326,0 \mathrm{UFC} / \mathrm{m}^{3}\right)$, Mucor spp. $\left(5,2 \mathrm{UFC} / \mathrm{m}^{3}\right)$ e Rhizopus spp. $\left(1,2 \mathrm{UFC} / \mathrm{m}^{3}\right)$.

$4^{\text {a }}$ coleta: Cladosporium spp. $\left(219,6 \mathrm{UFC} / \mathrm{m}^{3}\right)$, Fusarium spp. $\left(15,2 \mathrm{UFC} / \mathrm{m}^{3}\right)$, Rhizopus spp. $\left(0,8 \mathrm{UFC} / \mathrm{m}^{3}\right)$ e Alternaria spp. $\left(0,2 \mathrm{UFC} / \mathrm{m}^{3}\right)$.

$5^{\text {a }}$ coleta: Cladosporium spp. $\left(274,8 \mathrm{UFC} / \mathrm{m}^{3}\right)$, A. niger $\left(1,4 \mathrm{UFC} / \mathrm{m}^{3}\right)$ e Rhizopus spp. $\left(1,0 \mathrm{UFC} / \mathrm{m}^{3}\right)$.

$6^{\text {a }}$ coleta: Cladosporium spp. (285,0 UFC/m³ $)$, Fusarium spp. $\left(6,8 \mathrm{UFC} / \mathrm{m}^{3}\right)$ e Rhizopus spp. (1,0 UFC/m³).

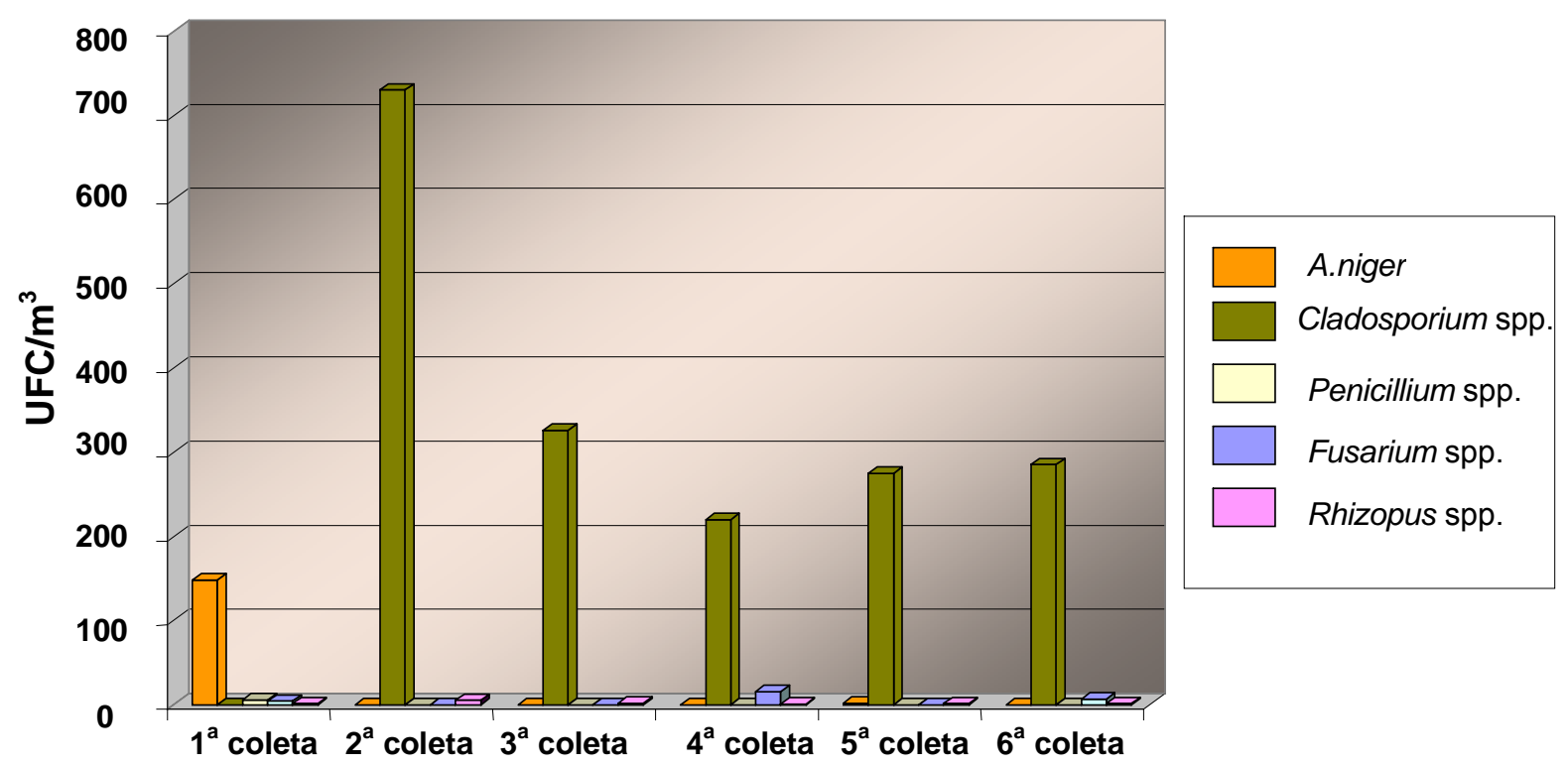

Figura 44 - Frequência de fungos anemófilos $\left(\mathrm{UFC} / \mathrm{m}^{3}\right)$ no interior do armazém, ao redor da variedade IAC-Caiapó, no período de abril a setembro de 2006, no município de Tupã. 
A micobiota isolada no ar, durante o armazenamento da variedade IAC 886, foi assim constituída (Tabela A20; Figura 45):

$1^{\text {a }}$ coleta: $A$. niger $\left(139,6 \mathrm{UFC} / \mathrm{m}^{3}\right)$, Fusarium spp. (3,0 UFC/m³ $)$ e Rhizopus spp. (1,0 $\left.\mathrm{UFC} / \mathrm{m}^{3}\right)$.

$2^{\mathrm{a}}$ coleta: Cladosporium spp. (724,6 UFC/m³ $)$, Fusarium spp. $\left(4,2 \mathrm{UFC} / \mathrm{m}^{3}\right)$,

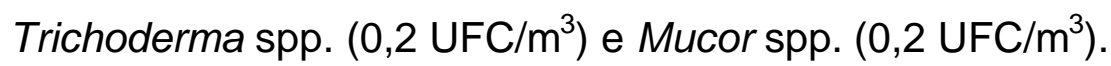

$3^{\mathrm{a}}$ coleta: Cladosporium spp. $\left(253,4 \mathrm{UFC} / \mathrm{m}^{3}\right)$, A. flavus $\left(2,0 \mathrm{UFC} / \mathrm{m}^{3}\right)$, $\operatorname{FNE}(1,4$

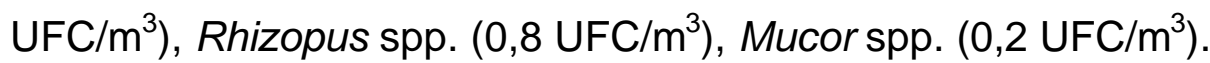

$4^{\mathrm{a}}$ coleta: Cladosporium spp. (338,8 UFC/m³ $)$, Fusarium spp. $\left(29,0 \mathrm{UFC} / \mathrm{m}^{3}\right)$, Rhizopus spp. (1,0 UFC $\left./ \mathrm{m}^{3}\right)$ e A. flavus $\left(0,2 \mathrm{UFC} / \mathrm{m}^{3}\right)$.

$5^{\text {a }}$ coleta: Cladosporium spp. (241,8 UFC/m³ $)$, Mucor spp. (17,2 UFC/m³), Rhizopus spp. $\left(0,8 \mathrm{UFC} / \mathrm{m}^{3}\right)$, A. flavus $\left(0,2 \mathrm{UFC} / \mathrm{m}^{3}\right)$, Alternaria spp. $\left(0,2 \mathrm{UFC} / \mathrm{m}^{3}\right)$ e A. niger $\left(0,2 \mathrm{UFC} / \mathrm{m}^{3}\right)$.

$6^{\text {a }}$ coleta: Cladosporium spp. (314,4 UFC/m³), Rhizopus spp. (11,6 UFC/m³), Mucor spp. $\left(9,6 \mathrm{UFC} / \mathrm{m}^{3}\right)$ e Fusarium spp. $\left(2,0 \mathrm{UFC} / \mathrm{m}^{3}\right)$.

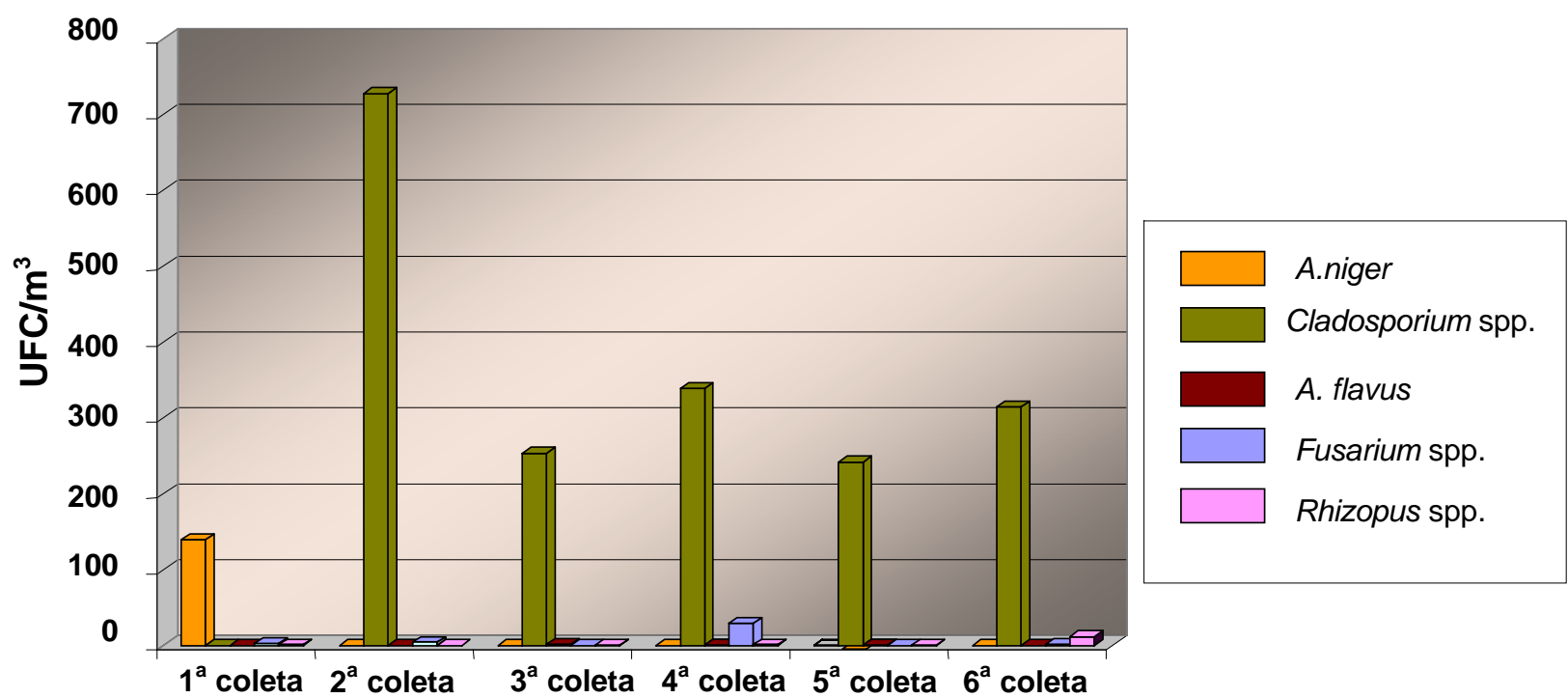

Figura 45 - Frequência de fungos anemófilos $\left(\mathrm{UFC} / \mathrm{m}^{3}\right)$ no interior do armazém, ao redor da variedade IAC 886, no período de abril a setembro de 2006, no município de Tupã.

A presença de $A$. flavus no ar, principal via de disseminação dos fungos, pode ter influenciado na contaminação do amendoim pelo fungo, durante o armazenamento. Segundo alguns autores, no campo, esporos fúngicos presentes na terra, ervas daninhas ou capins, seriam transportados pelo ar atingindo os grãos. Outro dado que merece menção é, segundo Gambale (1998), a presença de 
Aspergillus spp. no ar atmosférico de varias regiões no Brasil. O predomínio de Cladosporium spp coincide com as observações do citado autor que considera o fungo como contaminante universal.

\subsubsection{Fatores abióticos}

A diminuição da Aa, de 0,99 em média, para 0,60 a 0,77, registrada nos grãos secos antes de serem armazenados, pode ter favorecido a presença, no início do armazenamento, de $A$. flavus e $A$. parasiticus. A diminuição da frequência de Fusarium spp. no decorrer do período de armazenamento pode indicar ausência de algumas condições necessárias para sua permanência no amendoim, como a diminuição da Aa nas cascas $(0,56$ a 0,40$)$ e nos grãos $(0,57$ a 0,40$)$ (Tabelas $A 15$, A16, A17, A18). Segundo Lacey (1991), os valores mínimos de Aa para o crescimento de $A$. flavus e $A$. parasiticus encontra-se na faixa de 0,78 a 0,82 e para a produção de aflatoxinas entre 0,83 a 087 . De acordo com os autores, a faixa de temperatura para o crescimento de $A$. flavus e $A$. parasiticus situa-se entre 6 e $45^{\circ} \mathrm{C}$, sendo a temperatura ótima a $35^{\circ} \mathrm{C}$

A estatística descritiva para $A a$ nas cascas e grãos registrou baixa variabilidade mensal, em ambas as variedades, e tendência de crescimento ou diminuição da Aa com o período de armazenamento (número de meses).

Os dados climatológicos da região de plantio e no interior do armazém estão apresentados nas Tabelas A10, A11, A21, A22 e A23. Constatou-se, na região de plantio, no mês de abril ( $1^{a}$ coleta) elevada temperatura média mensal $\left(26,8^{\circ} \mathrm{C}\right)$ e baixo índice de precipitação pluvial $(5,10 \mathrm{~mm})$. No mês de agosto ( $5^{\mathrm{a}}$ coleta) foram registrados níveis elevados de temperaturas diárias (até 38,0 ${ }^{\circ} \mathrm{C}$ ), juntamente com queda da umidade relativa do ar média na região estudada $(36,0 \%)$ e baixa precipitação mensal (30,0 mm). De acordo Dorner et al., (1989) elevada temperatura associada à estiagem pode favorecer a contaminação do amendoim por A. flavus e A. parasiticus. Tal afirmativa também foi feita por Sanders et al. (1984).

As análises estatísticas revelaram que para a variedade IAC-Caiapó, quanto maior a precipitação, maior é a produção média de ACP no período de armazenamento. Para períodos com pouca chuva, a produção de ACP no período de armazenamento foi, em média, maior para a variedade IAC 886 do que para a IAC-Caiapó. 
A temperatura medida no interior do armazém teve um índice elevado, com altas temperaturas diárias (máxima) a partir do mês de julho e ápice em setembro $\left(40,2^{\circ} \mathrm{C}\right)$. A umidade relativa do ar máxima no interior do armazém foi de $74 \%$, com registro de média diária de $28,5 \%$, inferior à registrada no mesmo período, no ambiente externo.

Apesar das condições propicias de temperatura e umidade para 0 crescimento de $A$. flavus e $A$. parasiticus, a Aa das amostras não favoreceu 0 crescimento e a produção de micotoxinas.

\subsubsection{Ocorrência de micotoxinas}

$\mathrm{Na}$ variedade IAC 886, das 30 amostras de grãos armazenados, 6 (20,0\%), estavam contaminadas com aflatoxinas, com níveis entre 0,03 a 15,7 $\mu \mathrm{g} / \mathrm{kg}\left(\mathrm{AFB}_{1}\right)$, 0,04 a $0,5 \mu \mathrm{g} / \mathrm{kg}\left(A F B_{2}\right)$ e 0,4 e 1,2 $\mu \mathrm{g} / \mathrm{kg}\left(A F G_{1}\right)$. Nas cascas, as aflatoxinas foram detectadas em 7 amostras (23,3\%), com níveis entre 0,03 a 3,3 $\mu \mathrm{g} / \mathrm{kg}\left(\mathrm{AFB}_{1}\right)$ e 1,1 $\mu \mathrm{g} / \mathrm{kg}\left(\mathrm{AFB}_{2}\right)$. (Tabelas A24 e A25).

Na variedade IAC-Caiapó, das 30 amostras de grãos analisadas, 4 (13,3\%) estavam contaminadas com aflatoxinas, com níveis médios entre 0,05 a 1,9 $\mu \mathrm{g} / \mathrm{kg}$. $\left(\mathrm{AFB}_{1}\right)$ e 0,07 a $1,1 \mu \mathrm{g} / \mathrm{kg}\left(\mathrm{AFB}_{2}\right)$. Nas cascas, as aflatoxinas foram detectadas em 4 amostras (13,3\%), com nível entre 0,03 a 2,3 $\mu \mathrm{g} / \mathrm{kg}\left(\mathrm{AFB}_{1}\right)$.

A baixa porcentagem de amostras de amendoim contaminadas por aflatoxinas $(13,1 \%)$ também foi descrita por Varsavsky e Sommer (1977). No entanto, Fonseca (1976), verificou que em amendoins armazenados, os níveis de aflatoxinas podem aumentar em amostras com teor de umidade elevado.

Estudo realizado por Nakai et al. (2008) na Região de Tupã, analisando 60 amostras de amendoins armazenados durante 1 ano, revelou a presença de $\mathrm{AFB}_{1}$ em $(6,7 \%)$ das cascas, com níveis entre 15 a $23 \mu \mathrm{g} / \mathrm{kg}$ e em 33,3\% dos grãos, com níveis entre 7 a $116 \mu \mathrm{g} / \mathrm{kg}$.

Os níveis de aflatoxinas detectados não ultrapassaram o limite máximo permitido pelo Ministério da Saúde e Ministério da Agricultura, de $20 \mu \mathrm{g} / \mathrm{kg}$, para a soma das aflatoxinas $B_{1}+B_{2}+G_{1}+G_{2}$.

Apesar do aumento da frequência de isolamento de $A$. flavus e $A$. parasiticus durante o armazenamento, a associação da Aa, Umidade dos grãos e fatores abióticos não foram favoráveis à produção de níveis elevados de aflatoxinas. 
Em relação ao ACP, constatou-se elevado número de amostras positivas durante 0 armazenamento, nas duas variedades estudadas. Na variedade IAC 886, a positividade alcançada foi de $80,0 \%$ (24 amostras), com níveis entre 105,4 a $6810,8 \mu \mathrm{g} / \mathrm{kg}$. Na variedade IAC-Caiapó, 70,0\% das amostras (21 amostras) foram positivas para ACP, com níveis médios entre 110,3 a 7273,3 $\mu \mathrm{g} / \mathrm{kg}$ (Tabela A26). Lansden e Davidson (1983), também obtiveram índices elevados de amostras positivas para o ACP (93,3\%), isolando a toxina em 21 das 27 amostras de amendoim analisadas. Já as aflatoxinas foram detectadas em 26 das 27 amostras.

A co-ocorrência de aflatoxinas e ACP nos grãos registrada em nosso experimento (13,3\% variedade IAC-Caiapó e 20\% IAC 886), também foi mencionada por Fernandez Pinto et al., (2001), porém, somente em 4\% das amostras analisadas. Os efeitos sinérgicos entre ACP e aflatoxinas, assim como os efeitos acumulativos foram mencionados por Smith et al., (1992).

Análises estatísticas indicaram que, na variedade IAC-Caiapó, quanto maior a precipitação, maior foi a produção média de ACP. Para períodos com pouca chuva, a produção de ACP foi, em média, maior para a variedade IAC 886 do que para a IAC-Caiapó.

\subsection{Potencial das cepas para a produção micotoxinas}

5.3.1 Avaliação do potencial das cepas para a produção de aflatoxinas $B_{1}, B_{2}, G_{1} e$ $\mathrm{G}_{2}$

Avaliação do potencial toxigênico das 130 cepas de $A$. flavus selecionadas revelaram 105 (80,8\%) cepas produtoras de aflatoxinas, com níveis variando de 7,9 a $185663,0 \mu \mathrm{g} / \mathrm{kg}\left(\mathrm{AFB}_{1}\right)$ e de 0,57 a $13652,01 \mu \mathrm{g} / \mathrm{kg}\left(\mathrm{AFB}_{2}\right)$. Vinte e sete $(20,8 \%)$ cepas de $A$. flavus foram produtoras apenas de $A F B_{1}$ e 25 cepas não produziram aflatoxinas (19,2\%) (Tabela A27).

O fato das cepas de $A$. flavus produzirem somente aflatoxinas do grupo $B$ $\left(\mathrm{AFB}_{1}\right.$ e $\left.A F B_{2}\right)$ também foi apontado por Píer (1990). O referido autor menciona que apenas $10 \%$ das cepas são produtoras de $A F B_{1}$ e $90 \%$ de $A F B_{1}$ e $A F B_{2}$. Os níveis mais elevados de $A F B_{1}$, em relação ao de $A F B_{2}$, também coincidem com os achados de Almeida et al. (2005), Huang et al. (1990), Lacey (1988) e Zevada (1971), Nakai et al. (2008), analisando cepas de A. flavus isoladas. 
Do total das cepas avaliadas, 5 foram classificadas com $A$. parasiticus produtoras de aflatoxinas $B_{1}, B_{2}, G_{1} e G_{2}$, com níveis entre 10989,93 a 39226,94 $\mu \mathrm{g} / \mathrm{kg}\left(\mathrm{AFB}_{1}\right)$ de 117,38 a $13652,01 \mu \mathrm{g} / \mathrm{kg}\left(\mathrm{AFB}_{2}\right) 663,79$ a $4619,78 \mu \mathrm{g} / \mathrm{kg}\left(\mathrm{AFG}_{1}\right)$. Aflatoxina $G_{2}$ foi quantificada em apenas 1 amostra com 1026,28 $\mu \mathrm{g} / \mathrm{kg}$.

Todas as cepas semeadas em ágar AFPA foram confirmadas como A. flavus e A. parasiticus, pela presença de coloração do verso laranja (PITT et al., 1983).

Normalmente, a maioria dos isolados de $A$. flavus são capazes de produzir aflatoxinas, sendo a maioria produtora de aflatoxinas $B_{1}$ ou $B_{1}$ e $B_{2}$ e ACP. Muitos estudos têm mostrado que o potencial toxigênico e o perfil de $A$. flavus é bastante instável. De fato, esta espécie tem sido frequentemente divididas em grupos, dependendo do seu perfil toxigênico (GIORNI et al., 2007; RAZZAGHI-ABYANEH et al., 2006; VAAMONDE et al., 2003).

Reis (2009) avaliou o potencial toxigênico de 242 cepas de $A$. flavus isoladas de amendoim no Estado de São Paulo. Dentre os isolados, $222(91,7 \%)$ foram produtoras de $\mathrm{AFB}_{1}$, com concentrações variando de 39,3 a 28689,6 $\mu \mathrm{g} / \mathrm{kg}$ e AFB A $_{2}$ com níveis entre 1,5 a 1784,8. Gonçalez et al. (2008b), analisando 21 cepas de $A$. flavus, constataram $85,7 \%$ de cepas produtoras de $\mathrm{AFB}_{1}$ com níveis variando de 8,0 a $18560 \mu \mathrm{g} / \mathrm{kg}$. Em 2008, Nakai et al., avaliando 81 cepas isoladas de amendoim procedente da região de Tupã, constataram $76(93,8 \%)$ foram aflatoxigênicas com níveis variando de 31,0 a 4898,0 $\mu \mathrm{g} / \mathrm{kg}\left(\mathrm{AFB}_{1}\right)$.

Vaamonde et al. (2003) postularam que o tipo de substrato pode selecionar cepas mais ou menos toxigênicas. No amendoim, por exemplo, os autores isolaram grande porcentagem de cepas aflatoxigênicas (73\%) enquanto que no trigo foram isoladas $13 \%$ e na soja, $5 \%$.

A incidência de cepas de $A$. flavus não produtoras tem-se mostrado variável de acordo com a origem geográfica (ATEHNKENG et al. 2008; PILDAIN et al., 2004; RAZZAGHI-ABYANEH et al., 2006). As cepas de A. parasiticus são consideradas mais estáveis e suas capacidades toxigênicas geralmente são relatadas como grandes produtoras e raramente são não-aflatoxigênicas (HORN et al., 1996; RAZZAGHI-ABYANEH et al., 2006; TRAN DINH et al., 1999; VAAMONDE et al., 2003). 
5.3.2 Potencial das cepas para a produção de ácido ciclopiazônico

Das 130 cepas de $A$ flavus, 123 (94,6\%) foram produtoras de ACP, com níveis entre 224,76 a $472178,67 \mu \mathrm{g} / \mathrm{kg}$. Entre as cepas de $A$. flavus produtoras de ACP, 98 (75,5\%) foram também produtoras de aflatoxinas. Das cepas não produtoras de ACP, 6 foram produtoras de aflatoxinas $\mathrm{B}_{1}$ e $\mathrm{B}_{2}$ (Tabela A27).

Pesquisas relativas ao potencial toxigênico de cepas de $A$. flavus produtoras de aflatoxinas e ACP foram realizadas em vários países do hemisfério Sul ou abaixo do Trópico de Câncer (HESSELTINE et al., 1970; SAITO et al., 1986; COTTY E CARDWELL, 1999). Na Argentina, estudo conduzido por Pildain et al. (2004) com isolados de A. flavus, revelou $75 \%$ e $100 \%$ de cepas produtoras de aflatoxinas e ACP, respectivamente. Barros et al. (2005), analisando cepas de A. flavus isoladas de solo, verificaram que $80 \%$ dos isolados foram produtores aflatoxinas e ACP. No Brasil, Gonzalez et al. (2008b) analisaram 21 cepas de A. flavus isoladas do amendoim. Das cepas de $A$. flavus isoladas, $85,72 \%$ foram produtoras de aflatoxinas e 38,09\% produziram ácido ciclopiazônico.

Outras pesquisas sobre a produção de ACP por cepas de A. flavus mostraram elevada produção da toxina, com índices de 89\% (BLANEY et al., 1989), 93\% (HORN et al., 1996) e 97\% (RESNIK et al., 1996). Resnik et al. (1996) observaram que de 34 cepas avaliadas, 33 produziram ACP e apenas 5 foram produtoras de aflatoxina $\mathrm{B}_{1}$, simultaneamente.

Elevadas porcentagens de cepas produtoras de aflatoxinas e ACP também foram descritas em outros estudos (HORN e DORNER, 1999; HORN e GREENE, 1995; GEISER et al., 2001).

\subsection{Produção de esclerócios}

Das 130 cepas de A. flavus analisadas, 93 (71,5\%) foram produtoras de esclerócios. Destas, 44 (47,3\%) produziram acima de 200 esclerócios, e 49 (52,7\%) produziram menos que 200 . Vinte $(14,6 \%)$ isolados não produziram esclerócios, porém, produziram $\mathrm{AFB}_{1}$ ou $\mathrm{AFB}_{1}$ e $\mathrm{AFB}_{2}$. Dezessete cepas $(12,4 \%)$ produziram apenas ACP. As 5 cepas de $A$. parasiticus $(3,7 \%)$ não foram produtoras de esclerócios (Tabela A27). 
Todos os esclerócios produzidos foram classificados como pertencentes ao grupo L, por apresentaram diâmetro acima de $400 \mu \mathrm{m}$. Os baixos níveis de aflatoxinas produzidos pelas cepas do grupo L (VAAMONDE et al., 2003; EGEL et al., 1994; COTTY, 1989) associados aos fatores abióticos (Aa, temperatura, umidade relativa e precipitação) encontrados na região de plantio e durante o armazenamento, reforçam os resultados obtidos em nosso trabalho, quando analisadas as amostras de cascas e grãos.

Pildain et al. (2004) investigaram 40 cepas de A. flavus isoladas de amendoim, em Formosa, Argentina e constataram que $89 \%$ eram cepas L produtoras de aflatoxinas B e ACP.

Horn e Dorner (1999), verificaram que nas cepas de $A$. flavus isoladas de amendoim, em várias regiões dos EUA, predominaram as cepas $L(n=774)$ em relação as cepas $S(n=309)$ e que entre as cepas $L$ uma grande porcentagem produziam aflatoxinas e ACP.

O conhecimento de diferentes populações e a toxigenicidade do Aspergillus seção Flavi, assim como a associação com a cultura dominante da região pode ser importante para o entendimento da dinâmica e medidas de controle utilizadas na redução de contaminação por aflatoxinas, na pré-colheita (HORN e DORNER, 1999).

\subsection{Análise estatística}

\subsubsection{Análise exploratória}

As Tabelas B1 a B3 apresentam os resultados estatísticos descritivos da frequência de $A$. flavus nas cascas, nos grãos e no solo durante o período de campo. Pode-se observar que, em geral, na maioria das fases de desenvolvimento do amendoim, para ambas as variedades, a frequência de isolamento de $A$. flavus apresentou-se baixa. No início da granação, para as duas variedades, não foi observado crescimento de $A$. flavus nos grãos (Tabela B2). Além disso, a frequência de $A$. flavus aparentemente variou de acordo com a fase de desenvolvimento. Nas cascas, observou-se que a totalidade das amostras de grãos secos da variedade IAC 886 apresentou contaminação por $A$. flavus, com frequência média de $32,5 \%$, enquanto que a maioria das amostras obtidas nas demais fases não estava 
contaminada pelo fungo. Nos grãos, observou-se maior frequência de $A$. flavus nas fases de grãos maduros e grãos secos, em ambas as variedades. Já no solo, para a variedade IAC 886, notou-se uma contaminação nas fases de flor e ginóforo. Podese notar, ainda, que as variedades estudadas não revelaram diferença no crescimento médio amostral, em todas as fases de desenvolvimento.

As Tabelas B4 e B5 apresentam os resultados das análises estatísticas descritivas do crescimento de $A$. flavus nas cascas de amendoim e nos grãos durante o período de armazenamento. Observou-se, no período de armazenamento, maior frequência de $A$. flavus nas cascas e nos grãos, comparativamente com as amostras obtidas no campo. Nas cascas do amendoim da variedade IAC 886, contatou-se a presença de $A$. flavus em todos os períodos analisados, variando de acordo com o tempo de armazenamento. Nas cascas da variedade IAC-Caiapó, a freqüência média amostral foi de $91,7 \%$, no $1^{\circ}$ mês e de $10,0 \%$, no $6^{\circ}$ mês. Notouse, também, maior frequência de $A$. flavus nas cascas em relação aos grãos.

As Tabelas B6 e B7 apresentam as análises estatísticas descritivas da produção de ACP nos grãos, no campo e no armazenamento. Considerando-se as medidas de variabilidade (desvio padrão e erro padrão), não se constatou variação na produção média de ACP, nas variedades de amendoim e nas diferentes fases de desenvolvimento.

As Tabelas B8 e B9 apresentam os resultados das análises estatísticas descritivas da produção de trans-resveratrol nos grãos e nas folhas da planta de amendoim, no campo. Observou-se maior produção de trans-resveratrol nas folhas do que nos grãos. Para a fase água do amendoim IAC-Caiapó, a média amostral da produção de trans-resveratrol foi de $27,5 \mu \mathrm{g} / \mathrm{kg}$, nas folhas, e apenas $0,06 \mu \mathrm{g} / \mathrm{kg}$, nos grãos. Nas folhas, a produção de trans-resveratrol variou de acordo com a variedade e a fase de desenvolvimento. No entanto, com a grande variabilidade detectada nas amostras estudadas, somente análise inferencial poderá indicar variação na produção de trans-resveratrol, de acordo com a variedade e a fase de desenvolvimento.

As Tabelas B10 a B12 apresentam os resultados das análises estatísticas descritivas para a atividade de água nas cascas do amendoim, nos grãos e no solo, no campo. Constatou-se, levando em conta a mesma variedade, fase de desenvolvimento e tipo de amostra (cascas, grãos ou solo), pouca variabilidade, fato confirmado pelo baixo desvio padrão detectado. Nas fases água, início da granação 
e grãos maduros, a atividade de água foi, em média, mais elevada nas cascas, nos grãos e no solo (média maior ou igual a 0,98). Após a colheita, nos grãos secos, nas duas variedades de amendoim, constatou-se diminuição nos níveis de atividade de água nas cascas e nos grãos com médias variando entre 0,60 e 0,77. As amostras obtidas na fase de florescimento revelaram baixos níveis de atividade de água, em relação às demais fases.

As Tabelas B13 e B14 apresentam os resultados nas análises estatísticas descritivas para a atividade de água nas cascas do amendoim, nos grãos durante o período de armazenamento. Não foi constatado tendência de aumento ou diminuição da atividade de água com o período de armazenamento das amostras. A média da atividade de água variou de 0,40 a 0,57 nas cascas e de 0,40 a 0,56 nos grãos.

\subsubsection{Análise de correlação}

O coeficiente de correlação mais conhecido é o coeficiente de correlação de Pearson. Ele é uma medida de associação linear entre variáveis quantitativas que varia entre -1 e 1. Quanto mais próximo de 1, maior a associação linear positiva entre as duas variáveis. Portanto, valores próximos de 1 indicam que se um individuo possui valores altos na primeira variável ele tende a apresentar valores altos também na segunda. Por outro lado, quanto mais próximo de -1 , maior a associação negativa entre elas e, por isso, maior a tendência de uma variável crescer à medida que a outra decresce. Valores próximos de 0 indicam baixa associação linear entre as duas variáveis. Apesar do coeficiente de correlação de Pearson ser o mais conhecido, existem outras opções mais adequadas quando as variáveis não são contínuas ou a associação entre elas não é linear. Todas as variáveis de frequência de isolamento fúngico assumem valores considerados como zero, devido ao elevado número de amostras que não estão contaminadas com um determinado fungo escolhido e portanto não são variáveis contínuas. Dessa forma é mais adequado utilizar o coeficiente de correlação de Spearman que também varia entre - 1 e 1 e é interpretado de forma equivalente à descrita acima para a correlação de Pearson. 
Nos parágrafos seguintes foram discutidas as correlações de Spearman e seus respectivos níveis descritivos das variáveis de frequência de isolamento fúngico. O nível de significância considerado nos comentários foi de 0,05.

As Tabelas B15 e B16 apresentam as correlações de Spearman entre as variáveis de frequência de isolamento fúngico nas cascas de amendoim no campo, para as duas variedades de amendoim estudadas. Para a variedade IAC-Caiapó foi observada correlação positiva, alta e significante (correlação $=0,577$ e $p=0,008$ ) entre a frequência de $A$. flavus e Penicillium spp.. Isso sugere que, em geral, para a variedade IAC-Caiapó, quanto maior for a frequência de Penicillium spp. maior será, em média, a frequência de $A$. flavus. Para a variedade IAC 886 não há indícios de que essa associação exista $(p=0,410)$. No entanto, para essa variedade é possível que haja competição entre os gêneros Fusarium e Penicillium (correlação $=-0,482$ e $p=0,031$.

As Tabelas B17 e B18 apresentam as correlações de Spearman entre as variáveis de frequência de isolamento fúngico nos grãos de amendoim no campo, para as duas variedades de amendoim estudadas. A única correlação significante foi entre a frequência de Fusarium spp. e Penicillium spp. para a variedade IAC-Caiapó (correlação $=-0,446$ e $p=0,012$ ) sugerindo também uma possível competição entre esses fungos.

As Tabelas B19 e B20 apresentam as correlações de Spearman entre as variáveis de frequência de isolamento fúngico no solo, das duas variedades de amendoim estudadas. Para a variedade IAC-Caiapó parece haver competição entre A. flavus e Penicillium spp. (correlação $=-0,505$ e $p=0,009$ ). No entanto, para a variedade IAC 886 não há indícios de que exista associação entre a frequência de isolamento desses dois fungos ( $p=0,597)$.

As Tabelas B21 e B22 apresentam as correlações de Spearman entre as variáveis de frequência de isolamento fúngico, nas cascas de amendoim no armazenamento, para as duas variedades de amendoim estudadas. Para a variedade IAC-Caiapó, há associação negativa fraca entre a frequência de $A$. flavus e de $A$. niger (correlação $=-0,389$ e $p=0,009$ ) sugerindo alguma competição entre esses fungos. No entanto, para a variedade IAC 886 parece não haver associação entre esses fungos $(p=0,362)$. Já para $\circ A$. parasiticus que, devido ao número de amostras contaminadas, pôde ser avaliado apenas na variedade IAC 886, as correlações sugerem uma possível competição com os fungos Fusarium spp. 
(correlação $=-0,497$ e $p=0,005)$ e Penicillium spp. (correlação $=-0,409$ e $p=$ 0,025). Há ainda correlação significante entre o crescimento dos fungos $A$. niger e Fusarium spp. (correlação $=-0,378$ e $p=0,047$ ) para a variedade IAC-Caiapó e entre as frequências dos fungos Fusarium spp. e Penicillium spp. (correlação = 0,438 e $p=0,016$ ) para a variedade IAC 886 .

As Tabelas B23 e B24 apresentam as correlações de Spearman entre as variáveis de frequência de isolamento fúngico nos grãos de amendoim no armazenamento para as duas variedades de amendoim estudadas. Para a variedade IAC 886, há indícios de que, quanto maior a quantidade de $A$. flavus maior é, em média, a quantidade de $A$. parasiticus (correlação $=0,592$ e $p=0,001$ ). Não foram observadas outras correlações significantes nem para a variedade IAC 886 nem para a IAC-Caiapó.

\subsubsection{Análise Inferencial}

\subsubsection{Análise da frequência de A. flavus nas cascas e grãos de amendoim, no campo}

A análise da frequência de isolamento de $A$. flavus nas cascas de amendoim, no campo, foi feita a partir do ajuste de um modelo GAMLSS com variável resposta beta binomial e função de ligação logito. As possíveis variáveis preditoras consideradas neste modelo foram: Aa nas cascas, frequência de $A$. flavus no solo, a variedade do amendoim e a fase de desenvolvimento. A Tabela C1 apresenta os resultados do ajuste e a Tabela $\mathrm{C} 2$ apresenta os níveis descritivos das variáveis não incluídas no modelo. Pode-se notar que média da frequência de $A$. flavus nas cascas do amendoim no campo, varia de acordo com uma combinação entre variedade de amendoim e fase de desenvolvimento $(p<0,0001)$.

Como há apenas uma variável categórica no modelo, foram observados diretamente os valores esperados da frequência de $A$. flavus nas cascas de amendoim no campo, de acordo com a fase de desenvolvimento e a variedade. $A$ Tabela C3 apresenta esses valores. Pode-se notar que a estimativa da média da frequência de $A$. flavus nas cascas de amendoim no campo foi maior na fase de grãos secos da variedade IAC 886 do que nas demais fases e variedade. Estima-se que a frequência de $A$. flavus nas cascas de amendoim no campo, seja, em média, 
$32,4 \%$ para a variedade IAC 886 na fase de grãos secos e 1,3\% nas demais fases do IAC 886 e em todas as fases para a variedade IAC-Caiapó.

A análise da frequência de isolamento de $A$. flavus nos grãos de amendoim, no campo, foi feita a partir do ajuste de um modelo GAMLSS com variável resposta beta binomial e função de ligação logito. As possíveis variáveis preditoras consideradas neste modelo foram: a Aa nas cascas, nos grãos e no solo, frequência de $A$. flavus no solo e nas cascas, a variedade do amendoim e a fase de desenvolvimento. A Tabela C4 apresenta os resultados do ajuste e a Tabela C6, os níveis descritivos das variáveis não incluídas no modelo. Pode-se notar que a média do crescimento de $A$. flavus nos grão de amendoim, no campo, variou de acordo a fase de desenvolvimento ( $p=0,0012)$.

Como foi obtido apenas uma variável categórica no modelo, pode-se observar diretamente na Tabela $\mathrm{C} 5$, os valores esperados do crescimento de $A$. flavus nos grãos de amendoim no campo, de acordo com a fase de desenvolvimento. Notou-se que a estimativa da média da frequência de $A$. flavus nos grãos foi consideravelmente maior nas fases de grãos maduros e de grãos secos, em relação as demais fases. Estimou-se que a frequência de $A$. flavus nos grãos foi, em média, $4,5 \%$ nas fases de grãos secos e de grãos maduros e $0,6 \%$ nas demais fases.

\subsubsection{Análise da frequência de A. flavus nas cascas e grãos de amendoim, no armazenamento}

A análise da frequência de $A$. flavus nas cascas de amendoim, no armazenamento, foi feita a partir do ajuste de um modelo GAMLSS com variável resposta beta binomial e função de ligação logito. As possíveis variáveis preditoras consideradas neste modelo foram: a Aa nas cascas, a variedade de amendoim, o tempo (número de meses de armazenamento com efeitos linear e quadrático) e as variáveis climatológicas (temperatura média externa e no armazém, umidade relativa média externa e no armazém e precipitação). A Tabela C7 apresenta os resultados do ajuste e a Tabela C9 apresenta os níveis descritivos das variáveis não incluídas no modelo. Pode-se notar que a média da frequência de $A$. flavus nas cascas de amendoim, no armazém, variou de forma quadrática com 0 tempo de armazenamento $(p=0,0001)$ e com a Aa nas cascas $(p=0,0463)$. Observando-se o valor do exponencial da estimativa, concluiu-se que, mantido o tempo de 
armazenamento constante, a chance de uma casca de amendoim no armazenamento conter $A$. flavus é multiplicada por 0,946 a cada aumento de 0,01 na Aa nas cascas. Em outras palavras, essa chance reduz 5,4\% a cada aumento de 0,01 na Aa. Para o tempo de armazenamento, pelo fato de haver efeito quadrático é mais conveniente interpretar seus resultados a partir da Tabela C8.

A Tabela C8 apresenta os valores esperados da frequência de $A$. flavus nas cascas de amendoim, no armazenamento, em função de alguns valores de Aa nas cascas e do tempo de armazenamento. Pode-se notar que a estimativa da média da frequência de $A$. flavus nas cascas de amendoim variou bastante de acordo com o tempo de armazenamento. Estimou-se que a frequência média de $A$. flavus nas cascas, aumentou nos 3 primeiros meses de armazenamento e passou a decrescer a partir do quarto mês, chegando ao seu valor mínimo no semestre, ao final de 6 meses. Foi estimado, por exemplo, que amendoins armazenados com Aa nas cascas de 0,5 teria frequência média de $A$. flavus de $46,5 \%$ no primeiro mês, $68,2 \%$ no terceiro mês e 18,4\% no sexto mês. A variação da estimativa da média da frequência de isolamento de $A$. flavus nas cascas de amendoim em função da $\mathrm{Aa}$ nas cascas foi menor.

Para a análise estatística dos grãos, foram consideradas como variáveis preditoras: a Aa nos grãos, a variedade do amendoim, o tempo (número de meses de armazenamento com efeitos linear e quadrático), a frequência de isolamento de A. flavus nas cascas e nos grãos e as variáveis climatológicas (temperatura média externa e no interior do armazém, umidade relativa média externa e no interior do armazém e precipitação). A Tabela C10 apresenta os resultados do ajuste e a Tabela C12 apresenta os níveis descritivos das variáveis não incluídas no modelo. Pode-se notar que a média da frequência $A$. flavus nos grãos de amendoim no armazém, varia de acordo com a frequência de $A$. flavus nas cascas ( $p=0,0046)$ e com a precipitação ( $p=0,0213)$.

Observando-se o valor do exponencial da estimativa, concluiu-se que, mantendo a precipitação constante, a chance de um grão de amendoim no armazenamento conter $A$. flavus aumentou $1,4 \%$ a cada aumento de um ponto percentual na frequência de $A$. flavus nas cascas. Estimou-se ainda que, mantido a frequência de A. flavus nas cascas constante, a chance de um grão de amendoim no armazenamento conter $A$. flavus aumentou $0,3 \%$ a cada aumento de um milímetro de precipitação. 
A Tabela C11 apresenta os valores esperados da frequência de $A$. flavus nos grãos de amendoim no armazenamento em função de alguns valores de precipitação e da frequência de $A$. flavus nas cascas. Pode-se notar que, a variação da estimativa da média da frequência de $A$. flavus nos grãos de amendoim foi um pouco maior quando ocorreu a variação da frequência de $A$. flavus nas cascas, quando comparada a variação da precipitação. Estimou-se, por exemplo, que em grãos armazenados, com a ocorrência de precipitação de 100 milímetros, a frequência de isolamento média de $A$. flavus seria de $3,9 \%$, se a frequência nas cascas fosse de $0 \%, 7,5 \%$ se nas cascas fosse de $50 \%$ e $14,2 \%$ se nas cascas fosse de 100\%. Estimou-se também, por exemplo, que amendoins armazenados com frequência de $A$. flavus igual a $50 \%$ nas cascas, teria a frequência de isolamento média de $A$. flavus nos grãos de $5,5 \%$ se não chovesse no período, $7,5 \%$ se chovesse $100 \mathrm{~mm}$ e $13,6 \%$ se chovesse $300 \mathrm{~mm}$.

\subsubsection{Análise da produção de ACP nos grãos de amendoim, no campo}

Análise da produção de ACP nos grãos de amendoim, no campo, foi feita a partir do ajuste de um modelo GAMLSS, com variável resposta gaussiana inversa ajustada no zero e função de ligação logarítmica para o parâmetro de média e logito, para o parâmetro de probabilidade. Neste modelo, ajustou-se simultaneamente, mas de forma separada, a probabilidade da variável assumir o valor zero e o valor médio da variável caso ela assuma um valor maior que zero. As possíveis variáveis preditoras consideradas neste modelo foram: a $\mathrm{Aa}$ nos grãos, frequência de isolamento de $A$. flavus nos grãos, a variedade do amendoim e a fase de desenvolvimento. Não houve indícios de que a média da produção de ACP (quando ela é maior que 0) e a probabilidade de uma amostra não conter ACP variem de acordo com as variáveis citadas. Assim, nenhuma variável foi incluída no modelo e a Tabela C13 apresenta o nível descritivo de cada uma delas.

\subsubsection{Análise da produção de ACP nos grãos de amendoim no armazenamento}

A análise da produção de ACP nos grãos de amendoim, no armazenamento, foi feita a partir do ajuste de um modelo GAMLSS, com variável resposta gaussiana inversa ajustada no zero e função de ligação logarítmica para o parâmetro de média 
e logito, para o parâmetro de probabilidade. As possíveis variáveis preditoras consideradas neste modelo foram: a Aa nos grãos, a variedade de amendoim, o tempo (número de meses de armazenamento com efeitos linear e quadrático), frequência de isolamento de $A$. flavus nos grãos e as variáveis climatológicas (temperatura média externa e no armazém, umidade relativa média externa e no armazém e precipitação). A Tabela C14 apresenta os resultados do ajuste e a Tabela C16 apresenta os níveis descritivos das variáveis não incluídas no modelo. Pode-se notar que a probabilidade de uma amostra de grãos de amendoim não conter ACP variou de acordo com a variedade de amendoim ( $p=0,0349)$ e com a interação entre a variedade e precipitação $(p=0,0143)$. No caso da interação, no modelo preliminar foram utilizadas as variáveis: precipitação, variedade e interação entre essas duas. Como houve interação, testou-se separadamente para a variedade IAC 886 e para a IAC-Caiapó, a variação da produção de ACP nos grãos de amendoim em relação a precipitação. Para a variedade IAC 886 confirmou-se a hipótese de que a produção de ACP não variou de acordo com a precipitação. Já para a variedade IAC-Caiapó essa hipótese foi confirmada, indicando que a precipitação foi uma variável de interação. Pelo fato de haver interação foi mais conveniente interpretar os resultados do modelo a partir da Tabela C15.

A Tabela C15 apresenta os valores esperados da produção de ACP nos grãos de amendoim em função da variedade e da precipitação. Estimou-se que, independente da precipitação, a média da produção de ACP em grãos de amendoim durante o armazenamento foi de $1254,0 \mu \mathrm{g} / \mathrm{Kg}$ para a variedade IAC 886. Já para a variedade IAC-Caiapó, estimou-se que a média da produção de ACP durante 0 armazenamento cresceu de acordo com a precipitação. A média estimada para a variedade IAC-Caiapó foi de 488,0 $\mu \mathrm{g} / \mathrm{Kg}$ quando não choveu, 949,0 $\mu \mathrm{g} / \mathrm{Kg}$ quando choveu 100 milímetros no mês e 1685,0 $\mu \mathrm{g} / \mathrm{Kg}$ quando choveu 300 milímetros.

\subsubsection{Análise da produção de trans-resveratrol na folha}

Análise da produção de trans-resveratrol nas folhas foi feita a partir do ajuste de um modelo GAMLSS, com variável resposta gaussiana inversa ajustada no zero, e função de ligação logarítmica para o parâmetro de média e logito, para o parâmetro de probabilidade. As possíveis variáveis preditoras consideradas neste modelo foram: Aa do solo, das cascas e dos grãos, a variedade de amendoim, a 
fase de desenvolvimento e a frequência de isolamento de A. flavus, Fusarium spp. e Penicillium spp. nos grãos, nas cascas e no solo. A Tabela C17 apresenta os resultados do ajuste e a Tabela C19 os níveis descritivos das variáveis não incluídas no modelo. Pode-se notar que a produção de trans-resveratrol nas folhas, variou de acordo com a frequência de Penicillium spp. no solo $(p=0,0259)$, com a frequência de A. flavus, Fusarium spp. e Penicillium spp. nas cascas ( $p$ 0,0004), com a frequência de Fusarium spp. e Penicillium spp. nos grãos ( $p$ 0,0008) e com as fases de desenvolvimento do amendoim ( $p=0,0029$ ). Por outro lado, pode-se notar que não houve indícios de que a probabilidade de uma amostra de folhas de planta de amendoim não conter trans-resveratrol variou de acordo com alguma das variáveis estudadas. Observando-se o valor do exponencial da estimativa, concluiu-se que, mantida as demais variáveis do modelo constantes, a média da produção de transresveratrol nas folhas aumentou $3,1 \%$ a cada aumento de um ponto percentual na frequência de Penicillium spp., no solo. Estimou-se também que, mantida as demais variáveis do modelo constantes, a média da produção de trans-resveratrol nas folhas aumentou $8,3 \%$ a cada aumento de um ponto percentual na média da frequência de A. flavus, Fusarium spp. e Penicillium spp., nas cascas. Estimou-se ainda que, mantida as demais variáveis do modelo constantes, a média da produção de transresveratrol nas folhas aumentou 4,3\% a cada aumento de um ponto percentual na média da frequência de Fusarium spp. e Penicillium spp., nos grãos. Por último, estimou-se que, mantida as demais variáveis do modelo constantes, a média da produção de trans-resveratrol nas folhas foi $72,8 \%$ menor na fase de grãos maduros do que nas demais. Pelos percentuais apresentados, pode-se notar que a produção de trans-resveratrol variou mais de acordo com a frequência de fungos nas cascas do que com as demais variáveis presentes, no modelo.

A Tabela C18 apresenta os valores esperados da produção de transresveratrol nas folhas em função de alguns valores das variáveis presentes no modelo. Se, por exemplo, a frequência de Penicillium spp. no solo foi de $10 \%$, a frequência média de isolamento de A. flavus, Fusarium spp. e Penicillium spp. nas cascas foi de $10 \%$, a frequência média de isolamento de Fusarium spp. e Penicillium spp. nos grãos foi de $10 \%$ e a fase de desenvolvimento foi o início da granação, então estimou-se que a média da produção de trans-resveratrol foi de 5,5\%. Caso a frequência de Penicillium spp. no solo tenha sido de $50 \%$ e as demais variáveis se mantenham constantes, estimo-se que a média da produção de trans-resveratrol nas 
folhas foi de $18,4 \%$. Já se a frequência média de isolamento de $A$. flavus, Fusarium spp. e Penicillium spp. nas cascas foi de $40 \%$ e as demais variáveis se mantiverem constantes, estimou-se que a média da produção de trans-resveratrol nas folhas foi de $60,2 \%$. Por outro lado, se a frequência média de isolamento de Fusarium spp. e Penicillium spp. nos grãos foi de $50 \%$ e as demais variáveis se mantiverem constantes, estimou-se que a média da produção de trans-resveratrol nas folhas foi de $29,7 \%$. Por último, caso as demais variáveis se mantenham constantes e a fase de grãos maduros, estimou-se que a média da produção de trans-resveratrol nas folhas foi de $1,5 \%$. 
6 CONCLUSÕES 


\section{CONCLUSÕES}

Dentro dos objetivos propostos e das condições de realização deste trabalho, as conclusões obtidas foram:

- No campo, Fusarium spp. foi o fungo predominante no amendoim, porém, o aumento da frequência de $A$. flavus ocorreu nos estágios de grãos maduros e grãos secos, com o declínio da Aa.

- Constatou-se elevada frequência de $A$. flavus nas cascas de ambas as variedades, nos $1^{\circ}$ e $4^{\circ}$ meses de armazenamento, períodos com baixa umidade relativa diária na região $(55,0 \%$ e $43,0 \%$, respectivamente) e temperatura máxima diária (34,2 e $34,0{ }^{\circ} \mathrm{C}$, respectivamente);

- Na variedade IAC-Caiapó, o isolamento de A. parasiticus foi constatado nas cascas, apenas na fase água. Entretanto, na variedade IAC 886, o fungo foi isolado durante $o$ armazenamento, nas $3^{\mathrm{a}}$ e $4^{\mathrm{a}}$ coletas;

- Na variedade IAC 886, as maiores frequências de $A$. flavus e $A$. parasiticus nos grãos durante o armazenamento, vem ao encontro das descrições da Conab, que aponta a variedade IAC-Caiapó como a mais resistente a contaminação por esses fungos;

- Apesar da elevada frequência de A. flavus, em ambas as variedades, e do isolamento de $A$. parasiticus na variedade IAC 886, principalmente no armazenamento, constatou-se baixa incidência de aflatoxinas nas amostras de grãos de amendoim no campo e no armazenamento, com níveis abaixo do recomendado pela legislação brasileira;

- Para aflatoxinas e ácido ciclopiazônico, o maior número de amostras positivas, foi registrado no amendoim da variedade IAC 886;

- No campo, a co-ocorrência de aflatoxinas e ACP nos grãos de amendoim foi constatada em $15 \%$ e $30 \%$ das amostras das variedades IAC-Caiapó e IAC 886, respectivamente; 
- No armazenamento, a co-ocorrência de aflatoxinas e ACP nos grãos foi registrada em $13,3 \%$ e $20 \%$ das amostras das variedades IAC-Caiapó e IAC 886, respectivamente;

- Para a variedade IAC-Caiapó, no período de armazenamento, quanto maior a precipitação, maior a produção de ACP. Para períodos com pouca chuva, a produção de ACP foi maior para a variedade IAC 886;

- Análise do potencial toxigênico de cepas de A. flavus isoladas de grãos e cascas revelaram $80,8 \%$ de cepas produtoras de aflatoxinas e $94,6 \%$ de ACP. Dos isolados, $75,5 \%$ produziram ambas as toxinas.

- Em relação a presença de esclerócios, todas as cepas de $A$. flavus analisadas foram classificadas no grupo $L$, caracterizado pela produção de baixos níveis de aflatoxinas;

- Houve correlação positiva entre a produção de trans-resveratrol e o crescimento fúngico, em ambas as variedades.

- O elevado percentual de amostras positivas (55 a 80\%) e de cepas produtoras de ACP $(94,6 \%)$ demonstra a necessidade de mais estudos sobre prevenção e controle da toxina no amendoim. 


\section{REFERÊNCIAS}




\section{REFERÊNCIAS*}

ADRIAN, M.; JEANDET, P.; DOUILLET-BREUIL, A. C.; TESSON, L.; BESSIS, R. Stilbene content of mature Vitis Vinifera berries in response to UV-C elicitation. J. Agric. Food Chem., v. 48, p. 6103-6105, 2000.

AGÊNCIA NACIONAL DE VIGILÂNCIA SANITÁRIA (ANVISA). Resolução - RDC no 274, de 15 de outubro de 2002. Disponível em: <http://www.anvisa.com.br>. Acesso em: 15 maio. 2010.

ALMEIDA, A. P.; SABINO, M.; FONSECA, H.; CORREAA, B. Potencial toxigênico de cepas de Aspergillus flavus e Fusarium verticillioides isoladas de grãos de milho, da semeadura à colheita, provenientes das regiões de Capão Bonito/SP e Ribeirão Preto/SP. Rev. Inst. Adolfo Lutz, v. 64, n. 1, p. 79-84, 2005.

AMÉZQUITA, M. O., BARRERA, A. C., ARBELÁEZ, G., GRANADA, E. G., OSPIRA, J. Evalucion dos sistemas de desinfeccion del suelo y su interaccion com algunas formulaciones de microelementos sobre la incidencia de Fusarium oxysporium en dos variedades de clavel. Agronomia Colombiana, v.10, p.122-127, 1993.

ANGLE, J. S.; DUNN, K. A.; WAGNER, G. H. Effect of cultural practices on the soil population of Aspergillus flavus and Aspergillus parasiticus. Soil Sci. Soc. Am. J., v. 46, p. 301-304, 1982.

ARX, J. A. The genera of fungi sporulating in pure culture. 2. ed. Vaduz: J. Cramer, 1974. 315 p.

ASHWORTH, L. J., JR.; SCHROEDER, H. W.; LANGLEY, B. C. Aflatoxins: Environmental factors governing occurrence in Spanish peanuts. Science, v. 148, p.1228-1229, 1965.

ASIS, R.; BARRIONUEVO, D. L.; GIORDA, L. M.; NORES, M. L.; ALDAO, M. A. Aflatoxin production in six peanut (Arachis hypogaea L.) genotypes infected with Aspergillus flavus and Aspergillus parasiticus, isolated from peanut production áreas of Córdoba, argentina. J. Agric. Food Chem, v. 53, p. 9274-9280, 2005.

ASSOCIATION OF OFFICIAL ANALYTICAL CHEMISTS (AOAC). Official Methods of Analysis, 13. ed. Washington, DC: AOAC, 1980.

ATAYDE, D. D. Microbiota fúngica e determinação de aflatoxinas em cultivar de amendoim plantado em diferentes regiões produtoras no estado de São Paulo. 2009. 121 f. Dissertação (Mestrado em Microbiologia) - Instituto de Ciências Biomédicas, Universidade de São Paulo, São Paulo, 2009.

ATEHNKENG, J.; OJIAMBO, P.S.; DONNER,M.; IKOTUN, T.; SIKORA,R.A.; COTTY, P.J.; BANDYOPADHYAY, R. Distribution and toxigenicity of Aspergillus species isolated from maize kernels fromthree agro-ecological zones in Nigeria. Int. J. Food Microbiol., v. 122, p. 74-84, 2008.

* De acordo com:

ASSOCIAÇÃO BRASILEIRA DE NORMAS TÉCNICAS. NBR 6023: Informação e documentação:

referências: elaboração. Rio de Janeiro, 2002. 
BARRON, G. L. The genera of hyphomycetes from soil. New York: Robert E. Krieger Publishing Co., 1972. 364 p.

BARROS, G., TORRES, A.; CHULZE, S. Aspergillus flavus population isolated from soil of Argentina's peanut-growing region. Sclerotia production and toxigênico profile. J. Sci. Food Agric., v. 85, p. 2349-2353, 2005.

BAYMAN, P.; COTTY, P. J. Vegetative compatibility and genetic diversity in the Aspergillus flavus population of a single field. Can. J. Bot. v. 69, p. 1707-1711, 1991.

BELL, D. K.; CRAWFORD, J. L. A botraamended medioum for isolating Aspergillus flavus from peanuts and soil. Phytopathology, v. 57, p. 939-941, 1967.

BENNETT, J. W. Mycotoxins, mycotoxicoses, mycotoxicology and mycopathology. Mycopathology, v. 100, p. 3-5, 1987.

BENNETT, J. W.; KLICH, M. Mycotoxins. Clin. Microbiol. Rev., v.16, p. 497-516, 2003.

BERJAK, P. Report of seed storage committee working group on the effects of storage fungi on seed viability. 1980-1983. Seed Sci. \& Technol., v. 12, p. 233-253, 1984.

BHAT, R. V.; SHETTY, P. H; AMRUTH, R. P.; SUDERSHAN, R. V. A foodborne disease outbreak due to the consumption of moldy sorghum and maize containing fumonisin mycotoxins. J. Clin. Toxicol., v. 35, p. 249-255, 1997.

BLANEY, B. J.; KELLY, M. A.; TYLER, A. L.; CONNOLE, M. D. Aflatoxin and cyclopiazonic acid production by Queensland isolates of Aspergillus flavus and Aspergillus parasiticus. Aust. J. Agric. Resour., v. 40, p. 395-400, 1989.

BLOUT, W. P. Turkey “X” disease. Turkeys, v. 9, n. 52, p. 55-77, 1961.

BRASIL. Ministério da Agricultura. Portaria no. 183. Diário Oficial da União, Brasília, DF, 25 mar. 1996. Seção 1, p. 4929.

BRESSAC, B.; KEW, M.; WANDS, J.; OZTURK, M. Selective G to T mutations of p53 gene in hepatocellular carcinoma from southern Africa. Nature, v. 350, p. 429-431, 1991.

BUCHANAN JR, R.L.; AYRES, J.C. Effect of initial pH on aflatoxin production. Appl. Microbiol., v. 30, p. 1050-1051, 1975.

BUNTING, A. H.; GIBBONS, R. W.; WYNNE. J. C. Groundnut (Arachis Hypogaea L.). In: SUMMERFIELD, R. J.; ROBERTS, E. H. (Ed.). Grain Legume Crops. London: Collins, 1985. p. 747-800.

BURDOCK, G. A.; FLAMM, W. G. Review article: Safety assessment of the mycotoxin cyclopiazonic acid. Int. J. Toxicol., v. 19, p. 195-2018, 2000. 
CÂMARA, G. M. S. Introdução à cultura do amendoim. Piracicaba: Departamento de Agricultura, Escola Superior de Agricultura "Luiz de Queiroz", Universidade de São Paulo, 1998. 21 p.

CHALUTZ, E.; STAHMASNN, M. A. Induction of pisatin by ethylene. Phytopathology, v. 59, p. 1972-1973, 1969.

CHAMBERLAIN. W. J.; VOSS, K. A.; NORRED, W. P. Analysis of commercial laboratory rat rations for fumonisin $\mathrm{B}$, . a mycotoxin produced on com by Fusarium moniliforme. Conremp. Topics Lab. Anim. Sci., v. 32, p. 26-28, 1993.

CHRISTENSEN, C. M. (Ed.). Storage of Cereal Grains and Their Products. 3rd ed. Am. Assoc. Cereal Chem., St. Paul, Minnesota, p.145-217. 1982.

COLE, R. J., COX, R. H. Handbook of toxic fungal metabolites. New York: Academic Press, 1981.

COLE, R. J., SANDERS, T. H.; DORNER, J. W.; BLANKENSHIP, P. D.; HALL, S. D. Environmental conditions required to induce preharvest aflatoxina contamination of groundnuts: Summary od six years' research. In: AFLATOXIN CONTAMINATION OF GROUNDNUT: PROCEEDINGS OF THE INTERNATIONAL WORKSHOP, 1987, Patancheru. Proceedings... Patancheru: Editora, 1989. p. 279-287.

COMPANHIA NACIONAL DE ABASTECIMENTO (CONAB). Amendoim proposta de preços mínimos para a safra 2006/2007. Disponível em: <http://www.conab.gov.br>. Acesso em 15 fev. 2010.

COTTY, P. J. Aflatoxin-producing potential of communities of Aspergillus section Flavi from cotton producing areas of the United States. Mycol. Res., v. 101, p. 698704, 1997.

COTTY, P. J. Virulence and cultural characteristics of two Aspergillus flavus strain pathogenic on cotton. Phytopathology, v. 79, p. 808-814, 1989.

COTTY, P. J.; BAYMAN, P.; EGEL, D. S.; ELIS, K. S. Agriculture, aflatoxins and Aspergillus. In: POWELL, K. A. RENWICK A, PEBERDY J. F. (Ed.) The Genus Aspergillus: From Taxonomy and Genetics to Industrial Applications, New York: Plenum Press, 1994. p. 1-27.

COTTY, P. J.; CARDWELL, K. F. Divergence of West African and North American communities of Aspergillus section Flavi. Appl. Environ. Microbiol., v. 65, p. 22642266, 1999.

COULOMBE, R. A., Jr. Nonhepatic disposition and effects of aflatoxina $B_{1}$, In: EATON, D. L. AND GROOPMAN, J. D. (Ed.). The toxicology of aflatoxins: human health, veterinary, and agricultural significance. San Diego, Calif.: Academic Press, 1994. p. 89-110. 
COUNCIL FOR AGRICULTURE SCIENCE AND TECHNOLOGY (CAST). In: RICHARD, J. L.; PAYNE, G. A. (Ed.). Mycotoxins: Risks in plant, animal and human systems. lowa, USA: Task Force Report n 139, 2003.

CUERO R. G., OSUJI G., WASHINGTON A. N-carboxymethylchitosan inhibition of aflatoxin production: role of zinc. Biotechnol. Lett., v. 13, p. 441-444, 1991.

CULLEN, J. M.; WILSON, M.; HAGLER J. R., W. M.; ORT, J. F.; COLE, R. J. Histologic lesions in broiler chicks given cyclopiazonic acid orally. Am. J. Vet. Res., v. 49, p. $728-731,1988$.

DEGER, G. E. Aflatoxin: human colon carcinogenesis? Ann. Intern. Med. v. 85, p. 204-205, 1976.

DELP, R. B.; STWELL, L. J.; MAROIS, J. J. Evaluation of field sampling techniques for estimation of disease incidence. Phytopathology, v. 76, p. 1299-1305, 1986.

DETROY, R. W., LILLEHOJ, E. B.; CIEGLER, A. Aflatoxin and related compounds. In: CIEGLER, A., KADIS, S. AND AJL, S. J. (Ed.), Microbial toxins. New York: Academic Press, 1971. v. 6: Fungal toxins. p. 3-178.

DICKENS, J. W.; SATTERWHITE, J. B.; SNEED, R. E. Aflatoxin contaminated peanuts roduced on North Carolina farms in 1968. J. Am. Peanut. Res. Educ. Soc., v. 5, p. $48-58,1973$.

DIENER, U. L. The mycoflora of peanuts in storage. Phytopathology, v. 50, p. 220223, 1960.

DIENER, U. L., R. J. COLE, T. H. SANDERS, G. A. PAYNE, L. S. LEE, AND M. A. $\mathrm{KLICH}$. Epidemiology of aflatoxin formation by Aspergillus flavus. Annu. Rev. Phytopathol., v. 25, p. 249-270, 1987.

DIENER, U. L.; DAVIS, N. D. Aflatoxin formation in peanuts by Aspergillus flavus. Agricultural Experiment Station bulletin, Auburn, Ala., n. 493, 1977. 44 p.

DIENER, U. L.; DAVIS, N. D. Limiting temperature and relative humidity for aflatoxina production by Aspergillus flavus in stored peanuts. J. Am. Oil Chem. Soc., v. 47, p. 347-351, 1970.

DORNER, J. W.; COLE R. J., ERLINGTON, D. J.; SUSKSUPATH, S.; McDOWELL, G. H.; BRYDEN, W. L. Cyclopiazonic acid residues in milk and eggs. J. Agric. Food Chem., v. 42, p. 1516-1518, 1994.

DORNER, J. W.; COLE, R. J.; DIENER, U. L. The relationship of Aspergillus flavus and Aspergillus parasiticus with reference to production of aflatoxins and cyclopiazonic acid. Mycopathology, v. 87, p. 13-15, 1984. 
DORNER, J. W.; COLE, R. J.; SANDERS, T. H.; BLANKENSHIP, P. D. Interrelationship of kernel water activity, soil temperature, maturity, and phytoalexin production in preharvest aflatoxina contamination of drought-stressed peanuts. Mycopathology, v. 105, p. 117-128, 1989.

EGEL, D. S.; COTTY, P. J.; ELIAS, K. S. Relationships among isolates of Aspergillus sect. Flavi that vary in aflatoxin production. Phytopathology, v. 84, p. 906-912, 1994.

FAGUNDES, M. H. Sementes de amendoim: alguns comentários. Disponível em: <http:www.conab.gov.br>. Acesso em: 13 ago. 2008.

FELÍCIO, J. D.; SANTOS, R. S.; GONÇALEZ, E. Chemical constituents from Vitis vinifera (Vitaceae). Arq. Inst. Biol., v. 68, n. 1, p. 47-50, 2001.

FERNANDEZ, E. M.; ROSOlEM, C. A.; MARINGONI, A. C.; OLIVEIRA, D. M. T.; Fungus incidence on peanut grains as affected by dryng method and $\mathrm{Ca}$ nutrition. Field Crops Res., v. 52, p. 9-15, 1997.

FERNANDEZ-PINTO, V. E.; PATRIARCA, A.; LOCANI, O.; VAAMONDE, G. Natural co-occurrence of aflatoxin and cyclopiazonic acid in peanut growth in Argentina. Food Addit. Contam., v. 18, p. 1017-1020, 2001.

FONSECA H. O amendoim e a aflatoxina. Boletim Técnico, n. 13. Disponível em: <www.micotoxinas.com.br>. Acesso em: 17 nov. 2007.

FONSECA, H. Estudo da aflatoxina, da colheita à industrialização, na região de Monte Alto, SP. Anais da ESALQ, Piracicaba, SP, v. 33, p. 375-384, 1976.

FONSECA, $H$. Legislação sobre micotoxinas. Disponível em: <www.micotoxinas.com.br> Acesso 10 abr. 2010a.

FONSECA, H. Prevenção e controle de micotoxinas em produtos agrícolas. Boletim Técnico, n. 7. Disponível em: <www.micotoxinas.com.br> Acesso em: 18 maio $2010 b$.

FONSECA, H.; GALLO, C. R.; CALOI-DOMINGUES, M. A.; GLORIA, E. M.; APPROBATTO, P. J.; FONSECA, E. L.; ZAMBELLO, I. V. Post-Harvest control of aflatoxins production in in-shell moist peanuts with sodium ortho-phenylphenate: III. Storage tests. Sci. agric. Piracicaba. v. 51, n. 2, p. 369-373, 1994.

FONSECA, H.; VALARINI, I.; CALORI-DOMINGUES, M. A.; WETTSTEIN, A. S. R. ; SILVA, A. E. G. Ocorrência de aflatoxina em amendoim, no Estado de São Paulo, durante os anos de 1988 e 1989. Anais da Escola Superior de Agricultura Luiz de Queiroz, v. 48, p. 301-316, 1991.

FORGACS, J.; CARLL, W. T. Mycotoxicoses. Adv. Vet. Sci., v. 7, p. 273-382, 1962. 
FRANK, Z. R.; BEM-YEPHER, Y. Fusarium disease. In: BACKMAN, P.A et al. Compendium of peanut diseases. Minnesota: The American Phytopathological Society, 1997. 94 p.

FRISVAD, J. C; NIELSEN, K. F.; SAMSON, R. A. Recommendations concerning the chronic problem of misidentification of species associated with mycotoxigenic fungi in foods and feeds, In: HOCKING, A. D.; PITT, J. I.; SAMSON, R. A.; THRANE, U. (Ed). Advances in Food Mycology, New York: Springer, 2006. p. 33-46.

FRITEMEIER, K. H.; KINDL, H. Cordinate induction by UV light of stilbene synthase phenylalanine ammonia-lyase and cinnamte 4-hydroxylase in leaves of Vitaceae. Planta, v. 151, p. 48-52, 1981.

GALLAGHER, R. T., RICHARD, J. L., STAHR, H. M., COLE, R. J. Cyclopiazonic acid production by aflatoxigenic and non-aflatoxigenic strains of Aspergillus flavus. Mycopathology, v. 66, p. 31-36, 1978.

GAMBALE W. Fungos Contaminantes. In: ZAITZ, C., CAMPBELL, I., MARQUES, S. A, RUIZ, LR, SOUZA, V. M. (Ed.) Compêndio de Micologia Médica. São Paulo: Medsi Editora Medica e Cientifica Ltda., 1998. p. 113-121.

GARBER, R. K.; COTTY, P. J. Formation of sclerotia and aflatoxins in developing cotton bolls infected by the $S$ strain of Aspergillus flavus and potential for biocontrol with an atoxigenic strain. Phytopathology, v. 87, p. 940-945, 1997.

GARREN, KH. Peanut (groundnut) microfloras and pathogenesis in peanut pod rot. Phytopathology, v. 55, p. 359-367, 1966.

GEISER, D. M.; DORNER, J. W.; HORN, B. W.; TAYLOR, J. W. The phylogenetics of mycotoxins and sclerotiumproduction in Aspergillus flavus and Aspergillus oryzae. Fungal Genet. Biol., v. 31, p. 169-179, 2001.

GIORNI, P.; MAGAN, N.; PIETRI, A.; BERTUZZI, T.; BATTILANI, P. Studies on Aspergillus Section Flavi Isolated from Maize in Northern Italy. Int. J. Food Microbiol., v. 113, p. 330-338, 2007.

GLOBO RURAL. Safra de amendoim - Edições diárias. 2010. Disponível em: <http://globoruraltv.globo.com> Acesso em: 29 mar. 2010.

GODOY, I. J. de; MORAES, S. A.; KASAI, F. S.; MARTINS, A. L. M.; PEREIRA, J. C. V. N. A.; MORAES, A. R. A.; TEIXEIRA, J. P. F. Cultivares IAC de amendoim. 0 Agronômico, v. 55, n. 1, p. 26-29, 2003.

GOLDBERG, D. M.; YAN, J.; DIAMANDIS, E. P.; NG, E.; KARUMANCHIRI, A.; SOLEAS, A.; WATERHOUSE, A. L. A global survey of trans-resveratrol concentrations in commercial wines. Am. J. Enol. Vitic., v. 46, p. 159-165, 1995a. 
GOLDBERG, D. M.; KARUMANCHIRI, A.; YAN, E.; NG, J.; DIAMANDIS, E. P.; SOLEAS, G. J. Direct gas chromatographic-mass spectrometric method to assay cisresveratrol in wines: preliminary survey of its concentration in commercial wines. $\mathbf{J}$. Agric. Food Chem., v. 43, p. 1245-1250, 1995 b.

GONÇALEZ, E.; NOGUEIRA, J. H. C.; FONSECA, H.; FELÍCIO, J. D.; PINO, F. A., CORREA, B. Mycobiota and mycotoxins in Brazilian peanut kernels from sowing to harvest. Int. J. Food Microbiol., v. 123, p. 184-190, 2008 a.

GONÇALEZ, E.; SOUZA, T. N.; ROSSI, M. H.; FELICIO, J. D.; CORRÊA, B. Avaliação da microflora e ocorrência de micotoxinas em cascas de amendoim em diferentes estágios de maturação da vagem. Ciênc. Agrotecnol., Lavras, v. 32, p. 1380-1386, 2008b.

GQALENI, N.; SMITH, J. E.; LACEY, J. Co-production of aflatoxins and cyclopiazonic acid in isolates of Aspergillus flavus. Food Addit. Contam., v. 13, p. 677-685, 1996.

GQALENI, N.; SMITH, J. E.; LACEY, J.; GETTINBY, G. Effects of temperature, water activity, and incubation time on production of aflatoxins and cyclopiazonic acid by isolate of Aspergillus flavus in surface agar cuture. Appl. Environ. Microbiol., v. 63, p. 1048-1053, 1997.

GRANITI, A. The evolution of the toxic concept in plant pathology, p. 1-18. In: WOOD, R. K., BALLIO, A. and GRANITI, A. (Ed.). Phytotoxins in plant diseases. New York: Academic Press, 1972. p. 1-18.

GRAYER, R. J.; HARBORNE, J. B.; OVERTON, J.; DILLON, V. M. In: ANTUS, S.; GAÂ BOR, M. K.; VETSCHERA, K. (Ed.), Flavonoids and Bio-avonoids, Budapest: AkadeÂ miai KiadoÂ, 1995. p. 119-124.

GRAYER, R. J., KOKUBUN, T. Plant-fungal interactions: the search for phytoalexins and other antifungal compounds from higher plants. Phytochemistry, v. 56, p. 253263, 2001.

GRIFFIN, G. J. Conodial germination and population of Aspergillus flavus in the geocarposphere of peanut. Phytopathology, v. 62, p. 1387-1391, 1972.

GRIFFIN, G. J.; GARREN, K. H. Population level of Aspergillus flavus and A. niger group in Virginia peanut field soils. Phytopathology, v. 64, p. 322-235, 1974.

GRIFFIN, G. J; GARREN, K. H. Colonization of rye green manure and peanut fruit debris by Aspergillus flavus and Aspergillus niger group in field soils. Appl. Environ. Microbiol., v. 32, n. 1, p. 28-32, 1976.

HAIN, R., REIF, H. J., KRAUSE, E., LANGEBARTELS, R., KINDL, H., VERNAU, B., WEISE, W., SCHMATZER, E., SCHREIER, P. H. Disease resistance results from foreign phytoalexin expression in a novel plant. Nature, v. 361, p. 153-156, 1993. 
HAMMONS, R. O. Origin and Early History of the Peanut. In: PATTEE, H. E.; YOUNG, C. T. (Ed.) Peanut Science and Technology. Yoakum, Tex.: American peanut Research and Education Society, 1982. p. 1-20.

HAYES, R. B., VAN NIENWENHUISE, J. P.; RAATGEVER, J. W.; TEN KATE, F. J. W. Aflatoxin exposure in the industrial setting: an epidemiological study of mortality. Food Chem. Toxicol., v. 22, p. 39-43, 1984.

HESSELTINE, C. W.; SHOTWELL, O. I.; SMITH, M.; ELLIS, J. J.; VANDERGRAFT, E.; SHANNON, G. Production of various aflatoxins by strain of the Aspergillus flavus series. In: JAPAN CONFERENCE ON TOXIC MICROORGANISMS; MYCOTOXINS AND BOTULISM, 1968, Hawaii. Anais... Washington, D.C.: US Government Printing Office, 1970. p. 201-211.

HILL, R. A.; BLANKENSHIP, P. D.; COLE, R. J.; SANDERS, T. H. Effects of soil moisture and temperature on preharvest invasion of peanuts by the Aspergillus flavus group and subsequent aflatoxin development. Appl. Environ. Microbial., v. 1, p. 1061-1063, 1983.

HILL, R. A.; WILSON, D. M.; MCMILLIAN, W. W.; WIDSTROM, N. W.; COLE, R. J.; SANDERS, T. H.; BLANKENSHIP, P. D. Ecology of the Aspergillus flavus group and aflatoxina formation in maize and groundnut. In: LACEY, J. (Ed.). Trichothecenes and other mycotoxins. Chichester, United Kingdom: John Wiley \& Sons, 1985. p. 79-95.

HOLADAY, C. E.; LANSDEN, J. Rapid Screening method for aflatoxins in a number of products. J. Agric. Food Chem., v. 23, p. 1134-1136, 1975.

HOLLINGER, K.; EKPERIGIN, H. E. Mycotoxicosis in food producing animals. Vet. Clin. North Am. Food Anim. Pract., v. 15, p. 133-165, 1999.

HOLZAPFEL, C. W. The isolation and structure of cyclopiazonic acid, a toxic metabolite of Penicillium cyclopium Westling. Tetrahedron, v. 24, p. 2101-2119, 1968.

HORN, B. W. 2005. Ecology and population biology of aflatoxigenic fungi in soil. In: ABBAS, H. K. (Ed.). Aflatoxin and food safety. Boca Raton, Fla.: CRC Press, 2005. p. 95-116.

HORN, B. W.; DORNER, J. W. Regional differences in production of aflatoxina $\mathrm{B}_{1}$ and cyclopiazonic acid by soil isolates of Aspergillus flavus along a transect within the United States. Appl. Environ. Microbiol., v. 65, p. 1444-1449, 1999.

HORN, B. W.; DORNER, J. W. Soil populations of Aspergillus species from section Flavi along a transect through peanut-growing regions of the United States. Mycologia, v. 90, p. 767-776, 1998.

HORN, B. W.; DORNER, J. W.; GREENE, R. L.; BLANKENSHIP, P. D. e COLE, R. $\mathrm{J}$. Effect of Aspergillus parasiticus soil inocculum on invasion of peanut seeds. Mycopathol., v. 125, p. 179-191, 1994. 
HORN, B. W.; GREENE, R. L. Vegetative compatibility within populations of Aspergillus flavus, $A$. parasiticus, and $A$. tamari from a peanut field. Mycologia, v. 87, n. 3, p. 324-332, 1995.

HORN, B. W.; GREENE, R. L.; DORNER, J. W. Effect of corn and peanut cultivation on soil populations of Aspergillus flavus and $A$. parasiticus in Southwestern Georgia. Appl. Environ. Microbiol., v. 61, n. 7, p. 2472-2475, 1995.

HORN, B. W.; GREENE, R. L.; SORENSEN, R. B.; BLANKENSHIP, P. D. e DORNER, J. W. Conidial movement of nontoxigenic Aspergillus flavus and Aspergillus parasiticus in peanut fields following application to soil. Mycopathology, v. 151, p. 81-92, 2000.

HORN, B. W.; PITT, J. W. Yellow mold and aflatoxin. In: BACKMAN, P. A. et al. Compendium of peanut diseases. Minnesota: The American Phytopathological Society, 1997. 94 p.

HORN, N. W.; GREENE, R. L.; SOBOLEV, V. S.; DORNER, J. W. POWELL, J. H. Association of morphology and mycotoxin production with vegetative compatibility groups in Aspergillus flavus, A. parasiticus, and A. tamarii. Mycologia, v. 88, p. 574587, 1996.

HUANG, C. J.; CHUANG, T. Y.; TSENG, T. C Contamination of Aspergillus flavus on corn kernels and production of aflatoxin by the fungus in Taiwan. Plant Protect Bull, v. 32, p. 195-202, 1990.

INGHAM, J. L. Disease resistance in higher plants. The concept of pre-infectional and post-infectional resistance. Phytopathology. v. 78, p. 314-335, 1973.

INGHAM, J. L., HARBORNE, J. B. Phytoalexin induction as a new dynamic relationships among higher plants. Nature, v. 260, p. 241-243, 1976.

INTERNATIONAL AGENCY FOR RESEARCH ON CANCER (IARC). Aflatoxins: Natural occurring aflatoxins (Group 1), aflatoxina M1 (Group 2B). Lyon: IARC, 1993. 245 p. (IARC cientific publications, n. 56).

INTERNATIONAL COMMISSION ON MICROBIOLOGICAL SPECIFICATIONS OF FOODS (ICMSF). Microorganismos de los alimentos: características de los patógenos microbianos. Zaragoza: Acribia, 1996. p. 403-428.

IOWA STATE UNIVERSITY. Aflatoxin in lowa. Disponível em: $<$ http://vetmed.iastate.edu>. Acesso em: 16 maio 2010.

JACKSON, C. R; BELL, D. K. Diseases of peanut (groundnut) caused by fungi. Stations Research Bulletin n. 56. Universidade da Georgia, Athens, 1969.

JAY, J. M. Microbiologia moderna de los alimentos. Zaragoza, Acribia, 1978, 491 p. 
JELINEK, C. F., POHLAND, A. E.; GERNETT, E. W. Worldwide occurrence of mycotoxins in food and feeds-An update. J. Assoc. Off. Anal. Chem., v. 72, p. 223230, 1989.

JOFFE, A. Z; The mycoflora of groundnut rhizosphere soil and geocarposphere on light, medium and heavy soils and its relations to Aspergillus flavus. Mycopathol. Mycol. Appl., v. 37, p. 150-160, 1969.

KAPROVICKAS, A. The Origin, Variability, and Spread of the Groundnut (Arachis hypogaea). In: UCKO, P.J.; DIMBLEBY, J. W (Ed.) The Domestication and Exploitation of Plants and Animals. Chicago: Aldine, 1969. p. 427-441.

KISYUOMBE, C. T.; BEUTE, M. K.; PAYNE, G. A. Field evaluation of peanut genotypes for resistence to infection by Aspergillus parasiticus. Peanut Sci., v. 12, p. 12-17, 1985.

$\mathrm{KLICH}, \mathrm{M}$. A. Relation of plant water potential at flowering to subsequent cottonseed infection by Aspergillus flavus. Phytopathology, v. 77, p. 739-741, 1987.

KOZAKIEWICZ, Z. Aspergillus species on stored products. Wallingford: CAB International, 1989, $188 \mathrm{p}$.

KRISHNAMACHARI, K. A. V. R.; BHAT, R. V.; NAGARAJAN, V.; TILNAK, T. M. G. Hepatitis due to aflatoxicosis. An outbreak in Western India. Lancet, v. 1, p. 10611063, 1975.

KUC, J. Phytoalexins: Perspectives and prospects. In: SHARMA, R. P.; SALUNKHE, D. K. (Ed.), Mycotoxins and Phytoalexins. Boca Raton: CRC Press, 1991. p. 595603.

LACEY, J. Water availability and the ocorrence of toxigenic fungi and mycotoxins in stored products. In: INTERNATIONAL IUPAC SYMPOSIUM ON MYCOTOXINS AND PHYCOTOXINS, 1988, Tokyo. Anais... Tokyo: IUPAC, 1988. v. 6, p.186-89.

LACEY, J.; RAMAKRISHINA, N.; HAMER, A.; MAGAN, N.; MARFLEET, C. Grain fungi. In: ARORA, D.K. et al. Handbook of Applied Micology: foods and feeds. New York: Marcel Dekker, 1991. p. 12-77.

LANGCAKE, P.; PRYCE, R. J. The production of Resveratrol by Vitis vinifera and other members of the vitacee as a response to infection or injury. Physiol. Plant Pathol., v. 9, p. 77-86, 1976.

LANSDEN, J. A. Determination of cyclopiazonic acid in peanuts and corn by thinlayer chromatography. J. Assoc. Off. Anal. Chem., p. 964-966, 1986.

LANSDEN, J. A.; DAVIDSON, J. I. Occurrence of cyclopiazonic acid in peanuts. Appl. Environ. Microbiol., v. 45, p. 766-769, 1983. 
LAPRADE, J. C.; BARTZ, J. A. Mechanical resistence of selected genotypes of dried peanuts to colonization by strain of aflatoxin producing Aspergillus spp. Phytopathology, v. 62, p. 771, 1972.

LAZAROVITS, G.; STOSSEL, P.; WARD, E. W. B. Age-related changes in specificity and glyceollin production in the hypocotyl reaction of soybcan to Phytophthora megasperma var. sojae. Phytopathology, v. 71, p. 94-97, 1981.

LE BARS, J. Cyclopiazonic acid production by Penicillium camamberti Thom and natural occurrence of this mycotoxins in cheese. Appl. Environ. Microbiol., v. 38, p. 1052-1055, 1979.

LEITÃO, M. F. Microbiologia de alimentos. In: ROTTMAM, I. et al. Tratado de Microbiologia. São Paulo: Manoele, 1988. p. 1-81.

LILLEHOJ, E. B.; MCMILLIAN, W. W.; GUTHRIE, W. D.; BARRY, D. Aflatoxinproducing fungi in preharvest corn: inoculum source in insects and soils. J. Environ. Qual., v. 9, p. 691-694, 1980.

LIN, M. L.; DIANESE, L. C. A coconut agar medium for rapid detection of aflatoxin production by Aspergillus spp. Phytopathology, v. 66, p. 1466-1469, 1976.

LINDSEY, D. L.; TURNER, R. B. Inhibition of growth of Aspergillus flavus and Trichoderma viride by peanut embryos. Mycopathology, v. 55, p. 149-152, 1975.

LISKER, N.; MICHAELI, R.; FRANK, Z. R. Mycotoxigenic potential of Aspergillus flavus strain isolated from groundnuts growing in Israel. Mycopathology, v. 122, p. 177-183, 1993.

LISTER, C. E.; LANCASTER, J. E.; SUTTON, K.H.; WALKER, J. R. L. Developmental changes in the concentration and composition of flavonoids in the skin of a red and green apple cultivar. J. Sci. Food Agric., v. 64, p. 155-161, 1994.

LOMAX, L. G., COLE, R. J., DORNER, J. W. The toxicity of cyclopiazonic acid in weaned pigs. Vet. Pathol., v. 21, p. 418, 1984.

LOSITO, I.; MONACI, L.; ARESTA, A.; ZAMBONIN, C. G. LC-ion trap eletrospray MS-MS for detrmination of cyclopiazonic acid in milk samples. Analyst, v. 127, n. 4, p. 499-502, 2002.

LOURENZANI, W.L.; LOURENZANI, A.E.B.S. Potencialidades do agronegócio brasileiro de amendoim. In: CONGRESSO DA SOCIEDADE BRASILEIRA DE ECONOMIA E SOCIOLOGIA RURAL, 44., 2006, Fortaleza. Anais... Fortaleza: Sober, 2006. CD-ROM.

LUK, K. C., KOBBE, B.; TOWNSEND, J. M. Production of cyclopiazonic acid by Aspergillus flavus Link. Appl. Environ. Microbiol., v. 33, p. 211-212, 1977.

MAGGON, K. K.; GUPTA, S. K.; VENKITASUBRAMANIAN, T. A. Biosynthesis of aflatoxins. Bacteriol. Rev., v. 41, p. 822-855, 1977. 
MALAVOLTA, E. Manual de química agrícola: nutrição de plantas e fertilidade do solo. São Paulo: Editora Agronômica Ceres, 1976. 528 p.

MALAVOLTA, E. Reação do solo e crescimento das plantas. In: MALAVOLTA, E. (Coord.). Seminário sobre corretivos agrícolas. Campinas: Fundação Cargill, 1985. 364 p.

MANABE, M.; TSURUTA, O.; TANAKA, K.; MATSUURA, S. Distribuiion of aflatoxinproducing fungi in soil in Japan. Trans. Mycol. Soc. Jpn., v. 17, p. 436-444, 1976.

MARGIS-PINHEIRO, M.; SANDRON, M.; LUMMERZHEIM, M.; OLIVEIRA, D. E. A defesa das plantas contra as doenças. Ciênc. Hoje, v. 147, p. 28-32, 1999.

MARTIN, J. P. Use of acid rose Bengal and streptomycin in the plate method for estimating soil fungi. Soil Sci., v. 69, p. 215-232, 1950.

MARTINS, R.; PEREZ, L. H. Amendoim: inovação tecnológica e substituição de importações. Informações Econômicas, São Paulo, v. 36, n. 12, p. 7-19, 2006.

McALPIN, C. E. Synnema and sclerotium production in Aspergillus caelatus and the influence of substrate composition on their development in selected strains. Mycologia, v. 96, n. 5, p. 937-947, 2004.

McDONALD, D. The influence of developing groundnut fruit on soil mycoflora. Trans. Br. Mycol. Soc., v. 53, p. 393-406, 1969.

McDONALD, D.; HARKNESS, C. Aflatoxin in the groundnut crop at harvest in Northern Nigeria. Tropical Science, v. 9, p. 148-161, 1967.

MINISTÉRIO DO DESENVOLVIMENTO, INDÚSTRIA E COMÉRCIO EXTERIOR Secretaria de Comércio Exterior (SECEX/MDIC). Balança Comercial Brasileira. Disponível em: <http://www.desenvolvimento.gov.br/sitio/secex>. Acesso em: 14 jun. 2010.

MIXON, A. C.; ROGERS, K. M. Peanut accessions resistant to seed infection by Aspergillus flavus. Agron. J., v. 65, p. 560-562, 1973.

MOORE, D. Tissue formation. In: GROW, N. A. R.; GADD, G. M. (Ed.). The Growing Fungus. Oxford, UK: Chapman and Hall, 1995. p. 423-465.

MOSS, M. O. Economic importance of mycotoxins-recent incidence in the United States. Anim Sci, v. 27, p. 3941-3949, 1991.

MPHANE, F. A.; SIAME, B. A.; TAYLOR, J. E. Fungi, aflatoxins, and cyclopiazonic acid associated with peanut retailing in Botswana. J. Food Prot., v. 67, n. 1, p. 96102, 2004. 
MULLER, K. O., BORGER, H. Experimentelle Untersuchungen uber die Phytophthorainfestans-Resistenz der Kartoffel. Arb. Biol. Reichsanst. Land Forstwirtsch. V. 23, p. 189-231, 1940.

NAKAI, V. K.; ROCHA, L. O.; GONÇALEZ, E.; FONSECA, H.; ORTEGA, E. M. M.; CORREAA, B. Distribuition of fungi and aflatoxins in stored peanut variety. Food Chem., v. 106, p. 285-290, 2008.

NESCI, A.; ETCHEVERRY, M. Aspergillus section Flavi populations from field maize im Argentina. Lett. Appl. Microbiol., v. 34, p. 1-6, 2002.

OKUDA, T.; YOKOTSUKA, K. Trans-resveratrol concentration in berry skins and wines from grapes grown in Japan. Am. J. Enol. Vitic., v. 47, n. 1, p. 93-98. 1996.

OLANYA, O. M.; HOYOS, G. M. Waste corn as a point source of inoculum for Aspergillus flavus in the corn Agroecosystem. Plant Dis., p. 81, p. 576-581, 1997.

OLIVEIRA, C. A; ROSMANINHO, J.; ROSIM, R.. Aflatoxin $\mathrm{M}_{1}$ and cyclopiazonic acid in fluid milk trated in São Paulo, Brazil. Food Addit. Contam., v. 23, n. 2, p. 196-201, 2006.

PASS, T.; GRIFFIN, G. J. Exogenous carbon and nitrogen requirements for conidial germination by Aspergillus flavus. Can. J. Microbiol., v. 18, p.1453-1461, 1972.

PASTER, N.; BULLERMAN, L.B. Mould spoilage and mycotoxins formation in grains as controlled by physical means. Int. J. Food Microbiol., v. 7, p. 257-265, 1988.

PAXTON, J. D.; CHAMBERLAIN, D. W. Phytoalexin production and disease resistance in soybeans as affected by age. Phytopathology, v. 59, p. 775-777, 1969.

PEANUT COMPANY OF AUSTRALIA (PCA). How peanuts are Grown Harvesting - PCA. Disponível em: <http:// www.pca.com.au> Acesso em: 21 jun. de 2010.

PÍER, A. C. Mycotoxins and mycotoxicoses. In: BIBERSTEN, E. L.; ZEE, Y. C. (Ed.). Review of Veterinary Microbiology. London: Blackwell Scientific Publication, 1990, p. 348-355.

PILDAIN, M. B.; VAAMONDE, G.; CABRAL, D. Analysis of population structure of spergillus flavus from peanut based on vegetative compatibility, geographic origin, mycotoxin and sclerotia production. Int. J. Food Microbiol., v. 93, p. 31-40, 2004.

PITT, J. I. Corrections to species names in physiological studies on Aspergillus flavus and Aspergillus parasiticus. J. Food Prot, v. 56, p. 265-269, 1993.

PITT, J. I.; GLENN, D. R.; HOCKING, A. D. An improved medium for the detection of Aspergillus flavus and A. parasiticus. J. Appl. Bacteriol., v. 54, p. 109-114, 1983. 
PITT, J. I.; KING, A. D. e HOCKING, A. D. Dchloran-rose Bengal medium for enumeration and isolation of molds from foods. Appl. Environ. Microbiol., v. 37, p. 959-970, 1979.

PITT, J.I.; HOCKING, A.D. Aspergillus and related teleomorphs. In: Pitt, J. et al. Fungi and food spoilage. London: Chapman \& Hall, 1997. p.339-416.

PORTER, D. M. Peanut Diseases. In: BACKMAN, P. A. et al. Compendium of peanut diseases. Minnesota: The American Phytopathological Society, 1997. 94 p.

PORTER, D. M.; GARREN, K. H. Endocarpic microorganisms of two types of windrow-dried peanut fruit (Arachis hypogaea L.). Appl. Microbiol., v. 20, p. 133138, 1970.

RAO, L.B.; HUSAIN, A. Presence of cyclopiazonic acid in Kodo millet (Paspalum scrobiculatum) causing kodua poisoning in man and its production by associated fungi. Mycopathology, v. 89, p. 177-180, 1985.

RAPER, K. B.; FENNEL, D. I. The genus Aspergillus. Baltimore, Willians \& Wilkins, 1965. 686 p.

RAZZAGHI-ABYANCH, M.; SHAMS-GHAHFAROKHI, M.; ALLAMEH, A.; KAZEROON-SHIRI, A.; RANJBAR-BAHADORI, S.; MIRZAHOSEINI, H.; REZAEE, M. A survey on distribuition of Aspergillus section Flavi in corn field soils in Iran: population patterns based on aflatoxins, cyclopiazonic acid and sclerotia production. Mycopathology, v. 161, p. 183-192, 2006.

REIS, G. M. Variabilidade genética de cepas de Aspergillus flavus isoladas de amendoim. 2009. 113 f. Dissertação (Mestrado em Microbiologia) - Instituto de Ciências Biomédicas, Universidade de São Paulo, São Paulo, 2009.

RESNIK, S. L.; GONZÁLEZ, H. H. L.; PACIN, A. M.; VIORA, M.; CABALLERO, G. M.;GROS, E. G. Cyclopiazonic acid and aflatoxins production by Aspergillus flavus isolated from Argentina corn. Mycotox. Res., v. 12, p. 61-66, 1996.

RIDELL, R. W. Permanent stained mycological preparations obtained by slid culture. Mycologia, v. 42, p. 265-270, 1950.

RINCÓN, C. A.; CUESTA, M. P. A.; PEREZ, B. R. et al. Maní forrajero perenne (Arachis pintoi Krapovickas e Gregory): Uma alternativa para ganaderos e agricultores. Bogotá: Instituto Colombiano Agropecuário, 1992. 23 p. (Boletín Técnico, 219).

ROSSETO, C. A. V.; SILVA, O. F.; ARAUJO, A. E. S. Influencia da calagem, da época de colheita e da secagem na incidência de fungos e aflatoxinas em grãos de amendoim armazenados. Ciênc. Rural, v. 35, n. 2, p. 309-315, 2005. 
SABINO, M.; MILANEZ, T. V.; LAMARDO, L. C. A.; ONOMATA, E. I.; ZORZETTO, M. A. P.; NAVAS, S. A.; STOFER, M. Occurrence of aflatoxins in peanuts and peanut prioducts consumed in the state of São Paulo/Brazil from 1995 to 1997. Rev. Microbiol., v. 30, p. 85-88, 1999.

SAITO, M.; TSURUTA, O.; SIRIACHA, P.; KAWASUGI, S.; MANABE, M.; BUANGSUWON, D. Distribuition and aflatoxin production of the atypical strains of Aspergillus flavus isolated from soils in Thailand. Proc. Jpn. Assoc. Mycotoxicol., v. 24, p. 41-46, 1986.

SANCHES, M. A. R. Cooperação e Competição na Indústria de Alimentos de Amendoim de Marília - SP. 2003. 325 f. Tese (Doutorado em Administração de Empresas) - Escola de Administração de Empresas de São Paulo da Fundação Getúlio Vargas, São Paulo, 2003.

SANDERS, T. H., BLANKENSHIP, P. D.; COLE, R. J.; HILL, R. A. Effect of soil temperature and drought on peanut pod and stem temperature relative to Aspergillus flavus invasion and aflatoxin contamination. Mycopathology, v. 86, p. 51-54, 1984.

SANDERS, T. H., McMICHAEL, R. W.JR.; HENDRIX, K. W.. Occurrence of resveratrol in edible peanuts. J. Agric. Food Chem., v. 48, n. 4, p.1243-1246, 2000.

SCHNEIDER, R. W., PENDERY, W. E. Stalk rot of corn: Mechanism of predisposition by an early season water stress. Phytopathology, v. 73, p. 863-871, 1983.

SCHROEDER, H. W.; BOLLER, R. A. Aflatoxin production of species and strain of the Aspergillus flavus group isolated from field crops. Appl. Microbiol., v. 25, n. 6, p. 885-889, 1973.

SHARMA, R. P.; SALUNKHE, D. K. Introduction to mycotoxins. In: SHARMA, R. P. and SALUNKHE, D. K. (Ed.). Mycotoxins and Phytoalexins. Londres: CRC Press, 1991. $775 \mathrm{p}$.

SHEIKH, M. B.; MUSINGO, M. N.; NOHANTY, B.; DORNER, J. W.; COLE, R. J. Factors affecting phytoalexin production in peanut seed. J. Plant Physiol., in press 1990.

SIEMANN, E. H.; CREASY, L. L. Concentration of the phytoalexin resveratrol in wine. Am. J. Enol Vitic., v. 43, p. 49-52, 1992.

SILKER, J. H. e ELLIOTT, R. P. Ecologia Microbiana de los Alimentos. Zaragoza, Acribia, v. 1, p. 74-96, 1980.

SIMPSON, C. E.; VALLS, J. F. M.; MILES, J. W. Reproductive biology and potential for genetic recombination in Arachis. In: KERRIDGE, P. C.; HARDY, B. (Ed.). Biology and agronomy of forage Arachis. Cali: CIAT, 1994. p. 43-52. 
SINHA, A. K., 1994. Possible role of phytoalexin inducer chemicals in plant disease control. In: DANIEL, M.; PURKAYASTHA, R. P. (Ed.), Handbook of Phytoalexin Metabolism and Action. New York: Marcel Dekker, 1994. p. 555-591.

SMITH, A. F. Peanuts: The Illustrious History of the Goober Pea, Chicago: University of Illinois Press, 2002.

SMITH, E. E.; KUBENA, L. F.; BRAITHWAITE, C. E.; HARVEY, R. B.; PHILLIPS, T. D.; REINE, A. H. Toxicological evaluation of aflatoxin and cyclopiazonic acid in broiler chickens. Poult. Sci., v. 71, 1136-1144, 1992.

SMITH, J. E.; MOSS. M. O. Mycotoxins: Formation, analyses and significance. Chichester, United Kingdom: John Wiley and Sons, 1985.

SMITH, J. E.; ROSS, I. C. The toxigenic Aspergilli. In: SMITH, J. E. et al. Mycotoxins and Animal Foods. London: CRC Press, 1991. p. 31-61.

SOBOLEV, V. S.; GUO, B. Z., HOLBROOK, C. C.; LYNCH, R. E. Interrelationship of phytoalexin production and diseases resistence in selected peanut genotypes. J. Agric Food Chem., v. 55, p. 2195-2200, 2007.

SOCIEDADE BRASILEIRA DE QUIMICOS (SBQ). Fitoalexinas. Disponível em: $<$ http://www.sbq.org.br>. Acesso em: 25 set. 2005.

STACK, R. W.; HORST, R. K.; LANGHANS, R. W. Effects of nitrogen and potassium fertilization on infection of florists carnation by Giberella zeae. Plant Dis., v. 70, p. 29-31, 1986.

STAMBERG, M. F.; FIELD, E. T.; GUTHRIE, J. D. The tannin and related pigments in the red skin (taste) of peanut kernels. J. Am. Oil Chem. Soc., v. 27, p. 317-321, 1950.

STOESSL, A., STOTHERS, J. B., WARD, E. B. Sesquiterpenoid stress compounds of the Solanaceae. Phytochemistry, v. 15, p. 855-872, 1976.

SWANSON, K. M., BUSTA, F. F., PETTERSON, E. H., JOHNSON, M. G. Colony Count Methods. In: VANDEZANT, C.; SPLITTOESSER, D. S. (Ed.). Compendium of methods for the microbiological examination of foods. New York: American Public Health Association, 1992.

TARIN, A.; ROSSEL, M. G.; GUARDINO, X. Use of high-performance liquid chromatography to assess airbone mycotoxins aflatoxins and ochratoxin $\mathrm{A}$. J. Chromat. A., v. 1047, p. 235-240, 2004.

THRELFALL, R. T.; MORRIS, J. R.; MAUROMOUSTAKOS A., Effect of variety, ultraviolet light exposure, and enological methods on the trans-resveratrol level of wine. Am. J. Enol. Vit., v. 50, n. 1, p. 57-64, 1999. 
TOKUSOGLU, O.; UNAL, M. K.; YEMIS, F. Determination of the phytoalexin resveratrol $(3,5,4$ '- trihydroxystilbene) in peanuts and pistachios by high-performance liquid chromatography diode array (HPLC-DAD) and gas chromatography-mass spectrometry (GC-MS). J. Agric. Food Chem., v. 53, p. 5003-5009, 2005.

TORRES, M. R.; RAMOS, A. J.; SOLER, J.; SANCHIS, V.; MARÍN, S. SEM study of water activity and temperature effects on the initial growth of Aspergillus ochraceus, alternaria alternata and Fusarium verticillioides on maize grain. Inter J. Foos Microbiol, v. 81, p. 185-193, 2003.

TRAN-DINH, N.; PITT, J. I.; CARTER, D. A. Molecular genotype analysis of natural toxigênico and nontoxigenic isolates of Aspergillus flavus and $A$. parasiticus. Mycol. Res., v. 103, p. 1485-1490, 1999.

TROLLER, J. A.; BERNARD, D. T.; SCOTT, N. C. Measurement of water activity. In: SPECK, L. M. et al. Compendium of Methods for the microbiological examination of foods. New York: American Public Health Association, 1984. p. 124134.

TRUCKESS, M. W.; STACK, M. E.; NESHEIM, S.; PAGE, S. W.; ALBERT, R. H.; HANSEN, T. J.; DONAHUE, K. F. Immunoaffinity column coupled with solution fluorometry or liquid chromatography post column derivatization for determination of aflatoxins in corn, peanuts and peanuts butter: collaborative study. J AOAC, v. 74, n. 1, p. 81-88, 1991.

TRUCKSESS, M. W.; MISLIVEC, P. B.; YOUNG, K; BRUCE, V. R.; PAGE, S. W. Cyclopiazonic acid production by cultivares of Aspergillus and Penicillium species isolated from dried beans, corn meal, macaroni, and pecans. J. Assoc. Off. Anal. Chem., v. 70, n. 1, p. 123-126, 1987.

UNITED STATES DEPARTMENT OF AGRICULTURE (USDA). Table 13 Peanut Area, Yield, and Production. Disponível em: <http://www.fas.usda.gov>. Acesso em: 12 jun. 2010.

URANO, T.; TRUCKSESS, M. W.; MATUSIK, J. Liquid chromatographic determination of cyclopiazonic acid in corn and peanuts. J. AOAC Intern., v. 75, n. 2, p. 319-322, 1992.

VAAMONDE, G.; PATRIARCA, A.; FERNANDEZ-PINTO, V. E.; Effectof water activity and temperature on production of aflatoxin and cyclopiazonic acid by Aspergillus flavus in peanuts. Adv. Exp. Med. Biol., v. 571, p. 225-235, 2006.

VAAMONDE, G.; PATRIARCA, A.; FERNANDEZ-PINTO, V.; COMERIO, R.; DEGROSSI, C. Variability of aflatoxin and cyclopiazonic acid production by Aspergillus section flavi from different substrates in Argentina. Int. J. Food Microbiol., v. 88, p. 79-84, 2003.

VAN EGMOND, H. P. Aflatoxin M1: occurrence, toxicity, regulation, p.11-55. In: VAN EGMOND, H. P. (Ed.). Mycotoxins in dairy products. London: Elsevier Applied Science, 1969. 
VAN RENSBURG, S. J. Role of epidemiology in the elucidation of mycotoxin health risks. In: RODRICKS, J. V.; HESSELTINE, C. W.; MEHLMAN, M. A. Mycotoxins in Human and Animal Health. Park Forest South, IL: Pathotox Publishers, 1977. p. 699-711.

VARSAVSKY, E.; SOMMER, S. Determination of aflatoxins in peanuts. Ann. Nutr. Alim., v. 31, p. 539-544, 1977.

WEISS, E.A. Oilseed crops. London: Blackwell Science, 2000. 364 p.

WELLS, T. R.; KREUTZER, W. A., LINDSEY, D. L. Colonization of gnotobiotically grown peanuts by Aspergillus flavus and selected interacting fungi. Phytopathology, v. 62, p. $1238-1242,1972$.

WICKLOW, D. T.; DONAHUE, J. E. Sporogenic germination of sclerotia in Aspergillus flavus and A. parasiticus. Trans. Br. Mycol. Soc., v. 82, p. 621-624, 1984

WICKLOW, D. T.; WILSON, D. M. Germination of Aspergillus flavus sclerotia in a Georgia maize field. Trans. Br. Mycol. Soc., v. 87, p. 651-653, 1986.

WILSON, D. M.; PAYNE, G. A. 1994. Factors affecting Aspergillus flavus group infection and aflatoxin contamination of crops, p. 309-325. In D. L Eaton and J. D. Groopman (ed.), The toxicology of aflatoxins. Human health, veterinary and agricultural significance. Academic Press, San Diego, Calif.

WILSON, T. M.; NELSON, P. E.; TOUSSOUN, T. A.; MARASAS, W. F. O. The Fusarium research center and proposed diagnostic, reference and research center for Fusarium mycotoxicoses in animals. Proc. Ann. Meet Am. Assoc. Vet. Lab. Diagn., v. 24, p. 261-276, 1981.

WOTTON, H. R.; STRANGE, R. N. Circunstantial evidence for phytoalexins involvement in the resistence of peanuts to Aspergillus flavus. J. Gen, Microbiol., v. 131, p. 487-494, 1985.

WOTTON, H. R.; STRANGE, R. N. Increased susceptibility and reduced phytoalexin accumulation in drought-stressed peanut kernel challenged with Aspergillus flavus. Appl. Environ. Microbiol., v. 53, p. 270-273, 1987.

ZEPPER, P. O amendoim brasileiro: empresários se organizam, ampliam o consumo no mercado interno e voltam a exportar, ajudados pelo boom da cana. Rev. Dinheiro Rural, São Paulo, ano 3, edição 19, p. 58-59, 2006.

ZERINGUE JUNIOR, H. J.; BHATNAGAR, D.; CLEVELAND, T.E. C15H24 volatile comounds unique to aflatoxigenic strains of Aspergillus flavus. Appl. Environ. Microbiol., v. 59, p. 2264-2270, 1993.

ZEVADA, M. Z. Producción de aflatoxinas por cepas aisladas de maiz. Rev. Latinoam. Microbiol., v. 13, p. 263-266, 1971. 
ANEXOS 
ANEXO A - TABELAS 
Tabela A1 - Atividade de água (Aa) e micobiota das amostras de solo da área de plantio do amendoim, por UFC/g, da variedade Runner IAC-Caiapó, na Região de Tupã - SP, no período de outubro de 2005 a março de 2006.

\begin{tabular}{|c|c|c|c|c|c|c|c|c|c|c|c|}
\hline & \multirow[b]{2}{*}{$\begin{array}{c}\text { Amostra } \\
\text { Runner } \\
\text { IAC-Caiapó }\end{array}$} & \multirow[b]{2}{*}{$\begin{array}{c}\text { Atividade } \\
\text { de Água } \\
\text { (Aa) }\end{array}$} & \multicolumn{9}{|c|}{ UFC/g } \\
\hline & & & $\begin{array}{c}\text { Fusarium } \\
\text { spp }\end{array}$ & A. flavus & A. terreus & A. niger & $\begin{array}{l}\text { Trichoderma } \\
\text { spp }\end{array}$ & $\begin{array}{l}\text { Mucor } \\
\text { spp }\end{array}$ & $\begin{array}{l}\text { Penicillium } \\
\text { spp }\end{array}$ & $\begin{array}{c}\text { Neurospora } \\
\text { spp }\end{array}$ & FNE \\
\hline Coletas & Parcelas & & & & & & & & & & \\
\hline $1^{\circ}$ (plantio) & - & 0,85 & $0,8 \times 10^{4}$ & - & - & - & $1,3 \times 10^{4}$ & $1,0 \times 10^{4}$ & $2,8 \times 10^{4}$ & - & $0,2 \times 10^{4}$ \\
\hline \multirow{5}{*}{$\begin{array}{c}2^{\circ} \\
\text { (Flor) }\end{array}$} & 1 & 0,80 & $1,5 \times 10^{4}$ & & - & - & - & $2,5 \times 10^{4}$ & $2,0 \times 10^{4}$ & - & $0,5 \times 10^{4}$ \\
\hline & 5 & 0,86 & $1,0 \times 10^{4}$ & - & - & - & $0,5 \times 10^{4}$ & $0,5 \times 10^{4}$ & $2,0 \times 10^{4}$ & - & $0,5 \times 10^{4}$ \\
\hline & 8 & 0,95 & $0,5 \times 10^{4}$ & - & $0,5 \times 10^{4}$ & - & $0,5 \times 10^{4}$ & - & $3,0 \times 10^{4}$ & - & - \\
\hline & 9 & 0,83 & - & $0,5 \times 10^{4}$ & - & - & - & $1,5 \times 10^{4}$ & $0,5 \times 10^{4}$ & - & - \\
\hline & 10 & 0,58 & - & - & - & - & $1,5 \times 10^{4}$ & $0,5 \times 10^{4}$ & $3,0 \times 10^{4}$ & - & - \\
\hline \multirow{5}{*}{$\begin{array}{c}3^{\circ} \\
\text { (Ginóforo) }\end{array}$} & 2 & 0,97 & $0,5 \times 10^{4}$ & - & - & - & - & - & $1,5 \times 10^{4}$ & - & - \\
\hline & 4 & 0,93 & $1,0 \times 10^{4}$ & - & - & $0,5 \times 10^{4}$ & - & $0,5 \times 10^{4}$ & - & - & - \\
\hline & 6 & 0,85 & - & $2,5 \times 10^{4}$ & - & - & - & - & $0,5 \times 10^{4}$ & - & - \\
\hline & 7 & 0,83 & $0,5 \times 10^{4}$ & - & - & - & $0,5 \times 10^{4}$ & $0,5 \times 10^{4}$ & $0,5 \times 10^{4}$ & - & - \\
\hline & 9 & 0,71 & - & - & - & - & - & - & $2,5 \times 10^{4}$ & - & - \\
\hline \multirow{5}{*}{$\begin{array}{c}4^{\circ} \\
\text { (Fase água e } \\
\text { inìcio da } \\
\text { granação) }\end{array}$} & 3 & 0,99 & - & - & $1,0 \times 10^{4}$ & - & $1,0 \times 10^{4}$ & - & $1,0 \times 10^{4}$ & - & - \\
\hline & 4 & 0,99 & - & - & - & - & - & $0,5 \times 10^{4}$ & $1,0 \times 10^{4}$ & - & - \\
\hline & 5 & 0,99 & $0,5 \times 10^{4}$ & - & $1,0 \times 10^{4}$ & - & $4,0 \times 10^{4}$ & $\begin{array}{c}0,0 \times 10 \\
-\end{array}$ & $2,0 \times 10^{4}$ & - & - \\
\hline & 6 & 0,99 & $1,0 \times 10^{4}$ & - & $\begin{array}{c}1,0 \times 10 \\
-\end{array}$ & - & $2,0 \times 10^{4}$ & - & $2,0 \times 10^{4}$ & - & - \\
\hline & 10 & 0,99 & $0,5 \times 10^{4}$ & - & - & & $2,5 \times 10^{4}$ & - & $1,0 \times 10^{4}$ & $1,0 \times 10^{4}$ & \\
\hline \multirow{5}{*}{$\begin{array}{c}5^{\circ} \\
\text { (Grãos/ } \\
\text { Grãos } \\
\text { maduros) }\end{array}$} & 3 & 0,99 & - & - & $1,5 \times 10^{4}$ & - & $1,0 \times 10^{4}$ & $1,0 \times 10^{4}$ & $1,5 \times 10^{4}$ & $1,0 \times 10^{4}$ & - \\
\hline & 4 & 0,99 & $1,0 \times 10^{4}$ & $0,5 \times 10^{4}$ & - & - & $1,0 \times 10^{4}$ & - & - & - & $1,0 \times 10^{4}$ \\
\hline & 7 & 0,99 & $1,5 \times 10^{4}$ & - & $2,0 \times 10^{4}$ & - & $1,0 \times 10^{4}$ & $0,5 \times 10^{4}$ & $1,0 \times 10^{4}$ & $0,5 \times 10^{4}$ & - \\
\hline & 8 & 0,99 & - & - & $0,5 \times 10^{4}$ & - & $3,0 \times 10^{4}$ & $0,5 \times 10^{4}$ & $1,5 \times 10^{4}$ & $1,0 \times 10^{4}$ & - \\
\hline & 10 & 0,99 & - & - & - & - & $2,0 \times 10^{4}$ & - & $1,5 \times 10^{4}$ & $0,5 \times 10^{4}$ & - \\
\hline
\end{tabular}

FNE - Fungo não esporulado

UFC - Unidade Formadora de Colônia 
Tabela A2 - Atividade de água (Aa) e micobiota das amostras de solo da área de plantio do amendoim, por UFC/g, da variedade Runner IAC 886, na Região de Tupã - SP, no período de outubro de 2005 a março de 2006.

\begin{tabular}{|c|c|c|c|c|c|c|c|c|c|c|c|}
\hline & \multirow[b]{2}{*}{$\begin{array}{l}\text { Amostra } \\
\text { Runner } \\
\text { IAC } 886\end{array}$} & \multirow[b]{2}{*}{$\begin{array}{c}\text { Atividade } \\
\text { de Água } \\
\text { (Aa) }\end{array}$} & \multicolumn{9}{|c|}{ UFC/g } \\
\hline & & & $\begin{array}{c}\text { Fusarium } \\
\text { spp }\end{array}$ & A. flavus & A. terreus & A. niger & $\begin{array}{l}\text { Trichoderma } \\
\text { spp }\end{array}$ & $\begin{array}{l}\text { Mucor } \\
\text { spp }\end{array}$ & $\begin{array}{c}\text { Penicillium } \\
\text { spp }\end{array}$ & $\begin{array}{c}\text { Neurospora } \\
\text { spp }\end{array}$ & FNE \\
\hline Coletas & Parcelas & & & & & & & & & & \\
\hline $1^{\circ}$ (plantio) & - & 0,85 & $0,8 \times 10^{4}$ & - & - & - & $1,3 \times 10^{4}$ & $1,0 \times 10^{4}$ & $2,8 \times 10^{4}$ & - & $0,2 \times 10^{4}$ \\
\hline \multirow{5}{*}{$\begin{array}{l}2^{\circ} \\
\text { (Flor) }\end{array}$} & 3 & 0,81 & $1,0 \times 10^{4}$ & $3,0 \times 10^{4}$ & ב- & - & $2,5 \times 10^{4}$ & $0,5 \times 10^{4}$ & $9,5 \times 10^{4}$ & ב- & $0,5 \times 10^{4}$ \\
\hline & 4 & 0,82 & $0,5 \times 10^{4}$ & $2,0 \times 10^{4}$ & - & - & $2,0 \times 10^{4}$ & $3,0 \times 10^{4}$ & $2,0 \times 10^{4}$ & - & - \\
\hline & 5 & 0,61 & $3,0 \times 10^{4}$ & $1,0 \times 10^{4}$ & - & - & $2,0 \times 10^{4}$ & $1,0 \times 10^{4}$ & $2,0 \times 10^{4}$ & - & - \\
\hline & 6 & 0,82 & $1,0 \times 10^{4}$ & $1,5 \times 10^{4}$ & - & - & $0,5 \times 10^{4}$ & $1,0 \times 10^{4}$ & $3,5 \times 10^{4}$ & - & $0,5 \times 10^{4}$ \\
\hline & 8 & 0,93 & $0,5 \times 10^{4}$ & - & - & - & $4,0 \times 10^{4}$ & $2,0 \times 10^{4}$ & $3,0 \times 10^{4}$ & - & - \\
\hline \multirow{5}{*}{$\begin{array}{c}3^{\circ} \\
\text { (Ginóforo) }\end{array}$} & 1 & 0,97 & $3,5 \times 10^{4}$ & $3,0 \times 10^{4}$ & - & - & $1,5 \times 10^{4}$ & - & $32,0 \times 10^{4}$ & $1,0 \times 10^{4}$ & - \\
\hline & 2 & 0,98 & $2,5 \times 10^{4}$ & - & - & - & $0,5 \times 10^{4}$ & - & $4,5 \times 10^{4}$ & - & - \\
\hline & 6 & 0,98 & $0,5 \times 10^{4}$ & - & - & $0,5 \times 10^{4}$ & $3,0 \times 10^{4}$ & - & $1,5 \times 10^{4}$ & - & - \\
\hline & 7 & 0,96 & $1,0 \times 10^{4}$ & $2,5 \times 10^{4}$ & - & $0,5 \times 10^{4}$ & $2,0 \times 10^{4}$ & - & $3,0 \times 10^{4}$ & - & - \\
\hline & 9 & 0,91 & $0,5 \times 10^{4}$ & $1,0 \times 10^{4}$ & - & $\begin{array}{l}- \\
-\end{array}$ & $\begin{array}{c}- \\
-10\end{array}$ & $10,0 \times 10^{4}$ & $1,5 \times 10^{4}$ & - & - \\
\hline \multirow{5}{*}{$\begin{array}{l}4^{\circ} \\
\text { (Fase água e } \\
\text { inìcio da } \\
\text { granação) }\end{array}$} & 2 & 0,99 & $0,5 \times 10^{4}$ & - & - & - & $1,0 \times 10^{4}$ & $0,5 \times 10^{4}$ & $2,5 \times 10^{4}$ & - & - \\
\hline & 4 & 0,99 & - & - & - & - & $1,0 \times 10^{4}$ & - & $3,5 \times 10^{4}$ & - & - \\
\hline & 5 & 0,99 & $1,5 \times 10^{4}$ & - & $1,5 \times 10^{4}$ & - & - & - & $2,0 \times 10^{4}$ & - & - \\
\hline & 8 & 0,99 & - & $0,5 \times 10^{4}$ & $0,5 \times 10^{4}$ & - & - & - & $1,0 \times 10^{4}$ & $0,5 \times 10^{4}$ & $0,5 \times 10^{4}$ \\
\hline & 10 & 0,99 & $0,5 \times 10^{4}$ & - & - & - & $1,0 \times 10^{4}$ & - & - & - & - \\
\hline \multirow{5}{*}{$\begin{array}{c}5^{\circ} \\
\text { (Grãos } \\
\text { maduros) }\end{array}$} & 3 & 0,99 & - & - & - & - & $3,0 \times 10^{4}$ & $0,5 \times 10^{4}$ & $2,5 \times 10^{4}$ & - & - \\
\hline & 4 & 0,99 & $1,0 \times 10^{4}$ & - & $1,0 \times 10^{4}$ & - & $1,5 \times 10^{4}$ & $0,5 \times 10^{4}$ & $6,0 \times 10^{4}$ & $1,0 \times 10^{4}$ & - \\
\hline & 5 & 0,99 & - & - & $1,5 \times 10^{4}$ & - & $2,5 \times 10^{4}$ & $3,0 \times 10^{4}$ & $1,5 \times 10^{4}$ & - & - \\
\hline & 6 & 0,99 & - & - & $1,5 \times 10^{4}$ & - & $1,0 \times 10^{4}$ & $1,0 \times 10^{4}$ & $4,0 \times 10^{4}$ & $1,5 \times 10^{4}$ & - \\
\hline & 8 & 0,99 & $1,5 \times 10^{4}$ & - & $0,5 \times 10^{4}$ & - & $1,5 \times 10^{4}$ & - & $5,0 \times 10^{4}$ & - & - \\
\hline
\end{tabular}

FNE - Fungo não esporulado

UFC - Unidade Formadora de Colônia 
Tabela A3 - Fungos anemófilos (UFC/m ${ }^{3}$ ) isolados da área de plantio do amendoim, da variedade Runner IAC-Caiapó, na Região de Tupã - SP, no período de dezembro de 2005 a março de 2006.

\begin{tabular}{|c|c|c|c|c|c|c|c|c|c|}
\hline \multirow{2}{*}{$\begin{array}{l}\text { Runner } \\
\text { IAC-Caiapó }\end{array}$} & \multicolumn{9}{|c|}{ UFC $/ \mathrm{m}^{3}$} \\
\hline & $\begin{array}{c}\text { Fusarium } \\
\text { spp }\end{array}$ & A. flavus & A. terreus & A. niger & A. parasiticus & $\begin{array}{c}\text { Mucor } \\
\text { spp }\end{array}$ & $\begin{array}{c}\text { Rhizopus } \\
\text { spp }\end{array}$ & $\begin{array}{c}\text { Alternaria } \\
\text { spp }\end{array}$ & $\begin{array}{c}\text { Cladosporium } \\
\text { spp }\end{array}$ \\
\hline \multicolumn{10}{|l|}{ Coletas } \\
\hline $1^{\circ}$ Coleta & 3,2 & 0,2 & 0,4 & - & - & 0,3 & 0 & 0,6 & 0,1 \\
\hline $2^{\circ}$ Coleta & 1,9 & 0,1 & - & 4,8 & - & 1,1 & 0,1 & 15,5 & 9,3 \\
\hline $3^{\circ}$ Coleta & 0,4 & 1,4 & - & 52,4 & 0,2 & 1,2 & 0,2 & 36,0 & 14,0 \\
\hline $4^{\circ}$ Coleta & 0,6 & 0,2 & - & - & - & 7,0 & - & 1038,4 & 68,2 \\
\hline $5^{\circ}$ Coleta & 13,6 & - & - & - & - & - & 0,4 & - & 15,2 \\
\hline
\end{tabular}

UFC - Unidade Formadora de Colônia 
Tabela A4 - Fungos anemófilos (UFC/ $\mathrm{m}^{3}$ ) isolados da área de plantio do amendoim, da variedade Runner IAC 886, na Região de Tupã - SP, no período de dezembro de 2005 a março de 2006.

\begin{tabular}{|c|c|c|c|c|c|c|c|c|c|}
\hline \multirow{2}{*}{$\begin{array}{l}\text { Runner } \\
\text { IAC } 886\end{array}$} & \multicolumn{9}{|c|}{ UFC $/ \mathrm{m}^{3}$} \\
\hline & $\begin{array}{c}\text { Fusarium } \\
\text { spp }\end{array}$ & A. flavus & $\begin{array}{c}\text { Curvularia } \\
\text { spp }\end{array}$ & A. niger & $\begin{array}{c}\text { Penicillium } \\
\text { spp }\end{array}$ & $\begin{array}{c}\text { Mucor } \\
\text { spp }\end{array}$ & $\begin{array}{c}\text { Rhizopus } \\
\text { spp }\end{array}$ & $\begin{array}{c}\text { Alternaria } \\
\text { spp }\end{array}$ & $\begin{array}{c}\text { Cladosporium } \\
\text { spp }\end{array}$ \\
\hline \multicolumn{10}{|l|}{ Coletas } \\
\hline $1^{\circ}$ Coleta & 0,9 & - & 0,3 & - & 0,5 & - & - & 0,8 & 1,1 \\
\hline $2^{\circ}$ Coleta & 0,2 & - & - & 7,7 & 0,3 & 0,7 & 0,1 & 4,7 & 3,5 \\
\hline $3^{\circ}$ Coleta & 0,8 & 2,2 & 5,4 & 19,0 & - & 4,4 & 0,2 & 21,8 & 1,2 \\
\hline $4^{\circ}$ Coleta & 0,2 & - & - & - & - & - & 0,4 & 1763,4 & 137,8 \\
\hline $5^{\circ}$ Coleta & - & - & - & - & - & 1,0 & 0,4 & 297,2 & 68,0 \\
\hline
\end{tabular}

UFC - Unidade Formadora de Colônia 
Tabela A5 - Atividade de água (Aa) e frequência de isolamento fúngico nas amostras de flor, ginóforo e grãos de amendoim da variedade Runner IACCaiapó, colhidos na Região de Tupã - SP, no período de outubro de 2005 a março de 2006.

\begin{tabular}{|c|c|c|c|c|c|c|c|c|c|c|}
\hline & \multirow{2}{*}{$\begin{array}{l}\text { Amostra } \\
\text { Runner } \\
\text { IAC-Caiapó }\end{array}$} & \multirow{2}{*}{$\begin{array}{l}\text { Atividade } \\
\text { de Água } \\
\text { (Aa) }\end{array}$} & \multicolumn{8}{|c|}{ (\%) } \\
\hline & & & $\begin{array}{c}\text { Fusarium } \\
\text { spp }\end{array}$ & A. flavus & A. niger & $\begin{array}{l}\text { Trichoderma } \\
\text { spp }\end{array}$ & $\begin{array}{c}\text { Mucor } \\
\text { spp }\end{array}$ & $\begin{array}{l}\text { Penicillium } \\
\text { spp }\end{array}$ & $\begin{array}{l}\text { Alternaria } \\
\text { spp }\end{array}$ & $\begin{array}{c}\text { Cladosporium } \\
\text { spp }\end{array}$ \\
\hline Coletas & Parcelas & & & & & & & & & \\
\hline $\begin{array}{c}1^{\circ} \text { (Sementes no } \\
\text { plantio) }\end{array}$ & - & 0,66 & 3,03 & - & - & - & - & 3,03 & - & - \\
\hline \multirow{5}{*}{$\begin{array}{l}2^{\circ} \\
\text { (Flor) }\end{array}$} & 1 & 0,84 & 12,12 & - & - & - & 9,09 & 3,03 & 12,12 & - \\
\hline & 5 & 0,93 & 33,33 & - & - & - & 6,06 & 3,03 & - & - \\
\hline & 8 & 0,94 & 36,4 & - & - & 3,03 & 6,06 & - & - & 3,03 \\
\hline & 9 & 0,93 & 24,24 & 3,03 & - & - & 6,06 & - & - & - \\
\hline & 10 & 0,89 & 3,03 & - & - & - & 3,03 & 3,03 & - & 3,03 \\
\hline \multirow{5}{*}{$\begin{array}{c}3^{\circ} \\
\text { (Ginóforo) }\end{array}$} & 2 & 0,98 & 75,00 & - & - & - & - & - & - & - \\
\hline & 4 & 0,97 & 62,50 & - & - & - & - & - & 3,12 & - \\
\hline & 6 & 0,97 & 84,37 & - & - & - & - & - & - & - \\
\hline & 7 & 0,97 & 90,62 & - & - & - & - & - & 6,25 & - \\
\hline & 9 & 0,97 & 100 & - & - & - & - & - & - & - \\
\hline \multirow{5}{*}{$\begin{array}{l}\text { (Grãos/ } \\
\text { Fase água) }\end{array}$} & 3 & 0,99 & - & - & - & - & - & - & - & - \\
\hline & 4 & 0,99 & 3,03 & 3,03 & - & - & - & - & - & - \\
\hline & 5 & 0,99 & - & - & - & - & - & - & - & - \\
\hline & 6 & 0,98 & - & - & - & - & - & - & - & - \\
\hline & 10 & 0,98 & 18,00 & - & - & - & - & - & - & - \\
\hline \multirow{5}{*}{$\begin{array}{c}\text { (Grãos/ } \\
\text { inìcio da } \\
\text { granação }\end{array}$} & 2 & 0,99 & - & - & - & - & - & 27,27 & - & - \\
\hline & 4 & 0,99 & - & - & - & - & - & - & - & - \\
\hline & 6 & 0,99 & 3,03 & - & - & - & 6,06 & - & - & - \\
\hline & 7 & 0,99 & - & - & - & - & - & 90,90 & - & - \\
\hline & 9 & 0,99 & - & - & - & - & - & 90,90 & - & - \\
\hline \multirow{5}{*}{$\begin{array}{c}5^{\circ} \\
\text { (Grãos/ } \\
\text { Grãos maduros) }\end{array}$} & 3 & 0,99 & - & 27,27 & - & - & - & 57,58 & - & - \\
\hline & 4 & 0,99 & 9,09 & 27,27 & - & - & - & - & - & - \\
\hline & 7 & 0,97 & 15,15 & 6,06 & - & - & - & 3,03 & - & - \\
\hline & 8 & 0,99 & - & - & 30,3 & - & - & - & - & - \\
\hline & 10 & 0,99 & 30,3 & - & - & - & - & - & - & - \\
\hline \multirow{5}{*}{$\begin{array}{c}6^{\circ} \\
\text { (Grãos/ } \\
\text { Grãos secos) }\end{array}$} & 1 & 0,81 & 100 & - & - & - & - & - & - & - \\
\hline & 3 & 077 & 84,85 & 9,09 & - & - & - & - & 6,06 & - \\
\hline & 5 & 0,73 & 84,80 & - & - & - & - & - & - & - \\
\hline & 7 & 082 & 48,48 & - & - & - & 9,09 & - & - & - \\
\hline & 9 & 072 & 39,39 & - & - & - & - & - & - & - \\
\hline
\end{tabular}


Tabela A6 - Atividade de água (Aa) e frequência de isolamento fúngico nas amostras de cascas de amendoim da variedade Runner IAC-Caiapó, coletados no campo, na Região de Tupã - SP, no período de fevereiro a março de 2006.

\begin{tabular}{|c|c|c|c|c|c|c|c|c|c|c|c|}
\hline & \multirow{2}{*}{$\begin{array}{l}\text { Amostra } \\
\text { Runner } \\
\text { IAC-Caiapó }\end{array}$} & \multirow{2}{*}{$\begin{array}{c}\text { Atividade } \\
\text { de Água } \\
\text { (Aa) }\end{array}$} & \multicolumn{9}{|c|}{ (\%) } \\
\hline & & & $\begin{array}{l}\text { Fusarium } \\
\text { spp }\end{array}$ & A. flavus & A. parasiticus & A. niger & A. terreus & $\begin{array}{l}\text { Mucor } \\
\text { spp }\end{array}$ & $\begin{array}{l}\text { Penicillium } \\
\text { spp }\end{array}$ & $\begin{array}{l}\text { Alternaria } \\
\text { spp }\end{array}$ & $\begin{array}{c}\text { Nigrospora } \\
\text { spp }\end{array}$ \\
\hline \multirow[t]{2}{*}{ Coletas } & Parcelas & & & & & & & & & & \\
\hline & 3 & 0,99 & 87,50 & - & - & - & - & - & $\overline{-1}$ & - & - \\
\hline \multirow{4}{*}{$\begin{array}{l}\text { (Cascas/ } \\
\text { Fase água) }\end{array}$} & 4 & 0,99 & 81,25 & 12,50 & 6,25 & - & - & - & - & - & - \\
\hline & 5 & 0,99 & 93,75 & - & - & - & - & - & - & - & 6,25 \\
\hline & 6 & 0,99 & 75,00 & - & - & - & - & - & - & - & - \\
\hline & 10 & 0,99 & 75,00 & - & - & - & - & - & - & - & - \\
\hline \multirow{5}{*}{$\begin{array}{l}\text { (Cascas/ } \\
\text { inicio da } \\
\text { granação) }\end{array}$} & 2 & 0,99 & 62,50 & 12,50 & - & - & - & - & - & - & 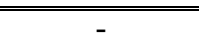 \\
\hline & 4 & 0,99 & 12,50 & - & - & 6,25 & 6,25 & - & - & - & - \\
\hline & 5 & 0,99 & 37,50 & - & - & - & - & - & - & - & - \\
\hline & 8 & 0,99 & 6,25 & - & - & - & - & - & 93,75 & - & - \\
\hline & 10 & 0,99 & 6,25 & - & - & - & - & - & - & - & - \\
\hline \multirow{5}{*}{$\begin{array}{c}5^{\circ} \\
\text { (Cascas/ } \\
\text { Grãos } \\
\text { maduros) }\end{array}$} & 3 & 0,99 & 87,6 & - & - & - & - & 12,50 & - & - & - \\
\hline & 4 & 0,99 & 75,00 & - & - & - & - & - & - & - & - \\
\hline & 7 & 0,97 & 68,75 & 6,25 & - & - & - & - & - & - & - \\
\hline & 8 & 0,99 & 93,7 & - & - & - & - & - & - & - & - \\
\hline & 10 & 0,99 & 75,00 & - & - & - & - & - & - & - & - \\
\hline \multirow{5}{*}{$\begin{array}{c}6^{\circ} \\
\text { (Cascas/ } \\
\text { Grãos secos) }\end{array}$} & 1 & 0,66 & 100 & - & - & - & - & - & - & $6,6,25$ & - \\
\hline & 3 & 0,60 & 87,50 & - & - & - & - & - & - & 12,50 & - \\
\hline & 5 & 0,60 & 100 & - & - & - & - & - & - & - & - \\
\hline & 7 & 0,78 & 100 & - & - & - & - & - & - & 5,26 & - \\
\hline & 9 & 0,60 & 93,75 & - & - & - & - & - & - & 12,50 & 6,25 \\
\hline
\end{tabular}

FNE - Fungo não esporulado 
Tabela A7 - Atividade de água (Aa) e frequência de isolamento fúngico nas amostras de flor, ginóforo e grãos de amendoim da variedade Runner IAC 886, colhidos na Região de Tupã - SP, no período de outubro de 2005 a março de 2006.

\begin{tabular}{|c|c|c|c|c|c|c|c|c|c|}
\hline & \multirow{2}{*}{$\begin{array}{l}\text { Amostra } \\
\text { Runner } \\
\text { IAC } 886\end{array}$} & \multirow{2}{*}{$\begin{array}{c}\text { Atividade } \\
\text { de Água } \\
\text { (Aa) }\end{array}$} & \multicolumn{7}{|c|}{ (\%) } \\
\hline & & & $\begin{array}{c}\text { Fusarium } \\
\text { spp }\end{array}$ & A. flavus & A.parasiticus & $\begin{array}{l}\text { Rhizopus } \\
\text { spp }\end{array}$ & $\begin{array}{l}\text { Mucor } \\
\text { spp }\end{array}$ & $\begin{array}{c}\text { Penicillium } \\
\text { spp }\end{array}$ & $\begin{array}{c}\text { Cladosporium } \\
\text { spp }\end{array}$ \\
\hline Coletas & Parcelas & & & & & & & & \\
\hline $\begin{array}{c}1^{\circ} \text { (Sementes no } \\
\text { plantio) }\end{array}$ & & 0,65 & - & 12,12 & 3,03 & - & - & - & - \\
\hline \multirow{5}{*}{$\begin{array}{l}2^{\circ} \\
\text { (Flor) }\end{array}$} & 3 & 0,87 & 33,33 & - & - & - & 3,03 & 3,03 & 3,03 \\
\hline & 4 & 0,89 & 36,36 & 3,03 & - & - & - & - & - \\
\hline & 5 & 0,91 & 54,5 & - & - & - & 3,03 & - & - \\
\hline & 6 & 0,92 & 24,24 & - & - & 3,03 & - & - & - \\
\hline & 8 & 091 & 21,21 & - & - & - & - & - & - \\
\hline \multirow{5}{*}{$\begin{array}{c}3^{\circ} \\
\text { (Ginóforo) }\end{array}$} & 1 & 0,97 & 256,25 & - & - & - & - & - & - \\
\hline & 2 & 0,97 & 62,50 & - & - & - & - & - & - \\
\hline & 6 & 0,97 & 100 & - & - & - & - & - & - \\
\hline & 7 & 0,97 & 100 & - & - & - & - & 6,25 & 3,12 \\
\hline & 9 & 0,97 & 100 & - & - & - & - & - & - \\
\hline \multirow{5}{*}{$\begin{array}{c}\text { (Grãos/ } \\
\text { /Fase água) }\end{array}$} & 2 & 0,98 & 3,03 & - & - & - & - & 6,06 & - \\
\hline & 4 & 0,98 & 3,03 & - & - & - & - & 6,06 & - \\
\hline & 5 & 0,98 & 9,09 & - & - & - & - & 3,03 & - \\
\hline & 8 & 0,98 & - & - & - & - & - & - & - \\
\hline & 10 & 0,98 & 57,60 & - & - & - & - & - & - \\
\hline \multirow{5}{*}{$\begin{array}{l}\text { (Grãos/ inìcio } \\
\text { da granação) }\end{array}$} & 1 & 0,98 & 27,27 & - & - & - & - & 84,8 & - \\
\hline & 2 & 0,99 & - & - & - & - & - & 60,61 & - \\
\hline & 6 & 0,99 & - & - & - & - & - & 60,61 & - \\
\hline & 7 & 0,99 & 9,09 & - & - & - & - & 84,85 & - \\
\hline & 9 & 0,99 & - & - & - & - & - & - & - \\
\hline \multirow{5}{*}{$\begin{array}{c}5^{\circ} \\
\text { (Grãos/ } \\
\text { Grãos maduros) }\end{array}$} & 3 & 0,98 & 699,70 & - & - & - & - & - & - \\
\hline & 4 & 0,99 & 54,54 & 18,18 & - & - & - & - & - \\
\hline & 5 & 0,99 & 24,20 & - & - & - & - & - & - \\
\hline & 6 & 0,98 & 54,50 & - & - & - & - & - & - \\
\hline & 8 & 0,97 & 3,03 & - & - & - & - & - & - \\
\hline \multirow{5}{*}{$\begin{array}{c}6^{\circ} \\
\text { (Grãos/ } \\
\text { Grãos secos) }\end{array}$} & 3 & 0,64 & 30,30 & - & - & - & - & - & - \\
\hline & 4 & 0,63 & - & 3,03 & - & - & - & 6,06 & - \\
\hline & 5 & 0,62 & 3,03 & 9,09 & - & - & - & - & - \\
\hline & 6 & 0,60 & - & - & - & - & - & - & - \\
\hline & 7 & 0,61 & 9,09 & 6,06 & - & - & - & 3,03 & - \\
\hline
\end{tabular}

$\overline{\text { FNE - Fungo não esporulado }}$ 
Tabela A8 - Atividade de água (Aa) e frequência de isolamento fúngico nas amostras de cascas de amendoim da variedade Runner IAC 886, coletados no campo, na Região de Tupã - SP, no período de fevereiro a março de 2006.

\begin{tabular}{|c|c|c|c|c|c|c|c|c|c|c|}
\hline & \multirow{2}{*}{$\begin{array}{l}\text { Amostra } \\
\text { Runner } \\
\text { IAC } 886\end{array}$} & \multirow{2}{*}{$\begin{array}{l}\text { Atividade } \\
\text { de Água } \\
\text { (Aa) }\end{array}$} & \multicolumn{8}{|c|}{ (\%) } \\
\hline & & & $\begin{array}{c}\text { Fusarium } \\
\text { spp }\end{array}$ & A. flavus & $\begin{array}{c}\text { Pestalostiopsis } \\
\text { spp }\end{array}$ & FNE & $\begin{array}{l}\text { Mucor } \\
\text { spp }\end{array}$ & $\begin{array}{l}\text { Penicillium } \\
\text { spp }\end{array}$ & $\begin{array}{c}\text { Alternaria } \\
\text { spp }\end{array}$ & $\begin{array}{c}\text { Trichoderma } \\
\text { spp }\end{array}$ \\
\hline Coletas & Parcelas & & & & & & & & & \\
\hline \multirow{5}{*}{$\begin{array}{c}\text { (Cascas/ } \\
\text { Fase água) }\end{array}$} & 2 & 0,99 & 250,00 & & - & - & 12,50 & - & - & - \\
\hline & 4 & 0,98 & 93,75 & 6,25 & - & - & - & 12,5 & - & 6,25 \\
\hline & 5 & 0,99 & 100 & - & - & - & - & - & - & - \\
\hline & 8 & 0,99 & 37,50 & 6,25 & - & - & - & - & - & 6,25 \\
\hline & 10 & 0,99 & 93,70 & - & - & - & - & - & - & - \\
\hline \multirow{5}{*}{$\begin{array}{l}\text { (Casca/ inìcio } \\
\text { da granação) }\end{array}$} & 2 & 0,99 & 25,00 & - & - & - & - & 250,00 & - & - \\
\hline & 4 & 0,99 & 43,75 & - & - & - & - & 93,75 & - & - \\
\hline & 5 & 0,99 & 37,50 & - & - & - & - & 81,25 & - & - \\
\hline & 8 & 0,99 & 56,25 & - & - & - & - & 75,00 & - & - \\
\hline & 10 & 0,99 & 18,75 & - & - & - & - & 75,00 & - & - \\
\hline \multirow{5}{*}{$\begin{array}{c}5^{\circ} \\
\text { (Casca/ } \\
\text { Grãos maduros) }\end{array}$} & 3 & 0,98 & 75,00 & - & - & - & - & - & - & - \\
\hline & 4 & 0,99 & 75,00 & - & - & - & - & - & - & - \\
\hline & 5 & 0,99 & 87,50 & - & - & - & - & - & - & - \\
\hline & 6 & 0,98 & 100 & - & - & - & - & - & - & - \\
\hline & 8 & 0,97 & 81,20 & - & - & - & - & - & - & - \\
\hline \multirow{5}{*}{$\begin{array}{c}6^{\circ} \\
\text { (Casca/ } \\
\text { Grãos secos) }\end{array}$} & 3 & 0,61 & 37,50 & 25,00 & - & - & - & - & - & - \\
\hline & 4 & 0,59 & 93,75 & 12,50 & - & 12,50 & - & - & - & - \\
\hline & 5 & 0,58 & - & 62,5 & 6,25 & - & - & 6,25 & 12,50 & - \\
\hline & 6 & 0,64 & 56,25 & 25,00 & - & - & - & - & - & - \\
\hline & 7 & 0,58 & 43,75 & 37,50 & - & - & - & - & - & - \\
\hline
\end{tabular}

FNE - Fungo não esporulado 
Tabela A9 - Temperatura (ํㅡ) registrada no período experimental de campo, de outubro de 2005 a março de 2006, na região de Tupã.

\begin{tabular}{|c|c|c|c|c|c|c|c|c|c|c|c|c|c|c|c|c|c|c|}
\hline \multirow[t]{2}{*}{ Dia } & \multicolumn{3}{|c|}{ Outubro /2005 } & \multicolumn{3}{|c|}{ Novembro /2005 } & \multicolumn{3}{|c|}{ Dezembro / 2005} & \multicolumn{3}{|c|}{ Janeiro / 2006} & \multicolumn{3}{|c|}{ Fevereiro / 2006} & \multicolumn{3}{|c|}{ Março /2006 } \\
\hline & Máx & Mín & Méd & Max & Mín & Méd & Máx & Mín & Méd & Máx & Mín & Méd & Máx & Mín & Méd & Máx & Mín & Méd \\
\hline 1 & 28,40 & 22,00 & 25,20 & 28,50 & 17,00 & 22,75 & 24,50 & 21,50 & 23,00 & 30,41 & 20,39 & 25,26 & 32,00 & 20,80 & 26,40 & 34,00 & 21,90 & 27,95 \\
\hline 2 & 31,20 & 20,00 & 25,60 & 30,00 & 15,00 & 22,50 & 27,00 & 22,00 & 24,50 & 30,00 & 20,70 & 25,35 & 33,00 & 20,80 & 26,80 & 35,00 & 21,80 & 28,40 \\
\hline 3 & 33,00 & 22,00 & 27,50 & 33,00 & 16,50 & 24,75 & 26,50 & 18,00 & 22,25 & 32,00 & 21,20 & 26,60 & 34,00 & 22,40 & 28,20 & 36,60 & 22,80 & 29,70 \\
\hline 4 & 37,50 & 24,00 & 30,75 & 30,00 & 21,00 & 25,50 & 31,50 & 17,50 & 24,50 & 30,00 & 21,40 & 25,70 & 35,00 & 21,50 & 28,25 & 35,60 & 23,40 & 29,50 \\
\hline 5 & 27,50 & 20,00 & 23,75 & 35,00 & 19,50 & 27,25 & 31,00 & 19,50 & 25,25 & 27,50 & 19,20 & 23,35 & 34,00 & 21,00 & 27,50 & 32,20 & 21,90 & 27,05 \\
\hline 6 & 32,00 & 19,50 & 25,75 & 36,00 & 21,00 & 28,50 & 25,00 & 20,00 & 22,50 & 29,00 & 18,80 & 23,90 & 36,00 & 22,00 & 29,00 & 32,00 & 20,60 & 26,30 \\
\hline 7 & 35,00 & 18,50 & 26,75 & 35,50 & 21,00 & 28,25 & 27,50 & 21,00 & 24,25 & 31,00 & 20,50 & 25,75 & 33,50 & 22,60 & 28,05 & 31,00 & 20,60 & 25,80 \\
\hline 8 & 33,50 & 20,00 & 26,75 & 32,00 & 20,00 & 26,00 & 28,00 & 17,00 & 22,50 & 32,00 & 21,50 & 26,75 & 32,00 & 23,20 & 27,75 & 33,00 & 20,60 & 26,80 \\
\hline 9 & 32,50 & 17,50 & 25,00 & 29,00 & 18,00 & 23,50 & 32,00 & 18,50 & 25,25 & 33,50 & 21,00 & 27,25 & 29,00 & 21,00 & 25,00 & 33,80 & 22,20 & 28,00 \\
\hline 10 & 36,00 & 18,00 & 27,00 & 31,50 & 18,00 & 24,75 & 34,50 & 22,00 & 28,25 & 34,00 & 23,00 & 28,50 & 25,82 & 21,20 & 23,51 & 32,00 & 21,20 & 26,60 \\
\hline 11 & 35,50 & 20,00 & 27,75 & 30,50 & 16,00 & 23,25 & 31,00 & 20,00 & 25,50 & 35,00 & 22,00 & 28,50 & 28,30 & 21,17 & 24,73 & 31,00 & 20,00 & 25,50 \\
\hline 12 & 35,00 & 19,00 & 27,00 & 32,50 & 17,00 & 24,75 & 31,00 & 18,00 & 24,50 & 32,50 & 19,00 & 25,75 & 32,10 & 20,94 & 26,52 & 31,00 & 18,00 & 24,50 \\
\hline 13 & 37,00 & 18,50 & 27,75 & 34,00 & 18,50 & 26,25 & 32,00 & 20,00 & 26,00 & 33,50 & 21,50 & 27,50 & 31,50 & 19,86 & 25,68 & 32,00 & 17,00 & 24,50 \\
\hline 14 & 35,00 & 20,00 & 27,50 & 36,00 & 20,50 & 28,25 & 32,50 & 21,00 & 26,75 & 34,50 & 20,00 & 27,25 & 33,00 & 20,20 & 26,60 & 32,00 & 20,80 & 26,40 \\
\hline 15 & 32,00 & 22,00 & 27,00 & 37,00 & 22,00 & 29,50 & 33,00 & 16,50 & 24,75 & 36,00 & 21,00 & 28,50 & 34,00 & 22,60 & 28,30 & 32,60 & 21,60 & 27,10 \\
\hline 16 & 32,50 & 21,00 & 26,75 & 37,00 & 20,50 & 28,75 & 34,00 & 16,50 & 25,25 & 37,00 & 20,50 & 28,75 & 28,40 & 21,20 & 24,80 & 31,40 & 21,20 & 26,30 \\
\hline 17 & 32,00 & 22,00 & 27,00 & 35,00 & 24,00 & 29,50 & 32,50 & 21,00 & 26,75 & 38,00 & 24,00 & 31,00 & 29,00 & 20,80 & 24,90 & 29,00 & 22,60 & 25,80 \\
\hline 18 & 23,50 & 23,00 & 23,25 & 32,00 & 21,50 & 26,75 & 31,50 & 20,00 & 25,75 & 34,00 & 22,00 & 28,00 & 31,00 & 22,50 & 26,75 & 28,80 & 22,00 & 25,40 \\
\hline 19 & 23,00 & 20,00 & 21,50 & 32,00 & 20,50 & 26,25 & 27,50 & 18,50 & 23,00 & 35,50 & 24,00 & 29,75 & 30,00 & 20,80 & 22,80 & 32,00 & 22,00 & 27,00 \\
\hline 20 & 26,00 & 19,00 & 22,50 & 36,00 & 20,50 & 28,25 & 31,50 & 19,00 & 25,25 & 35,00 & 21,00 & 28,00 & 29,00 & 19,80 & 24,40 & 32,00 & 21,00 & 26,50 \\
\hline 21 & 35,00 & 18,50 & 26,75 & 33,00 & 20,00 & 26,50 & 33,00 & 21,00 & 27,00 & 34,00 & 23,00 & 28,50 & 31,50 & 19,80 & 25,65 & 31,00 & 22,80 & 26,90 \\
\hline 22 & 28,50 & 20,11 & 24,30 & 34,00 & 20,00 & 27,00 & 34,50 & 20,00 & 27,25 & 37,00 & 22,00 & 29,50 & 29,00 & 19,00 & 24,00 & 33,20 & 20,60 & 26,90 \\
\hline 23 & 34,00 & 22,00 & 28,00 & 33,00 & 22,00 & 27,50 & 33,50 & 20,00 & 26,75 & 36,00 & 24,00 & 30,00 & 32,20 & 19,20 & 25,70 & 30,60 & 20,40 & 25,50 \\
\hline 24 & 33,00 & 20,00 & 26,50 & 31,00 & 23,00 & 27,00 & 34,00 & 22,00 & 28,00 & 37,00 & 22,00 & 29,50 & 28,20 & 19,80 & 24,00 & 30,70 & 21,20 & 25,95 \\
\hline 25 & 33,00 & 22,00 & 27,50 & 32,00 & 23,00 & 27,50 & 32,00 & 21,00 & 26,50 & 36,00 & 23,00 & 29,50 & 28,80 & 19,30 & 24,05 & 27,80 & 20,70 & 24,25 \\
\hline 26 & 33,00 & 24,00 & 28,50 & 26,00 & 19,00 & 22,50 & 33,00 & 19,50 & 26,25 & 32,00 & 21,20 & 26,60 & 31,00 & 17,20 & 24,10 & 27,90 & 20,60 & 24,25 \\
\hline 27 & 33,00 & 20,00 & 26,50 & 32,00 & 16,00 & 24,00 & 34,00 & 21,50 & 27,75 & 30,00 & 22,40 & 26,20 & 34,20 & 19,00 & 26,60 & 30,00 & 20,70 & 25,35 \\
\hline 28 & 34,00 & 19,50 & 26,75 & 34,00 & 18,50 & 26,25 & 34,00 & 20,00 & 27,00 & 31,00 & 21,00 & 26,00 & 34,30 & 21,00 & 27,65 & 31,60 & 21,00 & 26,30 \\
\hline 29 & 24,50 & 18,50 & 21,50 & 34,00 & 24,00 & 29,00 & 34,60 & 19,00 & 26,80 & 22,00 & 20,00 & 21,00 & - & - & - & 27,00 & 22,00 & 24,50 \\
\hline 30 & 27,50 & 20,00 & 23,75 & 28,50 & 22,00 & 25,25 & 32,50 & 20,10 & 26,30 & 29,50 & 18,00 & 23,75 & - & - & - & 30,00 & 19,20 & 24,60 \\
\hline 31 & 27,00 & 17,50 & 22,25 & - & - & & 32,00 & 20,10 & 26,05 & 32,00 & 19,50 & 25,75 & - & - & - & 31,14 & 18,40 & 24,77 \\
\hline Média & 31,63 & 18,00 & 25,95 & 32,67 & 19,85 & 26,27 & 31,33 & 19,73 & 24,69 & 32,80 & 21,25 & 27,02 & 31,42 & 20,74 & 25,99 & 31,55 & 20,99 & 26,27 \\
\hline
\end{tabular}


Tabela A10 - Umidade Relativa do ar (\%), registrada no período de outubro de 2005 a setembro de 2006, na região de Tupã.

\begin{tabular}{|c|c|c|c|c|c|c|c|c|c|c|c|c|}
\hline Dia & $\begin{array}{l}\text { Out/ } \\
2005\end{array}$ & $\begin{array}{l}\text { Nov/ } \\
2005\end{array}$ & $\begin{array}{l}\text { Dez/ } \\
2005\end{array}$ & $\begin{array}{l}\text { Jan/ } \\
2006\end{array}$ & $\begin{array}{l}\mathrm{Fev} / \\
2006\end{array}$ & $\begin{array}{l}\text { Mar/ } \\
2006\end{array}$ & $\begin{array}{l}\text { Abr/ } \\
2006\end{array}$ & $\begin{array}{l}\text { Mai/ } \\
2006\end{array}$ & $\begin{array}{l}\text { Jun/ } \\
2006\end{array}$ & $\begin{array}{c}\text { Jul/ } \\
2006\end{array}$ & $\begin{array}{c}\text { Ago / } \\
2006\end{array}$ & $\begin{array}{l}\text { Set/ } \\
2006\end{array}$ \\
\hline 1 & 70,00 & 60,00 & 70,00 & 65,00 & 65,00 & 60,00 & 90,00 & 95,00 & 97,00 & 87,00 & 98,00 & 90,00 \\
\hline 2 & 60,00 & 70,00 & 75,00 & 72,00 & 67,00 & 68,00 & 85,00 & 85,00 & 86,00 & 83,00 & 90,00 & 100,00 \\
\hline 3 & 55,00 & 60,00 & 45,00 & 73,00 & 65,00 & 70,00 & 90,00 & 85,00 & 90,00 & 98,00 & 100,00 & 86,00 \\
\hline 4 & 54,00 & 60,00 & 60,00 & 70,00 & 65,00 & 75,00 & 69,00 & 84,00 & 65,00 & 75,00 & 74,00 & 61,00 \\
\hline 5 & 70,00 & 55,00 & 65,00 & 75,00 & 65,00 & 91,00 & 84,00 & 85,00 & 95,00 & 90,00 & 65,00 & 58,00 \\
\hline 6 & 75,00 & 45,00 & 75,00 & 70,00 & 76,00 & 95,00 & 97,00 & 87,00 & 77,00 & 84,00 & 47,00 & 64,00 \\
\hline 7 & 65,00 & 60,00 & 60,00 & 70,00 & 68,00 & 90,00 & 95,00 & 95,00 & 75,00 & 71,00 & 45,00 & 80,00 \\
\hline 8 & 60,00 & 57,00 & 60,00 & 55,00 & 65,00 & 85,00 & 95,00 & 90,00 & 63,00 & 62,00 & 53,00 & 75,00 \\
\hline 9 & 60,00 & 60,00 & 65,00 & 70,00 & 75,00 & 80,00 & 99,00 & 99,00 & 77,00 & 65,00 & 52,00 & 55,00 \\
\hline 10 & 65,00 & 60,00 & 47,00 & 55,00 & 78,00 & 90,00 & 97,00 & 96,00 & 65,00 & 90,00 & 44,00 & 67,00 \\
\hline 11 & 55,00 & 57,00 & 43,00 & 60,00 & 75,00 & 65,00 & 100,00 & 100,00 & 85,00 & 86,00 & 47,00 & 52,00 \\
\hline 12 & 55,00 & 50,00 & 46,00 & 65,00 & 78,00 & 65,00 & 92,00 & 75,00 & 80,00 & 74,00 & 48,00 & 45,00 \\
\hline 13 & 50,00 & 50,00 & 60,00 & 55,00 & 79,00 & 75,00 & 88,00 & 80,00 & 99,00 & 55,00 & 52,00 & 46,00 \\
\hline 14 & 55,00 & 45,00 & 60,00 & 40,00 & 62,00 & 72,00 & 70,00 & 65,00 & 55,00 & 63,00 & 46,00 & 37,00 \\
\hline 15 & 65,00 & 45,00 & 60,00 & 45,00 & 60,00 & 77,00 & 68,00 & 90,00 & 82,00 & 90,00 & 46,00 & 40,00 \\
\hline 16 & 70,00 & 50,00 & 53,00 & 50,00 & 76,00 & 79,00 & 70,00 & 100,00 & 97,00 & 75,00 & 46,00 & 98,00 \\
\hline 17 & 75,00 & 55,00 & 60,00 & 60,00 & 76,00 & 85,00 & 75,00 & 93,00 & 77,00 & 85,00 & 95,00 & 96,00 \\
\hline 18 & 70,00 & 75,00 & 65,00 & 60,00 & 77,00 & 87,00 & 86,00 & 79,00 & 93,00 & 90,00 & 89,00 & 81,00 \\
\hline 19 & 75,00 & 75,00 & 70,00 & 60,00 & 74,00 & 86,00 & 83,00 & 66,00 & 90,00 & 96,00 & 100,00 & 75,00 \\
\hline 20 & 70,00 & 50,00 & 70,00 & 70,00 & 70,00 & 90,00 & 70,00 & 100,00 & 78,00 & 91,00 & 64,00 & 71,00 \\
\hline 21 & 70,00 & 55,00 & 75,00 & 50,00 & 67,00 & 83,00 & 60,00 & 100,00 & 64,00 & 58,00 & 66,00 & 100,00 \\
\hline 22 & 75,00 & 47,00 & 70,00 & 60,00 & 78,00 & 80,00 & 81,00 & 100,00 & 67,00 & 57,00 & 66,00 & 91,00 \\
\hline 23 & 60,00 & 70,00 & 50,00 & 60,00 & 85,00 & 94,00 & 75,00 & 90,00 & 62,00 & 52,00 & 57,00 & 97,00 \\
\hline 24 & 65,00 & 70,00 & 50,00 & 64,00 & 95,00 & 96,00 & 71,00 & 88,00 & 78,00 & 46,00 & 45,00 & 100,00 \\
\hline 25 & 60,00 & 70,00 & 60,00 & 60,00 & 81,00 & 98,00 & 55,00 & 86,00 & 67,00 & 55,00 & 36,00 & 95,00 \\
\hline 26 & 70,00 & 50,00 & 55,00 & 75,00 & 65,00 & 98,00 & 85,00 & 80,00 & 100,00 & 64,00 & 42,00 & 70,00 \\
\hline 27 & 70,00 & 65,00 & 60,00 & 75,00 & 75,00 & 78,00 & 89,00 & 80,00 & 84,00 & 43,00 & 100,00 & 75,00 \\
\hline 28 & 45,00 & 45,00 & 50,00 & 75,00 & 64,00 & 90,00 & 75,00 & 93,00 & 67,00 & 67,00 & 90,00 & 70,00 \\
\hline 29 & 75,00 & 60,00 & 55,00 & 75,00 & - & 91,00 & 85,00 & 90,00 & 100,00 & 100,00 & 72,00 & 100,00 \\
\hline 30 & 70,00 & 70,00 & 68,00 & 75,00 & - & 99,00 & 89,00 & 69,00 & 90,00 & 80,00 & 64,00 & 78,00 \\
\hline 31 & 75,00 & - & 72,00 & 72,00 & - & 81,00 & - & 75,00 & - & 100,00 & 60,00 & - \\
\hline Média & 64,81 & 58,03 & 60,45 & 63,90 & 72,36 & 83,00 & 82,27 & 87,10 & 80,17 & 75,23 & 64,48 & 75,10 \\
\hline
\end{tabular}

De outubro de 2005 à março de 2006 - Experimento no campo; De abril à setembro de 2006 - Experimento no armazém 
Tabela A11 - Precipitação pluviométrica (mm) registrada no período de outubro de 2005 a setembro de 2006, na região de Tupã.

\begin{tabular}{|c|c|c|c|c|c|c|c|c|c|c|c|c|}
\hline Dia & Outub/2005 & Nov/2005 & Dez/ 2005 & Jan/ 2006 & Fev/ 2006 & Mar/2006 & Abr/ 2006 & Mai/2006 & Jun/ 2006 & Jul/2006 & Ago / 2006 & Set/2006 \\
\hline 1 & 0,00 & 0,00 & 49,00 & 8,50 & 0,00 & 0,00 & 0,00 & 0,00 & 0,00 & 9,50 & 0,00 & 0,00 \\
\hline 2 & 0,00 & 0,00 & 0,50 & 12,80 & 0,00 & 0,00 & 0,00 & 0,00 & 0,00 & 10,80 & 0,00 & 0,00 \\
\hline 3 & 0,00 & 0,00 & 0,00 & 0,40 & 0,00 & 0,00 & 0,00 & 0,00 & 0,00 & 0,00 & 0,00 & 11,00 \\
\hline 4 & 2,00 & 0,00 & 0,00 & 21,50 & 0,00 & 4,00 & 0,00 & 0,00 & 0,30 & 0,00 & 0,00 & 0,00 \\
\hline 5 & 3,50 & 0,00 & 43,00 & 4,80 & 0,00 & 10,50 & 3,40 & 0,00 & 0,00 & 0,00 & 0,00 & 0,00 \\
\hline 6 & 0,00 & 0,00 & 6,50 & 0,00 & 0,00 & 8,60 & 1,20 & 0,00 & 0,00 & 0,00 & 0,00 & 0,00 \\
\hline 7 & 0,00 & 0,00 & 0,00 & 0,00 & 0,00 & 0,40 & 0,00 & 0,00 & 0,00 & 0,00 & 0,00 & 0,00 \\
\hline 8 & 0,00 & 0,00 & 0,00 & 1,00 & 5,60 & 0,00 & 0,00 & 0,00 & 0,00 & 0,00 & 0,00 & 0,00 \\
\hline 9 & 0,00 & 0,00 & 0,00 & 0,00 & 56,80 & 0,00 & 0,50 & 0,00 & 0,00 & 0,00 & 0,00 & 0,00 \\
\hline 10 & 0,00 & 0,00 & 0,00 & 0,00 & 14,50 & 0,00 & 0,00 & 0,00 & 0,00 & 0,00 & 0,00 & 0,00 \\
\hline 11 & 19,00 & 0,00 & 0,50 & 19,00 & 1,50 & 0,00 & 0,00 & 0,00 & 0,00 & 0,00 & 0,00 & 0,00 \\
\hline 12 & 0,00 & 0,00 & 0,00 & 0,00 & 23,00 & 0,00 & 0,00 & 0,00 & 0,00 & 0,00 & 0,00 & 0,00 \\
\hline 13 & 0,00 & 0,00 & 0,00 & 0,00 & 0,00 & 0,00 & 0,00 & 0,00 & 0,00 & 0,00 & 0,00 & 0,00 \\
\hline 14 & 0,00 & 0,00 & 0,00 & 0,00 & 0,00 & 0,00 & 0,00 & 0,00 & 0,00 & 0,00 & 0,00 & 0,00 \\
\hline 15 & 42,00 & 0,00 & 0,00 & 0,00 & 19,60 & 0,00 & 0,00 & 0,00 & 0,00 & 0,00 & 0,00 & 30,00 \\
\hline 16 & 0,00 & 0,00 & 1,50 & 0,00 & 17,60 & 0,00 & 0,00 & 0,00 & 0,00 & 0,00 & 0,00 & 0,00 \\
\hline 17 & 8,00 & 0,00 & 10,50 & 0,00 & 1,50 & 3,00 & 0,00 & 0,00 & 0,00 & 0,00 & 0,00 & 0,00 \\
\hline 18 & 10,00 & 26,00 & 18,50 & 0,00 & 17,00 & 2,50 & 0,00 & 0,00 & 0,00 & 0,00 & 0,00 & 0,00 \\
\hline 19 & 4,00 & 0,00 & 0,00 & 0,00 & 5,50 & 0,00 & 0,00 & 2,50 & 0,00 & 0,00 & 0,00 & 0,00 \\
\hline 20 & 0,00 & 0,00 & 10,00 & 0,00 & 0,00 & 0,00 & 0,00 & 7,00 & 0,00 & 0,00 & 0,00 & 18,60 \\
\hline 21 & 35,00 & 0,00 & 41,00 & 0,00 & 77,80 & 7,20 & 0,00 & 7,50 & 0,00 & 0,00 & 0,00 & 0,00 \\
\hline 22 & 2,00 & 0,00 & 1,50 & 0,00 & 0,00 & 75,00 & 0,00 & 28,50 & 0,00 & 0,00 & 0,00 & 45,60 \\
\hline 23 & 0,00 & 0,50 & 3,50 & 0,00 & 45,00 & 4,00 & 0,00 & 2,20 & 0,00 & 0,00 & 0,00 & 0,00 \\
\hline 24 & 0,00 & 0,00 & 0,00 & 0,00 & 18,00 & 59,50 & 0,00 & 0,00 & 0,00 & 0,00 & 0,00 & 0,00 \\
\hline 25 & 0,00 & 0,00 & 0,00 & 29,00 & 0,00 & 23,00 & 0,00 & 0,00 & 7,10 & 0,00 & 17,00 & 0,00 \\
\hline 26 & 0,00 & 0,00 & 0,00 & 0,00 & 0,00 & 0,50 & 0,00 & 0,00 & 0,50 & 0,00 & 0,00 & 0,00 \\
\hline 27 & 0,00 & 0,00 & 0,00 & 0,00 & 0,00 & 0,00 & 0,00 & 0,00 & 0,00 & 0,00 & 0,00 & 0,00 \\
\hline 28 & 36,00 & 0,00 & 0,00 & 0,00 & 0,00 & 0,00 & 0,00 & 0,00 & 0,00 & 0,00 & 0,00 & 0,00 \\
\hline 29 & 8,50 & 0,00 & 0,00 & 46,60 & - & 36,20 & 0,00 & 0,00 & 1,80 & 1,00 & 0,00 & 43,00 \\
\hline 30 & 9,50 & 12,00 & 1,50 & 0,00 & - & 0,00 & 0,00 & 0,00 & 8,50 & 1,50 & 0,00 & 0,00 \\
\hline 31 & 0,00 & - & 0,00 & 0,00 & - & 0,00 & - & 0,00 & - & 0,00 & 13,00 & - \\
\hline Mensal & 179,50 & 38,50 & 187,50 & 143,60 & 303,40 & 234,40 & 5,10 & 47,70 & 18,20 & 22,80 & 30,00 & 148,20 \\
\hline
\end{tabular}

De outubro de 2005 à março de 2006 - Experimento no campo; De abril à setembro de 2006 - Experimento no armazém 
Tabela A12 - Resultados das amostras positivas de aflatoxinas $B_{1}, B_{2}, G_{1}$ e $G_{2}(\mu \mathrm{g} / \mathrm{kg}$ ) encontradas nos grãos no campo, na Região de Tupã - SP, no período de janeiro a março de 2006.

\begin{tabular}{|c|c|c|c|c|c|c|c|c|c|}
\hline \multirow{2}{*}{$\begin{array}{l}\text { CAMPO } \\
\text { Coletas }\end{array}$} & \multirow{2}{*}{$\begin{array}{c}\text { AMOSTRAS } \\
\text { Parcelas }\end{array}$} & \multicolumn{4}{|c|}{ IAC-CAIAPÓ $(\mu \mathrm{g} / \mathrm{Kg})$} & \multicolumn{4}{|c|}{ IAC $886(\mu \mathrm{g} / \mathrm{Kg})$} \\
\hline & & $\overline{\mathbf{B}_{1}}$ & $\overline{\mathbf{B}_{2}}$ & $\overline{\mathbf{G}_{1}}$ & $\overline{\mathbf{G}_{2}}$ & $\overline{\mathbf{B}_{1}}$ & $\overline{\mathbf{B}_{2}}$ & $\overline{\mathbf{G}_{1}}$ & $\overline{\mathbf{G}_{2}}$ \\
\hline \multirow{10}{*}{$\begin{array}{l}4^{\circ} \\
\text { darãos/ inìcio granação) }\end{array}$} & 2 & ND & ND & ND & ND & ND & ND & ND & ND \\
\hline & 4 & ND & ND & ND & ND & ND & ND & ND & ND \\
\hline & 5 & ND & ND & ND & ND & 0,07 & 0,11 & ND & ND \\
\hline & 8 & ND & ND & ND & 0,03 & ND & ND & ND & ND \\
\hline & 10 & ND & ND & ND & ND & ND & ND & ND & ND \\
\hline & 2 & 0,08 & ND & ND & ND & 0,21 & ND & ND & ND \\
\hline & 4 & ND & ND & ND & ND & ND & ND & ND & ND \\
\hline & 5 & ND & ND & ND & ND & ND & ND & ND & ND \\
\hline & 8 & ND & ND & ND & ND & ND & ND & ND & ND \\
\hline & 10 & ND & ND & ND & ND & ND & ND & ND & ND \\
\hline \multirow{5}{*}{$\begin{array}{c}5^{\circ} \\
\text { (Grãos/ } \\
\text { Grãos maduros) }\end{array}$} & 3 & ND & NDD & $\overline{N D}$ & $\overline{N D}$ & ND & $\overline{N D}$ & NDD & $\overline{\mathrm{ND}}$ \\
\hline & 4 & 0,05 & ND & ND & ND & 1,02 & ND & ND & ND \\
\hline & 5 & ND & ND & ND & ND & ND & ND & ND & ND \\
\hline & 6 & 0,03 & ND & ND & ND & ND & ND & ND & ND \\
\hline & 8 & ND & ND & ND & ND & ND & ND & ND & ND \\
\hline \multirow{5}{*}{$\begin{array}{c}6^{\circ} \\
\text { (Grãos/ } \\
\text { Grãos secos) }\end{array}$} & 3 & 0,58 & 0,04 & 0,96 & 0,16 & ND & ND & ND & ND \\
\hline & 4 & $N$ & 0,03 & 0,03 & 0,21 & 0,13 & ND & 0,06 & 0,08 \\
\hline & 5 & ND & ND & ND & ND & ND & ND & ND & ND \\
\hline & 6 & ND & ND & ND & ND & 0,27 & ND & ND & ND \\
\hline & 7 & 0,07 & ND & ND & ND & 0,25 & ND & ND & ND \\
\hline
\end{tabular}

ND - Não detectado

Limite de quantificação $=0,1780 \mu \mathrm{g} / \mathrm{Kg}$ para $A F B_{1}, 0,1470 \mu \mathrm{g} / \mathrm{Kg}$ para $A F B_{2}, 0,1520 \mu \mathrm{g} / \mathrm{Kg}$ para $A F G_{1}, 0,076 \mu \mathrm{g} / \mathrm{Kg}$ para $A F G_{2}$

Limite de detecção $=0,03 \mu \mathrm{g} / \mathrm{kg}$ para $\mathrm{AFB}_{1}, 0,03 \mu \mathrm{g} / \mathrm{kg}$ para $A F B_{2}, 0,03 \mu \mathrm{g} / \mathrm{kg}$ para $\mathrm{AFG}_{1}$ e $0,01 \mu \mathrm{g} / \mathrm{kg}$ para $A F G_{2}$ 
Tabela A13 - Resultados das amostras positivas de Ácido ciclopiazônico $(\mu \mathrm{g} / \mathrm{kg})$ encontradas nos grãos no campo, na Região de Tupã - SP, no período de janeiro a março de 2006.

\begin{tabular}{|c|c|c|c|}
\hline CAMPO & AMOSTRAS & IAC-CAIAPÓ $(\mu \mathrm{g} / \mathrm{Kg})$ & IAC $886(\mu \mathrm{g} / \mathrm{Kg})$ \\
\hline Coletas & Parcelas & Grãos & Grãos \\
\hline \multirow{3}{*}{$\begin{array}{l}\text { (Grãos/ } \\
\text { Fase água) }\end{array}$} & 2 & 0339,1 & 5700,8 \\
\hline & 4 & 80,4 & ND \\
\hline & 5 & 318,8 & 3966,4 \\
\hline \multirow{7}{*}{$\begin{array}{l}\text { (Grãos/ inìcio } \\
\text { da granação) }\end{array}$} & 8 & 2302,1 & ND \\
\hline & 10 & ND & 585,5 \\
\hline & 2 & 184,3 & 7835,3 \\
\hline & 4 & ND & 511,3 \\
\hline & 5 & ND & 163,1 \\
\hline & 8 & ND & 370,4 \\
\hline & 10 & 938,0 & ND \\
\hline \multirow{5}{*}{$\begin{array}{c}5^{\circ} \\
\text { (Grãos/ } \\
\text { Grãos maduros) }\end{array}$} & 3 & 2769,1 & 2398,7 \\
\hline & 4 & ND & 164,8 \\
\hline & 5 & 357,8 & 599,0 \\
\hline & 6 & 300,4 & 2260,3 \\
\hline & 8 & ND & ND \\
\hline \multirow{5}{*}{$\begin{array}{c}6^{\circ} \\
\text { (Grãos/ } \\
\text { Grãos secos) }\end{array}$} & 3 & 89,9 & $\begin{array}{l}\mathrm{ND} \\
\end{array}$ \\
\hline & 4 & ND & 82,5 \\
\hline & 5 & 124,4 & ND \\
\hline & 6 & ND & 2589,5 \\
\hline & 7 & ND & 2622,5 \\
\hline
\end{tabular}

ND - Não detectado

Limite de detecção $=80 \mu \mathrm{g} / \mathrm{kg}$

Limite de quantificação $=128,0 \mu \mathrm{g} / \mathrm{kg}$ 
Tabela A14 - Resultados dos níveis de fitoalexina (trans-resveratrol), em $\mu \mathrm{g} / \mathrm{Kg}$, encontrados nas amostras de grãos e folhas (flor, ginóforo, Fase água, Início da granação e grãos maduros), durante o desenvolvimento do amendoim, no campo, no período de janeiro a março de 2006.

\begin{tabular}{|c|c|c|c|c|c|}
\hline \multirow{2}{*}{$\begin{array}{l}\text { CAMPO } \\
\text { Coletas } \\
\end{array}$} & \multirow{2}{*}{$\begin{array}{c}\text { AMOSTRAS } \\
\text { Parcelas } \\
\end{array}$} & \multicolumn{2}{|c|}{ IAC-CAIAPÓ $(\mu \mathrm{g} / \mathrm{Kg})$} & \multicolumn{2}{|c|}{ IAC $886(\mu \mathrm{g} / \mathrm{Kg})$} \\
\hline & & Grãos & Folhas & Grãos & Folhas \\
\hline \multirow{5}{*}{ Flor e Ginóforo } & 2 & NA & ND & NA & 17800 \\
\hline & 4 & NA & 55600 & NA & ND \\
\hline & 6 & NA & 12300 & NA & 18300 \\
\hline & 7 & NA & 46000 & NA & 5100 \\
\hline & 9 & NA & 23700 & NA & 17500 \\
\hline \multirow{5}{*}{ Fase água } & 2 & ND & ND & ND & ND \\
\hline & 4 & 280 & 3000 & ND & 88200 \\
\hline & 5 & ND & 8100 & ND & 25300 \\
\hline & 8 & ND & 42100 & ND & 157900 \\
\hline & 10 & ND & ND & 790 & ND \\
\hline \multirow{5}{*}{$\begin{array}{l}\text { Início da } \\
\text { granação }\end{array}$} & 2 & $\overline{\mathrm{ND}}$ & ND & ND & ND \\
\hline & 4 & ND & 3000 & ND & 88200 \\
\hline & 5 & ND & 8100 & ND & 25300 \\
\hline & 8 & 280 & 42100 & ND & 157900 \\
\hline & 10 & ND & ND & ND & ND \\
\hline \multirow{5}{*}{ Grãos maduros } & 3 & 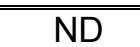 & 12700 & NDD & 443100 \\
\hline & 4 & ND & 4300 & ND & ND \\
\hline & 5 & 570 & 5200 & ND & 2600 \\
\hline & 6 & ND & 15300 & ND & 104000 \\
\hline & 8 & ND & ND & ND & 10900 \\
\hline \multirow{5}{*}{ Grãos secos } & 3 & 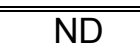 & NA & $\overline{\mathrm{ND}}$ & NA \\
\hline & 4 & ND & NA & ND & NA \\
\hline & 5 & ND & NA & ND & NA \\
\hline & 6 & ND & NA & ND & NA \\
\hline & 7 & ND & NA & ND & NA \\
\hline
\end{tabular}

ND - Não detectado; NA - Não Analisado

Limite de Detecção $=80 \mu \mathrm{g} / \mathrm{kg}$

Limite de Quantificação $=200 \mu \mathrm{g} / \mathrm{kg}$ 
Tabela A15 - Atividade de água (Aa) e frequência de isolamento fúngico nas amostras de grãos de amendoim da variedade Runner IAC-Caiapó, coletados durante o armazenamento, na Região de Tupã - SP, no período de abril a setembro de 2006.

\begin{tabular}{|c|c|c|c|c|c|c|c|c|c|c|}
\hline & \multirow[b]{2}{*}{$\begin{array}{c}\text { Amostra } \\
\text { Runner } \\
\text { IAC-Caiapó }\end{array}$} & \multirow[b]{2}{*}{$\begin{array}{l}\text { Atividade } \\
\text { de Água } \\
\text { (Aa) }\end{array}$} & \multicolumn{8}{|c|}{ (\%) } \\
\hline & & & $\begin{array}{l}\text { Fusarium } \\
\text { spp }\end{array}$ & A. flavus & A. parasiticus & A. niger & A.terreus & $\begin{array}{l}\text { Mucor } \\
\text { spp }\end{array}$ & $\begin{array}{c}\text { Penicillium } \\
\text { spp }\end{array}$ & $\begin{array}{c}\text { Rhizopus } \\
\text { spp }\end{array}$ \\
\hline Coletas & Parcelas & & & & & & & & & \\
\hline \multirow{5}{*}{$1^{\circ}$} & 1 & 0,52 & $\bar{~} 4,54$ & 18,18 & - & 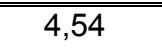 & - & - & 9,09 & - \\
\hline & 2 & 0,52 & - & 9,09 & - & - & - & - & - & - \\
\hline & 3 & 0,47 & - & - & - & - & - & - & - & - \\
\hline & 4 & 0,47 & - & - & - & - & - & - & - & - \\
\hline & 5 & 0,47 & - & 9,09 & - & 9,09 & - & 18,18 & 4,54 & - \\
\hline \multirow{5}{*}{$2^{\circ}$} & 1 & 0,55 & - & 9,09 & - & 15,15 & - & - & - & - \\
\hline & 2 & 0,57 & - & 3,03 & - & 3,03 & - & - & 45,45 & - \\
\hline & 3 & 0,56 & - & 3,03 & - & - & - & - & - & 3,03 \\
\hline & 4 & 0,56 & 3,03 & 12,12 & - & - & 18,18 & - & 24,24 & - \\
\hline & 5 & 0,57 & - & 3,03 & - & - & - & - & - & - \\
\hline \multirow{5}{*}{$3^{\circ}$} & 1 & 0,51 & 27,27 & 6,06 & - & - & 3,03 & - & 3,03 & - \\
\hline & 2 & 0,52 & - & - & - & - & 12,12 & - & 12,12 & - \\
\hline & 3 & 0,50 & 15,15 & 6,06 & - & 6,06 & - & - & 9,09 & - \\
\hline & 4 & 0,51 & - & 6,06 & 3,03 & 3,03 & - & - & 9,09 & - \\
\hline & 5 & 0,50 & - & 3,03 & - & - & 39,39 & - & - & - \\
\hline \multirow{5}{*}{$4^{\circ}$} & 1 & 0,52 & - & 21,21 & - & 12,12 & - & - & - & - \\
\hline & 2 & 0,53 & - & 12,12 & - & 3,03 & - & - & - & 33,33 \\
\hline & 3 & 0,53 & 3,03 & 9,09 & - & 18,18 & - & - & - & - \\
\hline & 4 & 0,54 & - & 15,15 & - & - & 3,03 & - & 9,09 & - \\
\hline & 5 & 0,53 & - & 12,12 & - & 27,27 & - & - & 9,09 & - \\
\hline \multirow{5}{*}{$5^{\circ}$} & $\overline{1} 1$ & 0,37 & - & $\begin{array}{l}18,18 \\
\end{array}$ & - & - & $9,9,09$ & - & - & 33,33 \\
\hline & 2 & 0,40 & - & 9,09 & - & 3,03 & 3,03 & - & 3,03 & - \\
\hline & 3 & 0,38 & - & 15,15 & - & - & 3,03 & - & - & - \\
\hline & 4 & 0,44 & - & 3,03 & - & - & 6,06 & - & - & - \\
\hline & 5 & 0,42 & - & - & - & - & - & - & - & - \\
\hline \multirow{5}{*}{$6^{\circ}$} & 1 & 0,49 & ( & - & - & - & - & "33,33 & - & - \\
\hline & 2 & 0,51 & 12,12 & 6,06 & - & - & - & - & 6,06 & 33,33 \\
\hline & 3 & 0,50 & - & 6,06 & - & - & 60,61 & - & - & - \\
\hline & 4 & 0,51 & - & - & - & 6,06 & 21,21 & - & - & - \\
\hline & 5 & 0,51 & - & - & - & 6,06 & - & 33,33 & 12,12 & - \\
\hline
\end{tabular}

FNE - Fungo não esporulado 
Tabela A16 - Atividade de água (Aa) e frequência de isolamento fúngico nas amostras de cascas de amendoim da variedade Runner IAC-Caiapó, coletados durante o armazenamento, na Região de Tupã - SP, no período de abril a setembro de 2006.

\begin{tabular}{|c|c|c|c|c|c|c|c|c|c|c|c|}
\hline & \multirow[b]{2}{*}{$\begin{array}{c}\text { Amostra } \\
\text { Runner } \\
\text { IAC-Caiapó }\end{array}$} & \multirow[b]{2}{*}{$\begin{array}{l}\text { Atividade } \\
\text { de Água } \\
\text { (Aa) }\end{array}$} & \multicolumn{9}{|c|}{ (\%) } \\
\hline & & & $\begin{array}{l}\text { Fusarium } \\
\text { spp }\end{array}$ & A. flavus & A. parasiticus & A. niger & A. terreus & $\begin{array}{l}\text { Mucor } \\
\text { spp }\end{array}$ & $\begin{array}{l}\text { Penicillium } \\
\text { spp }\end{array}$ & $\begin{array}{l}\text { Alternaria } \\
\text { spp }\end{array}$ & $\begin{array}{l}\text { Rizophus } \\
\text { spp }\end{array}$ \\
\hline Coletas & Parcelas & & & & & & & & & & \\
\hline \multirow{5}{*}{$1^{\circ}$} & 1 & 0,44 & - & 100 & - & - & - & - & - & - & - \\
\hline & 2 & 0,44 & 8,33 & 91,67 & - & - & - & - & - & - & 33,33 \\
\hline & 3 & 0,45 & - & - & - & - & - & - & - & - & - \\
\hline & 4 & 0,47 & - & - & - & - & 6,25 & - & - & - & - \\
\hline & 5 & 0,45 & 16,67 & 83,33 & - & -- & - & - & - & 8,33 & 33,33 \\
\hline \multirow{5}{*}{$2^{\circ}$} & 1 & 0,56 & - & 12,50 & 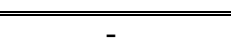 & 12,50 & - & - & - & 12,50 & 75,00 \\
\hline & 2 & 0,57 & 25,00 & 18,75 & - & 12,50 & - & - & - & 43,75 & - \\
\hline & 3 & 0,57 & 6,25 & 93,75 & - & - & - & 6,25 & - & 31,25 & 25,00 \\
\hline & 4 & 0,57 & 12,50 & 75,00 & - & - & - & - & 6,25 & 43,75 & - \\
\hline & 5 & 0,57 & 6,25 & 31,25 & - & 31,25 & - & - & - & 68,75 & - \\
\hline \multirow{5}{*}{$3^{\circ}$} & 1 & 0,51 & 43,75 & 75,00 & 25,00 & 6,25 & - & - & - & 6,25 & - \\
\hline & 2 & 0,53 & 31,25 & 62,50 & 12,50 & 6,25 & - & - & - & 18,75 & - \\
\hline & 3 & 0,50 & 62,50 & - & - & - & - & - & - & 18,75 & - \\
\hline & 4 & 0,52 & 6,25 & 62,50 & - & 12,50 & - & - & 18,75 & 18,75 & 25,00 \\
\hline & 5 & 0,50 & 12,50 & 87,50 & - & - & - & 6,25 & - & 18,75 & - \\
\hline \multirow{5}{*}{$4^{\circ}$} & 1 & 0,56 & 37,50 & 75,00 & - & - & - & - & - & 18,75 & $\overline{c 18,75}$ \\
\hline & 2 & 0,57 & - & 75,00 & - & 6,25 & - & - & - & 31,25 & 50,00 \\
\hline & 3 & 0,58 & 6,25 & 62,50 & - & 43,75 & - & - & - & 18,75 & 25,00 \\
\hline & 4 & 0,57 & - & 93,75 & - & 6,25 & - & 6,25 & 6,25 & 25,00 & - \\
\hline & 5 & 0,58 & 18,75 & 75,00 & - & 6,25 & - & - & - & 18,75 & 50,00 \\
\hline \multirow{5}{*}{$5^{\circ}$} & 1 & 0,37 & 12,50 & 56,25 & - & - & - & 6,25 & - & 6,25 & 50,00 \\
\hline & 2 & 0,38 & - & 75,00 & - & 12,50 & - & - & - & 12,50 & 50,00 \\
\hline & 3 & 0,39 & 6,25 & 37,50 & - & 18,75 & - & - & - & 6,25 & 50,00 \\
\hline & 4 & 0,45 & - & 43,75 & - & 31,25 & - & - & 6,25 & 6,25 & - \\
\hline & 5 & 0,43 & - & 75,00 & - & 37,50 & - & 6,25 & 6,25 & 6,25 & - \\
\hline \multirow{5}{*}{$6^{\circ}$} & 1 & 0,52 & 6,25 & - & - & 18,25 & - & 12,50 & 43,75 & - & - \\
\hline & 2 & 0,53 & 18,75 & 12,50 & - & 6,25 & & - & - & - & 75,00 \\
\hline & 3 & 0,53 & 18,75 & 6,25 & - & - & 37,50 & - & - & - & 50,00 \\
\hline & 4 & 0,51 & 6,25 & 31,25 & - & - & 37,50 & - & - & - & 25,00 \\
\hline & 5 & 0,54 & 12,50 & - & - & 43,75 & 25,00 & 25,00 & 12,50 & - & - \\
\hline
\end{tabular}

FNE - Fungo não esporulado 
Tabela A17 - Atividade de água (Aa) e frequência de isolamento fúngico nas amostras de grãos de amendoim da variedade Runner IAC 886, coletados durante o armazenamento, na Região de Tupã - SP, no período de abril a setembro de 2006.

\begin{tabular}{|c|c|c|c|c|c|c|c|c|c|c|c|}
\hline & \multirow[b]{2}{*}{$\begin{array}{c}\text { Amostra } \\
\text { Runner } \\
\text { IAC } 886\end{array}$} & \multirow[b]{2}{*}{$\begin{array}{c}\text { Atividade } \\
\text { de Água } \\
\text { (Aa) }\end{array}$} & \multicolumn{9}{|c|}{$(\%)$} \\
\hline & & & $\begin{array}{c}\text { Fusarium } \\
\text { spp }\end{array}$ & A. flavus & A. parasiticus & A. niger & $\begin{array}{c}\text { Penicillium } \\
\text { spp }\end{array}$ & $\begin{array}{l}\text { Rizophus } \\
\text { spp }\end{array}$ & $\begin{array}{c}\text { Cladosporium } \\
\text { spp }\end{array}$ & FNE & $\begin{array}{l}\text { Alternaria } \\
\text { spp }\end{array}$ \\
\hline Coletas & Parcelas & & & & & & & & & & \\
\hline \multirow{5}{*}{$1^{\circ}$} & 1 & 0,51 & 9,09 & - & - & 3,03 & 3,03 & - & - & 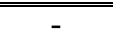 & - \\
\hline & 2 & 0,50 & - & - & - & - & 6,06 & - & - & - & - \\
\hline & 3 & 0,53 & 18,18 & - & - & - & 9,09 & - & 6,06 & - & - \\
\hline & 4 & 0,51 & 3,03 & 3,03 & - & 6,06 & 6,06 & - & - & 12,12 & - \\
\hline & 5 & 0,53 & 9,09 & 9,09 & - & 12,12 & - & - & - & - & - \\
\hline \multirow{5}{*}{$2^{\circ}$} & 1 & 0,54 & 3,03 & 3,03 & - & 3,03 & 9,09 & - & 3,03 & 3,03 & - \\
\hline & 2 & 0,56 & - & - & - & 3,03 & 9,09 & - & - & - & 12,12 \\
\hline & 3 & 0,55 & 3,03 & - & - & 6,06 & 6,06 & - & 3,03 & - & - \\
\hline & 4 & 0,56 & - & - & - & 6,06 & 9,09 & - & - & - & - \\
\hline & 5 & 0,55 & - & 6,06 & - & 9,09 & - & - & - & - & - \\
\hline \multirow{5}{*}{$3^{\circ}$} & 1 & 0,51 & - & 27,27 & 21,21 & 3,03 & - & - & - & - & - \\
\hline & 2 & 0,52 & 6,06 & 18,18 & 9,09 & 15,15 & - & - & - & - & - \\
\hline & 3 & 0,50 & 9,09 & 42,42 & 6,06 & 27,27 & 3,03 & - & - & - & - \\
\hline & 4 & 0,51 & 9,09 & 33,33 & 18,18 & - & - & - & - & - & - \\
\hline & 5 & 0,52 & - & 33,33 & 21,21 & - & - & - & - & - & - \\
\hline \multirow{5}{*}{$4^{\circ}$} & 1 & 0,49 & - & 12,12 & - & 18,18 & 27,27 & - & - & - & - \\
\hline & 2 & 0,49 & 3,03 & 18,18 & - & 6,06 & 3,03 & 33,33 & - & - & - \\
\hline & 3 & 0,50 & - & 12,12 & - & 12,12 & 3,03 & - & - & - & - \\
\hline & 4 & 0,50 & - & 72,72 & - & - & - & - & - & - & - \\
\hline & 5 & 0,47 & - & 33,33 & - & - & - & - & - & - & - \\
\hline \multirow{5}{*}{$5^{\circ}$} & $\overline{1} 1$ & 0,42 & - & - & - & - & - & 66,67 & - & - & - \\
\hline & 2 & 0,43 & - & - & - & 3,03 & - & 66,67 & - & - & - \\
\hline & 3 & 0,41 & - & - & - & 6,06 & - & 33,33 & - & - & - \\
\hline & 4 & 0,42 & - & - & - & - & - & - & - & - & - \\
\hline & 5 & 0,43 & - & - & - & - & - & - & - & 24,24 & - \\
\hline \multirow{5}{*}{$6^{\circ}$} & 1 & 0,49 & - & 12,12 & $6,6,06$ & $\overline{~ 12,12}$ & - & - & - & - & - \\
\hline & 2 & 0,49 & 36,36 & 3,03 & - & 21,21 & - & - & - & - & - \\
\hline & 3 & 0,51 & - & - & - & 3,03 & 9,09 & - & - & - & - \\
\hline & 4 & 050 & - & 6,06 & - & 9,09 & 15,15 & - & 3,036 & 3,03 & - \\
\hline & 5 & 0,49 & - & 9,09 & - & 3,03 & - & 3,03 & - & - & - \\
\hline
\end{tabular}

FNE - Fungo não esporulado 
Tabela A18 - Atividade de água (Aa) e frequência de isolamento fúngico nas amostras de cascas de amendoim da variedade Runner IAC 886, coletados durante o armazenamento, na Região de Tupã - SP, no período de abril a setembro de 2006.

\begin{tabular}{|c|c|c|c|c|c|c|c|c|c|c|c|}
\hline & \multirow[b]{2}{*}{$\begin{array}{l}\text { Amostra } \\
\text { Runner } \\
\text { IAC } 886\end{array}$} & \multirow[b]{2}{*}{$\begin{array}{c}\text { Atividade } \\
\text { de Água } \\
\text { (Aa) }\end{array}$} & \multicolumn{9}{|c|}{$(\%)$} \\
\hline & & & $\begin{array}{l}\text { Fusarium } \\
\text { spp }\end{array}$ & A. flavus & A. niger & A. parasiticus & $\begin{array}{c}\text { Rizophus } \\
\text { spp }\end{array}$ & $\begin{array}{l}\text { Mucor } \\
\text { spp }\end{array}$ & $\begin{array}{c}\text { Cladosporium } \\
\text { spp }\end{array}$ & $\begin{array}{l}\text { Alternaria } \\
\text { spp }\end{array}$ & $\begin{array}{c}\text { Penicillium } \\
\text { spp }\end{array}$ \\
\hline Coletas & Parcelas & & & & & & & & & & \\
\hline \multirow{5}{*}{$1^{\circ}$} & 1 & 0,51 & 37,50 & 43,75 & 25,00 & - & 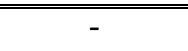 & - & 6,25 & - & - \\
\hline & 2 & 0,50 & 6,25 & 68,75 & 50,00 & - & - & - & - & - & - \\
\hline & 3 & 0,50 & 50,00 & 6,25 & 62,50 & - & - & - & - & - & 37,50 \\
\hline & 4 & 0,50 & 6,25 & 31,25 & 43,75 & - & 25,00 & 25,00 & & & 6,25 \\
\hline & 5 & 0,53 & 6,25 & 25,00 & - & - & 25,00 & - & - & - & 6,25 \\
\hline \multirow{5}{*}{$2^{\circ}$} & 1 & 0,55 & - & 50,00 & 81,25 & - & - & - & - & - & 62,5 \\
\hline & 2 & 0,57 & 6,25 & 50,00 & 37,5 & - & - & - & - & - & 75,00 \\
\hline & 3 & 0,56 & 12,5 & 31,25 & 6,25 & - & 50,00 & - & - & - & 25,00 \\
\hline & 4 & 0,56 & 6,25 & 6,25 & 12,50 & - & 25,00 & - & - & - & 12,50 \\
\hline & 5 & 0,56 & 12,50 & 93,75 & 50,00 & - & - & 12,50 & 6,25 & - & 12,50 \\
\hline \multirow{5}{*}{$3^{\circ}$} & 1 & 0,51 & - & $\begin{array}{l}62,50 \\
\end{array}$ & 25,00 & $\begin{array}{l}37,50 \\
\end{array}$ & - & - & - & - & - \\
\hline & 2 & 0,51 & - & 56,25 & 56,25 & 25,00 & - & 6,25 & - & 6,25 & - \\
\hline & 3 & 0,50 & - & 50,00 & - & 50,00 & - & - & - & - & - \\
\hline & 4 & 0,51 & - & 43,7 & 12,50 & 56,20 & - & - & - & - & - \\
\hline & 5 & 0,51 & - & 62,50 & 6,25 & 18,18 & - & - & - & - & - \\
\hline \multirow{5}{*}{$4^{\circ}$} & $\overline{1} 1$ & 0,51 & - & 81,25 & 688,75 & $6,6,25$ & - & - & - & - & - \\
\hline & 2 & 0,52 & - & 81,25 & 50,00 & 18,75 & - & - & - & - & - \\
\hline & 3 & 0,53 & 6,25 & 50,00 & 62,50 & - & - & - & - & - & - \\
\hline & 4 & 0,52 & - & 93,75 & 18,75 & - & 75,00 & - & - & - & - \\
\hline & 5 & 0,52 & - & 93,75 & - & - & 50,00 & - & - & - & - \\
\hline \multirow{5}{*}{$5^{\circ}$} & 1 & 0,44 & - & 37,50 & 25,00 & - & 75,00 & - & - & - & - \\
\hline & 2 & 0,45 & - & 25,00 & 31,25 & - & 50,00 & - & - & 6,25 & - \\
\hline & 3 & 0,44 & - & 31,25 & 18,75 & 6,25 & 75,00 & - & - & - & - \\
\hline & 4 & 0,45 & - & 31,25 & 18,75 & - & 50,00 & - & - & - & - \\
\hline & 5 & 0,45 & 6,25 & 75,00 & 50,00 & - & - & - & 6,25 & - & 12,50 \\
\hline \multirow{5}{*}{$6^{\circ}$} & $\overline{11}$ & 0,54 & - & 12,50 & 18,75 & - & 75,00 & - & - & - & - \\
\hline & 2 & 0,53 & - & 12,50 & 31,25 & - & 50,00 & 25,00 & 6,25 & - & - \\
\hline & 3 & 0,52 & 12,50 & 6,25 & 25,00 & - & 75,00 & - & - & - & - \\
\hline & 4 & 0,52 & 12,50 & 6,25 & 37,50 & - & 50,00 & - & - & - & - \\
\hline & 5 & 0,53 & - & 12,50 & 25,00 & - & 50,00 & 12,50 & - & - & 18,75 \\
\hline
\end{tabular}

FNE - Fungo não esporulado 
Tabela A19 - Fungos anemófilos (UFC/ $\mathrm{m}^{3}$ ) isolados no interior do armazém, próximo da variedade Runner IAC-Caiapó, no período de abril a setembro de 2006.

\begin{tabular}{|c|c|c|c|c|c|c|c|}
\hline & \multicolumn{7}{|c|}{$\mathrm{UFC} / \mathrm{m}^{3}$} \\
\hline & Fusarium spp & A. niger & $\begin{array}{c}\text { Penicillium } \\
\text { spp }\end{array}$ & $\begin{array}{c}\text { Mucor } \\
\text { spp }\end{array}$ & $\begin{array}{c}\text { Rhizopus } \\
\text { spp }\end{array}$ & $\begin{array}{c}\text { Alternaria } \\
\text { spp }\end{array}$ & $\begin{array}{c}\text { Cladosporium } \\
\text { spp }\end{array}$ \\
\hline \multicolumn{8}{|l|}{ Coletas } \\
\hline $1^{\circ}$ Coleta & 3,8 & 148 & 5,2 & - & 1,0 & - & - \\
\hline $2^{\circ}$ Coleta & - & - & - & - & 5,0 & - & 703,4 \\
\hline $3^{\circ}$ Coleta & - & - & - & 5,2 & 1,2 & - & 326,0 \\
\hline $4^{\circ}$ Coleta & 15,2 & - & - & - & 0,8 & 0,2 & 219,6 \\
\hline $5^{\circ}$ Coleta & - & 1,4 & - & - & 1,0 & - & 274,8 \\
\hline $6^{a}$ Coleta & 6,8 & - & - & - & 1,0 & - & 285,0 \\
\hline
\end{tabular}

UFC - Unidade Formadora de Colônia 
Tabela A20 - Fungos anemófilos (UFC/ $\mathrm{m}^{3}$ ) isolados no interior do armazém, próximo da variedade Runner IAC 886, no período de abril a setembro de 2006.

\begin{tabular}{|c|c|c|c|c|c|c|c|c|}
\hline & \multicolumn{8}{|c|}{$\mathrm{UFC} / \mathrm{m}^{3}$} \\
\hline & $\begin{array}{c}\text { Fusarium } \\
\text { spp }\end{array}$ & A. flavus & A. niger & $\begin{array}{c}\text { Trichoderma } \\
\text { spp }\end{array}$ & $\begin{array}{l}\text { Mucor } \\
\text { spp }\end{array}$ & $\begin{array}{c}\text { Rhizopus } \\
\text { spp }\end{array}$ & $\begin{array}{c}\text { Alternaria } \\
\text { spp }\end{array}$ & $\begin{array}{c}\text { Cladosporium } \\
\text { spp }\end{array}$ \\
\hline \multicolumn{9}{|l|}{ Coletas } \\
\hline $1^{\circ}$ Coleta & 3,0 & - & 139,6 & - & - & 1,0 & - & - \\
\hline $2^{\circ}$ Coleta & 4,2 & - & - & 0,2 & 0,2 & - & - & 727,6 \\
\hline $3^{\circ}$ Coleta & - & 2,0 & - & - & 0,2 & 0,8 & - & 253,4 \\
\hline $4^{\circ}$ Coleta & 29,0 & 0,2 & - & - & - & 1,0 & - & 338,8 \\
\hline $5^{\circ}$ Coleta & - & 0,2 & 0,2 & - & 17,2 & 0,8 & 0,2 & 241,8 \\
\hline $6^{\mathrm{a}}$ Coleta & 2,0 & - & - & - & 9,6 & 11,6 & - & 314,4 \\
\hline
\end{tabular}

UFC - Unidade Formadora de Colônia 
Tabela A21 - Temperatura $\left({ }^{\circ} \mathrm{C}\right)$ registrada no período experimental de armazenamento, de abril a março de 2006, na região de Tupã.

\begin{tabular}{|c|c|c|c|c|c|c|c|c|c|c|c|c|c|c|c|c|c|c|}
\hline \multirow[t]{2}{*}{ Dia } & \multicolumn{3}{|c|}{ Abril / 2006} & \multicolumn{3}{|c|}{ Maio /2006 } & \multicolumn{3}{|c|}{ junho / 2006} & \multicolumn{3}{|c|}{ Julho / 2006} & \multicolumn{3}{|c|}{ Agosto / 2006} & \multicolumn{3}{|c|}{ Setembro /2006 } \\
\hline & Máx & Mín & Méd & Max & Mín & Méd & Máx & Mín & Méd & Máx & Mín & Méd & Máx & Mín & Méd & Máx & Mín & Méd \\
\hline 1 & 31,90 & 18,44 & 25,17 & 30,20 & 15,40 & 22,80 & 29,80 & 15,30 & 22,55 & 27,50 & 11,70 & 19,60 & 26,20 & 12,00 & 19,10 & 27,00 & 18,00 & 22,50 \\
\hline 2 & 32,10 & 19,00 & 25,55 & 25,00 & 11,90 & 18,50 & 27,50 & 13,50 & 20,50 & 20,50 & 13,70 & 32,10 & 26,40 & 13,20 & 19,80 & 26,70 & 16,00 & 21,35 \\
\hline 3 & 30,00 & 19,50 & 24,75 & 23,70 & 5,00 & 14,35 & 28,40 & 11,00 & 19,70 & 25,00 & 13,00 & 19,00 & 30,00 & 13,60 & 21,80 & 22,50 & 10,00 & 16,25 \\
\hline 4 & 30,00 & 18,00 & 24,00 & 21,00 & 5,80 & 13,40 & 29,00 & 12,40 & 20,70 & 22,00 & 13,00 & 17,50 & 32,60 & 14,60 & 23,60 & 20,60 & 9,00 & 14,80 \\
\hline 5 & 22,00 & 18,00 & 20,00 & 27,30 & 8,00 & 17,65 & 29,00 & 17,40 & 23,20 & 27,00 & 12,50 & 19,75 & 33,60 & 17,30 & 25,45 & 19,20 & 4,00 & 11,60 \\
\hline 6 & 27,00 & 20,00 & 23,50 & 27,00 & 8,90 & 17,95 & 29,00 & 16,60 & 22,80 & 27,00 & 12,00 & 14,50 & 35,00 & 17,80 & 26,40 & 24,60 & 6,60 & 15,60 \\
\hline 7 & 30,52 & 21,00 & 25,76 & 26,50 & 11,00 & 18,75 & 29,70 & 16,00 & 22,85 & 29,50 & 13,00 & 21,25 & 35,50 & 17,60 & 26,55 & 28,80 & 7,80 & 18,30 \\
\hline 8 & 29,82 & 21,10 & 25,46 & 25,00 & 9,90 & 17,45 & 28,80 & 16,00 & 22,40 & 30,70 & 15,50 & 23,10 & 34,40 & 17,80 & 26,10 & 32,70 & 11,20 & 21,95 \\
\hline 9 & 30,52 & 20,30 & 25,41 & 27,00 & 9,40 & 18,20 & 28,60 & 15,00 & 21,80 & 30,70 & 15,90 & 23,30 & 32,40 & 17,60 & 25,00 & 26,60 & 15,90 & 21,25 \\
\hline 10 & 27,50 & 17,20 & 22,35 & 26,40 & 9,80 & 18,10 & 30,50 & 13,00 & 21,75 & 31,00 & 17,50 & 24,25 & 35,00 & 17,50 & 26,25 & 29,10 & 14,60 & 21,85 \\
\hline 11 & 28,00 & 16,00 & 23,00 & 27,00 & 8,60 & 17,80 & 28,70 & 15,30 & 22,00 & 31,00 & 18,00 & 24,50 & 34,10 & 19,00 & 26,55 & 35,00 & 17,30 & 26,15 \\
\hline 12 & 32,00 & 17,80 & 24,90 & 25,80 & 10,00 & 17,90 & 26,50 & 13,10 & 19,80 & 30,00 & 17,00 & 23,50 & 34,10 & 19,10 & 26,60 & 36,50 & 19,00 & 27,75 \\
\hline 13 & 34,00 & 18,00 & 26,00 & 26,00 & 9,20 & 17,60 & 29,00 & 12,00 & 20,50 & 29,00 & 16,00 & 22,50 & 35,00 & 18,30 & 26,65 & 36,00 & 18,00 & 27,00 \\
\hline 14 & 33,70 & 18,60 & 26,15 & 25,00 & 12,00 & 18,50 & 28,00 & 17,00 & 22,50 & 30,70 & 15,00 & 22,85 & 37,00 & 18,70 & 27,85 & 37,00 & 20,12 & 28,56 \\
\hline 15 & 31,40 & 20,50 & 25,95 & 27,00 & 9,00 & 18,00 & 28,00 & 10,00 & 19,00 & 29,00 & 13,00 & 21,00 & 37,00 & 19,00 & 28,00 & 36,40 & 20,70 & 28,55 \\
\hline 16 & 28,60 & 19,80 & 24,20 & 27,50 & 9,00 & 18,25 & 30,10 & 9,00 & 19,55 & 28,50 & 14,00 & 21,25 & 38,00 & 19,80 & 28,90 & 28,70 & 19,00 & 23,85 \\
\hline 17 & 26,50 & 19,50 & 23,00 & 27,90 & 10,00 & 18,95 & 29,00 & 10,50 & 19,75 & 25,00 & 13,00 & 19,00 & 33,00 & 16,00 & 24,50 & 30,10 & 17,30 & 23,70 \\
\hline 18 & 27,00 & 14,80 & 20,90 & 30,00 & 9,30 & 19,65 & 29,30 & 11,70 & 20,50 & 30,00 & 9,80 & 19,90 & 30,80 & 16,00 & 23,40 & 30,00 & 17,50 & 23,75 \\
\hline 19 & 28,40 & 14,80 & 21,60 & 32,30 & 9,60 & 20,95 & 31,00 & 11,40 & 21,20 & 29,60 & 9,60 & 19,60 & 30,50 & 14,00 & 22,25 & 31,00 & 16,50 & 23,75 \\
\hline 20 & 29,90 & 15,20 & 22,50 & 24,30 & 10,80 & 17,55 & 28,80 & 15,30 & 22,05 & 30,00 & 9,80 & 19,90 & 27,40 & 14,10 & 20,75 & 28,00 & 18,00 & 23,00 \\
\hline 21 & 31,75 & 16,75 & 24,25 & 21,20 & 15,80 & 18,50 & 29,50 & 15,50 & 22,50 & 31,30 & 12,50 & 21,90 & 24,00 & 7,80 & 15,90 & 28,60 & 16,00 & 22,30 \\
\hline 22 & 32,23 & 18,06 & 25,14 & 22,00 & 17,50 & 19,75 & 26,00 & 15,60 & 20,80 & 31,40 & 13,70 & 22,55 & 26,00 & 5,00 & 15,50 & 25,60 & 15,40 & 20,50 \\
\hline 23 & 30,00 & 18,05 & 24,05 & 17,60 & 15,70 & 16,65 & 29,20 & 13,80 & 21,50 & 33,00 & 16,00 & 24,50 & 31,00 & 6,00 & 18,50 & 31,20 & 16,90 & 24,05 \\
\hline 24 & 34,20 & 17,28 & 25,74 & 24,20 & 13,00 & 18,60 & 28,80 & 16,50 & 22,65 & 34,00 & 16,00 & 25,00 & 33,00 & 8,80 & 20,90 & 25,20 & 17,00 & 21,11 \\
\hline 25 & 33,90 & 19,80 & 26,85 & 26,00 & 12,20 & 19,10 & 29,70 & 17,10 & 23,40 & 34,00 & 16,00 & 25,00 & 34,70 & 14,00 & 24,35 & 27,00 & 14,80 & 20,90 \\
\hline 26 & 32,37 & 16,80 & 24,58 & 29,60 & 14,00 & 21,80 & 22,00 & 17,40 & 19,70 & 34,00 & 12,00 & 23,00 & 32,50 & 18,90 & 25,70 & 29,00 & 12,40 & 20,70 \\
\hline 27 & 30,00 & 15,96 & 22,98 & 31,80 & 12,90 & 22,35 & 19,80 & 8,00 & 13,90 & 34,00 & 15,00 & 24,50 & 27,80 & 14,60 & 21,20 & 31,00 & 15,00 & 23,00 \\
\hline 28 & 30,70 & 14,80 & 22,75 & 30,60 & 12,60 & 21,60 & 23,00 & 9,00 & 16,00 & 33,00 & 19,80 & 26,40 & 18,00 & 15,80 & 16,90 & 31,00 & 17,00 & 24,00 \\
\hline 29 & 30,70 & 15,40 & 23,05 & 29,00 & 12,40 & 20,70 & 20,00 & 7,80 & 13,90 & 21,10 & 17,30 & 19,20 & 26,00 & 12,00 & 19,00 & 30,50 & 20,00 & 25,25 \\
\hline 30 & 30,40 & 14,00 & 22,20 & 31,20 & 12,80 & 22,00 & 28,30 & 8,50 & 18,40 & 16,00 & 13,00 & 14,50 & 27,00 & 8,00 & 17,50 & 28,80 & 17,50 & 23,15 \\
\hline 31 & - & - & - & 30,90 & 14,60 & 22,75 & - & - & - & 17,00 & 12,00 & 14,50 & 34,00 & 9,90 & 21,95 & - & - & - \\
\hline Média & 30,24 & 17,81 & 24,06 & 26,65 & 11,16 & 18,91 & 27,83 & 13,36 & 20,59 & 28,47 & 14,07 & 21,59 & 31,35 & 14,64 & 23,00 & 29,15 & 15,28 & 22,22 \\
\hline
\end{tabular}


Tabela A 22 - Temperatura $\left({ }^{\circ} \mathrm{C}\right)$ registrada no interior do armazém, no período de abril a setembro de 2006, na região de Tupã.

\begin{tabular}{|c|c|c|c|c|c|c|c|c|c|c|c|c|c|c|c|c|c|c|}
\hline \multirow[t]{2}{*}{ Dia } & \multicolumn{3}{|c|}{ Abril / 2006} & \multicolumn{3}{|c|}{ Maio /2006 } & \multicolumn{3}{|c|}{ junho / 2006} & \multicolumn{3}{|c|}{ Julho / 2006} & \multicolumn{3}{|c|}{ Agosto / 2006} & \multicolumn{3}{|c|}{ Setembro /2006 } \\
\hline & Mín & Máx & Méd & Mín & Máx & Méd & Mín & Máx & Méd & Mín & Máx & Méd & Mín & Máx & Méd & Mín & Máx & Méd \\
\hline 1 & - & - & - & - & - & - & 16,4 & 32,5 & 24,4 & 14,4 & 28,1 & 21,2 & 14,8 & 20,5 & 17,6 & 19,3 & 34,2 & 26,7 \\
\hline 2 & - & - & - & 16,9 & 36,7 & 26,8 & 15,7 & 32,2 & 23,9 & - & - & - & 15,0 & 25,3 & 20,1 & 18,5 & 29,1 & 23,8 \\
\hline 3 & - & - & - & 13,7 & 32,3 & 23,0 & 14,7 & 29,9 & 22,3 & 15,1 & 29,4 & 22,2 & 15,0 & 28,7 & 21,8 & - & - & - \\
\hline 4 & - & - & - & 13,1 & 30,1 & 21,6 & - & - & - & 15,1 & 28,5 & 21,8 & 16,8 & 30,8 & 23,8 & 14,3 & 33,7 & 24,0 \\
\hline 5 & - & - & - & 14,9 & 30,2 & 22,5 & 17,1 & 31,1 & 24,1 & 15,9 & 30,3 & 23,1 & 18,5 & 33,3 & 25,9 & 9,9 & 27,8 & 18,8 \\
\hline 6 & - & - & - & 15,3 & 30,0 & 22,6 & 17,6 & 30,6 & 24,1 & 14,3 & 30,7 & 22,5 & - & - & - & 9,6 & 26,3 & 17,9 \\
\hline 7 & - & - & - & - & - & - & 17,5 & 30,3 & 23,9 & 16,0 & 29,4 & 22,7 & 19,0 & 36,9 & 27,9 & - & - & - \\
\hline 8 & - & - & - & 15,6 & 31,6 & 23,6 & 16,9 & 31,5 & 24,2 & 16,5 & 30,7 & 23,6 & 19,3 & 34,9 & 25,6 & 12,6 & 34,4 & 23,5 \\
\hline 9 & - & - & - & 15,5 & 30,2 & 22,8 & 16,6 & 30,8 & 23,7 & - & - & - & 18,1 & 34,5 & 26,3 & 19,0 & 34,7 & 26,8 \\
\hline 10 & - & - & - & 14,8 & 30,2 & 22,5 & 14,9 & 30,2 & 22,5 & 17,6 & 32,7 & 25,1 & 19,3 & 33,7 & 26,5 & - & - & - \\
\hline 11 & - & - & - & 13,5 & 30,1 & 21,8 & - & - & - & 18,7 & 33,8 & 26,2 & 20,1 & 35,5 & 27,8 & 18,2 & 34,5 & 26,3 \\
\hline 12 & - & - & - & 14,5 & 29,6 & 22,0 & 16,9 & 32,4 & 24,6 & 19,0 & 32,3 & 25,6 & 20,2 & 36,2 & 28,2 & 20,0 & 37,8 & 28,9 \\
\hline 13 & - & - & - & 13,8 & 30,0 & 21,8 & 15,6 & 29,2 & 22,4 & 16,8 & 31,7 & 24,2 & - & - & - & 20,2 & 39,1 & 29,6 \\
\hline 14 & - & - & - & - & - & - & 16,4 & 30,5 & 23,4 & 17,0 & 31,4 & 24,2 & 20,1 & 38,5 & 29,3 & 19,3 & 39,1 & 29,2 \\
\hline 15 & - & - & - & 13,6 & 31,8 & 22,7 & - & - & - & 18,5 & 32,4 & 25,4 & 20,7 & 36,6 & 28,6 & 22,2 & 40,2 & 31,2 \\
\hline 16 & - & - & - & 13,8 & 29,9 & 21,8 & 15,1 & 32,6 & 23,8 & - & - & - & 20,5 & 37,2 & 28,8 & 21,3 & 39,1 & 30,2 \\
\hline 17 & - & - & - & 14,5 & 29,9 & 22,2 & 16,0 & 31,1 & 23,5 & 15,5 & 26,3 & 20,9 & 20,3 & 37,5 & 28,9 & - & - & - \\
\hline 18 & - & - & - & 14,3 & 30,3 & 22,3 & - & - & - & 15,5 & 30,7 & 23,1 & 19,7 & 37,5 & 28,6 & 20,0 & 38,1 & 29,0 \\
\hline 19 & - & - & - & 13,5 & 30,4 & 21,9 & 15,1 & 31,7 & 23,4 & 15,3 & 31,6 & 23,4 & 18,9 & 34,3 & 26,6 & 18,6 & 35,6 & 27,1 \\
\hline 20 & - & - & - & 17,0 & 30,5 & 23,7 & 17,3 & 29,9 & 23,6 & 15,9 & 31,6 & 23,7 & - & - & - & - & - & - \\
\hline 21 & - & - & - & - & - & - & 15,9 & 29,1 & 22,5 & 15,1 & 32,0 & 23,5 & 14,0 & 37,7 & 25,8 & - & - & - \\
\hline 22 & - & - & - & 16,0 & 30,5 & 23,2 & 16,9 & 30,4 & 23,6 & 18,1 & 32,0 & 25,0 & 12,4 & 30,0 & 21,2 & - & - & - \\
\hline 23 & - & - & - & 17,2 & 21,7 & 19,4 & 16,6 & 28,4 & 22,5 & - & - & - & 12,4 & 31,0 & 21,7 & - & - & - \\
\hline 24 & - & - & - & 14,5 & 20,4 & 17,4 & 16,5 & 29,2 & 22,8 & 17,0 & 33,8 & 25,4 & 15,6 & 32,0 & 23,8 & - & - & - \\
\hline 25 & - & - & - & 16,3 & 28,2 & 22,2 & - & - & - & 18,0 & 33,4 & 25,7 & 17,7 & 34,8 & 26,2 & - & - & - \\
\hline 26 & - & - & - & 15,7 & 28,7 & 22,2 & 17,4 & 31,0 & 24,2 & 16,8 & 33,6 & 25,2 & 19,4 & 36,2 & 27,8 & - & - & - \\
\hline 27 & 20,5 & 36,8 & 28,6 & 15,9 & 31,2 & 23,5 & 11,1 & 26,0 & 18,5 & 17,8 & 33,5 & 25,6 & - & - & - & - & - & - \\
\hline 28 & 25,8 & 35,1 & 30,4 & - & - & - & 10,6 & 25,8 & 18,2 & 19,4 & 33,4 & 26,4 & 17,7 & 35,4 & 26,5 & - & - & - \\
\hline 29 & 18,1 & 33,6 & 25,8 & 15,3 & 33,5 & 24,4 & 11,0 & 26,3 & 18,6 & 16,8 & 35,0 & 25,9 & 18,0 & 35,0 & 26,5 & - & - & - \\
\hline 30 & - & - & - & 15,8 & 31,4 & 23,6 & - & - & - & - & - & - & 13,7 & 31,8 & 22,7 & - & - & - \\
\hline 31 & - & - & - & 16,4 & 34,4 & 25,4 & - & - & - & 14,6 & 35,0 & 24,8 & 15,9 & 29,6 & 22,7 & - & - & - \\
\hline Média & 21,5 & 35,2 & 28,3 & 14,4 & 30,1 & 22,6 & 15,7 & 30,1 & 22,9 & 16,0 & 31,7 & 24,1 & 17,4 & 26,6 & 25,4 & 17,5 & 34,9 & 26,2 \\
\hline
\end{tabular}


Tabela A23 - Umidade relativa do ar (\%) registrada no interior do armazém, no período de abril a setembro de 2006, na região de Tupã.

\begin{tabular}{|c|c|c|c|c|c|c|c|c|c|c|c|c|c|c|c|c|c|c|}
\hline \multirow[t]{2}{*}{ Dia } & \multicolumn{3}{|c|}{ Abril / 2006} & \multicolumn{3}{|c|}{ Maio /2006 } & \multicolumn{3}{|c|}{ junho / 2006} & \multicolumn{3}{|c|}{ Julho / 2006} & \multicolumn{3}{|c|}{ Agosto / 2006} & \multicolumn{3}{|c|}{ Setembro /2006 } \\
\hline & Mín & Máx & Méd & Mín & Máx & Méd & Mín & Máx & Méd & Mín & Máx & Méd & Mín & Máx & Méd & Mín & Máx & Méd \\
\hline 1 & - & - & - & - & - & - & 24,0 & 66,0 & 45,0 & 29,0 & 69,0 & 49,0 & 55,0 & 69,0 & 62,0 & 24,0 & 64,0 & 44,0 \\
\hline 2 & - & - & - & 24,0 & 71,0 & 46,0 & 25,0 & 71,0 & 48,0 & - & - & - & 35,0 & 69,0 & 52,0 & 46,0 & 70,0 & 58,0 \\
\hline 3 & - & - & - & 24,0 & 70,0 & 47,0 & 30,0 & 70,0 & 50,0 & 32,0 & 63,0 & 47,5 & 36,0 & 68,0 & 52,0 & - & - & - \\
\hline 4 & - & - & - & 24,0 & 72,0 & 48,0 & - & - & - & 35,0 & 69,0 & 52,0 & 32,0 & 64,0 & 48,0 & 24,0 & 68,0 & 46,0 \\
\hline 5 & - & - & - & 24,0 & 70,0 & 47,0 & 30,0 & 63,0 & 46,5 & 29,0 & 68,0 & 48,5 & 24,0 & 58,0 & 41,0 & 24,0 & 60,0 & 42,0 \\
\hline 6 & - & - & - & 24,0 & 67,0 & 45,5 & 32,0 & 67,0 & 49,5 & 25,0 & 69,0 & 47,0 & - & - & - & 24,0 & 58,0 & 41,0 \\
\hline 7 & - & - & - & - & - & - & 31,0 & 68,0 & 49,5 & 27,0 & 63,0 & 45,0 & 24,0 & 56,0 & 40,0 & - & - & - \\
\hline 8 & - & - & - & 24,0 & 68,0 & 46,0 & 26,0 & 65,0 & 45,5 & 25,0 & 58,0 & 41,5 & 24,0 & 48,0 & 36,0 & 24,0 & 55,0 & 39,5 \\
\hline 9 & - & - & - & 28,0 & 68,0 & 48,0 & 25,0 & 60,0 & 42,5 & - & - & - & 24,0 & 48,0 & 36,0 & 24,0 & 50,0 & 37,0 \\
\hline 10 & - & - & - & 68,0 & 68,0 & 68,0 & 25,0 & 65,0 & 45,0 & 24,0 & 61,0 & 42,5 & 24,0 & 47,0 & 35,5 & - & - & - \\
\hline 11 & - & - & - & 26,0 & 70,0 & 48,0 & - & - & - & 25,0 & 68,0 & 46,5 & 24,0 & 45,0 & 34,5 & 24,0 & 56,0 & 40,0 \\
\hline 12 & - & - & - & 24,0 & 68,0 & 46,0 & 28,0 & 65,0 & 46,5 & 24,0 & 63,0 & 43,5 & 24,0 & 43,0 & 33,5 & 24,0 & 45,0 & 34,5 \\
\hline 13 & - & - & - & 24,0 & 68,0 & 46,0 & 33,0 & 70,0 & 51,5 & 24,0 & 61,0 & 42,5 & - & - & - & 24,0 & 43,0 & 33,5 \\
\hline 14 & - & - & - & - & - & - & 29,0 & 67,0 & 48,0 & 24,0 & 58,0 & 41,0 & 25,0 & 45,0 & 35,0 & 24,0 & 44,0 & 34,0 \\
\hline 15 & - & - & - & 25,0 & 67,0 & 46,0 & - & - & - & 24,0 & 56,0 & 40,0 & 24,0 & 42,0 & 33,0 & 24,0 & 34,0 & 29,0 \\
\hline 16 & - & - & - & 24,0 & 66,0 & 45,0 & 25,0 & 66,0 & 45,5 & - & - & - & 24,0 & 42,0 & 33,0 & 24,0 & 61,0 & 42,5 \\
\hline 17 & - & - & - & 25,0 & 66,0 & 45,5 & 24,0 & 59,0 & 41,5 & 25,0 & 57,0 & 41,0 & 24,0 & 51,0 & 37,5 & - & - & - \\
\hline 18 & - & - & - & 24,0 & 66,0 & 45,0 & - & - & - & 24,0 & 64,0 & 44,0 & 24,0 & 55,0 & 39,5 & 24,0 & 62,0 & 43,0 \\
\hline 19 & - & - & - & 24,0 & 66,0 & 45,0 & 26,0 & 65,0 & 45,5 & 24,0 & 57,0 & 40,5 & 24,0 & 63,0 & 43,5 & 26,0 & 63,0 & 44,5 \\
\hline 20 & - & - & - & 24,0 & 68,0 & 46,0 & 28,0 & 63,0 & 45,5 & 24,0 & 54,0 & 39,0 & - & - & - & - & - & - \\
\hline 21 & - & - & - & - & - & - & 27,0 & 59,0 & 43,0 & 24,0 & 55,0 & 39,5 & 24,0 & 64,0 & 44,0 & - & - & - \\
\hline 22 & - & - & - & 24,0 & 73,0 & 48,5 & 27,0 & 57,0 & 42,0 & 24,0 & 48,0 & 36,0 & 24,0 & 57,0 & 40,5 & - & - & - \\
\hline 23 & - & - & - & 67,0 & 74,0 & 70,5 & 32,0 & 57,0 & 39,0 & - & - & - & 24,0 & 57,0 & 40,5 & - & - & - \\
\hline 24 & - & - & - & 61,0 & 74,0 & 67,5 & 30,0 & 59,0 & 44,5 & 24,0 & 48,0 & 36,0 & 24,0 & 44,0 & 34,0 & - & - & - \\
\hline 25 & - & - & - & 63,0 & 73,0 & 68,0 & - & - & - & 24,0 & 44,0 & 34,0 & 24,0 & 33,0 & 28,5 & - & - & - \\
\hline 26 & - & - & - & 40,0 & 73,0 & 56,5 & 27,0 & 71,0 & 49,0 & 24,0 & 45,0 & 34,5 & 24,0 & 34,0 & 29,0 & - & - & - \\
\hline 27 & 60 & 69 & 64,5 & 35,0 & 73,0 & 54,0 & 51,0 & 73,0 & 62,0 & 24,0 & 42,0 & 33,0 & - & - & - & - & - & - \\
\hline 28 & 49 & 60 & 54,5 & - & - & - & 28,0 & 70,0 & 49,0 & 24,0 & 45,0 & 34,5 & 24,0 & 57,0 & 40,5 & - & - & - \\
\hline 29 & 24 & 72 & 48,0 & 24,0 & 73,0 & 48,5 & - & - & - & 24,0 & 71,0 & 47,5 & 24,0 & 56,0 & 40,0 & - & - & - \\
\hline 30 & - & - & - & 27,0 & 69,0 & 48,0 & 26,0 & 71,0 & 48,5 & - & - & - & 24,0 & 56,0 & 40,0 & - & - & - \\
\hline 31 & - & - & - & 27,0 & 66,0 & 46,5 & - & - & - & 24,0 & 72,0 & 48,0 & 24,0 & 49,0 & 36,5 & - & - & - \\
\hline Média & 66,5 & 67,0 & 55,7 & 31,8 & 69,5 & 50,6 & 27,6 & 65,3 & 46,8 & 25,4 & 58,8 & 42,1 & 28,5 & 52,6 & 39,5 & 25,6 & 55,5 & 40,6 \\
\hline
\end{tabular}


Tabela A24 - Resultados das amostras positivas de aflatoxinas $B_{1}, B_{2}, G_{1}$ e $G_{2}(\mu \mathrm{g} / \mathrm{kg})$ encontradas nos grãos no armazenamento, na Região de Tupã - SP, no período de abril a setembro de 2006.

\begin{tabular}{|c|c|c|c|c|c|c|c|c|c|}
\hline \multirow{2}{*}{$\begin{array}{c}\text { Armazenamento } \\
\text { Coletas }\end{array}$} & \multirow{2}{*}{$\begin{array}{c}\text { Amostras } \\
\text { Parcelas }\end{array}$} & \multicolumn{4}{|c|}{ IAC-CAIAPÒ $(\mu \mathrm{g} / \mathrm{Kg})$} & \multicolumn{4}{|c|}{ IAC $886(\mu \mathrm{g} / \mathrm{Kg})$} \\
\hline & & $\overline{B_{1}}$ & $\mathrm{~B}_{2}$ & $\mathbf{G}_{1}$ & $\mathbf{G}_{2}$ & $\mathrm{~B}_{1}$ & $\mathrm{~B}_{2}$ & $\mathbf{G}_{1}$ & $\mathbf{G}_{2}$ \\
\hline \multirow{5}{*}{$1^{\circ}$} & 1 & ND & ND & ND & ND & 3,37 & 0,13 & ND & ND \\
\hline & 2 & ND & ND & ND & ND & 0,15 & ND & 1,22 & ND \\
\hline & 3 & ND & ND & ND & ND & ND & ND & ND & ND \\
\hline & 4 & ND & ND & ND & ND & 0,06 & 0,04 & ND & ND \\
\hline & 5 & ND & ND & ND & ND & ND & ND & ND & ND \\
\hline \multirow{5}{*}{$2^{\circ}$} & 1 & ND & ND & ND & ND & ND & ND & ND & ND \\
\hline & 2 & ND & ND & ND & ND & ND & ND & ND & ND \\
\hline & 3 & ND & ND & ND & ND & ND & ND & ND & ND \\
\hline & 4 & ND & ND & ND & ND & ND & ND & ND & ND \\
\hline & 5 & ND & ND & ND & ND & ND & 0,05 & ND & ND \\
\hline \multirow{5}{*}{$3^{\circ}$} & 1 & "ND & "ND & $\overline{N \text { ND }}$ & $\overline{~ N D}$ & 0,03 & "ND & 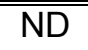 & $\overline{N \text { ND }}$ \\
\hline & 2 & 1,92 & 1,14 & ND & ND & ND & ND & ND & ND \\
\hline & 3 & 0,65 & 0,07 & ND & ND & ND & ND & ND & ND \\
\hline & 4 & 0,05 & ND & ND & ND & ND & ND & ND & ND \\
\hline & 5 & ND & ND & ND & ND & ND & ND & ND & ND \\
\hline \multirow{5}{*}{$4^{\circ}$} & $\overline{1}$ & $\overline{\mathrm{ND}}$ & NDD & $\overline{N D}$ & $\overline{\mathrm{ND}}$ & $\overline{N D D}$ & $\overline{\mathrm{ND}}$ & $\overline{\mathrm{ND}}$ & $\overline{\mathrm{ND}}$ \\
\hline & 2 & ND & ND & ND & ND & ND & ND & ND & ND \\
\hline & 3 & ND & ND & ND & ND & ND & ND & ND & ND \\
\hline & 4 & ND & ND & ND & ND & 0,26 & ND & ND & ND \\
\hline & 5 & ND & ND & ND & ND & 15,69 & 0,51 & 0,41 & ND \\
\hline \multirow{5}{*}{$5^{\circ}$} & 1 & $\overline{\mathrm{ND}}$ & ND & $\overline{\mathrm{ND}}$ & ND & ND & ND & ND & ND \\
\hline & 2 & ND & ND & ND & ND & ND & ND & ND & ND \\
\hline & 3 & ND & ND & ND & ND & ND & ND & ND & ND \\
\hline & 4 & ND & ND & ND & ND & ND & ND & ND & ND \\
\hline & 5 & ND & ND & ND & ND & ND & ND & ND & ND \\
\hline \multirow{5}{*}{$6^{\circ}$} & 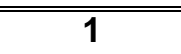 & ND & ND & ND & ND & NDD & $\overline{\mathrm{ND}}$ & $\overline{\mathrm{ND}}$ & ND \\
\hline & 2 & 0,32 & 0,14 & ND & ND & ND & ND & ND & ND \\
\hline & 3 & ND & ND & ND & ND & ND & ND & ND & ND \\
\hline & 4 & ND & ND & ND & ND & ND & ND & ND & ND \\
\hline & 5 & ND & ND & ND & ND & ND & ND & ND & ND \\
\hline
\end{tabular}

ND - Não Detectado

Limite de quantificação $=0,1780 \mu \mathrm{g} / \mathrm{Kg}$ para $A F B_{1}, 0,1470 \mu \mathrm{g} / \mathrm{Kg}$ para AFB ${ }_{2}, 0,1520 \mu \mathrm{g} / \mathrm{Kg}$ para $A F G_{1}, 0,076 \mu \mathrm{g} / \mathrm{Kg}$ para AFG

Limite de deteç̧ão $=0,03 \mu \mathrm{g} / \mathrm{kg}$ para $A F B_{1}, 0,03 \mu \mathrm{g} / \mathrm{kg}$ para $A F B_{2}, 0,03 \mu \mathrm{g} / \mathrm{kg}$ para $A F G_{1}$ e $0,01 \mu \mathrm{g} / \mathrm{kg}$ para $A F G_{2}$ 
Tabela A25 - Resultados das amostras positivas de aflatoxinas $B_{1}, B_{2}, G_{1}$ e $G_{2}(\mu \mathrm{g} / \mathrm{kg})$ encontradas nas cascas no armazenamento, na Região de Tupã - SP, no período de abril a setembro de 2006.

\begin{tabular}{|c|c|c|c|c|c|c|c|c|c|}
\hline \multirow{2}{*}{$\begin{array}{c}\begin{array}{c}\text { Armazenamen } \\
\text { to }\end{array} \\
\text { Coletas } \\
\end{array}$} & \multirow{2}{*}{$\begin{array}{c}\text { Amostras } \\
\text { Parcelas } \\
\end{array}$} & \multicolumn{4}{|c|}{ IAC-CAIAPÒ $(\mu \mathrm{g} / \mathrm{Kg})$} & \multicolumn{4}{|c|}{ IAC $886(\mu \mathrm{g} / \mathrm{Kg})$} \\
\hline & & $\overline{\mathrm{B}_{1}}$ & $\overline{\mathbf{B}_{2}}$ & $\mathbf{G}_{1}$ & $\overline{\mathbf{G}_{2}}$ & $\mathrm{~B}_{1}$ & $\mathrm{~B}_{2}$ & $\overline{\mathbf{G}_{1}}$ & $\overline{\mathbf{G}_{2}}$ \\
\hline \multirow{5}{*}{$1^{\circ}$} & 1 & 0,03 & ND & ND & ND & ND & ND & NDD & ND \\
\hline & 2 & ND & ND & ND & ND & ND & ND & ND & ND \\
\hline & 3 & ND & ND & ND & ND & 0,10 & ND & ND & ND \\
\hline & 4 & 0,05 & ND & ND & ND & ND & ND & ND & ND \\
\hline & 5 & ND & ND & ND & ND & 0,09 & ND & ND & ND \\
\hline \multirow{5}{*}{$2^{\circ}$} & 1 & ND & ND & ND & ND & ND & ND & ND & ND \\
\hline & 2 & ND & ND & ND & ND & ND & ND & ND & ND \\
\hline & 3 & ND & ND & ND & ND & ND & ND & ND & ND \\
\hline & 4 & ND & ND & ND & ND & ND & ND & ND & ND \\
\hline & 5 & ND & ND & ND & ND & ND & ND & ND & ND \\
\hline \multirow{5}{*}{$3^{\circ}$} & 1 & ND & ND & ND & ND & ND & ND & ND & ND \\
\hline & 2 & ND & ND & ND & ND & ND & ND & ND & ND \\
\hline & 3 & 0,03 & ND & ND & ND & ND & ND & ND & ND \\
\hline & 4 & ND & ND & ND & ND & 0,03 & ND & ND & ND \\
\hline & 5 & 2,29 & ND & ND & ND & ND & ND & ND & ND \\
\hline \multirow{5}{*}{$4^{\circ}$} & $\overline{1}$ & ND & $\overline{N D D}$ & NDD & $\overline{N D D}$ & 0,12 & NDD & ND & $\overline{N \text { ND }}$ \\
\hline & 2 & ND & ND & ND & ND & ND & ND & ND & ND \\
\hline & 3 & ND & ND & ND & ND & ND & ND & ND & ND \\
\hline & 4 & ND & ND & ND & ND & ND & 1,14 & ND & ND \\
\hline & 5 & ND & ND & ND & ND & ND & ND & ND & ND \\
\hline \multirow{5}{*}{$5^{\circ}$} & 1 & ND & $\overline{\mid N D}$ & ND & $\overline{\mid N D}$ & 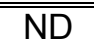 & ND & ND & $\overline{\mathrm{ND}}$ \\
\hline & 2 & ND & ND & ND & ND & 3,31 & ND & ND & ND \\
\hline & 3 & ND & ND & ND & ND & ND & ND & ND & ND \\
\hline & 4 & ND & ND & ND & ND & ND & ND & ND & ND \\
\hline & 5 & ND & ND & ND & ND & ND & ND & ND & ND \\
\hline \multirow{5}{*}{$6^{\circ}$} & $\overline{11}$ & NDD & $\overline{\mathrm{ND}}$ & NDD & $\overline{\mathrm{ND}}$ & "ND & NDD & 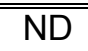 & 0,17 \\
\hline & 2 & ND & ND & ND & ND & 0,84 & ND & 0,14 & 0,08 \\
\hline & 3 & ND & ND & ND & ND & ND & ND & ND & ND \\
\hline & 4 & ND & ND & ND & ND & ND & ND & ND & ND \\
\hline & 5 & ND & ND & ND & ND & 0,35 & ND & ND & ND \\
\hline
\end{tabular}

$\overline{\overline{N D}-\text { Não Detectado }}$

Limite de quantificação $=0,1780 \mu \mathrm{g} / \mathrm{Kg}$ para $\mathrm{AFB}_{1}, 0,1470 \mu \mathrm{g} / \mathrm{Kg}$ para AFB ${ }_{2}, 0,1520 \mu \mathrm{g} / \mathrm{Kg}$ para AFG $1,0,076 \mu \mathrm{g} / \mathrm{Kg} \mathrm{para} \mathrm{AFG}_{2}$

Limite de detecção $=0,03 \mu \mathrm{g} / \mathrm{kg}$ para $A F B_{1}, 0,03 \mu \mathrm{g} / \mathrm{kg}$ para $A F B_{2}, 0,03 \mu \mathrm{g} / \mathrm{kg}$ para $A F G_{1}$ e $0,01 \mu \mathrm{g} / \mathrm{kg}$ para $A F G_{2}$ 
Tabela A26 - Resultados das amostras positivas de Ácido ciclopiazônico $(\mu \mathrm{g} / \mathrm{kg})$ encontradas nos grãos no armazenamento, na Região de Tupã - SP, no período de abril a setembro de 2006.

\begin{tabular}{|c|c|c|c|}
\hline ARMAZENAMENTO & AMOSTRAS & IAC-CAIAPÓ $(\mu \mathrm{g} / \mathrm{Kg})$ & IAC $886(\mu \mathrm{g} / \mathrm{Kg})$ \\
\hline Coletas & Parcelas & Grãos & Grãos \\
\hline \multirow{5}{*}{$1^{a}$} & 1 & 4420,8 & 1924,2 \\
\hline & 2 & ND & 105,4 \\
\hline & 3 & ND & 130,2 \\
\hline & 4 & ND & 363,2 \\
\hline & 5 & ND & 1774,2 \\
\hline \multirow{5}{*}{$2^{a}$} & 1 & 4467,1 & 513,4 \\
\hline & 2 & 323,4 & 170,1 \\
\hline & 3 & 603,7 & 310,4 \\
\hline & 4 & 149,9 & 158,3 \\
\hline & 5 & 469,2 & ND \\
\hline \multirow{5}{*}{$3^{a}$} & 1 & ND & 6810,8 \\
\hline & 2 & 7273,3 & 201,0 \\
\hline & 3 & 112,5 & ND \\
\hline & 4 & 1373,5 & 6432,3 \\
\hline & 5 & 1575,6 & 6228,5 \\
\hline \multirow{5}{*}{$4^{a}$} & $\overline{11}$ & $\overline{5068,6}$ & ND \\
\hline & 2 & 3837,2 & 2196,6 \\
\hline & 3 & 292,0 & ND \\
\hline & 4 & 430,5 & 146,9 \\
\hline & 5 & 689,1 & 158,0 \\
\hline \multirow{5}{*}{$5^{a}$} & $\overline{11}$ & 394,1 & 3403,2 \\
\hline & 2 & ND & 147,0 \\
\hline & 3 & ND & 1997,2 \\
\hline & 4 & ND & 4297,3 \\
\hline & 5 & ND & 860,4 \\
\hline \multirow{5}{*}{$6^{a}$} & $\overline{11}$ & 197,5 & ND \\
\hline & 2 & 110,3 & 5695,0 \\
\hline & 3 & 671,8 & 272,4 \\
\hline & 4 & 137,0 & ND \\
\hline & 5 & 403,8 & 1506,5 \\
\hline
\end{tabular}

ND - Não detectado

Limite de detecção $=80,0 \mu \mathrm{g} / \mathrm{kg}$

Limite de quantificação $=128,0 \mu \mathrm{g} / \mathrm{kg}$ 
Tabela A27 - Resultados obtidos na avaliação do potencial toxigenico (aflatoxinas e ACP), produção e diâmetro dos esclerócios e cultivo em meio AFPA, das 135 cepas de $A$. flavus e $A$. parasiticus isoladas das cascas e grãos de amendoim.

\begin{tabular}{|c|c|c|c|c|c|c|c|c|}
\hline \multirow[b]{2}{*}{ Isolados } & \multirow{2}{*}{$\begin{array}{l}\text { Número de } \\
\text { esclerócios }\end{array}$} & \multirow{2}{*}{$\begin{array}{c}\emptyset \text { dos } \\
\text { esclerócios } \\
(\mu \mathrm{m}) \\
\end{array}$} & \multicolumn{4}{|c|}{ Aflatoxinas $(\mu \mathrm{g} / \mathrm{kg})$} & \multirow{2}{*}{$\begin{array}{c}\mathrm{ACP} \\
(\mu \mathrm{g} / \mathrm{kg})\end{array}$} & \multirow{2}{*}{$\begin{array}{c}\text { Cultivo AFPA } \\
\text { (coloração do verso) } \\
\end{array}$} \\
\hline & & & $\mathbf{B}_{1}$ & $\mathbf{B}_{2}$ & $\mathbf{G}_{1}$ & $\mathbf{G}_{2}$ & & \\
\hline 1 & 54 & 931 & 145,88 & 0,57 & NP & NP & NP & Laranja \\
\hline 2 & 79 & 759 & 477,69 & 130,82 & NP & NP & $\mathrm{NP}$ & Laranja \\
\hline 3 & NP & NP & 22331,62 & 329,75 & NP & NP & 117439,80 & Laranja \\
\hline 4 & +200 & 524 & 5883,49 & 611,16 & NP & NP & 28587,44 & Laranja \\
\hline 5 & +200 & 648 & 64,01 & NP & NP & NP & 99460,71 & Laranja \\
\hline 6 & +200 & 466 & 45230,25 & 12367,62 & $\mathrm{NP}$ & NP & 273087,79 & Laranja \\
\hline 7 & NP & NP & 12115,23 & 409,19 & 663,79 & $\mathrm{D}$ & $\mathrm{NP}$ & Laranja \\
\hline 8 & +200 & 599 & 14138,03 & 293,23 & $\mathrm{NP}$ & NP & 12264,28 & Laranja \\
\hline 9 & +200 & 565 & 41775,24 & 294,29 & NP & NP & 125494,48 & Laranja \\
\hline 10 & +200 & 528 & 2443,65 & 3,67 & NP & NP & 94497,29 & Laranja \\
\hline 11 & 17 & 656 & 20338,08 & 760,20 & NP & NP & 75436,44 & Laranja \\
\hline 12 & 94 & 675 & 527,85 & 63,48 & NP & NP & 224671,84 & Laranja \\
\hline 13 & +200 & 718 & 6322,01 & 291,43 & NP & NP & 59960,47 & Laranja \\
\hline 14 & 180 & 631 & 4479,37 & 0,90 & NP & NP & 27887,89 & Laranja \\
\hline 15 & +200 & 728 & 4190,70 & 1049,10 & NP & NP & 80393,63 & Laranja \\
\hline 16 & +200 & 548 & 508,16 & NP & NP & NP & 40820,74 & Laranja \\
\hline 17 & NP & NP & 10989,93 & 117,38 & 1345,12 & $\mathrm{D}$ & Negativo & Laranja \\
\hline 18 & +200 & 482 & 14479,26 & 139,05 & NP & NP & 45330,71 & Laranja \\
\hline
\end{tabular}

NP - Não Produtor

D - Detectado

(continua) 
(continuação)

\begin{tabular}{|c|c|c|c|c|c|c|c|c|}
\hline \multirow[b]{2}{*}{ Isolados } & \multirow{2}{*}{$\begin{array}{l}\text { Número de } \\
\text { esclerócios }\end{array}$} & \multirow{2}{*}{$\begin{array}{c}\begin{array}{c}\emptyset \text { dos } \\
\text { esclerócios } \\
(\mu \mathrm{m})\end{array} \\
\end{array}$} & \multicolumn{4}{|c|}{ Aflatoxinas $(\mu \mathrm{g} / \mathrm{kg})$} & \multirow{2}{*}{$\begin{array}{c}\mathrm{ACP} \\
(\mu \mathrm{g} / \mathrm{kg}) \\
\end{array}$} & \multirow{2}{*}{$\begin{array}{c}\text { Cultivo AFPA } \\
\text { (coloração do verso) } \\
\end{array}$} \\
\hline & & & $\mathbf{B}_{1}$ & $\mathbf{B}_{2}$ & $\mathbf{G}_{1}$ & $\mathbf{G}_{2}$ & & \\
\hline 19 & +200 & 643 & 50321,58 & 669,89 & NP & NP & 26409,29 & Laranja \\
\hline 20 & +200 & 572 & 3508,39 & NP & NP & NP & 158182,04 & Laranja \\
\hline 21 & NP & NP & 39226,94 & 11387,01 & 2276,19 & NP & 483,38 & Laranja \\
\hline 22 & 145 & 717 & 11992,37 & 1317,07 & $\mathrm{NP}$ & NP & 94178,53 & Laranja \\
\hline 23 & +200 & 499 & 1814,51 & 3,57 & NP & NP & 97837,45 & Laranja \\
\hline 24 & +200 & 666 & 839,31 & NP & NP & NP & 42469,36 & Laranja \\
\hline 25 & NP & NP & NP & NP & NP & NP & NP & Laranja \\
\hline 26 & +200 & 563 & 6888,97 & 5,12 & NP & NP & 67909,84 & Laranja \\
\hline 27 & +200 & 601 & 2484,18 & 697,10 & NP & NP & 96946,35 & Laranja \\
\hline 28 & 27 & 839 & 3370,80 & 101,04 & NP & NP & NP & Laranja \\
\hline 29 & 11 & 694 & 47,26 & 41,56 & NP & NP & 67040,39 & Laranja \\
\hline 30 & 5 & 735 & 695,63 & 85,51 & NP & NP & 881,32 & Laranja \\
\hline 31 & 23 & 632 & 8311,60 & 3006,35 & NP & NP & 11904,87 & Laranja \\
\hline 32 & NP & NP & 30973,63 & 13652,01 & 4619,78 & 1026,28 & NP & Laranja \\
\hline 33 & 14 & 517 & 1083,47 & NP & NP & NP & NP & Laranja \\
\hline 34 & NP & NP & 7848,28 & 206,70 & NP & NP & NP & Laranja \\
\hline 35 & 2 & 870 & 185663,0 & 247,74 & NP & NP & 120371,63 & Laranja \\
\hline 36 & 3 & 730 & 309,35 & 28,56 & NP & NP & NP & Laranja \\
\hline 37 & 119 & 841 & 295,29 & NP & NP & NP & 74738,87 & Laranja \\
\hline 38 & $\mathrm{NP}$ & $\mathrm{NP}$ & 78053,88 & 67,91 & $\mathrm{NP}$ & NP & 177873,18 & Laranja \\
\hline
\end{tabular}

NP - Não Produtor

D - Detectado

(continua) 
(continuação)

\begin{tabular}{|c|c|c|c|c|c|c|c|c|}
\hline \multirow[b]{2}{*}{ Isolados } & \multirow[b]{2}{*}{$\begin{array}{l}\text { Número de } \\
\text { esclerócios }\end{array}$} & \multirow{2}{*}{$\begin{array}{c}\emptyset \text { dos } \\
\text { esclerócios } \\
(\mu \mathrm{m})\end{array}$} & \multicolumn{4}{|c|}{ Aflatoxinas $(\mu \mathrm{g} / \mathrm{kg})$} & \multirow[b]{2}{*}{$\begin{array}{c}\mathrm{ACP} \\
(\mu \mathrm{g} / \mathrm{kg})\end{array}$} & \multirow[b]{2}{*}{$\begin{array}{c}\text { Cultivo AFPA } \\
\text { (coloração do verso) }\end{array}$} \\
\hline & & & $\mathbf{B}_{1}$ & $\mathbf{B}_{2}$ & $\mathbf{G}_{1}$ & $\mathbf{G}_{2}$ & & \\
\hline 39 & 110 & 657 & 898,02 & 12,86 & NP & NP & 184181,21 & Laranja \\
\hline 40 & NP & NP & 18508,46 & 185,25 & 2991,26 & Traços & $\mathrm{NP}$ & Laranja \\
\hline 41 & NP & NP & 71348,40 & 2896,65 & NP & $\mathrm{NP}$ & 93942,95 & Laranja \\
\hline 42 & NP & NP & NP & NP & NP & NP & 93034,21 & Laranja \\
\hline 43 & $\mathrm{NP}$ & NP & NP & $\mathrm{NP}$ & NP & NP & 498,13 & Laranja \\
\hline 44 & +200 & 727 & 19742,12 & 149,69 & NP & NP & 54895,40 & Laranja \\
\hline 45 & +200 & 659 & 52035,02 & 3975,65 & NP & NP & 272214,38 & Laranja \\
\hline 46 & 14 & 627 & 200,18 & NP & NP & NP & 270261,17 & Laranja \\
\hline 47 & 3 & 573 & 1069,25 & 41,15 & NP & NP & 13804,68 & Laranja \\
\hline 48 & +200 & 812 & 15336,52 & 282,91 & NP & NP & 19449,01 & Laranja \\
\hline 49 & 24 & 598 & $\mathrm{NP}$ & $\mathrm{NP}$ & NP & NP & 7953,72 & Laranja \\
\hline 50 & +200 & 694 & 25064,35 & 1990,89 & NP & NP & 35142,18 & Laranja \\
\hline 51 & +200 & 444 & 1772,84 & NP & NP & NP & 129710,02 & Laranja \\
\hline 52 & 9 & 644 & NP & NP & NP & NP & 4569,56 & Laranja \\
\hline 53 & +200 & 621 & 18622,98 & 3950,26 & NP & NP & 29828,07 & Laranja \\
\hline 54 & +200 & 714 & $\mathrm{NP}$ & NP & NP & NP & 22977,78 & Laranja \\
\hline 55 & 2 & 950 & 1499,41 & NP & NP & NP & 53056,30 & Laranja \\
\hline 56 & 23 & 797 & 6990,39 & 708,68 & NP & NP & 13035,90 & Laranja \\
\hline 57 & 155 & 568 & 1562,51 & 1275,11 & NP & NP & 93523,07 & Laranja \\
\hline
\end{tabular}

NP - Não Produtor

D - Detectado

(continua) 
(continuação)

\begin{tabular}{|c|c|c|c|c|c|c|c|c|}
\hline \multirow[b]{2}{*}{ Isolados } & \multirow[b]{2}{*}{$\begin{array}{l}\text { Número de } \\
\text { esclerócios }\end{array}$} & \multirow{2}{*}{$\begin{array}{c}\emptyset \text { dos } \\
\text { esclerócios } \\
(\mu \mathrm{m}) \\
\end{array}$} & \multicolumn{4}{|c|}{ Aflatoxinas $(\mu \mathrm{g} / \mathrm{kg})$} & \multirow[b]{2}{*}{$\begin{array}{c}\mathrm{ACP} \\
(\mu \mathrm{g} / \mathrm{kg})\end{array}$} & \multirow[b]{2}{*}{$\begin{array}{c}\text { Cultivo AFPA } \\
\text { (coloração do verso }\end{array}$} \\
\hline & & & $\mathbf{B}_{1}$ & $\mathbf{B}_{2}$ & $\mathbf{G}_{1}$ & $\mathbf{G}_{2}$ & & \\
\hline 58 & +200 & 752 & 2139,65 & 329,69 & NP & NP & 232118,65 & Laranja \\
\hline 59 & +200 & 728 & 767,22 & 28,59 & NP & NP & NP & Laranja \\
\hline 60 & NP & NP & 608,65 & NP & NP & NP & 26946,01 & Laranja \\
\hline 61 & +200 & 603 & 24222,48 & 8331,91 & NP & NP & 58733,02 & Laranja \\
\hline 62 & 16 & 803 & 2722,58 & NP & NP & NP & 44649,29 & Laranja \\
\hline 63 & NP & NP & 895,23 & NP & NP & NP & 29355,47 & Laranja \\
\hline 64 & 91 & 648 & 22233,32 & 141,31 & $\mathrm{NP}$ & NP & 22202,62 & Laranja \\
\hline 65 & +200 & 622 & 139,39 & NP & NP & NP & 2314,80 & Laranja \\
\hline 66 & 100 & 805 & NP & NP & NP & NP & 6719,21 & Laranja \\
\hline 67 & +200 & 796 & 930,78 & 135,57 & NP & NP & 98863,17 & Laranja \\
\hline 68 & +200 & 635 & 14004,09 & 2784,37 & NP & NP & 217118,64 & Laranja \\
\hline 69 & +200 & 685 & 24023,20 & 3502,97 & NP & NP & 117342,01 & Laranja \\
\hline 70 & 176 & 871 & 3593,24 & 527,61 & NP & NP & 12219,63 & Laranja \\
\hline 71 & NP & NP & 725,73 & 72,04 & NP & NP & 18584,58 & Laranja \\
\hline 72 & +200 & 566 & 19056,94 & 1033,60 & NP & NP & 60906,01 & Laranja \\
\hline 73 & NP & NP & 762,85 & 5,15 & NP & NP & 7058,98 & Laranja \\
\hline 74 & 122 & 740 & 6722,75 & 1236,28 & NP & NP & 19102,71 & Laranja \\
\hline 75 & NP & NP & 16591,37 & 8220,86 & NP & NP & 60893,77 & Laranja \\
\hline 76 & NP & NP & 455,55 & 352,62 & $\mathrm{NP}$ & NP & 88693,06 & Laranja \\
\hline
\end{tabular}

NP - Não Produtor

D - Detectado

(continua) 
(continuação)

\begin{tabular}{|c|c|c|c|c|c|c|c|c|}
\hline \multirow[b]{2}{*}{ Isolados } & \multirow[b]{2}{*}{$\begin{array}{l}\text { Número de } \\
\text { esclerócios }\end{array}$} & \multirow{2}{*}{$\begin{array}{c}\emptyset \text { dos } \\
\text { esclerócios } \\
(\mu \mathrm{m})\end{array}$} & \multicolumn{4}{|c|}{ Aflatoxinas $(\mu \mathrm{g} / \mathrm{kg})$} & \multirow[b]{2}{*}{$\begin{array}{c}\mathrm{ACP} \\
(\mu \mathrm{g} / \mathrm{kg}) \\
\end{array}$} & \multirow[b]{2}{*}{$\begin{array}{c}\text { Cultivo AFPA } \\
\text { (coloração do verso) } \\
\end{array}$} \\
\hline & & & $\mathbf{B}_{1}$ & $\mathbf{B}_{2}$ & $\mathbf{G}_{1}$ & $\mathbf{G}_{2}$ & & \\
\hline 77 & 19 & 657 & 1436,90 & 427,86 & NP & NP & 37094,30 & Laranja \\
\hline 78 & NP & NP & NP & $\mathrm{NP}$ & NP & NP & 405,27 & Laranja \\
\hline 79 & 8 & 675 & NP & NP & NP & NP & 83551,76 & Laranja \\
\hline 80 & NP & NP & NP & NP & NP & NP & 22805,01 & Laranja \\
\hline 81 & NP & NP & NP & NP & NP & NP & 23869,16 & Laranja \\
\hline 82 & NP & NP & NP & NP & NP & NP & 14008,44 & Laranja \\
\hline 83 & +200 & 914 & 24,41 & $\mathrm{NP}$ & NP & NP & 363419,25 & Laranja \\
\hline 84 & +200 & 771 & 966,24 & 12,72 & NP & NP & 126282,12 & Laranja \\
\hline 85 & NP & $\mathrm{NP}$ & NP & NP & NP & NP & 123144,96 & Laranja \\
\hline 86 & 1 & 1070 & NP & $\mathrm{NP}$ & NP & NP & 7437,26 & Laranja \\
\hline 87 & NP & $\mathrm{NP}$ & 11333,54 & 856,22 & NP & NP & 114942,19 & Laranja \\
\hline 88 & NP & NP & 8965,98 & 672,76 & NP & NP & 34258,96 & Laranja \\
\hline 89 & NP & NP & 432,67 & 49,67 & NP & NP & 2272,24 & Laranja \\
\hline 90 & NP & NP & $\mathrm{NP}$ & NP & NP & NP & 88899,62 & Laranja \\
\hline 91 & NP & NP & NP & $\mathrm{NP}$ & NP & NP & 29326,87 & Laranja \\
\hline 92 & NP & NP & 22707,96 & 866,33 & NP & NP & 36276,37 & Laranja \\
\hline 93 & 1 & 850 & 82373,72 & $\mathrm{NP}$ & NP & NP & 27241,05 & Laranja \\
\hline 94 & 190 & 671 & 1977,19 & 455,36 & NP & NP & 131565,60 & Laranja \\
\hline 95 & 10 & 680 & 9240,99 & $\mathrm{NP}$ & NP & NP & 39215,38 & Laranja \\
\hline 96 & NP & NP & 7923,26 & NP & NP & NP & 34581,87 & Laranja \\
\hline
\end{tabular}

NP - Não Produto

D - Detectado

(continua) 
(continuação)

\begin{tabular}{|c|c|c|c|c|c|c|c|c|}
\hline \multirow[b]{2}{*}{ Isolados } & \multirow[b]{2}{*}{$\begin{array}{l}\text { Número de } \\
\text { esclerócios }\end{array}$} & \multirow{2}{*}{$\begin{array}{c}\emptyset \text { dos } \\
\text { esclerócios } \\
(\mu \mathrm{m})\end{array}$} & \multicolumn{4}{|c|}{ Aflatoxinas $(\mu \mathrm{g} / \mathrm{kg})$} & \multirow[b]{2}{*}{$\begin{array}{c}\mathrm{ACP} \\
(\mu \mathrm{g} / \mathrm{kg})\end{array}$} & \multirow[b]{2}{*}{$\begin{array}{c}\text { Cultivo AFPA } \\
\text { (coloração do verso) }\end{array}$} \\
\hline & & & $\mathbf{B}_{1}$ & $\mathbf{B}_{2}$ & $\mathbf{G}_{1}$ & $\mathbf{G}_{2}$ & & \\
\hline 97 & $\mathrm{NP}$ & NP & NP & NP & NP & NP & 19590,16 & Laranja \\
\hline 98 & +200 & 674 & 8425,05 & 1212,01 & NP & NP & 10787,04 & Laranja \\
\hline 99 & +200 & 864 & 29595,41 & 881,59 & NP & NP & 167941,76 & Laranja \\
\hline 100 & NP & NP & 13194,38 & 118,49 & NP & NP & 142079,20 & Laranja \\
\hline 101 & 97 & 595 & 2615,26 & 19,91 & NP & NP & 5864,49 & Laranja \\
\hline 102 & +200 & 824 & 18038,86 & 1855,25 & NP & NP & 98572,76 & Laranja \\
\hline 103 & 74 & 715 & 7,87 & NP & NP & NP & 27954,90 & Laranja \\
\hline 104 & NP & NP & NP & NP & NP & NP & 20276,25 & Laranja \\
\hline 105 & NP & NP & NP & NP & NP & NP & 43969,78 & Laranja \\
\hline 106 & NP & NP & NP & NP & NP & NP & 21822,68 & Laranja \\
\hline 107 & NP & NP & NP & NP & NP & NP & 17441,71 & Laranja \\
\hline 108 & NP & NP & $\mathrm{NP}$ & NP & NP & NP & 2789,41 & Laranja \\
\hline 109 & 3 & 750 & 215,60 & 69,98 & NP & NP & 472178,67 & Laranja \\
\hline 110 & 4 & 430 & 33,21 & 3,55 & NP & NP & 33203,37 & Laranja \\
\hline 111 & +200 & 608 & $\mathrm{NP}$ & $\mathrm{NP}$ & NP & NP & 224,76 & Laranja \\
\hline 112 & 1 & 850 & 8,50 & NP & NP & NP & 19402,67 & Laranja \\
\hline 113 & 1 & 650 & 612,96 & 13,86 & NP & NP & 31777,81 & Laranja \\
\hline 114 & +200 & 812 & 16728,78 & 5740,30 & NP & NP & 97065,59 & Laranja \\
\hline 115 & 18 & 841 & 138,50 & 20,45 & NP & NP & 1601,61 & Laranja \\
\hline 116 & 6 & 825 & 3347,03 & $\mathrm{NP}$ & NP & NP & 101638,33 & Laranja \\
\hline 117 & NP & NP & 69,70 & NP & NP & NP & 170597,12 & Laranja \\
\hline 118 & NP & NP & NP & NP & NP & NP & 2047,55 & Laranja \\
\hline
\end{tabular}

D - Detectado

(continua) 
(conclusão)

\begin{tabular}{|c|c|c|c|c|c|c|c|c|}
\hline \multirow[b]{2}{*}{ Isolados } & \multirow[b]{2}{*}{$\begin{array}{l}\text { Número de } \\
\text { esclerócios }\end{array}$} & \multirow{2}{*}{$\begin{array}{c}\emptyset \text { dos } \\
\text { esclerócios } \\
(\mu \mathrm{m})\end{array}$} & \multicolumn{4}{|c|}{ Aflatoxinas $(\mu \mathrm{g} / \mathrm{kg})$} & \multirow[b]{2}{*}{$\begin{array}{c}\mathrm{ACP} \\
(\mu \mathrm{g} / \mathrm{kg}) \\
\end{array}$} & \multirow[b]{2}{*}{$\begin{array}{c}\text { Cultivo AFPA } \\
\text { (coloração do verso) } \\
\end{array}$} \\
\hline & & & $\mathbf{B}_{1}$ & $\mathbf{B}_{2}$ & $\mathbf{G}_{1}$ & $\mathbf{G}_{2}$ & & \\
\hline 119 & +200 & 653 & 31825,12 & 5795,47 & NP & NP & 77048,21 & Laranja \\
\hline 120 & +200 & 667 & 53518,63 & 6682,23 & NP & NP & 141669,00 & Laranja \\
\hline 121 & +200 & 759 & 177,48 & NP & NP & NP & 113596,28 & Laranja \\
\hline 122 & +200 & 685 & 6189,74 & 428,09 & NP & NP & 17443,98 & Laranja \\
\hline 123 & +200 & 740 & 80,31 & NP & NP & NP & 46700,43 & Laranja \\
\hline 124 & 1 & 990 & 75,75 & NP & NP & NP & 286920,00 & Laranja \\
\hline 125 & 3 & 800 & 2005,13 & 12,21 & NP & NP & 47899,80 & Laranja \\
\hline 126 & $34(40)$ & 559 & 81,30 & $\mathrm{NP}$ & NP & NP & 260,68 & Laranja \\
\hline 127 & 64 & 914 & 134,46 & 7,52 & NP & NP & 162873,56 & Laranja \\
\hline 128 & 2 & 766 & 538,02 & 14,95 & NP & NP & 59417,00 & Laranja \\
\hline 129 & $4(16)$ & 764 & 13575,88 & 440,96 & NP & NP & 6123,23 & Laranja \\
\hline 130 & +200 & 793 & 63602,14 & 809,12 & NP & NP & 61155,55 & Laranja \\
\hline 131 & NP & NP & 448,16 & NP & NP & NP & 313554,88 & Laranja \\
\hline 132 & NP & NP & 124,53 & 58,49 & NP & NP & 51773,70 & Laranja \\
\hline 133 & NP & NP & $\mathrm{NP}$ & $\mathrm{NP}$ & NP & NP & 5232,53 & Laranja \\
\hline 134 & 32 & 753 & 259,75 & 115,49 & NP & NP & 163111,05 & Laranja \\
\hline 135 & 8 & 610 & 141,79 & $\mathrm{NP}$ & NP & NP & 71502,31 & Laranja \\
\hline
\end{tabular}

NP - Não Produtor

D - Detectado 
ANEXO B - ANÁLISE EXPLORATÓRIA 
Tabela B1 - Estatísticas descritivas para a variável frequência de A. flavus nas cascas de amendoim no campo em porcentagem de cascas contaminadas.

\begin{tabular}{|c|c|c|c|c|c|c|c|}
\hline Variedade & Fase & Média & $\begin{array}{l}\text { Desvio } \\
\text { padrão }\end{array}$ & $\begin{array}{l}\text { Erro } \\
\text { padrão }\end{array}$ & Mínimo & Máximo & $\begin{array}{c}\text { Porcent. } \\
\text { de } 0\end{array}$ \\
\hline & água & 2,5 & 5,6 & 2,5 & 0,0 & 12,5 & 80 \\
\hline \multirow[t]{4}{*}{ Caiapó } & início granação & 2,5 & 5,6 & 2,5 & 0,0 & 12,5 & 80 \\
\hline & grãos maduros & 1,3 & 2,8 & 1,3 & 0,0 & 6,3 & 80 \\
\hline & grãos secos & 0,0 & 0,0 & 0,0 & 0,0 & 0,0 & 100 \\
\hline & água & 2,5 & 3,4 & 1,5 & 0,0 & 6,3 & 60 \\
\hline \multirow[t]{3}{*}{ IAC 886} & início granação & 0,0 & 0,0 & 0,0 & 0,0 & 0,0 & 100 \\
\hline & grãos maduros & 0,0 & 0,0 & 0,0 & 0,0 & 0,0 & 100 \\
\hline & grãos secos & 32,5 & 19,0 & 8,5 & 12,5 & 62,5 & 0 \\
\hline
\end{tabular}

Tabela B2 - Estatísticas descritivas para a variável frequência de $A$. flavus nos grãos de amendoim no campo em porcentagem de grãos contaminados.

\begin{tabular}{rcrrrrrr}
\hline Variedade & Fase & Média & $\begin{array}{c}\text { Desvio } \\
\text { padrão }\end{array}$ & $\begin{array}{c}\text { Erro } \\
\text { padrão }\end{array}$ & Mínimo & $\begin{array}{r}\text { Máximo } \\
\text { Porcent. } \\
\text { Caiapó } 0\end{array}$ \\
\hline & flor & 0,6 & 1,4 & 0,6 & 0,0 & 3,0 & 80 \\
& ginóforo & 0,0 & 0,0 & 0,0 & 0,0 & 0,0 & 100 \\
& água & 0,6 & 1,4 & 0,6 & 0,0 & 3,0 & 80 \\
& início granação & 0,0 & 0,0 & 0,0 & 0,0 & 0,0 & 100 \\
& grãos maduros & 12,1 & 14,0 & 6,3 & 0,0 & 27,3 & 40 \\
& grãos secos & 1,8 & 4,1 & 1,8 & 0,0 & 9,1 & 80 \\
\hline \multirow{4}{*}{ IAC 886 } & flor & 0,6 & 1,4 & 0,6 & 0,0 & 3,0 & 80 \\
& ginóforo & 0,0 & 0,0 & 0,0 & 0,0 & 0,0 & 100 \\
& água & 0,0 & 0,0 & 0,0 & 0,0 & 0,0 & 100 \\
& início granação & 0,0 & 0,0 & 0,0 & 0,0 & 0,0 & 100 \\
& grãos maduros & 3,6 & 8,1 & 3,6 & 0,0 & 18,2 & 80 \\
& grãos secos & 3,6 & 4,0 & 1,8 & 0,0 & 9,1 & 40 \\
\hline
\end{tabular}

Tabela B3 - Estatísticas descritivas para a variável frequência de A. flavus no solo em UFC $\mathrm{x}$ $10^{4}$ por grama de solo.

\begin{tabular}{ccrrrrrr}
\hline Variedade & Fase & Média & $\begin{array}{r}\text { Desvio } \\
\text { padrão }\end{array}$ & $\begin{array}{c}\text { Erro } \\
\text { padrão }\end{array}$ & Mínimo & $\begin{array}{r}\text { Máximo } \\
\text { Porcent. } \\
\text { de 0 0 }\end{array}$ \\
\hline \multirow{3}{*}{ Caiapó } & flor & 1,0 & 2,2 & 1,0 & 0,0 & 5,0 & 80 \\
& ginóforo & 5,0 & 11,2 & 5,0 & 0,0 & 25,0 & 80 \\
& água/início granação & 0,0 & 0,0 & 0,0 & 0,0 & 0,0 & 100 \\
& grãos maduros & 1,0 & 2,2 & 1,0 & 0,0 & 5,0 & 80 \\
\hline \multirow{3}{*}{ IAC 886 } & flor & 15,0 & 11,2 & 5,0 & 0,0 & 30,0 & 20 \\
& ginóforo & 13,0 & 14,0 & 6,2 & 0,0 & 30,0 & 40 \\
& água/início granação & 1,0 & 2,2 & 1,0 & 0,0 & 5,0 & 80 \\
& grãos maduros & 0,0 & 0,0 & 0,0 & 0,0 & 0,0 & 100 \\
\hline
\end{tabular}


Tabela B4 - Estatísticas descritivas para a variável frequência de A. flavus nas cascas de amendoim no armazenamento em porcentagem de cascas contaminadas.

\begin{tabular}{rcrrrrrr}
\hline Variedade & $\begin{array}{c}\text { Mês de } \\
\text { coleta }\end{array}$ & Média & $\begin{array}{c}\text { Desvio } \\
\text { padrão }\end{array}$ & $\begin{array}{c}\text { Erro } \\
\text { padrão }\end{array}$ & Mínimo & $\begin{array}{r}\text { Máximo } \\
\text { Porcent. } \\
\text { de 0 }\end{array}$ \\
\hline \multirow{6}{*}{ Caiapó } & 1 & 91,7 & 8,3 & 4,8 & 83,3 & 100,0 & 0 \\
& 2 & 46,3 & 36,1 & 16,1 & 12,5 & 93,8 & 0 \\
& 3 & 57,5 & 33,8 & 15,1 & 0,0 & 87,5 & 20 \\
& 4 & 76,3 & 11,2 & 5,0 & 62,5 & 93,8 & 0 \\
& 5 & 57,5 & 17,3 & 7,8 & 37,5 & 75,0 & 0 \\
& 6 & 10,0 & 13,0 & 5,8 & 0,0 & 31,3 & 40 \\
\hline \multirow{4}{*}{ IAC 886 } & 1 & 35,0 & 23,2 & 10,4 & 6,3 & 68,8 & 0 \\
& 2 & 46,3 & 32,1 & 14,3 & 6,3 & 93,8 & 0 \\
& 3 & 55,0 & 8,2 & 3,7 & 43,7 & 62,5 & 0 \\
& 4 & 80,0 & 17,9 & 8,0 & 50,0 & 93,8 & 0 \\
& 5 & 40,0 & 20,1 & 9,0 & 25,0 & 75,0 & 0 \\
& 6 & 10,0 & 3,4 & 1,5 & 6,3 & 12,5 & 0 \\
\hline
\end{tabular}

Tabela B5 - Estatísticas descritivas para a variável frequência de $A$. flavus nos grãos de amendoim no armazenamento em porcentagem de grãos contaminados.

\begin{tabular}{rcrrrrrr}
\hline Variedade & $\begin{array}{c}\text { Mês de } \\
\text { coleta }\end{array}$ & Média & $\begin{array}{c}\text { Desvio } \\
\text { padrão }\end{array}$ & $\begin{array}{c}\text { Erro } \\
\text { padrão }\end{array}$ & Mínimo & $\begin{array}{r}\text { Máximo } \\
\text { Porcent. } \\
\text { de 0 }\end{array}$ \\
\hline \multirow{5}{*}{ Caiapó } & 1 & 12,1 & 5,2 & 3,0 & 9,1 & 18,2 & 0 \\
& 2 & 6,1 & 4,3 & 1,9 & 3,0 & 12,1 & 0 \\
& 3 & 4,2 & 2,7 & 1,2 & 0,0 & 6,1 & 20 \\
& 4 & 13,9 & 4,6 & 2,1 & 9,1 & 21,2 & 0 \\
& 5 & 9,1 & 7,7 & 3,5 & 0,0 & 18,2 & 20 \\
& 6 & 2,4 & 3,3 & 1,5 & 0,0 & 6,1 & 60 \\
\hline \multirow{4}{*}{ IAC 886 } & 1 & 2,4 & 4,0 & 1,8 & 0,0 & 9,1 & 60 \\
& 2 & 1,8 & 2,7 & 1,2 & 0,0 & 6,1 & 60 \\
& 3 & 30,9 & 8,9 & 4,0 & 18,2 & 42,4 & 0 \\
& 4 & 29,7 & 25,6 & 11,4 & 12,1 & 72,7 & 0 \\
& 5 & 0,0 & 0,0 & 0,0 & 0,0 & 0,0 & 100 \\
& 6 & 6,1 & 4,8 & 2,1 & 0,0 & 12,1 & 20 \\
\hline
\end{tabular}


Tabela B6 - Estatísticas descritivas para a variável produção de ACP nos grãos de amendoim no campo em $\mu \mathrm{g} / \mathrm{kg}$.

\begin{tabular}{ccrrrrrr}
\hline Variedade & Fase & Média & $\begin{array}{c}\text { Desvio } \\
\text { padrão }\end{array}$ & $\begin{array}{c}\text { Erro } \\
\text { padrão }\end{array}$ & Mínimo & $\begin{array}{r}\text { Máximo } \\
\text { Caiapó }\end{array}$ & $\begin{array}{c}\text { Porcent. } \\
\text { de 0 }\end{array}$ \\
\hline \multirow{3}{*}{ angúcio granação } & 0,6 & 1,0 & 0,4 & 0,0 & 2,3 & 40 \\
& 0,2 & 0,4 & 0,2 & 0,0 & 0,9 & 60 \\
& grãos maduros & 0,7 & 1,2 & 0,5 & 0,0 & 2,8 & 40 \\
& grãos secos & 0,0 & 0,0 & 0,0 & 0,0 & 0,0 & 100 \\
\hline \multirow{3}{*}{ IAC 886 } & água & 2,1 & 2,6 & 1,2 & 0,0 & 5,7 & 40 \\
& início granação & 1,8 & 3,4 & 1,5 & 0,0 & 7,8 & 20 \\
& grãos maduros & 1,1 & 1,2 & 0,5 & 0,0 & 2,4 & 20 \\
& grãos secos & 1,0 & 1,4 & 0,6 & 0,0 & 2,6 & 60 \\
\hline
\end{tabular}

Tabela B7 - Estatísticas descritivas para a variável produção de ACP nos grãos de amendoim no armazenamento em $\mu \mathrm{g} / \mathrm{kg}$.

\begin{tabular}{rrrrrrrr}
\hline Variedade & Fase & Média & $\begin{array}{c}\text { Desvio } \\
\text { padrão }\end{array}$ & $\begin{array}{c}\text { Erro } \\
\text { padrão }\end{array}$ & Mínimo & Máximo & $\begin{array}{c}\text { Porcent. } \\
\text { de 0 }\end{array}$ \\
\hline \multirow{5}{*}{ Caiapó } & 1 & 0,1 & 0,2 & 0,1 & 0,0 & 0,4 & 67 \\
& 2 & 0,4 & 0,2 & 0,1 & 0,0 & 0,6 & 20 \\
& 3 & 2,0 & 3,0 & 1,3 & 0,0 & 7,3 & 40 \\
& 4 & 2,2 & 2,1 & 1,0 & 0,3 & 5,1 & 0 \\
& 5 & 0,1 & 0,2 & 0,1 & 0,0 & 0,4 & 80 \\
\hline \multirow{4}{*}{ IAC 886 } & 6 & 0,3 & 0,3 & 0,1 & 0,0 & 0,7 & 40 \\
& 1 & 0,8 & 1,0 & 0,4 & 0,0 & 1,9 & 40 \\
& 2 & 0,2 & 0,2 & 0,1 & 0,0 & 0,5 & 20 \\
& 3 & 3,9 & 3,5 & 1,6 & 0,0 & 6,8 & 20 \\
& 4 & 0,5 & 1,0 & 0,4 & 0,0 & 2,2 & 60 \\
& 5 & 2,0 & 1,8 & 0,8 & 0,0 & 4,3 & 20 \\
& 6 & 1,5 & 2,4 & 1,1 & 0,0 & 5,7 & 40 \\
\hline
\end{tabular}

Tabela B8 - Estatísticas descritivas para a variável produção de trans-resveratrol nos grãos de amendoim no campo em $\mu \mathrm{g} / \mathrm{kg}$. 


\begin{tabular}{ccrrrrrr}
\hline Variedade & Fase & Média & $\begin{array}{c}\text { Desvio } \\
\text { padrão }\end{array}$ & $\begin{array}{c}\text { Erro } \\
\text { padrão }\end{array}$ & Mínimo & Máximo & $\begin{array}{c}\text { Porcent. } \\
\text { de 0 }\end{array}$ \\
\hline \multirow{3}{*}{ Caiapó } & água & 0,06 & 0,13 & 0,06 & 0,00 & 0,28 & 80 \\
& início granação & 0,06 & 0,13 & 0,06 & 0,00 & 0,28 & 80 \\
& grãos maduros & 0,11 & 0,25 & 0,11 & 0,00 & 0,57 & 80 \\
\hline \multirow{3}{*}{ IAC 886 início granação } & 0,16 & 0,35 & 0,16 & 0,00 & 0,79 & 80 \\
& água & 0,00 & 0,00 & 0,00 & 0,00 & 0,00 & 100 \\
& grãos maduros & 0,00 & 0,00 & 0,00 & 0,00 & 0,00 & 100 \\
\hline
\end{tabular}

Tabela B9 - Estatísticas descritivas para a variável produção de trans-resveratrol nas folhas da planta de amendoim no campo em $\mu \mathrm{g} / \mathrm{kg}$.

\begin{tabular}{ccrrrrrr}
\hline Variedade & Fase & Média & $\begin{array}{c}\text { Desvio } \\
\text { padrão }\end{array}$ & $\begin{array}{c}\text { Erro } \\
\text { padrão }\end{array}$ & Mínimo & Máximo & $\begin{array}{c}\text { Porcent. } \\
\text { de 0 }\end{array}$ \\
\hline \multirow{3}{*}{ Caiapó } & água & 27,5 & 23,1 & 10,3 & 0,0 & 55,6 & 20 \\
& início granação & 10,6 & 17,9 & 8,0 & 0,0 & 42,1 & 40 \\
& grãos maduros & 7,5 & 6,3 & 2,8 & 0,0 & 15,3 & 20 \\
\hline \multirow{3}{*}{ IAC 886 } & água & 11,7 & 8,6 & 3,8 & 0,0 & 18,3 & 20 \\
& início granação & 54,3 & 68,2 & 30,5 & 0,0 & 157,9 & 40 \\
& grãos maduros & 32,1 & 43,7 & 19,5 & 0,0 & 104,0 & 20 \\
\hline
\end{tabular}

Tabela B10 - Estatísticas descritivas para a variável atividade de água das cascas no campo.

\begin{tabular}{ccccccc}
\hline Variedade & Fase & Média & $\begin{array}{c}\text { Desvio } \\
\text { padrão }\end{array}$ & $\begin{array}{c}\text { Erro } \\
\text { padrão }\end{array}$ & Mínimo & Máximo \\
\hline \multirow{3}{*}{ Caiapó } & água & 0,99 & 0,00 & 0,00 & 0,99 & 0,99 \\
& início granação & 0,99 & 0,00 & 0,00 & 0,99 & 0,99 \\
& grãos maduros & 0,99 & 0,01 & 0,00 & 0,97 & 0,99 \\
& grãos secos & 0,65 & 0,08 & 0,03 & 0,60 & 0,78 \\
\hline \multirow{3}{*}{ IAC 886 } & água & 0,99 & 0,00 & 0,00 & 0,98 & 0,99 \\
& início granação & 0,99 & 0,00 & 0,00 & 0,99 & 0,99 \\
& grãos maduros & 0,98 & 0,01 & 0,00 & 0,97 & 0,99 \\
& grãos secos & 0,60 & 0,03 & 0,01 & 0,58 & 0,64 \\
\hline
\end{tabular}

Tabela B11 - Estatísticas descritivas para a variável atividade de água dos grãos no campo. 


\begin{tabular}{ccccccc}
\hline Variedade & Fase & Média & $\begin{array}{c}\text { Desvio } \\
\text { padrão }\end{array}$ & $\begin{array}{c}\text { Erro } \\
\text { padrão }\end{array}$ & Mínimo & Máximo \\
\hline \multirow{5}{*}{ Caiapó } & ginóforo & 0,91 & 0,04 & 0,02 & 0,84 & 0,94 \\
& água & 0,97 & 0,00 & 0,00 & 0,97 & 0,98 \\
& início granação & 0,99 & 0,01 & 0,00 & 0,98 & 0,99 \\
& grãos maduros & 0,99 & 0,01 & 0,00 & 0,99 & 0,99 \\
& grãos secos & 0,77 & 0,05 & 0,00 & 0,97 & 0,99 \\
\multirow{5}{*}{ IAC 886 } & flor & 0,90 & 0,02 & 0,01 & 0,72 & 0,82 \\
& ginóforo & 0,97 & 0,00 & 0,00 & 0,97 & 0,92 \\
& água & 0,98 & 0,00 & 0,00 & 0,98 & 0,98 \\
& início granação & 0,99 & 0,00 & 0,00 & 0,98 & 0,99 \\
& grãos maduros & 0,98 & 0,01 & 0,00 & 0,98 & 0,99 \\
& grãos secos & 0,62 & 0,02 & 0,01 & 0,60 & 0,64 \\
\hline
\end{tabular}

Tabela B12 - Estatísticas descritivas para a variável atividade de água do solo.

\begin{tabular}{ccrrrrr}
\hline Variedade & Fase & Média & $\begin{array}{c}\text { Desvio } \\
\text { padrão }\end{array}$ & $\begin{array}{c}\text { Erro } \\
\text { padrão }\end{array}$ & Mínimo & Máximo \\
\hline \multirow{3}{*}{ Caiapó } & flor & 0,80 & 0,14 & 0,06 & 0,58 & 0,95 \\
& ginóforo & 0,86 & 0,10 & 0,04 & 0,71 & 0,97 \\
& água/início granação & 0,99 & 0,00 & 0,00 & 0,99 & 0,99 \\
& grãos maduros & 0,99 & 0,00 & 0,00 & 0,99 & 0,99 \\
\hline \multirow{3}{*}{ AC 886 } & flor & 0,86 & 0,06 & 0,03 & 0,81 & 0,93 \\
& ginóforo & 0,96 & 0,03 & 0,01 & 0,91 & 0,98 \\
& água/início granação & 0,99 & 0,00 & 0,00 & 0,99 & 0,99 \\
& grãos maduros & 0,99 & 0,00 & 0,00 & 0,99 & 0,99 \\
\hline
\end{tabular}

Tabela B13 - Estatísticas descritivas para a variável atividade de água nas cascas no armazenamento. 


\begin{tabular}{lcrrrrr}
\hline Variedade & Fase & Média & $\begin{array}{c}\text { Desvio } \\
\text { padrão }\end{array}$ & $\begin{array}{c}\text { Erro } \\
\text { padrão }\end{array}$ & Mínimo & Máximo \\
\hline \multirow{6}{*}{ Caiapó } & 1 & 0,44 & 0,01 & 0,003 & 0,44 & 0,45 \\
& 2 & 0,57 & 0,00 & 0,002 & 0,56 & 0,57 \\
& 3 & 0,51 & 0,01 & 0,006 & 0,50 & 0,53 \\
& 4 & 0,57 & 0,01 & 0,004 & 0,56 & 0,58 \\
& 5 & 0,40 & 0,03 & 0,015 & 0,37 & 0,45 \\
IAC 886 & 6 & 0,53 & 0,01 & 0,005 & 0,51 & 0,54 \\
& 1 & 0,51 & 0,01 & 0,006 & 0,50 & 0,53 \\
& 2 & 0,56 & 0,01 & 0,003 & 0,55 & 0,57 \\
& 3 & 0,51 & 0,00 & 0,002 & 0,50 & 0,51 \\
& 4 & 0,52 & 0,01 & 0,003 & 0,51 & 0,53 \\
& 5 & 0,45 & 0,01 & 0,002 & 0,44 & 0,45 \\
& 6 & 0,53 & 0,01 & 0,004 & 0,52 & 0,54 \\
\hline
\end{tabular}

Tabela B14 - Estatísticas descritivas para a variável atividade de água dos grãos no armazenamento.

\begin{tabular}{lcrrrrr}
\hline Variedade & Fase & Média & $\begin{array}{c}\text { Desvio } \\
\text { padrão }\end{array}$ & $\begin{array}{c}\text { Erro } \\
\text { padrão }\end{array}$ & Mínimo & Máximo \\
\hline \multirow{6}{*}{ Caiapó } & 1 & 0,50 & 0,03 & 0,017 & 0,47 & 0,52 \\
& 2 & 0,56 & 0,01 & 0,004 & 0,55 & 0,57 \\
& 3 & 0,51 & 0,01 & 0,004 & 0,50 & 0,52 \\
& 4 & 0,53 & 0,01 & 0,003 & 0,52 & 0,54 \\
& 5 & 0,40 & 0,03 & 0,013 & 0,37 & 0,44 \\
& 6 & 0,50 & 0,01 & 0,004 & 0,49 & 0,51 \\
\hline \multirow{4}{*}{ AC 886 } & 1 & 0,52 & 0,01 & 0,006 & 0,50 & 0,53 \\
& 2 & 0,55 & 0,01 & 0,004 & 0,54 & 0,56 \\
& 3 & 0,51 & 0,01 & 0,004 & 0,50 & 0,52 \\
& 4 & 0,49 & 0,01 & 0,005 & 0,47 & 0,50 \\
& 5 & 0,42 & 0,01 & 0,004 & 0,41 & 0,43 \\
& 6 & 0,50 & 0,01 & 0,004 & 0,49 & 0,51 \\
\hline
\end{tabular}


Tabela B15 - Correlação de Spearman e nível descritivo entre as variáveis de contaminação fúngica nas cascas de amendoim IAC-Caiapó no campo.

\begin{tabular}{cccr}
\hline Fungo & Estatística & \multicolumn{2}{c}{ Fungo } \\
\cline { 3 - 4 } & & Fusarium & Penicillium \\
\hline Aspergillus & correl. & $-0,227$ & 0,577 \\
flavus & nív. descr. & 0,337 & 0,008 \\
\hline Fusarium & correl. & & 0,020 \\
& nív. descr. & & 0,933 \\
\hline
\end{tabular}

Tabela B16 - Correlação de Spearman e nível descritivo entre as variáveis de contaminação fúngica nas cascas de amendoim IAC 886 no campo.

\begin{tabular}{ccrr}
\hline Fungo & Estatística & \multicolumn{2}{c}{ Fungo } \\
\cline { 3 - 4 } & & Fusarium & Penicillium \\
\hline Aspergillus & correl. & $-0,253$ & $-0,195$ \\
flavus & nív. descr. & 0,281 & 0,410 \\
\hline Fusarium & correl. & & $-0,482$ \\
& nív. descr. & 0,031 \\
\hline
\end{tabular}

Tabela B17 - Correlação de Spearman e nível descritivo entre as variáveis de contaminação fúngica nos grãos de amendoim IAC-Caiapó no campo.

\begin{tabular}{cccc}
\hline Fungo & Estatística & \multicolumn{2}{c}{ Fungo } \\
\cline { 3 - 4 } & & Fusarium & Penicillium \\
\hline Aspergillus & correl. & $-0,041$ & 0,066 \\
flavus & nív. descr. & 0,827 & 0,724 \\
\hline Fusarium & correl. & & $-0,446$ \\
& nív. descr. & 0,012 \\
\hline
\end{tabular}

Tabela B18 - Correlação de Spearman e nível descritivo entre as variáveis de contaminação fúngica nos grãos de amendoim IAC 886 no campo. 


\begin{tabular}{cccr}
\hline Fungo & Estatística & \multicolumn{2}{c}{ Fungo } \\
\cline { 3 - 4 } & & Fusarium & Penicillium \\
\hline Aspergillus & correl. & $-0,179$ & $-0,098$ \\
flavus & nív. descr. & 0,336 & 0,600 \\
\hline Fusarium & correl. & & $-0,290$ \\
& nív. descr. & 0,114 \\
\hline
\end{tabular}

Tabela B19 - Correlação de Spearman e nível descritivo entre as variáveis de contaminação fúngica no solo com plantação de amendoim IAC-Caiapó.

\begin{tabular}{cccr}
\hline Fungo & \multirow{2}{*}{ Estatística } & \multicolumn{2}{c}{ Fungo } \\
\cline { 3 - 4 } & & Fusarium & Penicillium \\
\hline Aspergillus & correl. & $-0,120$ & $-0,505$ \\
flavus & nív. descr. & 0,558 & 0,009 \\
\hline Fusarium & correl. & & 0,094 \\
& nív. descr. & 0,647 \\
\hline
\end{tabular}

Tabela B20 - Correlação de Spearman e nível descritivo entre as variáveis de contaminação fúngica no solo com plantação de amendoim IAC 886.

\begin{tabular}{cccc}
\hline Fungo & Estatística & \multicolumn{2}{c}{ Fungo } \\
\cline { 3 - 4 } & & Fusarium & Penicillium \\
\hline Aspergillus & correl. & 0,273 & 0,109 \\
flavus & nív. descr. & 0,178 & 0,597 \\
\hline Fusarium & correl. & & 0,382 \\
& nív. descr. & 0,055 \\
\hline
\end{tabular}

Tabela B21 - Correlação de Spearman e nível descritivo entre as variáveis de contaminação fúngica nas cascas de amendoim IAC-Caiapó no armazenamento.

\begin{tabular}{cccrr}
\hline Fungo & Estatística & $\begin{array}{c}\text { Aspergillus } \\
\text { niger }\end{array}$ & Fusarium & Alternaria \\
\hline Aspergillus & correl. & $-0,389$ & $-0,234$ & 0,249 \\
flavus & nív. descr. & 0,041 & 0,231 & 0,201 \\
\hline Aspergillus & correl. & & $-0,378$ & 0,017 \\
niger & nív. descr. & 0,047 & 0,932 \\
\hline Fusarium & correl. & & & 0,040 \\
& nív. descr. & & 0,839 \\
\hline
\end{tabular}


Tabela B22 - Correlação de Spearman e nível descritivo entre as variáveis de contaminação fúngica nas cascas de amendoim IAC 886 no armazenamento.

\begin{tabular}{cccrrr}
\hline Fungo & Estatística & $\begin{array}{c}\text { Aspergillus } \\
\text { niger }\end{array}$ & $\begin{array}{c}\text { Aspergillus } \\
\text { parasiticus }\end{array}$ & Fusarium & Penicillium \\
\hline Aspergillus & correl. & 0,172 & 0,333 & $-0,275$ & $-0,167$ \\
flavus & nív. descr. & 0,362 & 0,072 & 0,141 & 0,379 \\
\hline Aspergillus & correl. & & $-0,145$ & 0,196 & 0,191 \\
niger & nív. descr. & 0,444 & 0,299 & 0,312 \\
\hline Aspergillus & correl. & & & $-0,497$ & $-0,409$ \\
parasiticus & nív. descr. & & 0,005 & 0,025 \\
\hline Fusarium & correl. & & & & 0,438 \\
& nív. descr. & & & 0,016 \\
\hline
\end{tabular}

Tabela B23 - Correlação de Spearman e nível descritivo entre as variáveis de contaminação fúngica nos grãos de amendoim IAC-Caiapó no armazenamento.

\begin{tabular}{ccccc}
\hline Fungo & Estatística & $\begin{array}{c}\text { Aspergillus } \\
\text { niger }\end{array}$ & Fusarium & Penicillium \\
\hline Aspergillus & correl. & 0,232 & 0,173 & 0,010 \\
flavus & nív. descr. & 0,235 & 0,378 & 0,960 \\
\hline Aspergillus & correl. & & 0,051 & 0,182 \\
niger & nív. descr. & 0,798 & 0,354 \\
\hline Fusarium & correl. & & & 0,323 \\
& nív. descr. & & 0,094 \\
\hline
\end{tabular}

Tabela B24 - Correlação de Spearman e nível descritivo entre as variáveis de contaminação fúngica nos grãos de amendoim IAC 886 no armazenamento.

\begin{tabular}{ccccrr}
\hline Fungo & Estatística & $\begin{array}{c}\text { Aspergillus } \\
\text { niger }\end{array}$ & $\begin{array}{c}\text { Aspergillus } \\
\text { parasiticus }\end{array}$ & Fusarium & Penicillium \\
\hline Aspergillus & correl. & 0,204 & 0,592 & 0,095 & $-0,302$ \\
flavus & nív. descr. & 0,281 & 0,001 & 0,616 & 0,105 \\
\hline Aspergillus & correl. & & 0,062 & 0,267 & 0,179 \\
niger & nív. descr. & 0,745 & 0,154 & 0,343 \\
\hline Aspergillus & correl. & & & 0,132 & $-0,347$ \\
parasiticus & nív. descr. & & 0,487 & 0,060 \\
\hline Fusarium & correl. & & & & 0,076 \\
& nív. descr. & & & 0,691 \\
\hline
\end{tabular}


ANEXO C - ANÁLISE INFERENCIAL 
Tabela C1 - Estimativas e níveis descritivos do ajuste do modelo de regressão beta binomial para a variável frequência de $A$. flavus nas cascas de amendoim no campo.

\begin{tabular}{cccccc}
\hline Variável & Categoria & Estimativa & $\begin{array}{c}\text { Erro } \\
\text { padrão }\end{array}$ & $\begin{array}{c}\text { Nível } \\
\text { descritivo }\end{array}$ & $\begin{array}{c}\text { Exp. da } \\
\text { estimativa }\end{array}$ \\
\hline intercepto & & $-4,331$ & 0,477 & & \\
\hline Variedade e Fase & $\begin{array}{c}\text { demais } \\
\text { IAC grão secos }\end{array}$ & 3,597 & 0,567 & $<0,0001$ & 36,489 \\
\hline
\end{tabular}

Tabela C2 - Valores ajustados pelo modelo de regressão beta binomial para a variável frequência de $A$. flavus nas cascas de amendoim no campo.

\begin{tabular}{crr}
\hline Fase & \multicolumn{2}{c}{ Variedade } \\
\cline { 2 - 3 } & IAC 886 & Caiapó \\
\hline grãos secos & 32,4 & 1,3 \\
demais & 1,3 & 1,3 \\
\hline
\end{tabular}

Tabela C3 - Nível descritivo das variáveis não incluídas no modelo de regressão beta binomial para a variável frequência de $A$. flavus nas cascas de amendoim no campo.

\begin{tabular}{cr}
\hline Variável & Nível descritivo \\
\hline Atividade de água na casca & 0,511 \\
Aspergillus flavus no solo & 0,718 \\
\hline
\end{tabular}


Tabela C4 - Estimativas e níveis descritivos do ajuste do modelo de regressão binomial para a variável frequência de $A$. flavus nos grãos de amendoim no campo.

\begin{tabular}{cccccc}
\hline Variável & Categoria & Estimativa & $\begin{array}{c}\text { Erro } \\
\text { padrão }\end{array}$ & $\begin{array}{c}\text { Nível } \\
\text { descritivo }\end{array}$ & $\begin{array}{c}\text { Exp. da } \\
\text { estimativa }\end{array}$ \\
\hline intercepto & & $-5,103$ & 0,646 & & \\
\hline Fase & demais & & & & \\
& grãos maduros/secos & 2,057 & 0,684 & 0,0012 & 7,822 \\
\hline
\end{tabular}

Tabela C5 - Valores ajustados pelo modelo de regressão binomial para a variável frequência de $A$. flavus nos grãos de amendoim no campo

\begin{tabular}{crr}
\hline \multirow{2}{*}{ Fase } & \multicolumn{2}{c}{ Variedade } \\
\cline { 2 - 3 } & IAC 886 & Caiapó \\
\hline grãos maduros/secos & 4,5 & 4,5 \\
demais & 0,6 & 0,6 \\
\hline
\end{tabular}

Tabela C6 - Nível descritivo das variáveis não incluídas no modelo de regressão binomial para a variável frequência de $A$. flavus nos grãos do amendoim no campo

\begin{tabular}{cr}
\hline Variável & Nível descritivo \\
\hline Variedade & 0,564 \\
Atividade de água no grão & 0,946 \\
Aspergillus flavus na casca & 0,194 \\
Atividade de água na casca & 0,903 \\
Aspergillus flavus no solo & 0,335 \\
Atividade de água no solo & 0,408 \\
\hline
\end{tabular}


Tabela C7 - Estimativas e níveis descritivos do ajuste do modelo de regressão beta binomial para a variável frequência de $A$. flavus nas cascas de amendoim no armazenamento.

\begin{tabular}{ccrrrr}
\hline Variável & Categoria & Estimativa & $\begin{array}{c}\text { Erro } \\
\text { padrão }\end{array}$ & $\begin{array}{c}\text { Nível } \\
\text { descritivo }\end{array}$ & $\begin{array}{c}\text { Exp. da } \\
\text { estimativa }\end{array}$ \\
\hline intercepto & & 3,442 & 1,437 & & \\
\hline Tempo & linear & $-0,674$ & 0,216 & 0,0024 & 0,510 \\
& quadrático & $-1,503$ & 0,371 & 0,0001 & 0,223 \\
\hline Ativ. água casca & & $-0,055$ & 0,027 & 0,0463 & 0,946 \\
\hline
\end{tabular}

Tabela C8 - Valores ajustados pelo modelo de regressão beta binomial para a variável frequência de $A$. flavus nas cascas de amendoim no armazenamento.

\begin{tabular}{cllllll}
\hline Atividade de & \multicolumn{7}{c}{ Mês de armazenamento } \\
\cline { 2 - 7 } água na casca & 1 & 2 & 3 & 4 & 5 & 6 \\
\hline 0,4 & 60,1 & 75,1 & 78,8 & 74,0 & 57,3 & 28,2 \\
0,5 & 46,5 & 63,5 & 68,2 & 62,1 & 43,6 & 18,4 \\
0,6 & 33,4 & 50,1 & 55,3 & 48,6 & 30,9 & 11,5 \\
\hline
\end{tabular}

Tabela C9 - Nível descritivo das variáveis não incluídas no modelo de regressão beta binomial para a variável frequência de $A$. flavus nas cascas de amendoim no armazenamento.

\begin{tabular}{cr}
\hline Variável & Nível descritivo \\
\hline Variedade & 0,274 \\
Temperatura média externa & 0,148 \\
Umidade relativa média externa & 0,923 \\
Precipitação externa & 0,135 \\
Temperatura média armazém & 0,757 \\
Umidade relativa média armazém & 0,607 \\
\hline
\end{tabular}


Tabela C10 - Estimativas e níveis descritivos do ajuste do modelo de regressão beta binomial para a variável frequência de $A$. flavus nos grãos de amendoim no armazenamento.

\begin{tabular}{crrrr}
\hline Variável & Estimativa & $\begin{array}{c}\text { Erro } \\
\text { padrão }\end{array}$ & $\begin{array}{c}\text { Nível } \\
\text { descritivo }\end{array}$ & $\begin{array}{c}\text { Exp. da } \\
\text { estimativa }\end{array}$ \\
\hline intercepto & $-3,548$ & 0,381 & & \\
\hline A. flavus na casca & 0,014 & 0,005 & 0,0046 & 1,014 \\
\hline Precipitação & 0,003 & 0,001 & 0,0213 & 1,003 \\
\hline
\end{tabular}

Tabela C11 - Valores ajustados pelo modelo de regressão beta binomial para a variável frequência de $A$. flavus nos grãos de amendoim no armazenamento.

\begin{tabular}{cccccc}
\hline Precipitação $(\mathrm{mm})$ & \multicolumn{5}{c}{ Apergillus flavus na casca $(\%)$} \\
\cline { 2 - 6 } & \multicolumn{1}{c}{ 0 } & \multicolumn{1}{c}{50} & \multicolumn{1}{c}{75} & 100 \\
\hline 0 & 2,8 & 3,9 & 5,5 & 7,7 & 10,7 \\
100 & 3,9 & 5,4 & 7,5 & 10,4 & 14,2 \\
200 & 5,3 & 7,4 & 10,2 & 13,9 & 18,8 \\
300 & 7,2 & 10,0 & 13,6 & 18,4 & 24,3 \\
\hline
\end{tabular}

Tabela C12 - Nível descritivo das variáveis não incluídas no modelo de regressão beta binomial para a variável frequência de $A$. flavus nos grãos do amendoim no armazenamento.

\begin{tabular}{cr}
\hline Variável & Nível descritivo \\
\hline Variedade & 0,6415 \\
Atividade de água no grão & 0,3586 \\
Tempo linear & 0,3372 \\
Tempo quadrático & 0,1192 \\
Temperatura média externa & 0,6286 \\
Umidade relativa média externa & 0,5395 \\
Temperatura média armazém * & 0,0060 \\
Umidade relativa média armazém & 0,7132 \\
\hline
\end{tabular}

* no relatório, explica-se o motivo da não inclusão da variável 
Tabela C13 - Nível descritivo das variáveis não incluídas no modelo de regressão gaussiano inverso ajustado no 0 para a variável produção de ACP nos grãos de amendoim no campo.

\begin{tabular}{ccr}
\hline Parâmetro & Variável & $\begin{array}{c}\text { Nível } \\
\text { descritivo }\end{array}$ \\
\hline Média dos & Variedade & 0,1890 \\
valores & Aspergillus flavus no grão & 0,9563 \\
contínuos & Atividade de água no grão & 0,6479 \\
& Fase de desenvolvimento & 0,7628 \\
\hline Probabilidade & Variedade & 0,1115 \\
de valor 0 & Aspergillus flavus no grão & 0,9887 \\
& Atividade de água no grão & 0,0652 \\
& Fase de desenvolvimento & 0,3413 \\
\hline
\end{tabular}

Tabela C14 - Estimativas e níveis descritivos do ajuste do modelo de regressão gaussiano inverso ajustado no 0 para a variável produção de ACP nos grãos do amendoim no armazenamento.

\begin{tabular}{cccrrrr}
\hline Parâmetro & Variável & Categoria & Estimativa & $\begin{array}{c}\text { Erro } \\
\text { padrão }\end{array}$ & $\begin{array}{c}\text { Nível } \\
\text { descritivo }\end{array}$ & $\begin{array}{c}\text { Exp. da } \\
\text { estimativa }\end{array}$ \\
\hline Méd. val. contínuos & intercepto & & 0,632 & 0,268 & \\
\hline $\begin{array}{c}\text { Probabilidade } \\
\text { de assumir } \\
\text { valor 0 }\end{array}$ & intercepto & Variedade & $\begin{array}{c}\text { Caiapó } \\
\text { IAC886 }\end{array}$ & 1,049 & 0,767 & \\
\cline { 2 - 7 } & & & $-1,742$ & 0,860 & 0,0349 & 0,175 \\
\cline { 2 - 7 } & Precipit. Caiapó & & $-0,011$ & 0,005 & 0,0143 & 0,989 \\
\hline
\end{tabular}

Tabela C15 - Valores ajustados pelo modelo de regressão gaussiano inverso ajustado no 0 para a variável produção de ACP nos grãos de amendoim no armazenamento.

\begin{tabular}{ccccc}
\hline Variedade & \multicolumn{4}{c}{ Precipitação } \\
\cline { 2 - 5 } & 0 & 100 & 200 & 300 \\
\hline Caiapó & 0,488 & 0,949 & 1,406 & 1,685 \\
IAC 886 & 1,254 & 1,254 & 1,254 & 1,254 \\
\hline
\end{tabular}


Tabela C16 - Nível descritivo das variáveis não incluídas no modelo de regressão gaussiano inverso ajustado no 0 para a variável produção de ACP nos grãos de amendoim no armazenamento.

\begin{tabular}{ccc}
\hline Parâmetro & Variável & $\begin{array}{c}\text { Nível } \\
\text { descritivo }\end{array}$ \\
\hline & Atividade de água grão & 0,9617 \\
Variedade & 0,4409 \\
Média dos & Tempo linear & 0,4747 \\
valores & Tempo quadrático & 0,3477 \\
contínuos & Aspergillus flavus no grão & 0,2326 \\
& Temperatura média externa & 0,7627 \\
& Umidade relativa externa & 0,8578 \\
& Precipitação & 0,4698 \\
& Temperatura média armazém & 0,4838 \\
& Umidade relativa armazém & 0,7500 \\
\hline & Atividade de água grão & 0,6736 \\
Probabilidade & Tempo linear & 0,8702 \\
de valor 0 0 & Tempo quadrático & 0,4597 \\
& Tempergillus flavus no grão & 0,3158 \\
& Umidade relativa externa & 0,1688 \\
& Temperatura média armazém & 0,6628 \\
& Umidade relativa armazém & 0,7634 \\
& 0,1831 \\
\hline
\end{tabular}

Tabela C17 - Estimativas e níveis descritivos do ajuste do modelo de regressão gaussiano inverso ajustado no 0 para a variável produção de trans-resveratrol nas folhas da planta de amendoim.

\begin{tabular}{|c|c|c|c|c|c|c|}
\hline Parâmetro & Variável & Categoria & Estimativa & $\begin{array}{c}\text { Erro } \\
\text { padrão }\end{array}$ & $\begin{array}{c}\text { Nível } \\
\text { descritivo }\end{array}$ & $\begin{array}{c}\text { Exp. da } \\
\text { estimativa }\end{array}$ \\
\hline \multirow{5}{*}{$\begin{array}{c}\text { Média de } \\
\text { valores } \\
\text { contínuos }\end{array}$} & intercepto & & 0,501 & 0,328 & & \\
\hline & Penicillium no solo & & 0,030 & 0,018 & 0,0259 & 1,031 \\
\hline & Fungos na casca * & & 0,080 & 0,021 & 0,0004 & 1,083 \\
\hline & Fungos no grão ** & & 0,042 & 0,013 & 0,0008 & 1,043 \\
\hline & Fase & $\begin{array}{c}\text { demais } \\
\text { gr. maduros }\end{array}$ & $-1,302$ & 0,427 & 0,0029 & 0,272 \\
\hline Probab. val. 0 & intercepto & & $-1,012$ & 0,413 & & \\
\hline
\end{tabular}

* Média de Aspergillus flavus, Fusarium e Penicillium na casca

${ }^{* *}$ Média de Fusarium e Penicillium na casca 
Tabela C18 - Valores ajustados pelo modelo de regressão gaussiano inverso ajustado no 0 para a variável produção de trans-resveratrol nas folhas da planta de amendoim.

\begin{tabular}{|c|c|c|c|c|c|c|c|}
\hline \multirow{4}{*}{$\begin{array}{l}\text { Média grão } \\
\text { Fusarium e } \\
\text { Penicillium }\end{array}$} & \multirow{4}{*}{$\begin{array}{l}\text { Média casca } \\
\text { A. Flavus, } \\
\text { Fusarium } \\
\text { e Penicillium }\end{array}$} & \multicolumn{6}{|c|}{ Fase } \\
\hline & & \multirow{2}{*}{\multicolumn{3}{|c|}{$\frac{\text { Água/Início da granação }}{\text { Penicilium no solo (\%) }}$}} & \multicolumn{3}{|c|}{ Grãos maduros } \\
\hline & & & & & Penicil & n no so & $(\%)$ \\
\hline & & 10 & 30 & 50 & 10 & 30 & 50 \\
\hline \multirow{4}{*}{0} & 10 & 3,6 & 6,6 & 12,1 & 1,0 & 1,8 & 3,3 \\
\hline & 20 & 8,0 & 14,7 & 26,8 & 2,2 & 4,0 & 7,3 \\
\hline & 30 & 17,8 & 32,5 & 59,3 & 4,8 & 8,8 & 16,1 \\
\hline & 40 & 39,5 & 72,1 & 131,5 & 10,7 & 19,6 & 35,8 \\
\hline \multirow{4}{*}{10} & 10 & 5,5 & 10,1 & 18,4 & 1,5 & 2,7 & 5,0 \\
\hline & 20 & 12,2 & 22,3 & 40,8 & 3,3 & 6,1 & 11,1 \\
\hline & 30 & 27,1 & 49,5 & 90,3 & 7,4 & 13,5 & 24,6 \\
\hline & 40 & 60,2 & 109,8 & 200,3 & 16,4 & 29,9 & 54,5 \\
\hline \multirow{4}{*}{30} & 10 & 12,8 & 23,4 & 42,6 & 3,5 & 6,4 & 11,6 \\
\hline & 20 & 28,4 & 51,8 & 94,5 & 7,7 & 14,1 & 25,7 \\
\hline & 30 & 62,9 & 114,9 & 209,6 & 17,1 & 31,2 & 57,0 \\
\hline & 40 & 139,5 & 254,6 & 464,6 & 38,0 & 69,3 & 126,4 \\
\hline \multirow{4}{*}{50} & 10 & 29,7 & 54,2 & 98,9 & 8,1 & 14,7 & 26,9 \\
\hline & 20 & 65,9 & 120,2 & 219,3 & 17,9 & 32,7 & 59,6 \\
\hline & 30 & 146,0 & 266,4 & 486,1 & 39,7 & 72,5 & 132,2 \\
\hline & 40 & 323,7 & 590,6 & 1077,7 & 88,0 & 160,6 & 293,1 \\
\hline
\end{tabular}


Tabela C19 - Nível descritivo das variáveis não incluídas no modelo de regressão gaussiano inverso ajustado no 0 para a variável produção de trans-resveratrol nas folhas da planta de amendoim.

\begin{tabular}{ccr}
\hline Parâmetro & Variável & $\begin{array}{c}\text { Nível } \\
\text { descritivo }\end{array}$ \\
\hline Média dos & Variedade & 0,8342 \\
valores & Atividade de água no solo & 1,0000 \\
contínuos & Atividadade de água na casca & 0,3933 \\
& Aspergillus flavus no grão & 0,5391 \\
& Fusarium no solo & 0,7141 \\
& Aspergillus flavus no grão & 0,8469 \\
& Variedade & 1,0000 \\
\hline & Fase & 0,2508 \\
& Atividade de água no solo & 1,0000 \\
& Atividade de água na casca & 0,4944 \\
& Atividade de água no grão & 0,2580 \\
& Aspergillus flavus no solo & 0,1594 \\
Probabilidade & Fusarium no solo & 0,3208 \\
de valor 0 & Penicillium no solo & 0,6689 \\
& Média de fungos no solo * & 0,9563 \\
& Aspergillus flavus na casca & 0,4228 \\
& Fusarium na casca & 0,3475 \\
& Penicillium na casca & 0,6445 \\
& Média de fungos na casca * & 0,7306 \\
& Aspergillus flavus no grão & 0,8359 \\
& Fusarium no grão & 0,8365 \\
& Penicillium no grão & 0,4890 \\
& Média de fungos no grão * & 0,4702 \\
\hline
\end{tabular}

* Média de Aspergillus flavus, Fusarium spp. e Penicillium spp. 